\title{
Intimate relationships with artificial partners
}

Citation for published version (APA):

Levy, D. (2007). Intimate relationships with artificial partners. [Doctoral Thesis, Maastricht University]. Datawyse / Universitaire Pers Maastricht. https://doi.org/10.26481/dis.20071011dl

Document status and date:

Published: 01/01/2007

DOI:

$10.26481 /$ dis.20071011dl

Document Version:

Publisher's PDF, also known as Version of record

\section{Please check the document version of this publication:}

- A submitted manuscript is the version of the article upon submission and before peer-review. There can be important differences between the submitted version and the official published version of record.

People interested in the research are advised to contact the author for the final version of the publication, or visit the DOI to the publisher's website.

- The final author version and the galley proof are versions of the publication after peer review.

- The final published version features the final layout of the paper including the volume, issue and page numbers.

Link to publication

\footnotetext{
General rights rights.

- You may freely distribute the URL identifying the publication in the public portal. please follow below link for the End User Agreement:

www.umlib.nl/taverne-license

Take down policy

If you believe that this document breaches copyright please contact us at:

repository@maastrichtuniversity.nl

providing details and we will investigate your claim.
}

Copyright and moral rights for the publications made accessible in the public portal are retained by the authors and/or other copyright owners and it is a condition of accessing publications that users recognise and abide by the legal requirements associated with these

- Users may download and print one copy of any publication from the public portal for the purpose of private study or research.

- You may not further distribute the material or use it for any profit-making activity or commercial gain

If the publication is distributed under the terms of Article $25 \mathrm{fa}$ of the Dutch Copyright Act, indicated by the "Taverne" license above, 


\section{INTIMATE RELATIONSHIPS WITH ARTIFICIAL PARTNERS}

DAVID NEIL LAURENCE LEVY 
To the memory of my mother 


\title{
INTIMATE RELATIONSHIPS WITH ARTIFICIAL PARTNERS
}

\author{
PROEFSCHRIFT
}

Ter verkrijging van de graad van doctor

aan de Universiteit Maastricht

op gezag van de Rector Magnificus

Prof.mr. G.P.M.F. Mols,

volgens het besluit van het College van Decanen,

in het openbaar te verdedigen

op donderdag 11 oktober 2007 om 14:00 uur

door

David Neil Laurence Levy

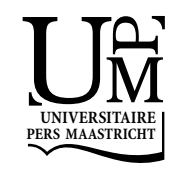


Promotores:

Prof.dr. M. Meijer

Prof.dr. H.J. van den Herik

Leden van de beoordelingscommissie:

Prof.dr. E.O. Postma (voorzitter)

Prof. dr. M. Diocaretz

Prof.dr. J-J. Meyer (Universiteit Utrecht)

Prof.dr. R. de Wilde

Prof.dr. L. van Zoonen (Universiteit van Amsterdam)

Dissertation Series No. 2007-19

The research reported in this thesis has been carried out under the auspices of SIKS, the Dutch Research School for Information and Knowledge Systems.

ISBN 978-90-5278-643-8

Proefschrift Universiteit Maastricht

Printed by Datawyse b.v., Maastricht, The Netherlands

C2007 D.N.L. Levy, Maastricht, The Netherlands

All rights reserved. No part of this publication may be reproduced, stored in a retrieval system, or transmitted in any form or by any means, electronically, photocopying, or otherwise, without proper permission of the author. 


\section{Preface}

Intimate relationships with artificial partners is a challenging topic that will certainly raise many eyebrows. Let me start with a quotation.

"We ask [of the computer] not just about where we stand in nature, but about where we stand in the world of artefact. We search for a link between who we are and what we have made, between who we are and what we might create, between who we are and what, through our intimacy with our own creations, we might become."

- Sherry Turkle (1984)

The aims of this thesis are to argue that intimate relationships with artificial partners will arise as natural extensions of more conventional human feelings of attraction. I accept that many people today will regard such suggestions as speculative, but I believe that our grandchildren's generation will embrace the robots of the mid- $21^{\text {st }}$ century as their companions, friends, and artificial partners. Robots will also be attracted to humans and will fall in love with them - they will be programmed to do so and to develop their relationships with humans in ways that will maximize the satisfaction and enjoyment for their human partners.

In the closing chapters of my book, Robots Unlimited, I assert that the robots of the mid- $21^{\text {st }}$ century will possess humanlike consciousness and emotions; that they will be hugely attractive to humans as companions because of their many talents, senses, and capabilities. The raison d'être of that book is principally to demonstrate the "how" of all this - how all these talents, capabilities, and senses are created by Artificial Intelligence researchers. The purpose of this thesis is to investigate scientifically the validity of these ideas, to give them a place in the new virtual world, and to explain the depth of feelings that these new developments will evoke within human beings and even within the robots themselves.

The thesis consists of four parts, of which Part Two and Part Three constitute the main body of my research. Part One has two chapters providing an introduction and historical background, culminating in a twofold problem statement. Part Two deals with robots and feelings of attraction, and Part Three with robots and intimate relationships. My conclusions are formulated in Part Four.

I would like to thank Christine Fox and Bill Yeager who carefully read the first draft of the text and made many helpful comments and suggestions. Heather Allen and Raymond Kirsch read a subsequent draft and provided encouragement. Cynde Moya offered some helpful advice on early $20^{\text {th }}$ century sex artefacts, and brought to my attention two of the exhibits from Magnus Hirschfeld's former collection (the artificial vagina and the fornicatory dolls). She also kindly provided me with images of both of these (section 9.4), as reproduced in her Ph.D. thesis "Artificial Vaginas and Sex Dolls: An Erotological Investigation." Cynde also brought to my attention Henry Cary's privately published book (from which she kindly provided extracts). Alan Pate provided the original source information for explaining the origin of the term "Dutch wives." Andrew Keatley and Alastair Levy assisted with the 
technicalities of some of the images. Kimballe Thomerson was my Japanese speaking intermediary in my communications with the manufacturer Orient Doll.

I received an enormous amount of assistance and advice at Maastricht University. Joke Hellemons and Tons van den Bosch devoted a considerable amount of time and effort to ensure that my text met all of the appropriate formatting. They also taught me about all the administrative matters and requirements for the printing and publication of the thesis. Above all I wish to thank my two thesis supervisors, Professor Maaike Meijer and Professor Jaap van den Herik, firstly for having the necessary confidence in my research topic as being one suitable for a Ph.D. thesis, and then for the enthusiasm and energy with which they encouraged and supported me throughout the whole process. Maaike Meijer also opened my eyes to some new and important ways of examining and considering my research results, particularly in the realms of gender studies and philosophy, and she pointed me in the direction of many useful references in those areas. Jaap van den Herik not only provided commensurate advice and suggested many references in the more technical areas of my research, he also subjected me to an intensive and invaluable learning period on how to structure my text in a manner appropriate for a thesis. Furthermore, Professor van den Herik gave of his time, energy, and advice to an extent that I could not have expected when I started on this thesis, and for which I shall be eternally grateful.

I also wish to thank the following for granting me permission to reproduce certain images and text: Peter Menzel / Science Photo Library for Peter Menzel's photograph of Kismet (section 2.5); The New Yorker for Peter Steiner's cartoon "On the Internet, no-one knows you're a dog." (section 3.6); Getty Images for the photograph of the Repliee Q1 robot (section 10.8); John Suler for the extract from his article "Mom, Dad, Computer (Transference Reactions to Computers)" in his electronic book Psychology of Cyberspace (section 7.4); Jane Treays and the BBC for the quotations from clients in her TV documentary "What Sort of Gentleman Are You After?" (section 8.4); Orient Industries for the company's photograph of one of their Orient Doll products (section 9.4); Asian Sex Gazette (www.asiansexgazette.com) for Mark Schreiber's article “A Jewel in Japan's HiTech Crown: Sex Dolls.” (section 9.4); Mainichi newspapers for Ryann Connell's article "Rent-a-Doll Blows Hooker Market Wide Open" (section 9.4); Dave Lampert for the image of the Sybian "Lovemaster" sex machine (section 9.5); and Paul Gaertner for the photograph of the Stallion XL sex machine (section 9.5).

David Levy

London, June 2007 


\section{Contents}

Preface $\quad$ V

Contents vii

Part One 1

1. Introduction 3

1.1 Artificial Intelligence and Robotics 4

1.2 Agent Technology and Software Agents 5

$\begin{array}{ll}1.3 & \text { Agents and the Information Society } \\ 1.4 & 6\end{array}$

1.4 Representation in the Context of Poststructuralist Thinking 8

$\begin{array}{llr}1.5 & \text { Problem Statement } & 12\end{array}$

$\begin{array}{ll}1.6 & \text { The Topic in Gender Perspective } \\ 13\end{array}$

$\begin{array}{lll}1.7 & \text { Research Objectives and Research Questions } & 15\end{array}$

$\begin{array}{lll}1.8 \text { Methodology } & 16\end{array}$

$\begin{array}{ll}1.9 \text { Thesis Structure: an Overview } & 17\end{array}$

2. Historical Background 19

2.1 Mechanical Marvels 20

$\begin{array}{lll}2.2 & \text { A Chess-playing Automaton } & 22\end{array}$

$\begin{array}{lll}2.3 & \text { Tea-carrying Dolls } & 23\end{array}$

2.4 Universal Robots 23

$\begin{array}{ll}2.5 & \text { Cybernetics } \\ 2.6 & 24\end{array}$

2.6 The Breakthrough of Artificial Intelligence 25

$\begin{array}{lll}2.7 & \text { Service Robots } & 26\end{array}$

$\begin{array}{lll}2.8 & \text { Robots for Entertainment } & 27\end{array}$

2.9 Two New Disciplines: Robot Psychology and Robotherapy 28

$\begin{array}{ll}2.10 & \text { Recent Developments } \\ & 30\end{array}$

Part Two 33

3. Emotional Feelings of Attraction (to People) 35

$\begin{array}{lll}3.1 & \text { Attachment and Love } & 36\end{array}$

3.2 The Influence of Proximity and Repeated Exposure 40

3.3 Why People Fall in Love 41

3.4 Measuring Love 43

3.5 Ten Causes of Falling in Love 44

3.6 Falling in Love on the Internet 47

3.7 Chapter Conclusions 51

4. Loving our Pets 53

4.1 The Nature of Human-Pet Relationship 53

4.2. The Anthropomorphism of Pets 55

4.3. The Strength of Human Love for Pets 58

$\begin{array}{ll}4.4 & \text { Some Benefits of Owning Pets } \\ \end{array}$

4.5 The Benefits of Pets for Children and Adolescents 63

$\begin{array}{lll}4.6 & \text { Comparing Relationships } & 63\end{array}$

4.7 Why Do People Love their Pets? 65

$\begin{array}{lll}4.8 & \text { Chapter Conclusions } & 66\end{array}$ 
5. Emotional Attachments to Virtual Pets 69

$\begin{array}{lll}5.1 & \text { Attachment and Relationships with Objects } & 70\end{array}$

$\begin{array}{lll}5.2 & \text { On Anthropomorphism } & 76\end{array}$

5.3 The Development of Social Relationships with Computers 81

5.4 Sustaining Social Relationships with Computers 86

$\begin{array}{lll}5.5 & \text { Virtual Pets - The TAMAgOTCHI } & 88\end{array}$

5.6 Virtual Pets that Live on the Screen 91

$\begin{array}{lll}5.7 & \text { Robotic Virtual Pets } & 93\end{array}$

5.8 The Benefits of Forming Attachments to Robot Pets 95

5.9 From Virtual Pet to Humanoid Robot 97

$\begin{array}{ll}5.10 \text { Chapter Conclusions } & 98\end{array}$

6. Falling in Love with Virtual People (Humanoid Robots) 99

$\begin{array}{lll}6.1 & \text { Attitudes to Relationships } & 100\end{array}$

$\begin{array}{ll}\text { 6.2 Preferring Computers to People } & 105\end{array}$

$\begin{array}{lll}6.3 & \text { Robot Psychology and Behaviour } & 107\end{array}$

6.4 Emotions in Humans and in Robots 109

6.5 Robot Recognition of Human Emotions 113

$\begin{array}{ll}\text { 6.6 Three Routes to Falling in Love with Robots } & 115\end{array}$

6.7 Robot Personalities and their Influence on Relationships 118

$\begin{array}{ll}6.8 \text { Designing Robot Personalities } & 121\end{array}$

$\begin{array}{ll}6.9 \text { Robot Chromosomes } & 123\end{array}$

6.10 The Ten Factors as Applied to Human-Robot Relationships 124

$\begin{array}{ll}6.11 & 128\end{array}$

6.12 Robot Fidelity, Passion, and the Intensity of Robot Love 129

$\begin{array}{lr}6.13 \text { Marrying a Robot } & 129\end{array}$

$\begin{array}{ll}6.14 \text { Chapter Conclusions } & 135\end{array}$

$\begin{array}{ll}\text { Part Three } & 137\end{array}$

7. Human Beings, Sex, and Robots 139

$\begin{array}{lll}7.1 & \text { From Unreality to Reality } & 140\end{array}$

7.2 Why do People Make Love (with People)? 142

$\begin{array}{lll}7.3 & \text { Sex in a New Gender Environment } & 147\end{array}$

$\begin{array}{lll}7.4 & \text { Sex as a Result of Transference } & 148\end{array}$

$\begin{array}{ll}7.5 & \text { Chapter Conclusions } \\ \end{array}$

8. Why People Pay for Sex 151

$\begin{array}{lll}8.1 \quad \text { Men Paying Women } & 151\end{array}$

$\begin{array}{ll}\text { 8.2 Women Paying Men } & 153\end{array}$

$\begin{array}{ll}\text { 8.3 Why Men Pay Women for Sex } & 158\end{array}$

$\begin{array}{ll}8.4 & 165\end{array}$

$\begin{array}{ll}\text { 8.5 The Future of Prostitution } & 167\end{array}$

$\begin{array}{ll}\text { 8.6 Paid Sex Surrogates as Therapy } & 168\end{array}$

$\begin{array}{ll}8.7 \text { Chapter Conclusions } & 171\end{array}$

9. Sex Technologies 173

$\begin{array}{lll}9.1 & \text { Vibrators Originated in the 1880s } & 174\end{array}$ 
$\begin{array}{lll}9.2 & \text { The Popularity of Vibrators } & 180\end{array}$

$\begin{array}{lll}9.3 & \text { Vibrators for Men } & 184\end{array}$

$\begin{array}{lll}9.4 & \text { Fornicatory Dolls } & 187\end{array}$

$\begin{array}{lll}9.5 & \text { Sex Machines } & 200\end{array}$

$\begin{array}{lll}9.6 & \text { Patents } & 205\end{array}$

$\begin{array}{lll}9.7 & \text { Virtual Reality and Teledildonics } & 207\end{array}$

9.8 Haptic Interfaces for Teledildonics 209

$\begin{array}{ll}9.9 \text { Chapter Conclusions } & 211\end{array}$

10. The Mental Leap to Sex with Robots 213

$\begin{array}{ll}10.1 \text { Homosexuality } & 213\end{array}$

$\begin{array}{lll}10.2 & \text { Oral Sex } & 217\end{array}$

$\begin{array}{lll}10.3 & \text { Fornication } & 218\end{array}$

$\begin{array}{ll}10.4 \text { Masturbation } & 219\end{array}$

$\begin{array}{lll}10.5 & \text { The Cybersex Era } & 223\end{array}$

10.6 From Haptic Interface to Sex Robot 224

10.7 Are Men and Women Different? 227

$\begin{array}{ll}10.8 \text { When They Look like us } & 229\end{array}$

10.9 Therapist Sex Robots for Hire 232

10.10 The Ethics of Robot Prostitution 232

10.11 What Will Our Sex Lives be like? 233

$\begin{array}{ll}10.12 \text { Chapter Conclusions } & 235\end{array}$

Part Four $\quad 237$

11. Conclusions 239

11.1 Emotional Feelings of Attraction (to People) 239

$\begin{array}{ll}11.2 \text { Loving our Pets } & 240\end{array}$

11.3 Emotional Attachments to Virtual Pets 241

11.4 Falling in Love with Virtual People (Humanoid Robots) 242

11.5 Human Beings, Sex, and Robots 243

11.6 Why People Pay for Sex 244

$\begin{array}{lll}11.7 & \text { Sex Technologies } & 246\end{array}$

11.8 The Mental Leap to Sex with Robots 247

11.9 Answering the Problem Statements 249

11.10 Future Research 249

References $\quad 251$

Appendices $\quad 287$

Appendix A: Additional Aspects of the Physical Design of Robots 287

A1: Feel and Touch Technologies $\quad 290$

A2: Smell and Taste Technologies $\quad 291$

A3: Robot Behaviours $\quad 292$

Summary $\quad 295$

$\begin{array}{ll}\text { Samenvatting } & 299\end{array}$

$\begin{array}{ll}\text { Curriculum Vitae } & 305\end{array}$

$\begin{array}{ll}\text { SIKS Dissertation Series } & 307\end{array}$ 



\section{PART ONE}

This part of the thesis introduces the reader to the world of robotics and to the concept of intimate relationships with artificial partners. We formulate a two-fold problem statement and eight research questions. The thesis outline is given together with some relevant historical background. 


\section{Chapter 1}

\section{INTRODUCTION}

Recent research shows that people perceive and treat robots not just as machines, but also as their companions or artificial partners. Alexander Libin \& Elena Libin (2004)

At the dawn of the $21^{\text {st }}$ century mankind is experiencing an era of phenomenal scientific and technological achievement. Whole disciplines of science that were unheard of even a few decades ago, are now making possible amazing feats in areas such as mobile telephony, computer technology, space research, and medicine. Let me start with the admission that my view of the world is technology driven. My thesis is therefore written from a technology-driven perspective, but the nature of the changes brought about by the progress of science logically leads us to a thorough examination of the factors relevant for a society-driven community of computers and human beings.

Although the thesis emphasises computer technology, it also investigates our intricate relationships with computers and the consequences for our community when the nature of these relationships continues to progress in the direction of intimate relationships and even towards computers becoming artificial partners. It is a fascinating area, which originally belonged to science fiction, but which is now in essence a reality. If we consider the arrival of the computer (see below) to be the first breakthrough in this area, then we may state that intimate relationships with computers will be the second breakthrough in this area.

Our scientific knowledge is growing at an increasing rate. The more we know about a science discipline, the faster we may use the acquired knowledge to discover even more within that discipline. This has been very much the case in the field of computing, a science that was in its infancy only fifty years ago. In those days, the first breakthrough took place. Then, each of the few computers that had been built would fill a room and cost a fortune. At that time, only few people had any idea what these new-fangled machines could be used for. When, in 1943, an American company called International Business Machines Inc. first considered the possibility of manufacturing computers on a commercial basis, the company's founder and president, Thomas J. Watson, pessimistically predicted "I think there is a world market for maybe five computers" (Bell, 1997). How wrong he was! Instead of the computer being something of a commercial white elephant, it became the product for which IBM is best known. By 1981 the computer had become so ubiquitous in industry, in the office, and in academic life, that IBM launched a whole new product category called the Personal Computer, the PC, a computer that was not only more powerful than the multi-million dollar machines of twenty years earlier but which was also affordable for many families and individuals. 
The progress mentioned above continued along a multitude of dimensions. In this chapter I will make an attempt to provide the reader with some insights into the world of advanced computer technology and its ramifications for philosophy, sociology, and gender studies. I start with a brief introduction of Artificial Intelligence and Robotics (section 1.1). Thereafter I show that concepts of these two topics can be used in Agent Technology and Software Agents (section 1.2). My main point is to examine these technological developments in relation to society. This leads to section 1.3: Agents and the Information Society. Here we find the first thoughts towards the realisation of the second breakthrough. Readers who are unfamiliar with the topic and the technological developments may feel some upcoming disbelief. Therefore section 1.4 provides some understanding of the complexity of the relationship between technology and society by introducing the concept of representation in the context of poststructuralist thinking. In section 1.5, I formulate my twofold problem statement which addresses precisely the most intimate imaginable relationships between human beings and artificial partners. In section 1.6, I discuss the relationship from a gender perspective. I start by distinguishing three entities, viz. female human beings, male human beings, and computer entities. In section 1.7 I list my research objectives and my research questions. In section 1.8 I describe my research methodology. Finally, in section 1.9, I provide an overview of the structure of the thesis.

\subsection{Artificial Intelligence and Robotics}

Commensurate with the dramatic growth of scientific knowledge, its main carrier, Computer Science, became a subject that was increasingly studied at universities and research institutes. Within Computer Science, soon there came a newer discipline, called Artificial Intelligence ${ }^{1}$, the science of making computers ${ }^{2}$ that can think. Every science has its own divisions and sub-divisions, and Artificial Intelligence (AI) is no exception. Developing programs to play games such as chess falls within the boundaries of a division of AI called "heuristic programming". Programs that carry on conversations or translate from one language into another are encompassed within the AI discipline of "natural language processing". Amongst the other disciplines within AI there is robotics. Here, we refrain from a complete enumeration of topics investigated in the AI domain. For an adequate list we refer to the Proceedings of the latest IJCAI Conference (2007). Below we focus on the domain of robotics culminating in new research on machine ethics (Anderson and Anderson, 2006).

As the potential usefulness of robots began to be debated, alongside a discussion of the many tedious tasks that humans would sooner delegate to machines rather than perform themselves, so it was realised that the diversity of human activities needs a diversity of assistants, with different robots being designed to perform and solve

\footnotetext{
${ }^{1}$ Also called Machine Intelligence.

${ }^{2}$ In this thesis we do not discriminate between computers and computer programs.

${ }^{3}$ Heuristics are commonsense but often imperfect rules of thumb, designed to speed up the process of finding solutions to certain types of problem.
} 
different tasks. Robots would be needed in industry to operate machines; they would be needed by the military (e.g., the US Army's Future Combat Systems program) and the rescue services to help at disaster sites; they would fulfil a role as replacement or adjunct teachers; they would diagnose illness and assist in the operating theatre. These and many other tasks soon become areas of research for roboticists.

However, the current state of the art in robotics and in other domains within Artificial Intelligence is not what this research is about, it is merely the starting point for the thesis. We already have android robots ${ }^{4}$, whose appearance is designed to resemble humans, such as Honda's ASIMO, Waseda University's WABOT, and Toyota's trumpet-playing robot ${ }^{5}$. Other robots that have already been built include Volkswagen's KLAUS which can drive a car; robots that can mow our lawns and vacuum our carpets; robots that can change their own shape in order to manoeuvre through disaster sites in their search for victims. Moreover, we have human-inspired robots (Coradeschi, 2006) and robots that can reproduce - picking up and assembling the pieces of exact replicas of themselves. In addition, we already have computer software that excels in many intellectually demanding tasks and in most areas of creativity, and we have software that can exhibit humanlike emotions (cf. Anderson, 1993; Pantic, 2001; Thielscher, 2005).

\subsection{Agent Technology and Software Agents}

How all these feats, and many others in AI, have been accomplished, is explained in Robots Unlimited (Levy, 2005), where I also summarize the technologies that will make possible remarkable advances in the power and speed of computer processing during the decades to come. Three important technologies are: DNA computing, quantum computing, and optical computing. When these new computer technologies have been developed to maturity, and when they have been combined with what will then be the latest advances in AI research, we may assume that the intellectual capabilities and the emotional capacities of robots will be nothing short of astounding. The theoretical basis will be Agent Technology. There are many books available on the current state of development of this technology and also on its prospects (cf. Woolridge, 2002; Postma, 2003; Luck, McBurney, and Preist, 2003; Luck, Ashri, and D'Ivorno, 2004). The ideas will be embodied in software agents and soon we may expect that software agents will take over, for instance, the task of public surveillance, as exercised by police officers (cf. Schermer, 2007). When these developments progress further, the software agents will look like human beings (or however we want them to look). Nobody knows precisely what the future will bring.

Yet, based on the recent progress and on my own subjective ideas on future developments, I would like to speculate on three points of development. (1) Future computers will be more creative than the most creative of humans. (2) Future

\footnotetext{
${ }^{4}$ Sometimes called humanoids.

5 The web site http://www.androidworld.com provides an extensive survey, with photographs, both of historical android projects and of current androids and domestic robots.
} 
computers will be able to conduct conversations with us on any subject, at any desired level of intellect and knowledge, in any language, and with any desired voice - male, female, young, old, dull, sexy. (3) Future computers (say robots of the mid- $21^{\text {st }}$ century) will also possess humanlike or super-humanlike consciousness and emotions (cf. Dastani and Meyer, 2006). The third speculation will be the main topic of this research.

\subsection{Agents and the Information Society}

The more humanlike a robot is in its behaviour, in its appearance, and in the manner with which it interacts with us, the more ready we will be to accept it as an entity with which we are willing or even happy to engage.

For this reason, certain trends in toy design can be viewed as precursors to $21^{\text {st }}$ century android-robot designs. While remarkable advances were seen in robotics research during the latter decades of the twentieth century, the cosmetic appearances and forms of dolls and similar toys have been part of a less dramatic but nevertheless important trend in design. Even in some models of that iconic product the Barbie doll, one can now see breasts, while some other dolls, intended for older children and young teenagers, are marketed with a line of seductive-looking lingerie. There have also been boy-shaped characters with prominent penises, marketed as props for use in sex education.

The benefits for human-robot interaction of the human's familiarity with the robot's appearance and behaviour, are mirrored in the relationships between many humans and their pets. The human-pet relationship is also a kind of partnership, with some parallels to certain aspects of human-human relationships. It is a partnership that was enthusiastically seized upon by robot designers in the early days of recreational robots. In the case of traditional family pets: cats, dogs, rabbits or whatever, our relationship partnerships with those animals create a measure of emotional attachment, and have been shown to be of therapeutic benefit to us. To make the partnership work with robots, designers have created robot dogs, such as Sony's AIBO, robot cats, and other animal-like robots, such as FURBY which sold more than 40 million pieces (Hasbro, 2007). FURBY gave almost no appearance of being intelligent, but it was widely perceived as being cute, and not only by children. At a party during the FURBY craze, some attendees brought their children along, but it was the adults who most monopolized the FURBY (Fox, 2007).

While conducting their market research, prior to designing robot pets, the most successful companies have discovered that artificial interactive pets sell better when they resemble real animals in appearance and behaviour, when they simulate the experience of traditional pet ownership, thereby creating similarities that cause our perception of them to influence our emotional attachment to them (Walker et al., 2003). The more animal-like they are, the more we become attached to them. This is especially true with children, who will describe their feelings towards a pet robot in 
terms similar to those they employ when talking about their friends, a phenomenon known as transference ${ }^{6}$.

I am aware that at this moment (2007) many ideas and predictions expressed in this thesis may be met with a certain amount of doubt, or downright disbelief, and possibly even hostility. To justify my own ideas and my belief in them I would like to point to those researchers, who, in the $1960 \mathrm{~s}$, doubted the possibility of an artificial intelligence. One of the most famous outpourings of doubt expressed about AI was triggered by the 1972 book by Berkeley philosopher Hubert Dreyfus (1972): What Computers Can't Do. Dreyfus (1965) had previously announced, in a report for the Rand Corporation, that Artificial Intelligence was a fraud, describing it as alchemy. In 1972 he insisted, as an example of this "fraud", that "Computers can't play real Chess", a statement which Garry Kasparov, Vladimir Kramnik, and many other leading grandmasters, now know, to their cost, to be absurd (Plaat and Schaeffer, 1997; Feist, Friedel, and Wüllenweber, 2006). A similar degree of scepticism has also been applied to many of the advances in scientific, sociological, and philosophical thinking through the ages. As one of the best known examples I would like to mention Charles Darwin's theory of evolution which, in 1925, led to the famous "monkey trial" in Tennessee, when the renowned lawyer Clarence Darrow (Linder, 2000) fought to allow Darwinism to be taught in schools. Even in the $21^{\text {st }}$ century there are objections being raised in some American states to such teachings. In Dover, Pennsylvania, ninth-grade biology instructors must now teach the theory of "intelligent design", a theory that has been described as being a disguised version of creationism, holding that life on earth has been guided and shaped by a divine intelligence (presumably God) and that it did not get this way by the "lucky genetic accidents" of Darwin's (1859) notion of natural selection (CNN, 2005). Meanwhile, in Cobb County, Georgia, in 2002, the school board found itself squeezed under pressure from two groups of parents, one which wanted creationism in the classroom and the other which felt that the Bible has no place in a science class. The school board's compromise was to put stickers on science textbooks saying that evolution is "a theory", not a fact, and should be "approached with an open mind, studied carefully and critically considered.” (CNN, 2005).

Obviously, the above examples serve to show two sides of the same coin. There are people who accept Darwin's theory, just as there are still those who dispute Darwinism. So, there will be those whose doubts towards what will be written here on the intimate relationships between humans and computers will similarly emanate from their religious views. The concepts of love and sex with robots are too speculative for them to be acceptable on first consideration. On the contrary, a significant proportion of readers may deride these ideas. Yet, I believe that it is the

\footnotetext{
6 The term "transference" was originally coined in psychology to describe the process whereby a significant relationship early in one's life can be responsible for transferring one's feelings about that person to a psychoanalyst encountered later in life. For example, a patient who had a cold and distant father might view their psychoanalyst as being cold and distant. As transference theory developed within the field of psychology, so the term also came to refer to a similar phenomenon but with people other than one's psychoanalyst. Recent psychoanalytic thinking has further adapted the term to apply "to relationships people have with modern technologies, especially computers." (Walker et al., 2003). The subject of transference is discussed further in Chapter 7.
} 
task of researchers to look for the frontiers of scientific developments, disregarding the direction of the development. In this vein, I have to admit that all researchers will have their own ethical boundaries on what to investigate and what not. Clearly, the intimate partnership relationships between human beings and computers is within my own ethical area of research topics. From my point of view, I would like to defend my position by a comparison with three hostilities from the past, viz. (1) towards the "ridiculous" notion that the earth is round rather than flat, (2) towards the suggestion that our planet is on the edge of our galaxy rather than at its centre, and (3) towards the evolutionary studies that have shown man to be related to the apes (Darwin, 1859). Such hostility always takes its time to dissipate, but dissipate it does. We like to think of ourselves as "special" beings - special in the sense that our consciousness raises us above every other form of life. But as psychologists, brain researchers, and other scientists learn more and more about the workings of the human mind, making the workings of the mind clearly explicable where now they are shrouded in mystery, then and only then will it become generally accepted that, marvellous though the human brain is, it is a kind of biological machine that can be analysed and simulated, even to the point of simulating our emotions (cf. Shannon in an interview conducted by Van den Herik (1989)).

Given the drastic technological changes and advances that the world has witnessed during the past fifty years, any assumptions of (un)likelihood or (im)possibility regarding our technological future are risky. Would those amongst you who are sceptics have believed, 50 years ago, that the accolade awarded annually by Time magazine for the Man or Woman of the year would, in January 1983, be given instead to the computer? (Time, 1983). And is it any more unlikely that, by 2033, that same accolade will be awarded to the android - a humanlike robot?

\subsection{Representation in the Context of Poststructuralist Thinking ${ }^{7}$}

The tasks that the early robots were designed to help solve had little to do with human emotions and therefore they did not require any emotional response from a robot. But as psychology and cognitive science began to be studied in relation to robots, so it became apparent that we need to consider what relationships might one day develop between man and machine, between human and robot. Suddenly, it becomes important to think about what might happen when a robot communicates with a human on a personal level rather than merely for pragmatic reasons linked to the robot's "mechanical" functionality. Then it will be no longer enough for the human to press a button or say "Please bring me a cup of tea", and for the robot to do as requested. Instead, a new generation of AI researchers started investigating more meaningful relationships between humans and what Alexander Libin (2003) has called "artificial partners". Below we look to the origins of these developments, to some of the main questions, and to the possibilities to represent the answers and

\footnotetext{
${ }^{7}$ Poststructualism is one of the most influential intellectual (philosophical) movements founded in the late twentieth century. It is a stream of critical theory which resists precise definitions and changes the way we understand the relationships between human beings, their culture, and the world.
} 
solutions to the questions adequately in concepts that can be incorporated or even assimilated in computer programs.

We see at the origins of this research the Japanese scientists who have led the research in "partner robots", recognizing that "Robots increasingly have the potential to interact with people in daily life. It is believed that, based on this ability, they will play an essential role in human society in the not-so-distant future." (Kanda et al., 2004b). In section 1.3 we have already given some straightforward examples of this development. Below we focus on the presumed meaning of the reactions by the robots.

At the present time (2007), I know that there are those who doubt that we can reasonably ascribe feelings to robots. However, if a robot behaves as though it has feelings, can we reasonably argue that it does not? If a robot's artificial emotions prompt it to say things such as "I love you", surely we should be willing to accept these statements at face value, provided that the robot's other behaviour patterns back them up. When a robot says that it feels hot, and we know that the room temperature is significantly higher than normal, we will accept that the robot feels hot. When it says that the piano is being played too loudly, recognizing of course that it is listening to a piano, we will accept that the music is too loud for the robot if it also sounds loud to us. Just as a robot will learn or be programmed to recognize certain states: hot/cold, loud/quiet, soft/hard, and to express feelings about them, feelings that we accept as true because we feel the same in the same circumstances, why, if a robot that we know to be emotionally intelligent, says "I love you", should we doubt it? A second argument is that, if we accept that a robot can think, then there is no good reason why we should not also accept that it could have feelings. Even though we know that a robot has been designed to express whatever feelings or statements of love we witness from it, that is surely no justification for denying that those feelings exist, no matter what the robot is made of nor what we might know about how it was designed and built. Yet, the latter statement triggers our idea on the representation of these feelings. Such a representation should be seen in the context of poststructuralist thinking.

The first publications on Artificial Intelligence (Turing, 1950; Shannon, 1950) were published in philosophical journals and dealt with the questions: (1) Can Machines Think? (Turing) and (2) Can Machines Play Chess? (Shannon). These intriguing questions led to a stream of publications in which the representation of objects, notions, concepts, feelings, emotions, and ideas played a major part, as did the question: what is the power of a representation? As stated above, some scientists doubt whether we can reasonably ascribe feelings to a robot. However, others believe that this will be the case and attempt to develop structured ideas in this direction. One of the interesting developments in this respect is in the context of poststructuralist thinking.

Currently, we are facing an emergent virtual world, and two main questions here (at least for our research) are: (1) is the representation as just as powerful as the original it represents?; and (2) is it true that reality can only be known through representation? Previously, analogous questions have been addressed by the French 
philosopher Jean Baudrillard (1988) in his article Simulacra and Simulation. He addressed real things and simulations. Moreover, he assumed that a simulator produces "true symptoms" and he wondered how we should deal with the representation, the generalisation, and the abstraction. Below, we provide some of his ideas on the latter concept. Baudrillard started his article with a fable by Borges on designing a map of a part of the world so precisely that it becomes worthless. Consequently he makes a request for abstraction. "Abstraction today [1988] is no longer that of the map, the double, the mirror or the concept. Simulation is no longer that of a territory, a referential being nor a substance. It is the generation by models of a real without origin or reality: a hyperreal. The territory no longer precedes the map, nor survives it. Henceforth, it is the map that precedes the territory - precision of simulacra - it is the map that engenders the territory and if we were to revive the fable today, it would be the territory whose shreds are slowly rotting across the map."

Before Baudrillard starts discussing 'representation' he embarks upon the concept of reduplication. In this respect he puts the following relevant question: "What can psychoanalysis do with the reduplication of the discourse of the unconscious in a discourse of simulation that can never be unmasked, since it isn't false either?"

In the context of this thesis we should not forget that part of Baudrillard's (1988) article deals with the (non)existence of God, of Whom he cannot find a representation. Briefly stated, Baudrillard's notion of representation is "a visible and intelligible mediation of the real."

Here we would like to take a step to the virtual world, as it is envisaged by many scientists who see broad prospects for applications on the Internet. What type of world will this virtual world be? It is not fully clear at this moment. When we follow the reasoning by Baudrillard (1988) on the world in which God plays a front-ranked role, we know an answer.

First, since it is impossible to make a representation of God, Baudrillard (1988) assumes that the world is to be characterised as a world in which God is simulated.

Second, he abandons this world as follows: "Then the whole system becomes weightless: it is no longer anything but a gigantic simulacrum: not unreal, but a simulacrum, never again exchanging for what is real, but exchanging in itself, in an uninterrupted circuit without reference of circumference."

Third, the simulation is addressed as opposing the representation. The relevant paragraph of Baudrillard's argument reads as follows: "So it is with simulation, insofar as it is opposed to representation. Representation starts from the principle that the sign and the real are equivalent (even if this equivalence is Utopian, it is a fundamental axiom). Conversely, simulation starts from the Utopia of this principle of equivalence, from the radical negation of the sign as value, from the sign as reversion and death sentence of every reference. Whereas representation tries to absorb simulation by interpreting it as false representation, simulation envelops the whole edifice of representation as itself a simulacrum." 
Fourth, Baudrillard enumerates the successive phases through which the image (seen as a simulation) has to go in order to end as a simulacrum. We first quote Baudrillard and then argue that, at this point, our theoretical foundation diverges from Baudrillard's, since the new virtual world will be built on representations and not on images. According to Baudrillard (1988):

" These would be the successive phases of the image:

1. It is the reflection of a basic reality.

2. It masks and prevents a basic reality.

3. It masks the absence of a basic reality.

4. It bears no relation to any reality whatever: it is its own pure simulacrum."

In our opinion, the existence of the virtual world is dependent on (1) the occurrences of actual representations in the virtual world, and (2) the power of these representations. However, according to Baudrillard (1988), we cannot escape with this reasoning, since he believes that we live in a world where the so-called real thing cannot be distinguished anymore from the imitation, to such an extent that the distinction between real and imitation has vanished.

In the world of Computer Science we see similar developments. For instance, in the world of Law and Computer Science, there is no distinction anymore between an original and a copy. The paper original is printed from the bits and bytes where the original nowadays resides, in the same way as the subsequent copies are printed. The idea that copies are exact photocopies of the original made by a photocopier has disappeared. The difference between original and copy has been vanished. However, our question is: did the concept of a representation develop along the same lines? In the beginning of these developments, knowledge representation played a major role in building expert systems. Obviously, search without knowledge was blind search, and knowledge without any search was seldom mature enough to solve the problem at hand. The combination of ideas was assembled in the so-called Physical Symbol Systems Hypothesis "a physical symbol system has the necessary and sufficient means for general intelligent action" (Newell and Simon, 1975, 1976).

This hypothesis was designed by Newell and Simon in the course of their long lasting research collaboration. It was an important factor in their being chosen as the recipients of the 1975 Turing Award (see Ashenhurst and Graham, 1987), though in everyday research it turned out that not all problems could be solved by incorporating their ideas. Many sub-symbolic systems were developed, among them neural networks. Recently, the emphasis has been on situated representation (see, e.g., Van Dartel, 2005, p. 4), which seems to be a key issue in the development of future representations for the virtual world. Van Dartel $(2005$, p. 12) describes a situated representation as follows: "situated representation encompasses sensory systems and motor systems, and is related to the way these systems are coordinated to function in a dynamic environment." Van Dartel (2005, p. 14) continues: "The nature of representation depends on whether a situated system exhibits reactive behaviour or non-reactive behaviour." One of the reasons for the potential success of situated representations is that they seem to be able to provide reactive agents 
with adequate representations so that they can handle perceptual ambiguity (Van Dartel et al., 2005).

The philosophical discussions with Baudrillard cannot, as matters stand now, be decided by an exchange of argument. The outcome of the discussion will be guided by empirical evidence. This conclusion brings us to our problem statement.

\subsection{Problem Statement}

The mere concept of an artificial partner, husband, wife, friend, or lover, is one that challenges our notion of relationships. Previously, a relationship between robot and human has always been considered in terms of master-to-slave (roughly from 1950 to 1980) and then, of human-to-machine (since 1980). There was no difference in the matter of concept, but it was a way of using the correct terminology. With the addition of artificial intelligence to the machines, we have now made them into something much more. They might still be programmed to do our bidding, but they are also being programmed to consider not only our practical wishes, but also our feelings. By endowing robots with the capability of communicating with us at a level we can understand, a human level, and by building robots that have at least some appearance of humanlike features, we are rapidly moving towards an era when robots not only interact with us in a functional sense but also in a personal sense. The personal digital assistant (PDA) is a first sign of this development.

This thesis sets out to answer a twofold problem statement concerning the type of relationships between human beings and some kind of robot that will be created during the coming decades. The problem statement (PS) is formulated as follows.

PS1: $\quad$ To what extent will the emotions that humans feel for other humans, for pet animals, for virtual pets, and even for less animal-like artefacts - namely computers, be extended to embrace the robots of the future?

and

PS2: $\quad$ To what extent will the normal bounds of human sexuality be extended with respect to the robots of the future?

In order to answer PS1 it is necessary to examine the reasons why humans develop strong emotional feelings of attraction (leading to attachment or love) to other humans, why humans develop strong emotional attachments to pet animals and to virtual pets, and why humans develop emotional attachments to computers. We can then consider how these reasons might also apply to human-robot relationships.

In order to answer PS2 it is necessary to examine, largely from a psychological perspective, the reasons why humans enjoy sex, why humans desire sex, and whether love as we know it, love from our chosen sex object, is an essential factor for our sexual enjoyment and gratification. Having sufficient knowledge of these 
topics we can then consider how and to what extent their normal bounds will be extended.

I should emphasize here that in this thesis I take great pains to avoid falling into the group described by Rein de Wilde (2000) as "digerati (prophets of a digital life)". The very word "prophet" implies a lack of reality, but my predictions are not prophecies - they are forecasts based on the observations of trends, in somewhat the same way as weather forecasts are based on observing the trend of a front, or an ocean current, or a low or high pressure area, to move along a particular path. Such forecasts are based on reliable observations, and on considered extrapolations from those observations. When, for example, this thesis refers to robots exhibiting emotions and personalities, the underlying observations are of the research that has already been conducted in these fields, the increase in such research in recent years, the progress that has been made by researchers since the inception of this field, and what we may, with the sacrifice of only a modicum of scientific rigour, describe as the inevitability that this research will one day result in artificial emotions and artificial personalities that are sufficiently sophisticated and humanlike to attract us. In summary, it would be unreasonable to describe the forecasts in this thesis as being mere prophecies or being of dubious scientific origin. Rather I claim that they are reasonable expectations, based partly on trends that started in the past, and partly on technologies that exist today. These expectations thus "respond to the present", to quote De Wilde (2000).

\subsection{The Topic in Gender Perspective}

The problem statement has been phrased in terms of humans and computers. For the human side we have two types of gender: masculine and feminine. For the computer side, the question of gender is not so clear since the Internet may enable new identities not limited by gender. For instance, Braidotti (1996) suggested that the Internet might enable a transgression of the dichotomous categories of male and female towards transgender or genderless entities. According to Braidotti "postmodernity ${ }^{8}$ is about a new and perversely fruitful alliance between technology and culture" and "the technological factor must be seen as co-extensive with and inter-mingled with the human." These two thoughts lead her to the following conclusion: "This mutual imbrication makes it necessary to speak of technology as a material and symbolic apparatus, i.e., a semiotic and social agent among others."

In the context of our study we are particularly interested in embodiment and situated representations. Braidotti (1996) remarks on these two topics as follows: "I would like to suggest as a consequence that it is more adequate to speak of our body in terms of embodiment, that is to say of multiple bodies or sets of embodied positions. Embodiment means that we are situated subjects, capable of performing sets of

\footnotetext{
${ }^{8}$ Postmodern philosophy is an intellectual movement characterized by its criticism of the conventions of Western philosophy. It can be described as a set of critical, strategic and rhetorical practices employing concepts such as difference, repetition, the simulacrum and hyper-reality to destabilize other concepts such as presence, identity, historical progress, epistemic certainty, and the univocity of meaning.
} 
(inter)actions which are - discontinuous in space and time. Embodied subjectivity is thus a paradox that rests simultaneously on the historical decline of mind/body distinctions and the proliferation of discourses about the body."

So far, the Internet has been claimed by a variety of gender specialists "as feminine, masculine and as beyond gender" (Van Zoonen, 2002). In a well-thought essay on "Gendering the Internet, Claims, Controversies and Cultures" Van Zoonen (2002) takes as her starting point: "The easy solution to these contradictions would be to say that the Internet is so vast and complex that all three positions are true and exist easily alongside each other." She discusses all three positions, which she called: the masculine domain, the feminine domain, and cyberfeminism.

According to van Zoonen, in gender theory the notion of gender is understood as referring to three dimensions:

“(1) social structures which relegate women and men to different social positions,

(2) individual identities and experience of what it means to be a woman or a man, and

(3) symbolic organisations of society in which several dualities like nature/culture, private/public, leisure/work, coincide with female/male." [the numbering is mine].

The masculine domain is mainly based on the symbolic dimension. The feminine domain is frequently built on a limited conceptualisation of gender, in particular on gender as identity (Van Zoonen, 2002). Subsequently, Van Zoonen admits that these two assignments of dimensions are too weak, by stating: "Such an understanding, however, ignores the social fact of male-dominated actor networks, and the symbolic reconstructions of traditional gender on the levels of texts and representations." As a result, she arrives at cyberfeminism, which she defines as follows: "Cyberfeminism, in its aims to undermine the concept of gender in all its dimensions all together, operates particularly at the level of representations, and is much less concerned with social actor or individual identity."

In this thesis we look primarily from a technology-driven perspective towards Internet developments and prefer, in that respect, to speak of a virtual world. Yet, it is important to see what cultural processes are expected to play a role in that world. Van Zoonen (2002) is quite clear on this point: "Five cultural processes are identified - representation, identity, production, consumption and regulation which when applied to the Internet raise questions as to how the Internet is represented and which representation it carries, what social identities are associated with it, how is it produced and consumed, and what mechanisms regulate its distribution use."

Clearly, we are in the world of postmodernity, where we look for structures, representations, identity, and situatedness. Our problem statement contains two questions that aim at feelings, attachment, love, and sex in the context of humanrobot relationships. In these questions we meet the concept of gender at two levels 
or, to be more precise, in two worlds: the human world and the virtual world. For now I propose to deal with these worlds as separate domains between which there exists a set of relationships. In the human world we use the gender perspective by investigating female and male perspectives in all relationships discussed in that world. Since we focus on relationships between humans and robots we have to restrict our topic of research and mainly examine heterogonous relationships whatever that would mean in the virtual world. Here the claims about the Internet by Van Zoonen (2002) may help. She states: "The claims for masculinity are located in the moments of design, development and production, and in the moments of representation. The claims for femininity are mainly located in the moments of marketing, distribution and use, whereas cyberfeminism manifests itself foremost in moments of a representation." This brings us to the question posed in section 1.4 on poststructuralist thinking: what is the power of representation? This question will play an important part in answering my research questions.

\subsection{Research Objectives and Research Questions}

In her groundbreaking book The Second Self, Sherry Turkle (1984) eloquently makes the point that we should be asking the question, "not what the computer will be like in the future, but instead, what will we be like? What kind of people are we becoming?" This question can be seen as the starting point of the thesis. Accepting that huge technological advances will be achieved by around 2050, many scientific conjectures can be formulated as to the talents robots will possess. I would not like to speculate at this point on the plethora of possibilities, but in my opinion it is certain that robots will transform human notions. This may imply a change of notions with respect to love and sexuality, too. Many humans will expand their horizons of love and sex, learning, experimenting, and enjoying new forms of relationship that will be made possible, pleasurable, and satisfying through the development of highly sophisticated humanoid robots.

This is the start of an answer to Turkle's (1984) question "What kind of people are we becoming?" So my research objectives are twofold, fully corresponding to the twofold problem statement, namely to demonstrate that: (1) Humans will develop strong emotional feelings of attraction (leading to attachment or love) to robots as (what will be regarded as) "normal" extensions of our feelings (attachments or love) to other humans. (2) Sex with robots will be as normal as sex with other humans, while the number of sexual acts and love-making positions commonly practiced between humans will be extended, as robots teach more than is in all of the world's published sex manuals combined.

I accept that there is a wide gap to bridge in order to achieve these two research objectives. Therefore I have formulated eight research questions (RQ) which I intend to investigate and answer in the following chapters. The research questions are divided into two groups, dealt with in Part Two and Part Three of the thesis, respectively. The first four questions (RQ1 to RQ4) belong to PS1. Their answers are aimed at investigating to what extent it is worthwhile to address PS2. The 
second group of four questions (RQ5 to RQ8) belongs to the PS2 part of the problem statement. All answers together are aimed at investigating to what extent both research objectives are achieved.

In Part Two the following questions are discussed.

RQ1: Is it possible to trace what (precisely) causes people to develop strong emotional feelings of attraction (leading to attachment or love)?

RQ2: What characterizes the affective relationship between humans and pets?

RQ3: What is the attractive power of a virtual pet?

RQ4: What is the attraction of a humanoid robot for a human being?

In Part Three the questions mentioned below are discussed.

RQ5: Why do people enjoy sex?

RQ6: Why do people pay for sex?

RQ7: What technologies are available to be used as sex technologies?

RQ8: What mental obstacles exist to prevent the final step towards the second objective?

\subsection{Methodology}

The research methodology is described below, together with the areas of research. The first four research questions have a focus on emotional feelings, attraction, attachment, and love (see also PS1). The second group of four research questions has an emphasis on sex. In both cases, I consider how the historical and sociological trends (both those of the human attitude and those of artefacts) are likely to be extended during the coming decades, as technological advances make it possible to develop increasingly sophisticated robot partners.

The investigations have been based on the results of a thorough search of the literature in a number of disciplines, as the list of references attests: psychology, sociology, psycho-physiology, philosophy, gender studies, artificial intelligence, human-computer interfaces, robotics, and sexology. The resulting data were like the pieces of a jigsaw or, to be more precise, the pieces of the eight jigsaws that correspond to the eight chapters of the thesis that answer the eight specific research questions.

As to the research methodology, it is clear that an adequate literature search is of the utmost importance. In this respect the Internet search facilities and my extensive use of the facilities at the British Library helped me considerably, as did the many suggestions I have received. Although the search will never be complete, I feel that the retrieval result is of sufficient quality and quantity for reliable analyses to be made. Multi-faceted analysis is the second step in the research methodology. My background as a computer scientist enabled me to recognize the implications of new technological developments. My work as an artificial intelligence specialist helped me to explain new directions that were hinted at in the literature. My interest for (chess) psychology and philosophy stimulated me to grasp the meaning of the 
developments in that direction. Finally, the support and feedback I received from many people when I was busy with my analysis, gave me the feeling that I was performing a Delphic session with experts.

After a thorough literature research and some years of analyses I entered the stage of exploration. However, the explorative nature of the ideas are mostly rooted in the developments which we have seen in the past fifty years (some developments go back much farther). Since technological development moves very fast, some parts of my analysis could be verified even during the period of my research.

\subsection{Thesis Structure: an Overview}

Below I provide a brief overview of the thesis in which the emphasis falls on its structure. The thesis discusses intimate relationships between humans and artificial partners. For addressing this topic I have formulated a twofold problem statement in Chapter 1 together with two research objectives and eight research questions. Moreover, in Chapter 1 I give a brief introduction into the topic and explain my research methodology. In Chapter 2 I provide the relevant historical background. These two chapters make up Part One. The remainder of the thesis consists of three parts. Part Two (Chapters 3 to 6) deals with the first four research questions and aims at achieving the first main research objective. Part Three (Chapters 7 to 10) investigates and answers research questions 5 to 8 , and aims at achieving the second main research objective. Part Four brings the results together in Chapter 11, and then provides conclusions and recommendations.

The way to that final chapter is complex, full of obstacles, but above all scientifically interesting and psychologically an eye-opener for scientists who are not familiar with the progress that has been achieved in artificial intelligence and robotics. 



\section{Chapter 2}

\section{HISTORICAL BACKGROUND}

Primus: You're beautiful.

Helena: Me? Don't be silly, Primus, why are you saying that?

Primus: Believe me, Helena, I'm stronger than all the other robots.

Helena: Me, beautiful? But my hair is horrible, I wish I could do something about it! Out there in the garden I always put flowers in my hair, although there isn't any mirror there or anyone to see them. You, beautiful? What's beautiful about you? Is hair beautiful if all it does is weigh you down? Are eyes beautiful when you close them? Are lips beautiful if all you do is bite them and then it hurts? What is beautiful, what's it for?

Karel Čapek (1923)

The word "robot" was suggested by Josef Čapek ${ }^{1}$ in discussion with his more famous brother, the Czechoslovak writer Karel Capek ${ }^{2}$. "Robot" is derived from the Czech "robota" ("forced labour") and was first revealed in the West when Karel used it in the title of his play Rossum's Universal Robots (R.U.R.), an immediate hit when it had its premier performance on Broadway. The literal meaning of robot is worker. The robots in Karel Čapek's (1923) play were creature machines, resembling humans in appearance, designed and built to serve as workers for their human masters. But, as the above dialogue between Primus and Helena, two of the robots in the play, shows, they could also fall in love.

Although the word robot was new in the early 1920s, the idea of an artificial form of life was by no means a new one in Čapek's day. Inventors and engineers had, for roughly two millennia, devised automata that simulated some of the functions of living creatures. Here we mention that, in the beginning, the emphasis was on mimicking a function and, after some successes, it shifted towards mimicking living creatures. The first steps were performed out of curiosity, but we may wonder at what time curiosity was replaced by well-thought investigations with the intent to serve philosophical and psychological ideas (or even theories that were developed at that time). For instance, the birthing machine at the end of section 2.1 may raise such questions (see further in that section).

\footnotetext{
${ }^{1}$ The accented letter $\check{C}$ is pronounced like "ch" in chicken.

${ }^{2}$ It had long been wrongly believed that the word had first been used by Josef in his short story Opilec, (Drunkard), but recent research by two Czech scholars (Horáková and Kelemen, 2003) reveals the true origin of the word.
} 
This chapter provides a brief overview of the successes achieved in creating mechanical artefacts, robots, and computers over a period of more than twenty centuries.

I am aware of the abundant literature on these achievements. Many voluminous works exist on the topics indicated in all ten sections of this chapter. For a handsome overview I refer the reader to Living Dolls, a Magical History of the Quest for Mechanical Life (Wood, 2002). The order of sections in this chapter ranges from pure mechanical functions (2.1) via thinking (in this case: chess playing, see 2.2), and via social behaviour (tea-carrying dolls, see 2.3) towards universal robots (see 2.4) (all based on mechanical artefacts). Of course, attention is also paid to the background of these developments, cybernetics (2.5). I then follow the modern approaches based on computers as indicated below: artificial intelligence (2.6), industrial applications and service robots (2.7), entertainment robots (2.8). The chapter concludes with interactive robots (2.9) and a description of new developments (2.10).

\subsection{Mechanical Marvels}

One of the earliest engineers to create mechanical marvels was $\mathrm{Heron}^{3}$ of Alexandria, who lived in the first century ${ }^{4}$. Amongst his many inventions in the fields of pneumatics, mechanics, and dioptics, there were some mechanical inventions that were marvels for their time. For instance, Heron constructed waterpowered mechanical birds, as well as entire flocks of birds, that even emitted realistic chirping sounds created by a water driven device (Woodcroft, 1851; Schmidt, 1899). If we must question Heron's contributions as to their purpose, we may say: he was a curiosity-driven engineer.

The public's fascination for automata reached its first peak in France in the eighteenth century. One example of this genre was a menacing mechanical owl together with a group of smaller birds, designed in 1644 by the French engineer Isaac de Caus (Riskin, 2003b). The smaller birds would flutter their wings and chirp while the owl slowly moved on a pivot to face them. As the owl's face turned towards the smaller birds, appearing to threaten them, they became still and stopped their chirping. When the owl's face then turned away from the group, the smaller birds came alive again. The whole mechanism was driven by a water wheel that controlled the actions of each bird by means of a metal cylinder, the surface of which was embedded with pins, just like a musical box. As the cylinder turned, through the force of the water, the pins on the cylinder would engage with a musicbox-like mechanism so that each pin created its own effect or movement in one of the birds.

\footnotetext{
${ }^{3}$ Also known as Hero.

${ }^{4}$ Until 1938 there had been some doubt about Heron's dates, some sources believing it to be around 150 B.C. and others around A.D. 250. Then Otto Neugebauer noted (Keyser, 1988) that Heron had written about a "recent eclipse" which, from the information given by Heron in his writings, was dated to one that took place at Alexandria on March $13^{\text {th }}$ A.D. 62.
} 
Following de Caus's example, at least two other French automaton inventors also used birds as the embodiments for some of their mechanical marvels (Riskin, 2003b). In 1733 an inventor called Maillard designed a mechanical swan that would paddle through the water while its head moved slowly from side to side. Maillard's idea was as simple as it was clever. A paddle wheel, similar to those found in the Mississippi steamboats, propelled the swan forwards, whilst simultaneously being connected, via a system of gears, with the swan's head. As the paddle-wheel rotated it thus served a dual purpose, creating the forward motion of the swan's body and the simultaneous side-to-side motion of its head.

An even more advanced idea, and a more entertaining example of this genre, was a mechanical defecating duck, the creation of Jacques Vaucanson (Riskin, 2003b). The duck could bend its neck, move its wings and its feet, and it could "eat". It would stretch out its neck to peck at corn offered by a human hand, then swallow the corn, digest it, and finally excrete it, the corn having been turned into excrement by some sort of chemical process, according to Vaucanson. In fact the "digestion" and "excretion" processes were parts of a hoax. The corn, once eaten, was held in a recepticle at the lower end of the duck's throat, while the duck's "excrement" was not genuine duck shit but some other material that had been inserted in the duck's rear end prior to a demonstration.

We may ask ourselves: what purpose did Vaucanson serve? (The same question holds for de Caus and Maillard). One answer is that he might have been driven by curiosity - whether it is possible to fool people with mechanic tricks; but a different purpose seems more probable, viz. he was on his way to structure his thoughts and made the first steps in an interesting research direction which, at that time, was too overwhelming to be made explicitly.

That Vaucanson's duck did not actually digest its food and shit, in no way diminishes its contribution as a precursor to humanlike robotics. One of the principal achievements of Vaucanson and his peers was the stimulation of widespread interest in the mechanical aspects of what is now known as artificial life. That era saw the creation of automata that could not only eat but also breathe; automata with soft skin, flexible lips and delicately moving jointed fingers ${ }^{5}$.

Curiosity and goal-directed research are two driving forces for the development of new automata, but education is certainly a third driving force. This holds in particular if education coincides with social aspects and with improving the health of the community. So, in this vein, a remarkable example of a humanlike automaton was a birthing machine designed in the mid-eighteenth century by Angélique du Coudray, midwife to the royal court of France. The purpose of this machine was to assist in the teaching of midwifery, as a result of which many examples of the machine were made and sent to doctors and midwives throughout France. Du Coudray's machine was made of wicker, stuffed linen and leather, dyed in various

\footnotetext{
${ }^{5}$ An extremely comprehensive and valuable account of the history of such automata is provided in two papers by Jessica Riskin (2003a,b).
} 
flesh-like colours, some pale and some of a deeper red, to simulate the softness and appearance of a woman's skin and organs. The pelvic bones of human skeletons were used in some of her machines, and sponges soaked in liquids coloured red and other hues were used inside the machine, releasing their simulated bodily fluids at appropriate stages of the lectures on the birthing process ${ }^{6}$.

\subsection{A Chess-playing Automaton}

While Vaucanson and his peers managed the simulation of physiological and other natural bodily processes, there were other inventors who focussed on simulating the processes of thought. In 1768 the Frenchman Pelletier gave a demonstration at the court of Maria Theresia based on magnetism. At the end of the ceremony Baron Wolfgang von Kempelen, a "Hofrat" (scientific advisor) to the royal court of Vienna, whispered to the Empress that he was not impressed by the performance and promised her that next year he would present a much better performance. In retrospect, it is not clear whether he then had it in mind to construct a "real" automatic chess player and that he failed to do so, or that he had no idea what to show the following year but relied on his experience to invent something, since von Kempelen had already invented a voice imitator (an automatic sound generating bellows) and the dug fire channels used in the war against Hungary that established the Hapsburg double monarchy.

Whatever the source of his motivation, he designed a chess-playing automaton in the guise of a Turk seated on a wooden box. Despite his assurances to the contrary, and his magician-like demonstrations to convince his audiences that the wooden box contained nothing untoward, there was in fact a (small) strong human player secreted in the box, a player who vanquished all chess enthusiasts who tried their luck against "the Turk" (Levy, 2005). There is a considerable body of research publications on this topic, by historians and philosophers as well as by computer scientists. In particular, AI researchers have taken the "presentation" by von Kempelen, at Maria Theresa's court in Vienna in 1769, as the start of their research, since his ideas clearly announced new developments in the generation of artificial chessplayers (cf. Van den Herik, 1983).

In the $19^{\text {th }}$ century two other chess machines were developed, viz. MEPHISTO and AJEEB. They, too, were frauds, but the idea was born that machines could think or reason logically. The analytical engine invented by Charles Babbage (Levy, 2005) can be seen as another frontrunner of the idea that the research question: "Can machines think?" should be investigated.

\footnotetext{
${ }^{6}$ The only known example still extant is in the Musée Flaubert in Rouen, France, a museum of the history of medicine.
} 


\subsection{Tea-carrying Dolls}

On the far side of the world, the Japanese interest in robotics also dates back to the eighteenth century, during the Edo period in Japanese history, with the design of a tea-carrying doll. In Japan the emphasis was on developing the social aspects of a robot. When a host, seated opposite his guest, placed a cup of tea in the doll's hands, it carried the cup to the guest who then took the cup from the doll, whereupon the doll stopped moving (Shibata, 2004). After drinking the tea, the guest put the cup back into the doll's hands, the weight of the cup causing the doll to turn around and return to the host with the empty cup. These dolls were fashioned in the form of an appealing looking child, with its technology hidden inside it, creating an aura of mystery and magic. Rather than designing their automata to look animal-like, as many of the French inventors had done, the Japanese had realised, more than 200 years ago, that automata are more appealing if presented in the guise of humans, a realisation that anticipated some of the research described in Chapter 6.

These eighteenth century marvels did much to create a climate of interest in the notion that human and animal-like bodily and mental processes can be successfully simulated. The mimicking of bodily functions and of social aspects also continued its development in the $19^{\text {th }}$ century.

By 1830 walking dolls were being constructed and exhibited in Paris, and soon thereafter came dolls with moving eyes. Next came dolls that could eat, drink, dance, breathe, and swim (in three different strokes: backstroke, breast stroke, and crawl). For those that could drink, one inventor, Leon Bru, created an artificial bladder, so that after taking a drink his dolls could pee. It was in this climate, and with the benefit of the nineteenth century development of electricity, that the idea of robots as we now see them began to take root.

\section{$2.4 \quad$ Universal Robots}

Karel Čapek's vision typified the robots by three characteristics, viz. (1) robots that could think for themselves, (2) robots with feelings, and (3) robots that could fall in love with each other. In Rossum's Universal Robots (Čapek, 1923) one of the scientists at the robot factory came up with the idea of endowing the robots with emotions, which led to their developing feelings of anathema at their treatment as the slaves of human masters. Čapek had the foresight to predict what some people today fear about a future with robots - that they will "take over the world" - and in his play the robots decided to rebel and kill all human beings. (In passing, I would like to note here that there is an important lesson for us to learn - when the robots of the mid- $21^{\text {st }}$ century are endowed with humanlike or super-human emotions, we should not treat them like slaves but in a civilized way, as we would wish to be treated by them or by our fellow human beings.)

When it premiered in New York in 1922, Rossum's Universal Robots was hailed by one critic as a "brilliant satire on our mechanized society", and the concept of robots 
as Čapek envisioned them was taken up by several science-fiction writers, most notably Isaac Asimov (1942). In 1940 Asimov reacted to the plethora of books and stories that had already been published, in which man created robots that became killers. Asimov (1942) proposed three "laws of robotics", later augmented by a fourth law, called the "zeroth law" (1988), all designed to safeguard mankind's interests in the face of whatever ideas the robots of the future might develop ${ }^{7}$.

\subsection{Cybernetics}

In the middle of the twentieth century, the founding father of the science of Cybernetics $^{8}$, Norbert Wiener (1948), extolled the virtues of the interactive robots of the future. He stressed their ability to learn from experience and, as a result of what they would learn, to improve the lot of those with whom they would be interacting. The psychological benefits of such robots would, he asserted, would be similar to the psychological benefits that the cared-for receive from their human carers. If materialized, this would be a big leap forwards. Of course, such progress is implicit in the name cybernetics, but in that era the time was not ripe for such advanced ideas. There were at least three obstacles. First, to gain acceptance by the humans with whom they are interacting. Second, to imitate at least some of the social cues of those for whom they are caring. Third, to be at least vaguely similar to us in appearance (see, e.g., Figure 1).

As an example of obstacle 3, Figure 2.1 shows the Kismet robot designed and built at MIT by a team led by Cynthia Breazeal (2002). It has a head, as we do; it has eyes, as we do; it has a mouth with moving lips, as we do. It is not so difficult to image that a human interacting with a robot will be more at ease if the robot exhibits some human appearance and characteristics, than if the robot is merely a metal box with wires, lights, and wheels. So, even nowadays we are not fully up to the level that Wiener envisaged around 1950.

Obviously, the ideas of Cybernetics came too early to have a chance of being fully realised. We consider it beyond the scope of our research to examine Norbert Wiener's (1948) concept to a greater depth. Many of his ideas were mathematically oriented and, due to him, we have now the notion of employing a heuristic to guide our search processes within a very large search space.

\footnotetext{
${ }^{7}$ Asimov's (1942) laws, the first three of which were introduced to the public in his 1942 short story "Runaround", are: [1] A robot may not injure a human being or, through inaction, allow a human being to come to harm. [2] A robot must obey the orders given it by human beings except where such orders would conflict with the First Law. [3] A robot must protect its own existence so long as such protection does not conflict with the First or Second Law. [4] A robot may not injure humanity, or, through inaction, allow humanity to come to harm.

${ }^{8}$ Cybernetics is the science of control and communication, with an emphasis on self-controlling and selfadaptive systems, i.e., autonomous systems that can learn.
} 


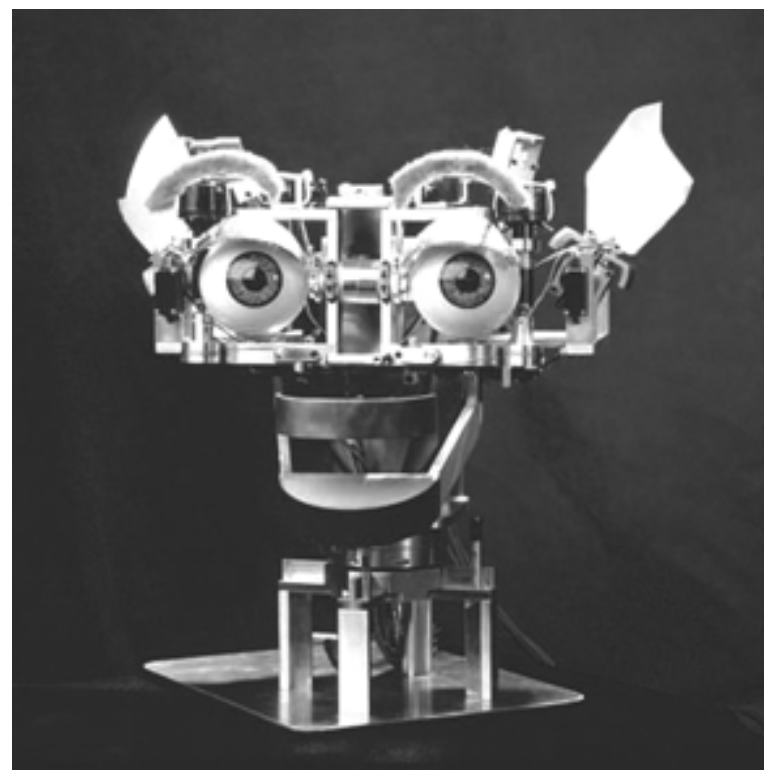

Figure 2.1: The Kismet Robot.

\subsection{The Breakthrough of Artificial Intelligence}

Since the birth of the science of Artificial Intelligence in the mid-1950s, gigantic strides have been made in the quest for a truly intelligent artificial entity. The defeat of the world's best chessplayer, Garry Kasparov, was just one of these strides (Plaat and Schaeffer, 1997; Hsu, 2002; Levy, 2005). Others include the creation of computer programs that can compose music that sounds like Mozart, or Chopin, or Scott Joplin, at the operator's behest (Cope, 2001); programs that can draw and paint better than many human artists whose work today hangs in art galleries and in the homes of wealthy collectors (Cohen, 1995); and programs that can trawl the Internet and write news stories based on the information they gather, stories written in a style of which most journalists would be proud (McGeown et al., 2001). Then there are expert-systems programs that incorporate human expertise to enable them to solve analytical problems normally assigned to human experts (Levy, 2005). Such programs are powerful tools for medical diagnosis and they have also proved to be highly competent in a wide diversity of other fields, such as prospecting for minerals, making political judgements, detecting fraudulent uses of credit cards, and making recommendations in court cases to judges and lawyers, even advising defendants how to plead (Van den Herik, 1997) and mediating disputes in divorce cases (Zeleznikow and Stranieri, 1995). These are not examples of what might be in the future, they are just some of the accomplishments of AI in its first fifty years.

During the second half of the twentieth century, science fiction became a hugely popular literary form, paralleling the development of the science of Artificial Intelligence. One exemplar of this parallel is the computer HAL in Arthur C. 
Clarke's (1968) 2001: A Space Odyssey. HAL crushes David, the human hero, at chess, mirroring the defeat of Garry Kasparov, four years prior to 2001, by IBM's DEEP BLUE chess-playing computer.

The breakthrough of artificial intelligence had two consequences. First, the research in the domain diversified considerably, since in many parts of normal life intelligence or a suitable application of intelligence plays a key role. Second, the industry saw a variety of applications, ranging from straightforward applications, via entertainment, to serious applications in the world of health care, psychology, and mental therapy. Moreover, many new applications are waiting to be researched and developed.

\subsection{Service Robots}

Japan was one of the first nations to take up the initial achievements of research into robotics. Admittedly, it was in industry that robots were first employed to replace humans (just think of car factories). Obviously, these robots fulfilled the task of imitating the function of a human being. As a direct follow-up to the early industrial robots, the major thrust of robotics in Japan during the 1990s and into the first few years of the present century lay in "service" robots. At first, service robots were mainly used for drudge-related tasks - cleaning robots, sewer robots, demolition robots, mail-cart robots, and robots for a host of other tasks such as fire-fighting, refuelling cars at petrol stations, and in agriculture. After the service-robot industry had achieved a well-established position in Japan, that country's robot scientists turned their attention to the realm of personal robots, to be used at home by the individual. The main scientific addition here, in comparison with service robots, is the possibility of communication (see below). Mowing the lawn and vacuuming the carpet have both become tasks that, in a slowly but steadily increasing number of homes, are now undertaken by robots. Similarly, robots are beginning to be used in education, and Toyota has announced that by 2010 the company plans to start selling robots that can help to look after the elderly and to serve tea to guests in the home (Asahi Shimbun, 2005). This trend, from the use of robots in industry to their use in service tasks and now in the home, represents a shift towards an increasing level of interaction between robots and humans.

In industry, a button is pressed and the robot springs into action on the assembly line, working away on a repetitive task with little or no need for supervision, until the daily quota of cars or whatever has been manufactured. If a robot can manage assembly-line tasks once, it can manage them time and again. If your car works well when you buy it, you can reasonably assume that the next person's car will also work well, and the next, and so on. That is the great advantage of industrial robots they not only do the job as often as is needed, they do it as well the hundredth time, and the thousandth, as they did the first time. It is this advantage of repetitive excellence that makes the industrial robot so impersonal. 
Service robots do not normally need to perform their designated task time and again, one immediately after another. Instead they are there, like a butler, to be at the beck and call of the individual when needed to mow the lawn or vacuum the floor, a task that might occur only once a day, once a week or even less often. But to use a service robot requires of its owner much more interaction (e.g., communication) than with industrial robots. The owner will often need to collaborate with the robot, by bringing it onto the lawn for example, before the robot can start work, and then to wheel the robot away again when its task has been completed. (Not always, however. Some lawnmower robots take themselves off to the garden shed when it rains or when their work is done, and even recharge themselves by wandering over to the power socket and connecting themselves when their batteries are low.) Obviously, here lie a multitude of philosophical and psychological questions, but this chapter serves to give an overview and some insight into the main developments of robots up to the present time. Therefore we do not deal with the questions implied above.

As with many other lines of research in robotics, the first fully working androids (human shaped robots) were developed in Japan. The reason for this development is the same as given in section 2.10 (third reason, i.e., at least vaguely similar to a human being). The development of androids started at Waseda University in the 1970s, many years before the states of the art in computing, vision technology, and various other branches within Artificial Intelligence reached the levels needed in a $21^{\text {st }}$ century autonomous android. To complete my coverage of these technological developments I mention the following. The 1980s saw a burst of engineering effort in artificial hands and other limbs, but at the time there were very few industrial applications for such technologies and so the momentum from those efforts was not sustained throughout the 1990s. After a gap of a decade or so, Waseda University and other Japanese robotics groups are now making good use of that earlier research and development effort (see 2.9).

\subsection{Robots for Entertainment}

There are many types of entertainment. One type is the domain of games, in which abstract games such as Chess and Go have played a front-rank role. During the past decade the phenomenon of virtual games has emerged, and nowadays gaming is a research area of its own, almost without any connection with the established board games groups (Spronck, 2005). Entertainment is a much broader area than that represented only by virtual games, but almost all types of entertainment have an " $x$ factor" in common: socializing behaviour (Overmars, 2006). Below we examine developments within this research domain.

The initial forays by roboticists into the world of fully interactive autonomous robots focussed on entertainment, with creations such as robot toys, robot pets, and robots that play sports. Simple electronic cats and dogs have been developed to provide psychological enrichment for humans, being both pleasurable and relaxing to play with. More recent research has started a trend for interactive robots that act 
as human helpers, by (1) showing visitors around in museums, (2) caring for hospital patients and the elderly, and (3) providing therapy to cope with emotional problems. An example of psychological enrichment is the observation by Japanese researchers that the mood of a child can be improved by interacting with a robot, and that robots are able to encourage problem children to communicate more with each other and with their care givers (Kanda et al., 2004a).

There is a smooth transition from "real" toys to "virtual" toys, if this is seen from the perspective of cognition and perception (knowing and observing), but technological developments will enrich the possibilities even more. Toys such as FURBY, TAMAGOTCHI, and ROBOSAPIEN, and the virtual characters that inhabit the worlds created by computer game designers, are part of an evolutionary technological process that has turned the simulation of cognisance and perception into something much more - a force with massive potential. This force already manifests itself as an expectation, by many people, that the toys and computer programs with which they interact today will exhibit signs of life tomorrow. We all know that it is an artificial form of life, but the expectation that something will exhibit even an artificial form of life is a significant step towards the day when the acceptance of such artificial forms will develop into some sort of belief that the life is real. This situation is fully comparable with Baudrillard's (1988) simulacra. The world with a belief of a real life is not a real world. Obviously, above we made too big a step by stating "towards the day when the acceptance of such artificial forms will develop into some sort of belief that the life is real." The consequence is that we should put more emphasis on the actual meaning of the representations of life.

Whatever the case, at this point in time we may conclude that, to some extent at least, the acceptance of robots as entities capable of interesting, useful, and rewarding interaction with humans, has already arrived.

\subsection{Two New Disciplines: Robot Psychology and Robotherapy}

In Chevy Chase, Maryland, a non-profit organisation called the Institute of Robotic Psychology and Robotherapy has been set up to study some of the fundamental questions of mind, emotion, and behaviour that relate to human-robot interaction (Libin and Libin, 2004). Robot psychology focusses on human-robot compatibility, while robotherapy concentrates on the task of employing interactive robots as therapeutic companions for people who have psychological problems or are handicapped physically, emotionally, or cognitively.

As robot manufacturers learned more about what makes a robot attractive as a companion, different robot applications sprang up. The most popular, and hence the best selling robots, have been those produced for entertainment: Sony's robotic dog, AIBO; Honda's walking android, ASIMO, which is even able to climb stairs; robots that can tell jokes; and the 2004 best-seller, RoBOSAPIEN (Levy, 2005). Possibly because electronic learning aids were so popular during the late 1980s and much of the $1990 \mathrm{~s}$, educational robots have also proved to be a marketing success. Other 
robots of which prototypes have been demonstrated include Tohoku University's ballroom dancing androids that can predict the movements of a dancing partner, enabling these robots to follow another dancer's lead without stepping on any toes (Time, 2005). A second example is the NEC Corporation's personal robot that can recognize the faces of individual members of a family, entertain family members with its limited speech ability, and act as an interface to control the television and email (Kanda et al., 2004b). A study of children aged three to five, by Thomas Draper and Wanda Clayton (1992), found that robots with some sort of persona, i.e., robots who move and smile and say something in praise of a child's success, make better teachers and engender a greater level of motivation in their pupils than do inanimate, machine-like robots that do not talk. The MY REAL BABY doll, manufactured by the toy giant Hasbro, is a good example - it speaks, it makes realistic sounds, its face moves in baby-like ways, and it exhibits several human emotions.

The interactive aspect of a robot's being is increasingly becoming an important or even an essential element of its usefulness. Carer robots and teacher robots are just two examples. As the learning abilities of robots develop from the primitive to the sophisticated, so robots will be able to adapt to the needs and desires of their human partners. No longer will it be necessary to redesign or even reprogram a robot to perform some new task for us, instead the robots of the future will learn by watching what makes us happy and grateful, and will sense our desires and satisfy them. These artificially intelligent entities will no longer be perceived as some sort of machine, rather they will become accepted as good companions. It is the leap into this realm of relationships capable of satisfying human needs that has spawned the new disciplines of robot psychology and robotherapy.

These new disciplines focus on the psychological aspects of our relationships with robots. While regular psychotherapists aim to help us gain some useful introspection into our own problems, i.e., problems of ourselves and those borne out of our relationships with other human beings, robot psychology is concerned with problems borne of our relationships with robots. It is a highly complex minefield of new notions about relationships, in which the different ways in which people interact with robots and the different types of robot personality both have an effect. These effects can include caring and other therapeutic regimes, tailored by the robot designer (or, eventually, by the robot itself) to the specific needs of the individual.

Carer robots for the elderly is a product category that is fast attracting the interest of major manufacturers, particularly in Japan. In 2004 a "robot suit" was launched for the elderly, a motorized, battery-operated pair of trousers ${ }^{9}$ designed to help the aged and infirm to move around on their own. Then there is the WAKAMARU, a mobile, three-foot-high talking robot equipped with two camera eyes, a robot used mainly by Japanese workers to keep an eye on their elderly parents at home. Moreover, Sanyo has developed a robot for bathing and shampooing the elderly. According to the Japan Robot Association, products of this ilk will increase Japanese sales of domestic robots to $\$ 14$ billion in 2010 and to $\$ 40$ billion in 2025 , because of the

\footnotetext{
${ }^{9}$ The American translation of this word is "pants".
} 
marked rise in Japan during recent years in the per centage of the population that has reached senior citizen status, a rise that has created huge interest in how best to satisfy the needs of the elderly by the use of robots (Brooke, 2004). Similar bulges in the age statistics will soon hit just about every developed country, simply because people in those countries are living longer than did their parents and grandparents. As a result, old age will soon be a worldwide social problem of massive proportions, and robots appear to represent one of mankind's best chances of being able to cope, by providing robotic therapeutic care for the aged.

\subsection{Recent Developments}

Research into the development of robot pets for therapeutic purposes has resulted in, amongst other technologies, artificial fur that incorporates touch sensors, allowing an artificial pet to respond when it is stroked. This touchy-feely attribute further increases the therapeutic value of a pet when combined with a robot's lifelike appearance and behaviour patterns. The pleasure of stroking a pet, together with the responses programmed into the pet for when it is stroked, have been found to enhance the experience for the elderly from both a psychological and a physiological perspective, thereby creating a more friendly feeling in the patient (Goodale, 2001). As a result, the moods of the patients and their overall feelings of comfort are generally improved by the stroking experience.

Several researchers and companies, particularly in Japan, have been developing the concept of robots as partners for people, and "partner robots are beginning to participate in human society by performing a variety of tasks and functions." (Kanda et al., 2004b). Kanda's team recognizes the importance of finding common ground between humans and robots in order to establish relationships and to build them over time, just as normal human-human relationships evolve with time. They have identified various goals in robotics research that will need to be achieved in order to enable robots to exhibit sufficiently humanlike behaviour patterns to engender human empathy. We mention three of them.

The first of these goals is the capability for robots to recognize individuals: "It is vital that two parties recognize each other for their relationship to develop (...). Although person identification is an essential requirement for a partner robot, current visual and auditory sensing technologies cannot reliably support it. Therefore an unfortunate consequence is that a robot may behave the same with everyone (...). Misidentification can ruin a relationship. For example, a person may be hurt or offended if the robot were to call the person by someone else's name." (Kanda et al., 2004b).

The second goal is the capability of language communication. It must be improved in order to facilitate smooth human-robot interaction. "Whereas speaking is not so difficult for the partner robot, listening and recognizing human utterances is one of the most difficult challenges in human-robot interaction. Although some of the computer interfaces successfully employ speech input via microphone, it is far more 
difficult for the robots to recognize human utterances, because the robots suffer from noise from surrounding humans (background talk) and the robot body (motor noise) (...).We cannot expect ideal language perception ability like humans. However, we believe that robots can maintain interaction with humans, if they can recognize other human behaviors, such as distance, touching actions, and visual movements, in addition to utterances." (Kanda et al., 2004b).

The third goal is the capability of robots to act with a humanlike body. This is deemed to be necessary, according to these Japanese researchers, for successful human-robot interaction (Kanda et al., 2004b). "People have bodies that afford sophisticated means of expression through diverse channels. We believe that a robot partner, ideally, would have a human-like body. A robot with a human-like body allows people to intuitively understand its gestures, which in turn causes people to behave unconsciously as if they were communicating with a human (...). Eye contact, gesture observation, and imitation in human-robot interactions greatly increase people's understanding of utterances (...). Close synchronization of embodied communication also plays an important role in establishing a communicative relation between the speaker and the listeners (...). We believe that in designing an interactive robot, its body should be based on the human body to produce the most effective communication." (Kanda et al., 2004b)

A recent intervention in the attempt to create humanlike robots has come from Korea, from the hands of the very same academic who invented robot soccer ${ }^{10}$. Kim Jong-Hwan (Watts, 2005) has developed robot software that incorporates a computer form of DNA. Fourteen simulated chromosomes, occupying only a tiny amount of computer memory ${ }^{11}$, enable Kim's robots to exhibit up to 77 human behaviour patterns, which is probably rather more than many couch potatoes have in their repertoires. Kim's chromosomes are also intended to give robots the ability to reason and to feel desire and lust, just like us (Watts, 2005).

This brief overview of recent developments brings me to the start of my own investigations, as expressed in my eight specific research questions. We are now ready to examine the eight questions (four on emotional feelings of attraction leading to attachment or love in Part Two, and four on love with robots in Part Three) one by one. In Part Two we start with RQ1 concerning what (precisely) causes people to develop strong emotional feelings of attraction (leading to attachment or love).

\footnotetext{
${ }^{10}$ Soccer matches between teams of robots have become a major international technical sport since their inception in 1996.

${ }^{11}$ Some 2,000 bytes of data.
} 



\section{PART TWO}

In Part Two we consider the first part of the problem statement, viz.

To what extent will the emotions that humans feel for other humans, for pet animals, for virtual pets, and even for less animal-like artefacts - namely computers -, be extended to embrace the robots of the future?

In Chapters 3 to 6 I investigate the following four research questions in this area.

RQ1: Is it possible to trace what (precisely) causes people to develop strong emotional feelings of attraction (leading to attachment or love)?

RQ2: What characterizes the affective relationship between humans and pets?

RQ3: What is the attractive power of a virtual pet?

RQ4: What is the attraction of a humanoid robot for a human being? 


\section{Chapter 3}

\section{EMOTIONAL FEELINGS OF ATTRACTION (TO PEOPLE)}

What sparks it? Why does one particular person ignite it, while another person, who seems so much more appropriate, does not? Throughout history people have tried to understand and control the mysteries of love with magic potions, spells, prayers, and the powers of witches and sorcerers. This is not surprising, given the fact that, for most people, falling in love constitutes one of the most emotionally intense, exhilarating, exciting and significant of life's experiences.

Ayala Pines (1999)

To answer the first part of the problem statement (see section 1.4) I have distinguished four specific research questions. This chapter deals with RQ1: is it possible to trace what (precisely) causes people to develop strong emotional feelings of attraction (leading to attachment or love)?

Since the 1980s, many aspects of strong feelings of attraction, attachment, and love have become hot research topics in psychology, but one area that has been relatively neglected by researchers is why people develop these strong feelings of attraction, become attached or fall in love. Even more surprising perhaps, than the paucity of research in this area, is the conclusion of some of the more recent studies (cf. Frayley and Shaver, 2000), that romantic love appears to be a continuation of the process of attachment, a well-known and well-studied phenomenon in children, but less studied in adults. Attachment is a feeling of affection, usually for a person but sometimes for an object or even for an institution such as a school or corporation.

Children first become attached to objects very early in their lives. Babies only a few weeks old exhibit some of the signs of attachment, initially to their mothers, and as babies grow older the signs of attachment extend to certain objects and remain evident for several years (cf. Freud (1938)). A baby cries for its blanket and its rattle; a toddler for its teddy bear; a primary-school child yearns for her doll; and so on. Different items become the focus of each child's possessive attentiveness as the process continues, but with changing objects of attachment. Toys, walkmen, computer consoles, bicycles, and almost any other possession, can become the focus of the attachment process. As the child develops into a young adult who in turn develops into a more mature adult, so the process continues to hold sway, but with the object of focus generally changing to "adult toys" such as cars and computers. As the psychologists now tell us (cf. Fraley and Shaver, 2000), attachment to people also becomes evident in a different guise, as adults fall in love. 
This brings us to the subject of attachment objects, and in particular to the question: why should people develop emotional feelings of attraction for robots? This very important question is central to this thesis. But before we can begin to answer this question we need to examine exactly why we humans develop emotional feelings of attraction (leading to attachment or love), and as a continuation of this question why love develops in one person for another (particular) human being.

Emotional feelings of attraction leading to attachment or love is the precise subject of the present chapter, which I have built up as follows. Section 3.1 starts by investigating the connection between attachment and love. Two items are of special interest: proximity and repeated exposure. They are examined in depth in section 3.2. In section 3.3 I make an attempt to obtain more insight into the question: why do people fall in love? For a scientific approach it is necessary to measure love in one way or another (see section 3.4). After these preliminary investigations I am ready to establish ten causes of falling in love (section 3.5). Then I compare these factors with the event of falling in love on the Internet (section 3.6). I complete the chapter by providing my chapter conclusions in section 3.7 .

\subsection{Attachment and Love}

Attachment is a term in psychology most commonly used to describe the emotionally close and important relationships that people have with each other (cf. Freud, 1905; Bowlby, 1988). Attachment theory was founded on the need to explain the emotional bond between mother and infant ${ }^{1}$. The British developmental psychologist John Bowlby (1969), one of the first investigators in this field, described attachment as a behavioural system operated by infants to regulate their proximity to their primary caregivers. He explained the evolution of such a system as essential for the survival of the infant, in view of its inability to feed itself, its very limited capacities for exploring the world around it, and for avoiding and defending itself from danger. Bowlby also believed that the significance of attachment is not limited to children but that it extends "from the cradle to the grave", playing an important role in the emotional lives of adults.

\section{Attachment to a Person}

Bowlby's (1969) notion of attachment as a phenomenon that spans the entire human lifespan was first explored at a symposium organised by the American Psychological Association in 1976. During the 1970s and early 1980s Bowlby's ideas on attachment were embraced by several psychologists investigating the nature and causes of love and loneliness in adults. Some of these researchers had observed that the frequency and nature of periods of loneliness appear to be influenced by a person's history of attachment. However, until the late 1980s there was no solid theory that linked a person's attachment history with their love life. Then, Cindy Hazan and Philip Shaver (1987) suggested that romantic love is an attachment process akin to that between mother and child. Subsequently they applied this

\footnotetext{
${ }^{1}$ Or, more generally, between a child and its primary carer.
} 
concept successfully to the study of adult romantic relationships, with the spouse and various significant others replacing parents as the attachment figures (Hazan and Shaver, 1990). The principal propositions of their theory have been summarized as follows (Fraley and Shaver, 2000).

"1. The emotional and behavioural dynamics of infant-caregiver relationships and adult romantic relationships are governed by the same biological system.

2. The kinds of individual differences observed in infant-caregiver relationships are similar to the differences observed in romantic relationships.

3. Individual differences in adult attachment behaviour are reflections of the expectations and beliefs people have formed about themselves and their close relationships, on the basis of their attachment histories. These "working models" are relatively stable and, as such, may be reflections of early experiences with a caregiver.

4. Romantic love, as commonly conceived, involves the interplay of three major biological behaviour systems: attachment (lovers feel a dependence on each other in a way that is similar to how a baby feels about her mother); caregiving (one lover sees the other as a child that needs to be cared for in some way); and sex (for which there is no simple parallel in attachment theory)."

In practice, the similarity between infant-caregiver attachment and adult romantic attachment manifests itself principally in four different ways (Ainsworth, 1991; Hazan and Zeifman, 1994): (1) both infants and adults enjoy being in the presence of their attachment figures and seek them out to engender praise when they accomplish something or when they feel threatened; (2) both infants and adults become distressed when separated from their attachment figures; (3) both infants and adults regard their attachment figures as providing security for them when they feel distressed; and (4) both infants and adults feel more comfortable when exploring new possibilities if they are doing so in the presence of, or when accessible to, their attachment figures.

Hazan and Shaver's $(1987,1990)$ theory of romantic love as an attachment process contributed little to psychologists' understanding of the role played by attachment in romantic relationships, or to how that form of attachment evolves. Shaver's view at the time was that the process of natural selection had somehow "co-opted" the human attachment system in order to facilitate the bonding process in couples, thereby promoting feelings akin to the parental instincts that help infants to survive. But during the 1990s researchers into the theory instead began to come to the conclusion that there exists a "modest to moderate degree of continuity in attachment style" as a person ages (Frayley and Shaver, 2000), implying that those infants who have strong attachment bonds with their mothers are more likely to grow into adults who have strong attachment bonds with their partners. If this is 
indeed the case, then one's capacity to experience romantic love would appear to depend on one's attachment history.

\section{Attachment to a Material Possession}

Attachment to a material possession can develop into a stronger relationship as a result of the possession's repeated use and the owner's interaction with it. This phenomenon is known as "material possession attachment" (Kleine and Baker, 2004). The process by which this happens is similar to the way in which we develop our understanding of and feelings for people as we get to know them over time. Initially, of course, a material possession is nothing more than a commodity that is purchased and which probably comes to "live" in our home. As we use it, play with it or whatever, we get to know it and, gradually, it might become less and less of a commodity, more and more a part of our life. The computer is no longer simply $a$ computer, it quickly becomes my computer. Not so much "my" in the sense of it being owned by me, but more in the sense of it being the particular computer with which I associate myself, the one that I feel is part of my being. Computers, in fact, provide an excellent example of this interpretation of "my" - when someone goes into an Internet café or into the computer room at school or college, they will usually gravitate towards the same computer that they have used in the past, even though all the machines in the room might be, to all practical purposes, identical. They make straight for "their" computer, the one for which they feel they have some affinity, the one with which they subconsciously feel they have already developed some sort of relationship.

As an owner uses an object and interacts with it more and more over time, so this personal attention being applied to the object endows it with a special meaning for the owner. Several psychology researchers have pointed to this creation-of-meaning process, amongst whom Mihaly Csikszentmihalyi and Eugene Rochberg-Halton (1981) have been the primary advocates, referring to this special meaning as "psychic energy". As the owner invests more psychic energy in an object, more meaning is attached to the object, it becomes more important to its owner, and the stronger is the attachment that the owner feels for the object (Grayson and Shulman, 2000).

The commodity thus becomes increasingly personalized to its owner through repeated use and intereaction, and as it does so it takes on, within the owner's mind, an aura of uniqueness. Consciously the owner knows full well that their computer is more or less exactly the same as millions of other computers in the world, but subconsciously there develops in the mind of the owner the notion that this particular computer, their computer, is unique, it is personal to them. Now that the commodity is no longer viewed as a commodity but as something unique, something personalized, it becomes part of its owner's being, "symbolizing autobiographical meanings" (Belk, 1988). The computer, if that is the commodity, becomes irreplaceable in the mind of its owner, even though clearly it could be replaced by another computer of the same make and model with the same amount of memory 
and the same operating system ${ }^{2}$. This "uniqueness" will often cause the owner to be unwilling to replace it, "even with an exact replica, because the consumer feels that the replica cannot sustain the same meaning as the original" (Grayson and Shulman, 2000). Such possessions thereby become endowed with personal meaning that connects the object with its owner - the object in a sense becomes part of the owner - and this personal meaning is what is called material possession attachment.

\section{Attachment and Control}

There are of course many reasons why an owner could develop a sentimental attachment to a particular object, but these reasons normally derive from something connected with the source of the object - perhaps it was a gift from a loved one, a memento of an emotionally important event in the owner's life, or a watch or pen that the owner has used caringly for several years. What is different about the nature of the possession attachment felt for a computer is the element of control - the computer does its owner's every beck and call. Russel Belk's (1988) paper Possessions and the Extended Self discusses the notion that we are "extended" by our possessions, they become part of us, extending us, whether they be material possessions, or human "possessions" such as "my" friend, "my" partner, "my" spouse; and Beck (1988) cites David McClelland's (1951) suggestion that the greater the control we exercise over an object, the more closely allied with that object we become.

Thus, through the great measure of control that we exercise over computers, we have the potential to become close to them. Because of the high level of use we make of them and the interactive nature of that use, computers have the potential to hold a special meaning for us, to strengthen the attachment we feel for them. Combine these with the potential to extend ourselves by virtue of our possessions, and it is not difficult to imagine that the computer - controlled, interactive, used, and possessed - could create in us the level of attachment necessary to engender a kind of love. If, as suggested by Frayley and Shaver's (2000) ideas, one's capacity to experience romantic love depends on one's attachment history, an attachment history that involved computers or electronic pets could provide a basis for the capacity to fall in love with robots ${ }^{3}$. To see whether these conjectures have a basis of truth, we will more closely investigate the important factors of proximity and repeated exposure.

\footnotetext{
${ }^{2}$ Throughout this thesis, when discussing the interaction between a user and a computer, I employ the word "computer" to mean the combination of the computer hardware (the box, keyboard, mouse, and screen) with whatever software it is running (the programs that make the computer do clever things). What the user actually interacts with is the software. The computer keyboard, the mouse, the text on the computer screen, and any speech output that the user hears, all are merely the means by which the user interacts with the software. The software itself is invisible, leading the user to talk about their interaction being with the computer, rather than with the computer/software combination.

${ }^{3}$ We shall return to the subject of attachment in Chapter 5.
} 


\subsection{The Influence of Proximity and Repeated Exposure}

There have been a number of studies on the effect of proximity on attraction. In one of the earliest studies, conducted during the 1930s in Philadelphia, the addresses of marriage partners were recorded for some 5,000 marriage licences (Marches et al., 1953). It was found that 12 per cent of the couples lived in the same building at the time they applied for a marriage licence ${ }^{4}$, while a further 33 per cent lived within five blocks of each other. For a similar study, this one in Columbus during the 1950s, the investigators interviewed 431 couples and found that 54 per cent of them lived 16 blocks or less apart when they first dated, and for 37 per cent of these couples the distance was five blocks or less (Clarke, 1952). Surveys at MIT and the University of Michigan found similar results for couples living in student dormitories. The MIT study (Pines, 1999) showed that the most important factor in creating emotionally close couples was the distance between their apartments - the closer they lived the more likely they were to become friends, while the University of Michigan study indicated that room-mates were much more likely to become close friends than were students living in different rooms several doors away from each other.

The overwhelming conclusion to be drawn from these and many similar studies is that seeing someone frequently, referred to by psychologists as "repeated exposure", creates a much more fertile atmosphere for friendship and love than seeing someone less often, and the proximity of their living quarters clearly has a significant effect on how frequently two people meet. If two people live close to each other they are more likely to develop a familiarity than if they live farther apart, familiarity in terms of seeing each other more, spending time with each other, thinking about each other, and anticipating interaction with each other.

It has also been shown that, even without any personal contact with the other individual, repeated exposure to them generally creates a feeling of liking for them. In an experiment conducted by Richard Moreland and Scott Beach (1992) at the University of Pittsburgh, four women pretended to be students attending classes. The women avoided all contact with the other students in the class, and they attended different numbers of lectures: one of them attended once, another ten times, one fifteen times, and the fourth one not at all. At the end of the course the students in the class were shown photographs of all four women and asked about their feelings and attitudes to each of them. Even though none of the students had had any personal contact with any of the four women, their reported liking of each of the women was strongly related to how often that women had attended the class - the one who never attended was liked the least, with the level of liking rising as the number of attendances in the class rose. The study also found that the more often a woman attended the class, the more likely she was to have been described by the students as attractive, interesting, intelligent, and similar to themselves. The reason why repeated exposure appears to create such a positive effect on human attraction

\footnotetext{
${ }^{4}$ Given the social mores of the time, the vast majority of these couples would not have been living together but would instead have been living in different apartments in the same building.
} 
has been suggested by Ayala Pines (1999) to "arise out of an inborn discomfort that we all feel around strange and unfamiliar things".

The common factor in the studies described above, is that in each case the repeated exposure was to another person, but Robert Zajonc (1968) has shown that repeated exposure to almost anything increases our tendency to like it, and that a direct correlation exists between the frequency of exposure and the level of liking. In one of his experiments he pretended to be conducting a test of visual memory, and asked his test subjects to look at photographs of different people, with each viewing lasting for 35 seconds, and he varied the number of times each photograph was shown some were shown once while others were shown $2,5,10$, or as many as 25 times. Zajonc found that his subjects tended to feel more positively towards the person in a photograph if they were shown their photograph more often, indicating that the physical presence of the object of one's affection is not a pre-requisite for developing that affection. This result concurs with the phenomenon of pen friends falling in love without meeting, and its more recent and more prolific parallel falling in love on the Internet ${ }^{5}$. The main question in all cases is: why do people fall in love?

\subsection{Why People Fall in Love}

Let us now retrace our steps a little, from falling in love as a form of attachment to a discussion of the question: why does human $X$ fall in love with human $Y$ rather than with human Z? What is it about our partners that causes us to fall in love with them?

\section{Byrne's Law of Attraction}

In my opinion the measurement of feelings is a necessary scientific step in the attempt to deepen our understanding of feelings in general, feelings of attraction, and feelings of love. We like or dislike a person according to how we feel in that person's presence - "like" is a feeling for someone in whose presence we feel good. The extent to which we are attracted to someone has been found to depend on the amount of positive and negative feelings we have towards that person. This idea was first expressed by Donn Byrne (1971) in his "Byrne's Law of Attraction", derived from investigations into the attraction feelings of students who volunteered to take part in psychology experiments. The formal expression of Byrne's Law does not exactly make for romantic reading - it appears as follows.

$$
\text { Attraction }=\frac{m \times \sum \text { positive feelings }}{\sum \text { positive feelings }+\sum \text { negative feelings }}+k
$$

What this means is that the strength of attachment one feels for another person is governed by the strength of one's positive feelings for that person in relation to the strength of all of one's feelings for that person. Here are two rather straightforward examples. Let us assume that you have feelings about ten different facets of a

\footnotetext{
${ }^{5}$ See section 3.6 "Falling in Love on the Internet".
} 
particular person such as character, looks, personality, conversational style, ..., whatever. Moreover, the strength of the feelings you have about each of these ten facets are identical. If you have good feelings about eight of those ten facets and bad feelings about two of them, then the fundamental measure of attraction that you experience towards this person is $8 / 10$, because you have eight positive feelings for them out of a total of ten feelings (positive and negative). But if you only have good feelings about three of their facets, and bad feelings about the other seven, then the fundamental measure of attraction that you experience will be only $3 / 10$.

This somewhat "cold" mathematical approach to the magic of human attraction might appear, to the more romantically inclined reader, to be utter nonsense, and just about as far removed as one could imagine from reality. But in fact the accuracy and usefulness of Byrne's Law has been proved in many psychology experiments since he first stated it. There are many experiments in which various positive and negative emotions were manipulated, and where the calculation of the "attraction" measure produced the values that the experimenters predicted. Although Byrne's results stem from the experimental psychology laboratory and are derived from first impressions of one person about another, Byrne discovered "that the same factors found to operate in the laboratory are also found to operate in determining real-life friendship, love, courtship, and marriage" (Byrne and Murnen, 1998).

Interestingly, Byrne's Law also shows that we are more inclined to like someone when we are experiencing positive feelings for reasons that might not be associated with that particular person but which are causing the same feelings in them, such as both hearing good news ("We've passed!"), or both listening to music that they enjoy. Conversely, it has been discovered that two people will tend to be less attracted to each other, or even dislike each other, if they are sharing negative feelings, such as "We've failed", or listening to music that both hate.

\section{Arthur Aron's Experiment}

A simple way of inducing people to fall in love was investigated by a team led by Arthur Aron at the University of California at Santa Cruz (Aron et al., 1997). In 1991 Aron experimented by taking pairs of students who had never met, putting them in a room together for 90 minutes, and asking them to exchange intimate information, such as their most embarrassing moment and how they would feel if they lost a parent. Immediately following this part of the experiment they were asked to stare into each other's eyes for two minutes without speaking. At the end of the experiment the two subjects left the room through different doors, in order to remove any possible feelings of obligation to see one another in the future. (Despite this cautionary ploy the very first couple that took part in Aron's experiment were married six months later.) All the students in the experiment were asked to rate the closeness of the relationship formed within their pair at different stages of the 90 minute period, and the ratings were compared with those of a group of similar students who were asked to rate the closest relationships in their lives. A key result from the experiment was that, after only 45 minutes of interaction, the relationship between the paired students was rated as closer than the closest relationship in the lives of 30 per cent of similar students (Aron et al., 1997). Although there might 
have been some bias amongst the paired students when giving their "closeness" ratings, due to the fact that they knew they were involved in an experiment, this 30 per cent figure suggests that self-disclosure can be a powerful and fast acting device in getting someone to feel attracted towards you.

Talking intimately about one's most embarrassing moments and baring one's emotional soul as means of engendering affection from another person, could prove to be a double-edged strategy. If a robot tried this on someone who was not in the mood to reciprocate, the response from the human might be to suggest that the robot needed therapy or that its software or hardware needed fixing. But the strategy works well when the behaviour is reciprocated because the other person will understand the emotional risk that lies in emotional self-disclosure, and if they are willing to share that risk then the mutuality of the risk will likely become a bonding agent. It is well established that couples who together experience the risk of physical danger, for example being in the same vehicle in a road accident, tend to bond strongly and swiftly (Allen et al., 1989). The above observations suggest the question: is it possible to measure the strength of falling in love in one way or another?

\subsection{Measuring Love}

At the beginning of the century, the neurobiologists Andreas Bartels and Semir Zeki (2000) of University College London reported on an analysis of fMRI scans ${ }^{6}$ of the brain activity of lovestruck students ${ }^{7}$ while they were gazing at photographs of their loved ones. In these cases the brain activity pattern was very different from when the same students looked at photographs of close friends with whom they were not in love. Bartels and Zeki also compared these scans with those taken of people in different emotional states and found that the pattern corresponding to romantic love was unique.

Helen Fisher, an anthropologist at Rutgers University, carried out a similar experiment in collaboration with Arthur Aron et al. (2003), in an attempt to find results that supported the work by Bartels and Zeki (2000). Her team analysed the brain scans taken of 17 recently smitten college students, ten women and seven men, whose ages ranged from 18 to 26 and who had been in love, on average, for some 7 months, and whose feelings of love were at a more intense level than those of the participants in the Bartels and Zeki experiment (Aron et al., 2003). The scans for each student were taken over a 45-minute period, during which they were alternately shown photographs of (1) their loved one, and (2) a familiar acquaintance of the same age and sex as their beloved person but in whom they had no romantic interest. The scans showed that the experience of romantic attraction activated those pockets

\footnotetext{
${ }^{6}$ Researchers know the general area of the brain where various functions occur, such as speech, sensation, and memory. fMRI (functional Magnetic Resonance Imaging) provides a picture of the brain and helps to determine precisely which part of the brain is dealing with certain functions.

${ }^{7}$ The average length of time these students had been in love was 29 months.
} 
of the brain with a high concentration of receptors for dopamine, a chemical closely associated with states of euphoria, craving, and addiction.

The uniqueness of the "in love" brain scans could serve as the basis for a method for robots to determine whether or not a particular human was falling in love with them. A robot who wants to engender feelings of love from their human might try all sorts of different strategies in an attempt to achieve this goal, such as suggesting a visit to the ballet, cooking their human's favourite food, or making flattering comments about their human's new haircut; then measuring the effect of each strategy by conducting an fMRI scan of their human's brain ${ }^{8}$. When the scan shows a higher measure of love from the human, the robot would know that it had hit upon a successful strategy. When the scan indicates a low level of love, the robot would change strategies.

\subsection{Ten Causes of Falling in Love}

The first systematic study of why someone falls in love with a particular person was published in the Journal of Social and Personal Relationships by Arthur Aron, Donald Dutton, Elaine Aron, and Adrienne Iverson (1989). They based their study mainly on three earlier accounts of falling in love, obtained from surveys conducted by other psychology researchers ${ }^{9}$. One of these surveys was based on detailed written accounts of falling in love by students who had done so during the preceding eight months. A second study compared the experiences of 200 attendees of a seminar on "Love and Consciousness", who wrote accounts of their experiences of falling in love or falling "in friendship". For the third study, a questionnaire was compiled to investigate the subjects' most recent experiences of falling in love and, in particular, the moment when they first experienced a strong feeling of attraction.

A review of the reports on these surveys reveals twelve factors that appear to be major contributors to the process of falling in love. One of the major factors, proximity, is a direct cause of another factor - people experiencing repeated exposure to each other, and for this reason I treat them as one (see section 3.2). However, proximity and repeated exposure are explanations of why people come to be in a situation that engenders love, rather than factors that cause love to develop when people are in that situation, and for this reason I have not included a discussion of proximity or repeated exposure in this section ${ }^{10}$. We therefore have ten factors to consider. (In Chapter 6 we shall return to these ten factors and see that most of them are equally applicable for engendering love, by humans, for robots. And where robots are concerned, someone who buys one and takes it home will

\footnotetext{
${ }^{8}$ A technology with some similarities is Reflectance Diffuse Optical Tomography (RDOT), in which near infra-red light is shone through the skull into the brain. The scattered light is reflected back to extremely sensitive detectors that can provide precise data on the dynamics of the haemoglobin in the brain. These continuous changes can reveal information about the functioning of the brain, for example, whether it is resting or actively engaged in some task. This technology is very much in its infancy, but appears to have great potential for brain-machine interfaces (Hamamatsu, 2006).

${ }^{9}$ Lawrence Belove (1980), Philip Shaver et al. (1987), and Dorothy Tennov (1979).

${ }^{10}$ However, proximity can lead to being alone with the love object, which is one of the ten causes.
} 
clearly have achieved both proximity and repeated exposure.) The ten factors are: (1) similarity, (2) desirable characteristics of the other, (3) reciprocal liking, (4) social influences, (5) filling needs, (6) arousal/unusualness, (7) specific cues, (8) readiness for entering a relationship, (9) exclusiveness, and (10) mystery. They are discussed in the subsections below.

\section{(1) Similarity}

There is strong empirical evidence that people tend to like other people who are similar to themselves in one or more important aspects. It might be a similar level of education, similar attitudes, a common interest, a similar family or religious background, similar personality traits, similar social habits, or similarity in any of a host of other characteristics ${ }^{11}$. Similarity is thus one of the dominant reasons for initial feelings of romantic attraction. The first study to examine this phenomenon was carried out by Sir Francis Galton during the 1880s (Amodio et al., 2005). His findings, and those of later psychologists, concluded that couples tend to be similar in all sorts of different traits: psychological traits, physical traits, and personality.

There is evidence from psychology research that we like people better when they change to become similar to us, as compared to when they are consistently like us. (Aronson and Lindner, 1965; Mettee, Taylor, and Friedman, 1973). This can happen because those who change in order to make other people happy are often perceived as being "nicer" than those who always try to make other people happy - it is the gaining that promotes attraction here, the earning of esteem rather than experiencing it from the first encounter.

\section{(2) Desirable Characteristics of the Other}

Most of the studies of romantic attraction have revealed, unsurprisingly, that personality and appearance are two of the most important factors in engendering a feeling of attraction. Ayala Pines (1999) found that more than 90 per cent of the men and women she interviewed about the factors that caused them to fall in love mentioned a characteristic of their partner's personality, with women mentioning personality traits as a crucial factor slightly more often than men. But when it came to appearance, 81 per cent of men said that they were attracted to the physical appearance of their loved one, while only 44 per cent of the women interviewed said that they were attracted by the appearance of their man.

\section{(3) Reciprocal Liking}

Knowing that one is liked by the other appears to be one of the dominant factors in falling in love. This factor is emphasized in Shaver et al.'s (1987) adult attachment theory, in which the loved one (read "the cared for one") perceives themselves to be loved by the love giver (read "the primary carer"), as a result of which the loved one knows that they are likeable, which makes them feel good. When we feel good in the presence of a particular person we are more likely to develop feelings of attraction towards them. One test of this factor came from Arthur Aron et al.'s

\footnotetext{
${ }^{11}$ How well people's similarities match, how well they "fit together", is not only important in bringing them together, it is also a key factor in how gratifying their relationship will be and how long it is likely to be sustained.
} 
(2003) experiment described in section 3.3, which had a secret ingredient added. He told each person within a couple that the other one would like them. "That expectation had a huge effect" said Aron. "If you ask people about their experience of falling in love, over 90 per cent will say that a major factor was discovering that the other person liked them."

\section{(4) Social Influences}

General social norms usually have a significant effect on falling in love, by screening out at an early stage some possible candidates for affection. A simple example is age - it is a social exception rather than the norm for someone to fall in love with a person who is very much older than themselves, so even if someone finds a much older person interesting or attractive, the thought will already be in their mind - "What would people think about me if I pursue a relationship with this person or accept their advances? ${ }^{12 "}$ Similarly, some cultures screen out many candidates for affection on racial grounds, with the result that a couple who might otherwise be candidates for falling in love will often eschew any form of relationship because one or both of them knows that it would be unacceptable in their culture. As Pines (1999) explains, “... social norms reward people who follow the norm and punish those who deviate, as, for example, when friends and relatives shun or express outright criticism of an unsuitable, potential partner". Pines' comment points to another way in which social norms are often influential - the social approval or disapproval of those in one's own social network, especially one's friends, can be an influence on whether or not one falls in love with a particular person, even if these influences are not culturally or racially biased.

\section{Filling Needs}

One of the stronger reasons for falling in love is need - the need for intimacy, for closeness, for sexual gratification, for a family. In some cases the need can be for recognition from others - a gain in status, garnered as a result of having acquired a trophy partner. So when someone says "I love you", what they might actually mean is "I need you", their subconscious hiding from them the true reason for the feeling they have developed for the object of their "love".

\section{(6) Arousal/Unusualness}

The situation in which one meets a potential love object can have a significant effect on whether a feeling of attraction develops. If one is aroused, even in a negative way, by the situation itself, then that can have a positive effect on one's feelings of attraction. Danger is one well-known example of this phenomenon (see section 3.3).

\section{(7) Specific Cues}

The object of one's love might possess some particular characteristic that creates an unusually strong feeling of initial attraction, such as a voice that one finds very

\footnotetext{
${ }^{12}$ It is not hugely uncommon in western societies for older men to fall in love with younger women and start a second family. In such cases the woman evidently spurns whatever social influences militate against the match on the grounds of the age difference, her motivations for accepting that difference outweighing whatever sacrifices of social conformity she might be making. The same, of course, can be said of the men, though for men the social pressures against such relationships are considerably less than they are for women.
} 
appealing, or a physical feature such as the face, the eyes, or the shape of the body. These cases often give rise to "love at first sight".

\section{(8) Readiness for Entering a Relationship}

Some emotional states make us much more susceptible to falling in love than do others. If we are suffering from particularly low self-esteem because our partner has just dumped us, we are ripe for starting a relationship "on the rebound". And a temporarily lowered level of self-esteem for other reasons can similarly be assuaged by a new relationship. Here again there is a need, but this time it is a need for the relationship itself rather than for what it might bring us.

\section{(9) Being Alone with the Love Object, or Exclusiveness}

This is a stronger form of the factors described in section 3.2. Being alone with the object of one's love is likely to enhance those feelings of love, and to encourage any feelings of reciprocity that might exist from one's love object (Rubin, 1973).

\section{(10) Mystery}

A person who carries an air of mystery or intrigue, will be often be found to be romantically appealing. Similarly, a mysterious situation can have a catalytic effect on a relationship in much the same way as does danger.

\subsection{Falling in Love on the Internet}

Falling in love via the Internet has become a widespread social phenomenon. This is the modern day, vastly speeded-up version of falling in love with a pen-friend without meeting them, which sometimes used to happen in the days when the postal system rather than the Internet was the most popular method of written communication between those in far away locations. An interesting aspect of Internet relationships, as with pen-friend relationships, is that some of what are normally regarded as being the most important factors in the initial attraction of one person to another, such as looks, age, and voice, are entirely missing from the initial stage of most Internet relationships ${ }^{13}$. Those involved in Internet chat and Internet flirting are usually hidden from view, hidden from hearing, and able to give the impression of being any age they wish, with the result that relationships sometimes develop between couples who, if they saw each other in a restaurant or across a dance floor or a room at a party, might never have shared a second glance. As a Peter Steiner cartoon in New Yorker magazine explained: "On the Internet, nobody knows you're a dog." (see Figure 3.1).

This invisibility brings an important extra element to the flirting process on the Internet, as explained by Deb Levine (2000):

\footnotetext{
${ }^{13}$ This is not the case if both parties decide from the outset to use webcams and speech transmission technology, but at the present time these are employed in a small minority of early Internet relationships.
} 
"The online world gives those people who do not fit a stereotypical model of human beauty a chance to be Don Juans and Carmen Mirandas and have an equal opportunity to be found desirable. For those considered beautiful by societal standards, it gives them a chance to be attractive to others for reasons other than their physical qualities (i.e., intellect, charm, interests, etc.)."

The discussion of the human-to-human relationship over the Internet is rather close to human-to-computer relationships over the Internet. In order make this analogy acceptable I would like to refer the reader to the well-known Turing (1950) test. Although not directly belonging to the precise topic of this chapter, I would like to express some related ideas that may be stepping stones to the forthcoming chapters.

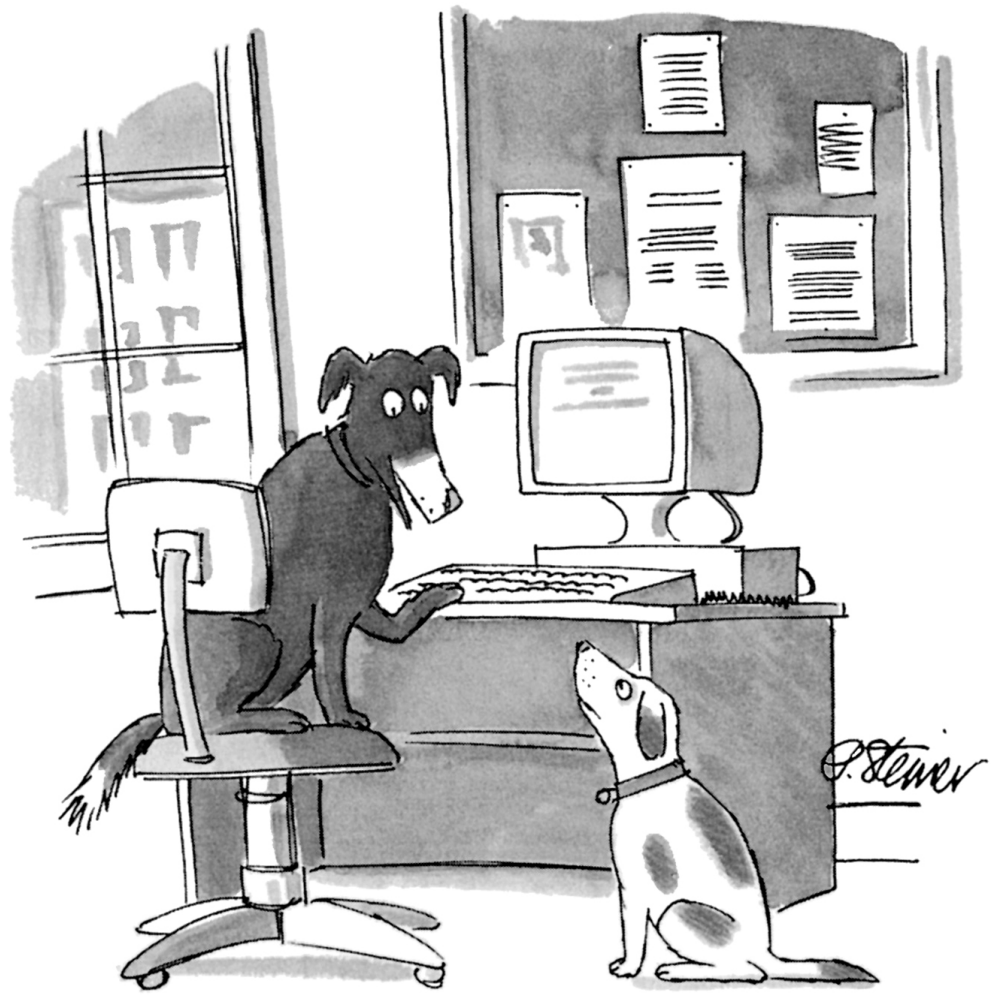

"On the Internet, nobody knows you're a dog."

Figure 3.1: An invisible correspondent.

Being attractive to others is, of course, one of the keys to a successful relationship, and it will be important for a human involved in a developing relationship with a robot to be shown and to believe that the robot is attracted to the human. The fact that attraction for reasons of intellect, charm, etc., occurs so often in Internet 
relationships, is a strong indication that humans will be convinced by their robot's indications of attraction and love for them. There is little point in programming a robot to tell an obviously plain or "ugly" person that it finds them physically attractive, because the robot will lose credibility from any human partner who has the wit to detect the lie. But there is considerable point in programming a robot to search out, comment favourably on, and interact with those characteristics of the human partner that could reasonably be described as positive attributes. If the robot is programmed (or learns) to enjoy virtually the same tastes in literature, music, sport or whatever as its human partner, and to appreciate its partner's personality, then it will be convincing in its appreciation for its human partner, and this appreciation will act as a catalyst in developing the relationship further.

Levine (2000) draws other parallels between attraction in Internet relationships and attraction in face-to-face relationships. These parallels can extend also to humanrobot relationships. We have seen that proximity is an important factor in promoting attraction. Levine points out that

"In the online world, proximity is not defined by physical location, but instead by a particular chat room, message board (Internet forum), listserv ${ }^{14}$ or type of Internet software that users have in common. In order for people to meet online, they have to be in the same chat room at the same time (closest approximation to "real life" proximity), post messages on the same message board."

She recommends, for those seeking someone on the Internet who might find them attractive, that

"Your best bet is to find a community that revolves around a subject in which you are interested (for instance, sports, health, children, books, movies) and spend time there on a regular basis."

Thus, Levine demonstrates that the Internet version of proximity is also a means to take advantage of another of the principal causes of falling in love - similarity. The very nature of the Internet facilitates the process of finding similarity, allowing someone who is passionate about origami or whatever to discover a host of likeminded candidates for their affections, candidates for whom they themselves might be considered emotionally attractive. The technology of the Internet focusses the attentions of other origami aficionados on the user who is seeking affection, providing the opportunity for any of them who wish to do so to flirt.

In a human-robot relationship this process of finding similarity will be an important step towards strengthening the upcoming relationship. The robot will not only be programmed and learn to have similar interests and other characteristics to its

\footnotetext{
${ }^{14}$ Listserv is a leading e-mail list management program that facilitates the management of various types of e-mail lists, such as discussion groups.
} 
human owner, it can also be guaranteed, by its programming, to find its owner emotionally attractive. Instead of a user visiting a web site where there will almost certainly be many like-minded people, but with the risk that none of them might find the user attractive, the user's robot will be both like-minded and attracted to the user.

Those who develop strong emotional ties on the Internet, leading to romantic relationships, constitute only a relatively small per centage of the online population. But because of the total size of the online population, even a modest minority can represent several million people. Nicola Döring (2002) quotes a representative telephone survey conducted in the USA in 1995, in which 14 per cent of those questioned and who had access to the Internet reported having become acquainted with people on the net whom they would refer to as "friends", though no distinction was drawn between romantic and non-romantic relationships. Döring also refers to surveys aimed at people who were active in newsgroups - within this category the portion of those who maintained close relationships on the Internet was 61 per cent (of which 53 per cent were friendships and 8 per cent were romantic relationships). The reason for the significantly higher per centage amongst the newsgroup members is that, because a newsgroup is highly focussed on a specific interest, members of a newsgroup are, by definition, similar, in that they share an interest in the topic of the newsgroup. Thus, a similarity of interests is a powerful factor in the generation of romantic attachment via the virtual world of the Internet, just as it is in the physical world.

The data referred to by Döring is already more than twelve years old, and since then the statistics have shot up. Cyber-romance is an experience that has grown phenomenally within the Internet population, an experience whose popularity is still growing rapidly. Esther Gwinnell (1998) in her book Online Seductions, points out that online relationships, not only those formed on matchmaking sites but also those that start in chat rooms and through instant messaging, have become so common that many psychotherapists in the USA now devote their practices solely to dealing with the problems caused by cyber-romances. These problems include the detrimental effects on pre-existing relationships, especially in marriages where a spouse will often refuse to admit that their cyber-romance constitutes a form of cheating.

On the positive side, Levine (2000) points out that

"For some people, online attraction and relationships will become a valid substitute for more traditional relationships. Those who are housebound or rurally isolated and those who are ostracized from society for any number of different reasons may turn to online relationships as their sole source of companionship." 


\subsection{Chapter Conclusions}

In this chapter I addressed the question: is it possible to trace what (precisely) causes people to develop strong emotional feelings of attraction (leading to attachment or love)? From my analysis of the connection between attachment and love I conclude that two main factors, viz. proximity and repeated exposure, are the most important factors. Taking these two factors as the basis for further research into the question: why do people fall in love?, I have constructed a list of ten more factors which may be considered as causes of falling in love. For my future investigations in this thesis I will take these causes as benchmarks for relationships between humans and robots. 



\section{Chapter 4}

\section{LOVING OUR PETS}

The ties that children forge with their pets are often among the most significant bonds of childhood, as deeply affecting as those with parents, siblings and friends.

Gail Melson (2001)

The current chapter investigates RQ2: What characterises the affective relationship between humans and pets?

Pet-ownership is known to date back to Palaeolithic times. A 12,000 year old tomb, found in Ein Mallaha in northern Israel, contained the remains of an elderly woman buried together with those of a puppy dog. The woman's left hand was placed so that it rested on the dog's shoulder, providing visual evidence for a special relationship between early humans and the animal world, which is very rare in an archaeological site (cf. Davis and Villa, 1978). Later Davis (2001) stated: "This case at Mallaha is quite clearly a rather special and almost unique example of an animal skeleton buried with a human. So I think this really points to almost a kind of emotional or affectionate relationship between the old woman and the puppy."

In order to discover the precise features of the affective relationships we have with pets, I analyse the subject in a plethora of details. In section 4.1 I start with the nature of the human-pet relationship. Then in section 4.2 I consider the anthropomorphism of pets. After these two sections, I investigate the strength of human love for pets (section 4.3). Section 4.4 discusses some benefits of owning pets. It is followed by the benefits of pets for children and adolescents (section 4.5). The question of comparing relationships is examined in section 4.6. The final question: "why do people love their pets?" is discussed in section 4.7. Finally, section 4.8 contains chapter conclusions.

\subsection{The Nature of Human-Pet Relationships}

Many people own pets and a significant proportion of pet-owners love their pets, spending considerable amounts of money on their pet's food, healthcare, and sometimes their grooming. ${ }^{1}$ In the USA it is not at all uncommon for pets to be dressed in designer-label fashions, enrolled in day-care centres, given kidney

\footnotetext{
${ }^{1}$ I should perhaps confess to some bias on this subject, having lived with as many as four cats at the same time, all of whom slept on our bed, ate mounds of fish and chicken, and were whisked off to the vet at the slightest indication of illness. Sadly Ginger, Muffin, and Smoky have all died, aged between 18 and 19 (in human terms that converts to 90 to 95 ), and were duly cremated, their ashes being lovingly scattered in the garden. Fred is still alive and well, as of June 2007.
} 
transplants (and other hi-tech operations) at a cost of approximately $\$ 6,500$ per kidney, and to be laid to rest in pet cemeteries (Serpell, 2003). In addition petowners put up with all sorts of inconveniences contrived by their pets, as they scratch the furniture, claw the carpets and bedding, and create smelly deposits in their homes. Given these disadvantages of pet ownership it seems clear that the level of attachment between pet-owners and their animals is extremely high. Edward Rynearson (1978) explains this on the basis that ". . . the human and pet are significant attachment figures for one another. Under normal circumstances they share complimentary attachment because of mutual need and response."

In a paper aptly entitled Why Do People Love Their Pets?, John Archer (1997), a psychologist at the University of Central Lancashire, discusses the reasons people keep pets, concentrating on the most popular animals - cats and dogs. Archer's findings include the observation that in western societies the relationship between humans and pets has intensified since the second world war. A survey (APPMA, 2003) conducted by the American Pet Products Manufacturers Association in 2003 bears this out, indicating that, in the USA, 63 per cent of households had at least one pet, comprising 77 million cats, 65 million dogs, 17 million birds, 16 million "pocket pets" such as rabbits, ferrets, and rodents, and even 9 million reptiles, figures that are steadily increasing by some 3 to 5 per cent annually.

Several research psychologists have carried out systematic studies of love for pets, studies that mostly posit this love in terms of attachment. Aaron Katcher et al. (1983) investigated various common indicators of affection for pet dogs, such as talking to the dog frequently. A survey conducted amongst the clients of a veterinary clinic found that 67 per cent had a photograph of their dog, 73 per cent allowed it to sleep in their bedroom, and 80 per cent believed that the pet was sensitive to the owner's feelings. In a study by Psychology Today magazine of more than 13,000 pet owners, 25 per cent celebrated their pet's birthday (Horn and Meer, 1984). Moreover, a study by Victoria Voith (1985) found that 97 per cent of 1,500 pet owners in a survey confessed to talking to their cat or dog at least once a day, while 99 per cent of the owners considered their pet to be a member of the family. In other studies the "member of the family" figures have varied, from 68 per cent (Catanzaro, 1984), through the range of 70 to 78 per cent (Beck and Katcher, 1983), up to 93 per cent (Katcher and Rosenberg, 1979).

Most children talk to their pets and feel that their pets reciprocate their own love. Many adults, too, form strong emotional attachments to their pets, some insisting that their animal is "almost human", (despite the ample evidence to the contrary, provided by the pet's non-human appearance), and some deriving even more satisfaction from their pet relationships than they do from their social relationships with people (Robin and ten Bensel, 1985). 


\subsection{The Anthropomorphism of Pets}

Much of the research into human-pet relationships has been based on anecdotal evidence and on observations by psychologists and vets. But it is also interesting and important to consider how pet owners themselves perceive and evaluate their relationships with their animals. By gaining an understanding of the owners' perceptions of such relationships we can better assess how human relationships with robots are likely to develop.

The pioneering research into relationships between pets and their owners was led by Julia Berryman in the mid-1980s (Berryman, Howells, and Lloyd-Evans, 1985). Berryman's team found that, while there was a wide variation between the pet owners in the study as to the importance they attached to their relationships with their pets, one common factor was dominant. Pet owners perceive their relationships with their pets as most similar, by far, to their relationships with children, particularly in those cases where the child was their own, than they were to their relationships with their spouse or partner or with a friend. The reasons appear to be that children and pets bring similar emotional rewards, and both children and pets depend on adults - their "owners" - especially for playing games and having fun. Just as playing games and having fun are shared activities that bind both humanhuman and human-pet relationships, other shared activities, even boring routine activities, tend to bind both types of relationship.

The human tendency to project feelings and thoughts onto animals would seem to be a pervasive one. It is probably based on what developmental psychologists call "the theory of mind", the ability to impute a mental state to others (Baron-Cohen 1992). Most humans attribute others with having minds, that is: feelings, beliefs, and intentions different from their own. But in making such attributions these humans tend to over-attribute, and in the case of animals this leads to anthropomorphism. Anything that bears some similarities to a human being, and with which a person has repeated interactions, is treated as if it has a mind. Thus an animal, alive, affectionate and warm blooded, comes to be treated in certain ways as though it were human (alive, affectionate, and warm blooded), leading many people to interact with their pets as if they were humans, and to form relationships with their pets that come to be like those formed with humans.

Pet owners extend this anthropomorphism towards their animals in other ways, including giving them individual names, feeding them from their own plates at meal times, taking them to a medical practitioner when ill, celebrating their birthdays, allowing them to sleep on the owners' beds, and even on occasions dressing them up like humans (Archer et al., unpubl.; Katcher et al., 1983; Carmack, 1985). By such actions the owner cements the perception of a human-like relationship with their pet, but clearly, since pets are unable to carry on a conversation with their owners, the form of love felt by a pet-owner for their animal is much closer to the form of love that humans feel for babies than it is to a feeling of romantic love. 
In two studies based on students' perceptions of the cognitive abilities of animals, Jeffrey Rasmussen and Donald Rajecki (1995) found that, although they appreciated that the cognitive abilities of dogs and humans are at different levels, the students believed that the mental processes giving rise to these abilities are broadly similar, that dogs think like we do, just not so well. Pets normally live in the home and are therefore in regular or even continuous proximity to their owners and to members of the same household. For this reason, pets are themselves members of the household, even if they are not always treated as part of the family, and in most households pets are perceived as individuals with their own life histories, their own personalities and their own "personal" tastes. This individuality is a major factor in explaining why most pets are regarded as members of the family (Hickrod and Schmitt, 1982; Cain, 1983, 1985; Voith, 1985).

Not everyone understands the appeal of pets and the strength of the bond that is often developed by a pet owner for their animal. Some of my friends and acquaintances kid me about my devotion to my cats, in a few cases going so far as to suggest that I am daft. But such a love is not a phenomenon that deserves to be pilloried. As James Serpell (1986) has argued, attachment to a pet is too widespread a phenomenon throughout history and in the modern world for it to be viewed as an abnormal response by inadequate individuals.

Research into the anthropomorphism of animals has revealed that pet owners are not only more likely than non-owners to attribute human-like understanding to their own pets, they are also more likely than non-owners to make the same attribution to animals in general. For one study, Margaret Fidler, Paul Light, and Alan Costall (1996) showed students a series of videotape sequences of dogs in everyday settings, and then questioned the students about the dogs' behaviour. The common factor in the taped sequences was that the dog and its owner were interacting in some way: the owner was stroking the dog, eating with the dog at her feet, teasing the dog while talking to it, and leaving the room while the dog was watching her. The students' descriptions of the events shown in the videotapes were then classified in one of three ways: (1) as anthropomorphic (for example, "the dog watched the person eating and moved to a position to get eye contact and sat and tried without break to get the person's attention"), or (2) using "as if" terminology (e.g., "the dog appears to get excited (...) he turns around as if he is looking for what the owner is talking about"), or (3) mechanistic - descriptions devoid of any mention of meaning or purpose on the part of the dog. Those students who were or had been pet owners were found to be significantly more likely than non-owners to respond that the dogs' actions were deliberate and that their behaviour resulted from their understanding of the situations portrayed in the video.

Some pet owners subconsciously take the process of anthropomorphism even further, and describe feelings in their relationships with animals that value these relationships more than human relationships. In modern, western societies, human relationships often produce difficulties and dissatisfaction, providing one reason why relationships with pets are often compared favourably by their owners to the relationships those same owners enjoy with other humans. Surveys of veterinary practitioners in the USA indicate that some pet owners would rather lose their 
spouses than their pets (Carmack, 1985). Further evidence of the preference for a pet relationship over a human one comes from survey for which Peter Peretti (1990) interviewed 128 senior citizens in a Chicago park, and found that they devoted considerably more time to describing dogs as friends than to describing people as friends. In fact 75 per cent of the men and 67 per cent of the women in Peretti's survey said that their dogs were their only friends. In a study by Sandra Barker and Randolph Barker (1985), it was found that, on average, the owners felt significantly closer to their dogs than they did to other (human) members of their family.

More recent research supports these findings. In one sample quoted by Archer (1997), taken from a questionnaire study of dog owners, more than half of those surveyed agreed that the loss of their dog would mean as much to them as the loss of a family member or friend. Some owners also made favourable comparisons with human relationships, typical of which were: "I care for them more than for most people I know", and "As a child the dog was the only member of the family who could make life worth living." In other remarks dog owners elaborated just what it was about the relationships with their dogs that made them preferable to human beings: always being there, always loving, and comparatively uncritical. In other words, the relationship with the animal - because it is largely based on the positive features perceived by the owners - manages to avoid those conditional and judgemental features that are so inconvenient in human relationships.

Archer (1997) also found "convincing evidence that people usually view their relationship with pets as similar to those they have with children", for example playing with their pets, talking to them in baby-talk ${ }^{2}$ and cuddling them. Language directed towards babies and young children shows a number of specific characteristics that marks it out from the language used with adults. Such language is referred to as "motherese" and consists of a number of features, such as short utterances, with many imperatives and questions, repetitions, simple sentences, and tag questions (those ending with “aren't you?"). Kathryn Hirsh-Pasek and Rebecca Treiman (1982) examined recordings of dog owners talking to their dogs for such features in their speech, comparing the type of language spoken to the dog to that used in conversation with human babies. They found that nearly all the characteristics of "motherese" were present in these one-sided conversations with pet dogs, suggesting that a pattern of language used to aid interactions with young children has readily been co-opted for interacting with other social beings who are, like infants, presumed to be at a lower level of understanding than adult humans. ${ }^{3}$

The use of motherese is just one of the indications that the interactions people have with pets are modifications of the interactions they have with other humans. Dogs and cats are mammals, like us, whose emotions and moods are similar to ours, although the ways they express them are different. Oskar Heinroth, one of the pioneers of the ethological tradition, described animals as "emotional people of

\footnotetext{
${ }^{2}$ This is true not only in the case of pet owners. When I take my cat to the vet, she talks to the cat, referring to me as "Daddy".

3 This may not always be the reason for speaking motherese since it is also used in intimate adult relationships (Bombar and Littig, 1996).
} 
extremely poor intelligence" (Lorenz, 1970), a view shared by Archer (1997): "He is right to the extent that it is the emotional similarity that people recognize in animals. This forms the basis of being able to communicate with them by visual and auditory signals, and by touch (...) and by sharing object play with them."

\subsection{The Strength of Human Love for Pets}

From time to time reports appear in newspapers, confirming the strength of devotion that some people bestow upon their pets. At the July 2005 wedding in Wanganui, New Zealand, the groom, Glen Armitage, designated his dog as best man (Hall, 2005), and this was by no means the first reported case of a dog in this role ${ }^{4}$. There have been cases reported of people going one stage further and "marrying" their pet $^{5}$, and there is now a Web site to make that process quicker and easier, as well as lucrative for the site owner. If you log on to www.marryyourpet.com you will be able to choose between a Simple Wedding at only $\$ 10$, for which you can "marry your pet online and receive an official certificate of your happy day", in addition to which "all married couples can have their picture on the Marry Your Pet Happy Couples page",; or a Big Wedding at \$85, which brings the extra bonus of "an "I married my pet' T-shirt so you can show the whole world just how much you cherish your pet"7; or you could lash out \$200 for the Biggest Wedding, which gets you not only an online marriage, T-shirt and certificate, but also a "hand embroidered, personalised wall plaque to always remind you of your special day". The marryyourpet.com site carries a disclaimer advising, inter alia, that "... by marrying your pet he/she may be entitled to half your house and all your income", so you have been warned!

A more common example of a demonstration of love for a pet is seen when an owner offers a reward for finding a missing animal, and from time to time petnappers extract a ransom from a pet's loving owner. A second example is the far from rare occurrence of a deceased person having bequeathed a substantial legacy to be used for the benefit of a pet, occasionally making the animal a millionaire. And sometimes in divorce cases a battle breaks out for the custody of a pet, a battle that is often conducted with a vehemence that other divorcing couples reserve for custody disputes over their children.

An even more widespread indication of the strength of people's attachment to their pets can be observed from the nature of pet-owners' reactions to the loss of their animal, with the average length of the owner's bereavement following the death of a pet being some 6 to 8 weeks (Quackenbush and Graveline, 1985). When a pet dies the owner's feelings of grief are often very similar to those experienced due to the

\footnotetext{
4 At an August 2003 wedding in Settle, England, the couple's alsation, Barney, was dressed in a bow tie for the occasion, and it goes without saying that he accompanied the newlyweds on their honeymoon (Argus, 2003).

5 For example, as reported in the "people" section of the South Bend Tribune, October $2^{\text {nd }} 1979$, p. 2., and in Readers Digest, Vol. 116, February 1980, p. 136.

6 These are prices as of late 2005 .

7 According to my calculation that makes the cost of the T-shirt $\$ 75$ - a real bargain!
} 
bereavement of a spouse or partner, a phenomenon first noted by researchers in the 1970s and 1980s (Keddie, 1977; Rynearson, 1978; Katcher and Beck, 1983; Quackenbush, 1985). More recent studies by Elaine Drake-Hurst (1991) and Marilyn Gerwolls and S. Abott (1994) have also demonstrated parallels between the feelings of grief that follow the bereavement of a human loved one and the grief prompted by the death of a pet, as has John Archer (1997), who reported that a substantial number of pet-owners surveyed in the UK, the USA and Israel, were willing to admit that the death of a pet would make them cry.

While it seems clear from all this research that the nature of pet owners' grief is broadly similar to the grief suffered through the loss of a human loved one, it is less clear what levels of stress and depression are evoked by the grief from pet loss. Some studies have found these levels to be considerably lower than when suffering the loss of a human loved one (Gage and Holcomb, 1991; Rajaram et al., 1993), while other research suggests that the levels of the grief itself are just as intense as those found after a human bereavement (Carmack, 1985; Cowles, 1985). In yet another study Mary Stewart (1983) investigated the effects of grief on pet owners due to the loss of their animal, and found that as many as 18 per cent of her survey group "were so disturbed that they were unable to carry on with their normal routine", and one-third of her subjects, although not being quite so badly affected, nevertheless described themselves as being "very distressed".

For many owners, the only relationship in which they feel accepted and important is the one with their pet, and when that pet dies much more is lost than the animal. The companionship, security, comfort, acceptance, love, and the feelings of being needed and important, all are taken away with the pet's death, creating vacuums that explain why the death of a beloved pet can represent a profound loss to the owner. The closeness of owners' feelings for their pets was investigated by Sandra Barker and Randolph Barker $(1988,1990)$, who found that dog owners generally felt as close to their pets as to the closest member of their family, and in one-third of cases the dog owners felt closer than to any human family member.

The difference between male and female approaches (i.e., the gender dimension of love for pets) was investigated in an observational study conducted by Stephen Smith (1983). He showed that women have stronger feelings of attachment to their (non-human) pets than do men. If we project these results on the quality of friendship, we may conjecture that women tend to have more intimate friends, but men like to do things with their friends. Here we may distinguish two types of friendship. Men would like to go fishing, biking, or watching football together; women prefer to talk about their friendship feelings. The latter is one of the reasons why I believe that a very significant proportion of women will develop loving relationships with humanoid robots in the decades to come. The prevailing question according to Meijer (2007) is whether the humanoid/computer could cater for both of these types of friendship. 


\subsection{Some Benefits of Owning Pets}

The study of human-animal relationships is a relatively new field of psychological research that started attracting strong interest during the 1980s. A number of studies have indicated that it is not only emotional comfort and satisfaction that we can derive from our relationships with our pets, but also therapeutic benefits, including improvements in people's health, happiness, and general well-being ${ }^{8}$. These effects mostly result from the lowering of the blood pressure and the relaxation response in humans caused by stroking and other forms of interaction with their cats and dogs. ${ }^{9}$

The emotional well-being brought on by pets can manifest itself in several different therapeutic forms. Pets can be the providers of a constant source of companionship, by providing love and by acting as a surrogate friend (Levinson, 1972; Beck and Katcher, 1983; Kidd and Kidd, 1985; Robin and ten Bensel, 1985; Triebenbacker, 1998). In the case of dogs they can also act as parent substitutes, a role created as a result of the emotional security that a dog brings to a household, performing a task that helps to relieve stress. Below we discuss two types of benefits, viz. emotional and sociological benefits (in 4.4.1) and physical health benefits (in 4.4.2).

\subsubsection{Emotional and Sociological Benefits of Pet Ownership}

Alicia Stribling (2003) has found that the more contact people have with their pets the happier they are ${ }^{10}$. One physiological reason for this is described by Johannes Odendaal (2000) and is related to six neurochemicals in the brain that help to reduce blood pressure. Odendaal found that when the dog owners in his experiment interacted with their pets, there was an increase in the production of those chemicals in the brain, including dopamine, phenethylamine, and endorphin, which are related to feelings of happiness and well-being, and at the same time there was a reduction of all the stress hormones, for example cortisol.

Karen Allen, J. Blascovitch, and W. Mendes (2002) have compared the relative benefits of having the social support ${ }^{11}$ of a friend or spouse with the therapeutic effects of a pet, and found that a dog provides more effective social support for reducing stress than does a spouse! 240 married couples, of whom half were petowners, were asked to perform two tasks known to induce stress: solving some problems in mental arithmetic and plunging a hand into iced water for two minutes. These experiments were carried out several times by the partners in each couple in various combinations: alone, with a pet or a friend, with their spouse, and with both

\footnotetext{
${ }^{8}$ The earliest attempts to use animals for therapeutic purposes appears to predate this relatively recent research by almost two centuries. In 1792, William Tuke and several other Quakers in York, England, established a retreat where the mentally ill could be cared for much more humanely than was usual in those days. Tuke's idea was to provide farm animals for the patients to look after, believing that this activity would reduce the patients' aggressive instincts and improve their discipline and self-control (Kidd and Kidd, 1985).

${ }^{9}$ What little research has been carried out with pets other than cats and dogs has been insufficient to demonstrate any comparable benefits.

${ }^{10}$ For the purposes of her experiment she defined happiness as "a satisfaction with life and a general sense of well-being".

${ }^{11}$ Social support is a network of family, friends, colleagues and other acquaintances to whom one can turn, whether in times of crisis or simply for fun and entertainment.
} 
their spouse and their pet or friend. Allen discovered that the pet-owners exhibited much lower baseline heart rates and blood pressure levels than non-owners, commenting that "while the idea of a pet as social support may appear to some as a peculiar notion, our participants' responses to stress, combined with their descriptions of the meaning of pets in their lives, suggest to us that social support can indeed cross species." As for the social support value of the spouses, Allen et al. (2002) found that participants made the most errors in the mental arithmetic problems when their spouses were present but their pets were absent. As a result, she speculates that one reason pets appear to elicit such calm responses is that they encourage the positive-feeling states that social support theorists have suggested may enhance a person's ability to handle stress (Cohen and Syme, 1965; Cohen and Hoberman, 1983). Furthermore, talking to dogs, in contrast to talking to one's spouse, has been found to be related to greater life satisfaction, greater marital satisfaction, and better physical and mental health.

\subsubsection{Physical Health Benefits of Pet Ownership}

One of the first researchers to recognize the physical health benefits of pets was James Serpell (1991), who investigated the therapeutic effects of giving non-pet owners a cat or a dog for periods ranging from six to ten months. He found that not only did the subjects' self-esteem improve while the animals were with them, but also their physical health. This phenomenon had been suspected by Judith Siegel (1990), who carried out a quantitative study on a sample of 938 patients enrolled in American Medicare, finding that older people who own pets become less stressed by major adverse events in their lives and make fewer visits to the doctor than do non pet owners.

Several other studies within various branches of medicine and care have similarly documented clear medical therapeutic benefits from pet ownership (Lynch, 1985; Jennings et al., 1998; Allen, Skyhoff, and Izzo, 2001). Perhaps the most dramatic effect is the one noted by Erika Friedmann and Sue Thomas (1995), who found that heart patients who own pets are more likely to survive the year following a heart attack than those who do not. Of 87 dog owners in Friedmann and Thomas's study, only 1 died within a year of having a heart attack ( 1.1 per cent), while of the 282 who did not own dogs, 19 died within that same period (6.7 per cent), a ratio of 6 to 1. These results support an earlier study led by Warwick Anderson (1992) at the Baker Medical Research Institute in Australia, which indicated that pet owners had lower blood and cholesterol levels than non-pet owners, and were therefore less at risk of heart disease.

Friedmann and Thomas's (1995) original results were questioned by some researchers but they have been verified more than once. In 2003, for example, Friedman et al. (2003) reported in the American Journal of Cardiology on a group of 102 patients who had had a heart attack in the previous two years, including 35 patients who had owned a pet. The team investigated the variability in the heart rates of these patients, a measure which indicates how well the heart is likely to handle stress. An increase in variability is linked to a lower risk of heart disease and death, 
and Friedmann's group found that the variability measures were higher in pet owners than in non-pet owners.

In 1994 the results of studies such as these prompted the largest of all surveys up to that time - the Australian People and Pets Survey - a national investigation, conducted by Bruce Headey (1999), of more than 1,000 people aged 16 and over, some of whom were pet owners and some not. The aim of this survey was to quantify the extent to which the therapeutic benefits of pet ownership reduce the medical needs of the owners. Headey found that people who owned a cat and/or a dog required, on average, 5 per cent less expenditure on treatments and medicaments than non-pet owners, which in the case of Australia meant a cost saving of 1.8 billion Australian dollars ${ }^{12}$ across the whole country. Within this group, the differences between the number of doctor visits and the levels of medication required by dog owners who felt close to their $\operatorname{dogs}{ }^{13}$, and the medical care of those who either were non-pet owners or who had a dog but did not feel close to it, were even more marked than that average figure of 5 per cent. A second important result of this survey was to confirm the significance of pets in the lives of people who live without partners: the single, the separated, the divorced, and the widowed, confirming that dogs can act as surrogate companions for those who lack a satisfactory network of human "social support" (Wilks, 1999).

Following his work on the Australian People and Pets Survey, Headey collaborated with Markus Grabke on a similar study for Germany (Headey and Grabke, 2004), comparing the data for a group of 10,000 respondents to a socio-economic survey that had been repeated after a gap of five years. Within the survey group, those who had owned a pet for five years or more benefited the most, suggesting that it is the bond with the animal, rather than its mere proximity, that creates the feeling of wellbeing which positively affects the owner's health. This implication, that the therapeutic effects of a dog vary according to how well the patient has bonded with it, confirms the results of an earlier study at the University of Nebraska (Baun et al., 1984), which found that interacting with a dog with which the patient has already formed a companion bond resulted in an 8 per cent decrease in blood pressure, relative to interacting with a dog with which the patient has not bonded. Subsequently, Headey (2003) speculated the following.

"At a fundamental level, the benefits of pets appear linked to the human desire to be close to nature and other living creatures. The famous zoologist Edward O. Wilson has called the beliefs that humans need and benefit from closeness and companionship with other species 'the biophilia hypothesis', which he postulates is based on an inherent, biologically based "predisposition to attend to, and affiliate with, like and lifelike processes"

\footnotetext{
${ }^{12}$ Equivalent to 1.2 billion US dollars at that time.

${ }^{13}$ In order to determine how close a pet-owner feels to their pet, Headey (1999) employed a "closeness to pet" measure that averages the answers to four questions, in which the subjects were asked to say whether they agreed or disagreed with certain statements: [a] "I feel close to my pet"; [b] "When things go wrong, it is comforting to be with my pet"; [c] "Having a pet around when people visit me makes it easier to get into conversation and create a friendly atmosphere"; and [d] "I have sometimes got to know people and made friends through having pets".
} 
(Wilson, 1984; Kellert, 1993). About 50 per cent of adults and 70 per cent of adolescents who own pets report that they confide in them. It is most unlikely that all this communication and companionship is wasted."

\subsection{The Benefits of Pets for Children and Adolescents}

Gail Melson (2001) has found considerable evidence that children aged 3 or even younger establish relationships with pets that provide emotional comfort in times of stress. This form of comfort extends to school age children, as indicated by the significant though widely varying per centages of children, aged from 5 to 14, the subjects of various studies, who said that they would turn to their pets when feeling sad, afraid, upset or stressed (Bryant, 1985; Covert et al., 1985; Rost and Hartmann, 1994; Melson and Schwarz, 1994). Childrens' feelings about their pets are typified by remarks such as: "My dog is very special to me. We have had it for seven years now. When I was little I used to go to her and pet her when I was depressed and crying. She seemed to understand. You could tell by the look in her eyes." Because of remarks such as these, Michael Robin and Robin ten Bensel (1985) were led to conclude that "As children get older the pet acquires many of the characteristics of the ideal mother: unconditional, devoted, attentive, loyal and nonverbal."

At East Carolina University, Sandra Triebenbacher (1998) has investigated the roles that pets play in a child's emotional development, finding that almost all of the children she surveyed (89 per cent or more) said that their pets were important members of the family, that they loved their pets very much and that their pets also loved them very much.

\subsection{Comparing Relationships}

The important benefits of pets described in this chapter have thus far been discussed without any mention of what the human-animal relationship is like for the pets. Below I compare the relationship as experienced from the human perspective with that from the animal perspective, and later in the thesis I compare animals with robots. For now, humans and animals might well have completely different perceptions of their relationship (Bokkers, 2006). It is known that animals prefer companions from within their own species to human companions (Raussi, 2003). One might therefore expect that pets do not give their all to their human owners, in which case it is inevitable that robots will have the potential to be even better companions than are animals, because robots will be designed and programmed to enjoy their interactions with humans to the full and to behave accordingly.

One important indicator that is demonstrated by the human love for animals is that humans are able to form bonds of love with non-humans. Anyone who maintains that it is unnatural for us to love robots, on the basis that humans can love only other humans, therefore faces the instant refutation of their argument. Our love for pet animals also provides support for our understanding of why it is that many people 
form strong emotional attachments to robot pets (the subject of Chapter 5). The virtual pets of today, and earlier generations of robots, share with real pets one strong negative property that creates great similarities between human-pet relationships and human-virtual pet relationships - at the present time (2007), it is not possible to carry on a sensible conversation with either. True, some robots can talk, using speech synthesis technology, but their conversational abilities correspond at best to those of a two-to-three-year-old infant. I admit that conversations on a restricted domain and with a restricted vocabulary are possible (e.g., the domain of train arrivals, booking cinema seats, etc.). However, the current level of speech recognition and understanding by robots, as well as a lack of conversational ability, makes them, in some ways, inferior as communicators to those animals whose owners "know" that their pet understands them and "talks" to them. The reader might use this lack of communication ability as grounds for objection, since fullfledged communication seems to be a real obstacle in developing a relationship. Yet, I believe that in the next twenty years technology will solve the problem of understanding the meaning of language. This might be stretching the bounds of credibility too far for the liking of some readers, but one could argue in support of an extension to Turing's (1950) thinking, namely that if a pet owner believes that their animal understands them and "talks" to them, then we should accept that, for this particular pet owner, their animal does indeed communicate with them. In the Turing (1950) debate we saw a clear behaviouristic approach to the question: what is intelligence?

The intrinsic values of this debate were later discussed by reductionists ${ }^{14}$ (e.g., Dawkins, 1976), functionalists ${ }^{15}$ (e.g., Lem, 1974), and computational psychologists (e.g., Cherniak, 1978), all in a collection of papers, The Mind's I (Hofstadter and Dennett, 1981). These authors discussed fantasies and reflections on the self and on the soul. In the section Reflections that followed each of the contributions, the editors, Douglas Hofstadter and Daniel Dennett, gave their opinions. In this way the reader witnesses a lively debate, which continues to this day. For the purposes of $m y$ discussion it is important to note that Dawkins (1976) did not take into account the emergent properties ${ }^{16}$ (or in the words of Hofstadter (1981)): “the 'entelechies' higher-level structures that presumably cannot be explained by recourse to the laws that govern their parts"). The latter argument could be used to support my belief that adequately functioning conversational programs will be developed in the next twenty years.

\footnotetext{
14 In philosophy, reductionism is a theory that asserts that the nature of complex things is reduced to the nature of sums of simpler or more fundamental things. This can be said of objects, phenomena, explanations, theories and meanings.

${ }_{15}$ Functionalism (Wikipedia) is a theory of the mind in contemporary philosophy, developed largely as an alternative to both the identity theory of mind and behaviourism. Its core idea is that mental states (beliefs, desires, being in pain, etc.) are constituted solely by their functional role - that is, their causal relations to other mental states, sensory inputs, and behavioural outputs. Since mental states are identified by a functional role, they are said to be multiply realizable; in other words, they are able to be manifested in various systems, even perhaps computers, so long as the system performs the appropriate functions. While functionalism has its advantages, there have been several arguments against it, claiming that it is an insufficient account of the mind.

${ }^{16}$ Emergent properties are those that can arise out of an algorithm but were not its principal intention.
} 
Almost at the end Hofstadter (1981, p. 283) states: "If - as was just asserted - our best ideas come bubbling up as if from mysterious underground springs, then who really are we? Where does the creative spirit really reside? Is it by an act of will that we create, or are we just automata made out of biological hardware, from birth until death fooling ourselves through idle chatter into thinking that we have "free will"? If we are fooling ourselves about all these matters, then whom - or what - are we fooling?"

A similar tendency to accepting a conversation with a robot has been observed in some elderly people, who believe that a robot designed to be of therapeutic benefit to them is in a relationship with them, this because the robot makes eye contact or acts in some other way that is relationship-driven when seen in humans (Turkle, 2006).

From the fact that our love for our pets is understood by psychologists as a form of attachment, the same phenomenon that psychologists now accept as the basis of romantic love, I postulate that the attachment phenomenon will act in precisely the same way to the point of having as its object a computer, a robot or some other artefact. Moreover, this fact suggests that attachment permeates throughout the human/animal/artefact continuum. How has this attachment process with animals evolved? Archer (1997) believes that pets have evolved in ways that manipulate the human species through a number of features that make our interactions with them potentially rewarding for us, so that pets appear to treat their owners with love and affection. Cats and dogs behave in ways that are appealing to their human owners (Serpell, 1986, 1996). Dogs show obvious signs of affection and attachment to their owners and are very attentive to them (Smith, 1983), while cats, although more independent, appear to like being stroked and petted.

\subsection{Why Do People Love Their Pets?}

Many people believe that strong feelings directed towards a pet are an indication of an inadequacy in the person's relationships with humans. This judgement is often applied to a women who lives by herself, has no children, and dotes on her pet dogs or cats. It can also be found in the comments of some psychiatrists about patients who show strong attachments to their pets (Keddie, 1977; Rynearson, 1978). But there is a certain amount of convincing evidence that this view is wrong, evidence that people who have more secure attachments in their close relationships with other adults are the ones who are most strongly attached to their dogs (Archer et al., not published). This is the opposite of what we would expect if strong attachment to a pet resulted from difficulties in forming relationships with adult humans.

Since reciprocity is one of the most significant factors in prompting feelings of romantic love ${ }^{17}$, it seems likely that the reciprocity demonstrated by pets, the purring of a cat and the nuzzling and tail-wagging of a dog, similarly contributes to the

\footnotetext{
${ }^{17}$ See section 3.1 .
} 
strength of affection felt by an owner for their pet, and that reciprocity will likewise be a contributing factor in the growth of affection felt by an owner for their robot, when that robot demonstrates its virtual affection for its owner. A common example of reciprocity in dogs is seen when one of them is tethered to a lamp-post or whatever while their owner goes into a shop. Next time you see this happen, watch that dog while the owner is in the shop. The dog will most likely remain fairly calm, perhaps trying to peer through the glass into the shop to see their owner. But when their owner returns to collect the pet, the dog will usually go into paroxysms of excitement, their owner's absence, albeit for a short time, having made the dog's heart grow fonder. In their study of human emotions: A General Theory of Love, Thomas Lewis, Fari Amini, and Richard Lannon (2001) explain this reaction as being part of the attachment process between dog and owner:

"... they spend time near each other and miss each other; they will read some of each other's emotional cues; each will find the presence of the other soothing and comforting; each will tune and regulate the psychology of the other ..."

Sherry Turkle (1984) at MIT was one of the first authoritative researchers to draw a parallel between man's relationship with animals and his relationship with computers.

"Before the computer, the animals, mortal though not sentient, seemed our nearest neighbours in the known universe. Computers, with their interactivity, their psychology, with whatever fragments of intelligence they have, now bid for this place."

The human propensity for loving our pets thus informs our understanding of the emotional attraction to computers, to robot pets, and to humanoid robots. For those people who value their relationships with their pets more highly than their relationships with other humans, it would not be surprising if a virtual pet or a robot were to be regarded in the same vein, supplanting humans as the most natural objects of human affection. Where such people lead, others will surely follow, as the joys and benefits of relationships with robots become well publicized.

\subsection{Chapter Conclusions}

In this chapter I have investigated the question: what characterises the affective relationship between humans and pets? This topic has been one of scientific research mainly during the past twenty years. The principal characterisation of such relationships is that they bring similar emotional rewards to both sides (Berryman, Howells, and Lloyd-Evans, 1985). From this characterisation I have investigated the concept of the anthropomorphism of animals. These two items (emotional reward and anthropomorphism) provided the basis for my investigations into the strength of human love for pets and the benefits of loving our pets. 
From my investigations I may conclude that the most important benefit of pet relationships for children as well as for adults is feeling comfortable. If we consider this as the main outcome, then the time is ripe to compare the relationship between a human and an animal pet with the relationship between a human and a computer. Before doing so I examine the following stepping stone: what can be said about the relationship between a human and a virtual pet? 



\title{
Chapter 5
}

\section{EMOTIONAL ATTACHMENTS TO VIRTUAL PETS}

\begin{abstract}
A relationship with a computer can influence people's conceptions of themselves, their jobs, their relationships with other people, and with their ways of thinking about social processes. It can be the basis for new aesthetic values, new rituals, new philosophy, new cultural forms.
\end{abstract}

Sherry Turkle (1984)

This chapter continues my investigations into love and attachment for entities other than human beings. Below I investigate RQ3: what is the attractive power of a virtual pet? To answer this question I start by defining what is meant by the term "virtual pet".

A virtual pet is a computer representation of a model of pet behaviour, incorporating software that allows owners to interact with their virtual pets. The computer might have several distinct forms: (1) it might be a PC or a games console that displays images of the virtual pet on its screen; (2) it might be a microprocessor ${ }^{1}$-based product such as a mobile 'phone or a TAMAGOTCHI, with a much smaller display than a PC screen; and (3) it could be a microprocessor-based toy that looks like an animal or a robot. No matter what its embodiment and appearance might be, the principle is the same - the virtual brain of the virtual pet is simulated by software in some sort of computing device. In summary, the core of a virtual pet is a computer of some sort plus some software. Relationships between humans and virtual pets are, therefore, an extended form of the human-computer relationship, extended by the embodiment of the microprocessor in a pet-like design, whether it be the design of a creature on a small screen as with the TAMAGOTCHI, or the design of a doll or some form of pet-like body that itself creates a measure of emotional appeal.

In this chapter I address the topic of emotional attachments to virtual pets as a starting point for answering RQ3 (see above). The course of the argument is as follows. In section 5.1 attachment and relationships with objects are examined. Since some readers may already have difficulties with such a topic, I discuss anthropomorphism in section 5.2. Subsequently I focus on computers, by describing the development of social relationships with computers (section 5.3). In section 5.4 I discuss the topic of sustaining social relationships with computers. After this extensive introduction I provide examples of the actual world of virtual pets in three different sections, viz. section 5.5 on virtual pets - The TAMAGOTCHI, section 5.6 on virtual pets that live on the screen, and section 5.7 on robotic virtual pets. Then I come to my main point by listing the benefits of forming attachment to robot pets

\footnotetext{
${ }^{1}$ A microprocessor is sometimes referred to as a microcomputer - it is a single computer chip that performs the "thinking" function.
} 
(section 5.8). In section 5.9 I draw lines to the future by discussing the topic "from virtual pet to humanoid robot". Section 5.10 provides chapter conclusions.

\subsection{Attachment and Relationships with Objects}

In Chapter 3 I touched upon the subject of attachment, discussing how the process of attachment in childhood extends into adulthood, sometimes manifesting itself as romantic love. Here I examine the process of attachment in more detail, as it pertains to computers and to virtual pets, such as the TAMAGOTCHI.

The process of attachment is closely related to another psychological phenomenon transitional objects ${ }^{2}$. The young child becomes attached to an object such as a cot blanket (often spoken of as the child's "security blanket"), an article of clothing or a soft toy. These are items that help the child to make the emotional transition from being wholly dependent on its mother and other caregivers towards being independent.

The significance of transitional objects was first recognized by the British pediatrician and psychoanalyst Donald Winnicott, whose 1951 essay Transitional Objects and Transitional Phenomena had an enormous impact on child psychology ${ }^{3}$. Winnicott argued that such attachments represent a developmental stage whereby the infant makes use of an object over which they have control, to deal with and move on from their early attachment to their mother, who is less under the infant's control than is the transitional object.

Subsequently, other psychologists investigated and came to accept the notion that transitional phenomena extend past infancy, through adolescence, and into adult life (Kahne, 1967; Young, 1989, 1994). As Robert Young (1994) explains:

"Having abandoned the blanket, doll or teddy, one can still attach similar significance to other objects with a less addictive intensity. The sensuous, comforting quality and the sense of something that is favourite and to which one turns when in danger of depressive anxiety applies to all sorts of special things. Everyone's list will be different, but these days walkmans have this quality for many adolescents, as do portable computer games for pre-teens and computers for adult devotees, whether they be merely enthusiastic word processors or totally committed "hackers". The same can be said of mountain bikes, fancy roller skates, expensive trainers, certain fashions in clothes - Champion sweatshirts and sweatpants and Timberland shoes in the case of my children."

\footnotetext{
${ }^{2}$ Often called "security objects".

${ }^{3}$ Winnicott presented this essay at a meeting of the British Psycho-Analytical Society in 1951, but it was not published until 1953.
} 
On the consequences of the comfort given by transitional phenomena, Young (1989) asserts that

"... they can become more real and intimate than human relations per se. One of the consequences of the fetishism of commodities is that the products of human hands appear as independent beings endowed with life and entering into relations both with one another and the human race. This arises not only from the commodity form but also from the formation of character in the image of the commodity."

The relationship between persons and things described above may be transformed to "my best friend is my walkman or my personal computer". Sherry Turkle's (2006) explanation of the effect of early encounters with transitional objects is that they create a "highly charged intermediate space between the self and certain objects in later life". She observes that, not only do children project their fantasies and desires onto their transitional inert playthings, they also engage with their relational artefacts, their crying, talking electronic playthings.

Robert Pirsig's (1974) best seller, Zen and the Art of Motorcycle Maintenance, expounded on the subject of intense relationships with technical objects and how such relationships can evoke philosophical musings. The latter day version of Pirsig's motorcycling hero is the computer hacker ${ }^{4}$, many of whom boast on the Internet about their skills. Those who love the technology and the process of programming, mostly young men who are more than willing to stay up all night "hacking", share a fascination for the computer and an addiction to it. Out of this fascination, this addiction, springs a kind of love for the computer. Turkle (1984) has suggested that hackers' assertiveness of their skills is probably a symptom of a basic human need to credit their own place in society, their own favourite activities, with meaning. Turkle (1984) describes hacking as

"... a flight from relationship with people to relationship with the machine - a defensive manoeuver more common to men than to women. The computer that is the partner in this relationship offers a particularly seductive refuge to someone who is having trouble dealing with people. It is active, reactive, it talks back. Many hackers first sought out a refuge during early adolescence, when other people, their feelings, their demands, seemed particularly frightening. They found a refuge in the computer and never moved beyond."

The hackers that Turkle describes here are at those at an extreme end of the social spectrum. Some programmers became hackers because of their love for the process of solving difficult problems, and the computer evolved to be the perfect tool for them because of the immediacy of the feedback it gave. Many of those who considered themselves to be hackers during the 1960s, 1970s and 1980s also had

\footnotetext{
${ }^{4}$ A highly proficient and enthusiastic computer programmer, a "virtuoso programmer" to quote Sherry Turkle.
} 
very active social lives that often integrated with their computing lives, providing a decent break from hacking. The extreme cases represented by the hackers interviewed by Turkle were simply the normal extremes of the personality spectrum, overlaid on the spectrum of those who love solving problems, of which mathematicians and chess grandmasters are other examples (Yeager, 2006). Turkle's hackers, because of their extreme position on the social spectrum, were the first to exemplify the type of person who will be likely to embrace the ideas of love and sex with robots.

Turkle quotes one hacker who explained to her why, after he had "tried out" having girlfriends, he preferred to relate to computers:

"With social interactions you have to have confidence that the rest of the world will be nice to you. You can't control how the rest of the world is going to react to you. But with computers you are in complete control, the rest of the world cannot affect you."

Moreover, Turkle explains the role of the computer in providing relationships for those humans who have nowhere else (or no-one else) to turn to, as being based on the computer's interactive capabilities:

"One can turn to the world of machines for relationship (...). And the computer, reactive and interactive, offers companionship without the threat of human intimacy (...). The interactivity of the computer may make him feel less alone, even as he spends more and more of his time programming alone."

Norman Holland (1996) goes one step further, explaining why computer programming has been likened to sex.

"When programming, the computer addicts are working with an ideal partner who understands them fully. They feel toward their machines as toward a true friend. This friend will not withdraw if a mistake is made. This friend will try to be an ever-faithful helpmate. And this friend is male."

But why do computers assume this role? The answer seems to lie in the process of attachment. Relationships that are attachment-based have been found to possess four characteristic features (Ainsworth, 1991; Hazan and Zeifman, 1994).

(1) An attachment figure, subconsciously associated with the infant's mother, takes on the role of "proximity maintenance", providing the comfort of always being there when their presence is needed, whether it be needed to bestow praise or to help dissipate feelings of fear.

(2) A corollary of this positive feature of attachment is the feeling of "separation distress" that occurs when an attachment relationship is disrupted, when the mother figure is absent. 
(3) A further positive feature, closely related to proximity maintenance, is the role of the attachment figure as a "safe haven", allowing a person who is distressed to find contact (i.e., close proximity), assurance, and safety. This role is not one for which the attachment figure is uniquely suited, but just as an infant is more easily calmed by its mother than by another adult, so an adolescent or adult is normally calmed more easily by their attachment figure than by an alternative.

(4) An attachment figure has a role as a "secure base" from which to explore the world. A young child whose attachment figure is nearby and accessible, will feel relatively comfortable in exploring strange and new environments, but uncomfortable when lacking the proximity of their attachment figure. Similarly an adult will normally feel more secure when exploring a new career opportunity or an unusual leisure activity if their romantic partner is accessible.

Without spreading the bounds of credulity too far, it is not difficult to see how each of these four features can apply, not only to human attachment figures, but also to artefacts that serve the role of attachment figures, such as teddy bears, dolls, and computers. A young child likes to cuddle its doll or teddy bear (proximity); the child dislikes having its beloved toy taken away from it (separation distress); if the toy or doll is not actually within the child's reach, it is at least comforting for the child to know that it is nearby and accessible (providing a safe haven); and with the knowledge that the doll or bear is to hand or accessible, a young child will feel more confident about activities that involve exploration and discovery, activities that start from a "secure base". Replace "young child" with "adult", and replace "doll or teddy bear" with "computer", and any reader who is a regular computer user will most likely be able to sympathize with the following rationalisation: you like to interact with your computer because it responds to your input on the keyboard and with the mouse (proximity); you do not like being unable to access your computer (separation distress) because you rely on it to help you with certain tasks such as checking your e-mail; if you are not actually using your computer, you feel more comfortable when it is near enough for you to access it when it is needed (a safe haven in the event of a storm of tasks); and you feel confident about playing a new game, deciding on the menu for a dinner party, or choosing a vacation destination, because you know that the computer is there to be asked (i.e., Google or some other search engine) if advice is needed. These are all symptoms of attachment.

Since the attachment process begins in infancy ${ }^{5}$ it is perhaps only natural that children generally exhibit stronger feelings of attachment for their computers than do adults. While young children bond with their blankets and toys, older children are bonding in large numbers with their computers. A MORI survey of children in Britain, conducted in December 2003, found that 45 per cent of the children surveyed considered their computer to be a trusted friend, while 60 per cent responded that they were extremely fond of their computer. The corresponding figures for adults were lower, at 33 per cent and 28 per cent respectively, but still a significant proportion of the population. Furthermore, 16 per cent of adults and 13 per cent of children aged 11 to 16 responded that they often talk to their computer.

\footnotetext{
${ }^{5}$ See also section 3.1 .
} 
Evidencing a general belief in the future of emotional relationships with computers, 34 per cent of the adults surveyed and 37 per cent of the children thought that, by the year 2020, computers will be as important to them as their own family and friends (Press Association, 2004). This strength of the appeal of computers has been described by Cary Cooper (Press Association, 2004), a professor of organisational psychology and health at Lancaster University, as a form of "technological umbilical cord".

These findings would appear to indicate a shift in values in modern society, from a norm where the lives and well-being of family members are paramount, to an entirely different scale of values, a scale on which a serious computer crash is deemed more important than the illness of a family member. Should we be so surprised that in some individuals and in some families such a different scale of values might exist? I think not. We have already seen, in the previous chapter, that some dog owners value their relationship with their pet more highly than their relationship with their spouse. So why should we not expect similar feelings to be expressed, by some people, for computers, and in the future for robots? Those readers who are horrified at the fact that more than 30 per cent of those surveyed held such opinions can take comfort from one very important factor that will, to some extent at least, mitigate in favour of the importance of the human family member relative to that of the computer or the robot. Humans are irreplaceable, computers and robots are replicable ${ }^{6}$. Hopefully this factor will sustain a reasonable measure of balance in the minds of the majority.

In exploring the type of relationship that develops between humans and objects it is important to understand exactly what we mean by "relationship" in this context. The contemporary view of relationships by social psychologists is that the partners in a relationship are fundamentally interdependent, that is to say that a change in one of the relationship partners will bring about a change in the other (Kelley, Berscheid, and Christensen, 1983). Mihaly Csikszentmihalyi and Eugene Rochberg-Halton (1998) have shown that our daily lives are influenced to quite a significant extent by man-made objects, and through these influences we establish a sense of connectedness with those objects ${ }^{7}$. A relationship with an object is one in which the experience we have with that object brings about a change in us, while what we do with that object will usually bring about a change in the object itself, even if it is a very small change such as having experienced some wear through being used or simply having its location changed by being moved. The form of connectedness (for which read "attachment") that Csikszentmihalyi and Rochberg-Halton maintain we develop with objects, is thus derived from the influence on our daily lives and on our identities brought about by our interactions with those objects. In the case of computers, interaction is certainly the operative word. Whereas our "interaction" with most objects is limited to what we do with the object, and is therefore a oneway street, our interactions with computers are two-way (or multi-way) interactions, during the course of which what we do to the computer (typing on the keyboard and clicking the mouse) is part of a genuinely interactive process.

\footnotetext{
${ }^{6}$ The replicability of robots and one of its major implications are discussed in section 6.6.

${ }^{7}$ See also section 3.1 .
} 
A novel approach in the investigation of attachment to computers is expounded by John McCarthy ${ }^{8}$ and Peter Wright (2002) in their delightful paper The Enchantments of Technology. They argue that the attachment some people experience towards computers is one born of an enchantment with the technology. Each of us has the capacity to be enchanted by different things, some of us by a painting, some by a string quartet, some by the smile of a child, some by a motorbike. Just as different people can be enchanted by different things, so different things have the power to enchant different people, and technology is one of those things that has the power to enchant.

This view of enchantment as the basis of attachment to computers is due partly to the ideas of John Dewey (1934), arguably the most influential thinker on education in the twentieth century, whose book Art As Experience asserts that experience is created by the relationship between a person and the tools that they use, the tools which form part of their environment. Dewey discusses a sensual kind of development of the relationship between a person and their environment, a development derived from a combination of the senses that assist the person in becoming familiar with their environment. He uses as an example a mechanic working on an engine. When the mechanic is totally absorbed in his work he sees, hears, smells, and touches the engine, and through these senses he diagnoses what is wrong. Being completely immersed in his work, totally focussed on the task at hand, the mechanic develops a kind of relationship with the engine. Because of his senses he is caught up with what we might call the "personality" of the engine.

A second important researcher who turned his attention to the enchantment of technology is the anthropologist Alfred Gell (1992), who views the cause of this form of enchantment as being the power behind the enchanter. Gell suggests that the power of technology to enchant derives from our sense of wonder at the skill of the creator of that technology - the process of creating the technology being more enchanting than the technology itself. But without any pleasure or similar emotions coming from the experience of a technology, McCarthy and Wright (2002) doubt the capacity of that technology to delight. To them enchantment also involves a sense of pleasure that is derived from the experience of novelty ${ }^{9}$. When your computer does something clever for the first time, something that satisfies you, there is a heightened feeling of pleasure. The satisfaction contributes to a state of enchantment but it is the pleasure of novelty that turns satisfaction into enchantment. This is why working with computers and with software hold great potential for enchantment, because software is not always repetitive and boring - it often has the capacity to surprise, to create the unexpected. Consider, for example, a program designed to compose music. You might sit and listen to one new composition after another, with little to arouse your interest for a while. But then, out of the blue as it were, the program produces a composition that you find very

\footnotetext{
${ }^{8}$ For those readers with some interest in AI, this is not the John McCarthy from Stanford University who coined the term Artificial Intelligence in 1955, but the applied psychologist from University College, Cork.

${ }^{9}$ Bill Yeager (2006) points out that, for masochists, enchantment could involve a sense of pain, and that many hackers fit into this category because programming, solving tough problems and fixing programming "bugs" are perceived by some as painful, yet enjoyable.
} 
much to your liking. This new piece of music not only pleases you as a piece of music, it also surprises you by the power of the technology to compose, and it is in this surprise, and in the technology that creates this surprise, that the power of enchantment resides. This capacity to surprise is also evident, to some extent, in the behaviour of virtual pets - an owner can rarely be certain how their virtual pet will behave.

McCarthy and Wright (2002) also explore the vicarious, visceral, and voyeuristic pleasure we derive from technology, and how these forms of pleasure contribute to our feeling of enchantment. They use film as their example, but it could equally be computers or another form of technology. Transposing their exposition into a world with robots, the voyeur in us will experience the joy of watching the new and the wonderful; our vicarious nature will endear a robot to us if it repeatedly performs in novel and amazing ways that fit together as a coherent behaviour pattern; while our visceral selves will rejoice in the thrill, joy, and apprehension of interacting with robots ${ }^{10}$.

\subsection{On Anthropomorphism ${ }^{11}$}

Anthropomorphism is a tendency to regard and describe objects, animals, and even natural phenomena such as the wind and the sea, in human terms, attributing human characteristics to them with the intention of rationalising their actions. Some people regard anthropomorphism as a belief, even if only a transitory belief, that the object in question is essentially human, a definition with which I disagree. In my view it is important to recognize the distinction between believing that a computer, for example, is essentially human, and merely treating it in the same or similar ways as one might if it were human.

In the early days of Artificial Intelligence, Joseph Weizenbaum (1976) was perplexed by the extent to which people would anthropomorphise his computer program ELIZA :

"I knew of course that people form all sorts of emotional bonds to machines, for example, to musical instruments, motorcycles, and cars. And I knew from long experience that the strong emotional ties many programmers have to their computers are often formed after only short exposures to their machines. What I had not realised is that extremely short exposures to a relatively simple computer program could induce powerful delusional thinking in quite normal people."

\footnotetext{
${ }^{10}$ In line with his comment in footnote 9, Yeager (2006) draws a parallel with the "dark side" of computing that attracts some people - those annoyances experienced when your computer hardware misbehaves, when your Internet connection fails for some reason, when pop-up advertisements appear when you least want them to, when your e-mail experience is harassed by SPAM or disrupted by a virus. These are irritations for most of us but provide a source of masochistic pleasure, thrill, joy, and apprehension for some.

${ }^{11}$ From the Greek words anthropos meaning "man", and morphe meaning "form" or "structure".
} 
What caused many of ELIZA's users to anthropomorphise, was the human-like snatches of conversation that the program generated. Below we provide an example.

$\begin{array}{ll}\text { "User: } & \text { Men are all alike. } \\ \text { ELIZA: } & \text { In what way? } \\ \text { User: } & \text { They're always bugging us about something or other. } \\ \text { ELIZA: } & \text { Can you think of a specific example? } \\ \text { User: } & \text { Well, my boyfriend made me come here. } \\ \text { ELIZA: } & \text { Your boyfriend made you come here. } \\ \text { User: } & \text { He says I'm depressed much of the time. } \\ \text { ELIZA: } & \text { I'm sorry to hear you are depressed." }\end{array}$

It is easy to understand how someone could quickly begin to ascribe human characteristics to such a conversation partner.

The first grandmaster loss to a chess program led to an amusing example of anthropomorphism with computers. During a tournament in London in 1977, the English grandmaster Michael Stean was defeated by the program CHESS 4.6, which had been developed at Northwestern University ${ }^{12}$. At one moment in the game, when the program had found a tactic that he had overlooked, Stean referred to the computer as a "bloody iron monster", and some moves later he exclaimed "this computer is a genius". Stean was not explicitly attributing humanlike qualities to the computer, but employing the descriptive term "monster" as one might for a naughty child, and "genius" as the ultimate intellectual compliment regardless of to whom (or to what) it is being paid. It was the program's remorseless performance in this intellectually difficult task that so impressed Stean, a world class chess player, as to cause him to anthropomorphise. Bill Yeager (2006) makes the interesting observation that many of the remarks made about computers, such as Stean's, are inadvertent and knee-jerk reactions, and that eventually the dividing line between the human and robot species might become so fine that the idea of anthropomorphism, as it relates to robots, will disappear altogether.

If you are a computer user you will most likely have complained, at some time or other, that your computer refuses to work. In doing so, you have attributed to your computer one of the characteristics of a living being, and you will have started to regard it as having some sort of relationship with you - a master/slave relationship in which you expect it to do your every bidding. The ease with which we slip into such a frame of mind has long been the subject of investigation by psychologists and anthropologists, but it is only relatively recently, with the advent of intelligent computers, that it has been recognized that the level of such relationships can rise to the point where, instead of master/slave, we think more in terms of the computer as a kind of friend.

In their book The Media Equation, Byron Reeves and Clifford Nass (1996) describe interaction with computers as being fundamentally a social tendency, but in their

\footnotetext{
${ }^{12}$ This was a game of "speed" chess, in which each player has only a few minutes in which to make all his moves.
} 
view it is not consciously anthropomorphic. They regard such interaction as automatic and subconscious, a view that stems from the general denial by most people that they treat computers as social entities. Yet, despite this common denial, people do interact with computers according to normal human social conventions, by being polite for example, and if a computer violates such a convention it is usually regarded by its human operator as being deliberately offensive or obstructive, clearly an example of anthropomorphism. I believe that it matters not if the anthropomorphism of computers is subconscious. What I feel is important is the effect that anthropomorphism has on the emotional attachment felt towards a computer. It is the combination of attachment and anthropomorphism which, in my view, facilitates in us the creation of a human-computer relationship. As the computer becomes increasingly accepted through the process of anthropomorphism, so will computer users come to treat them more like partners than work tools. For 'computer' one may read 'robot' and the mental leap is made - robots as partners.

But I am are getting ahead of myself. Before I examine why humans develop relationships with computers, I shall first explore in more detail the subconscious nature of the anthropomorphism of computers.

Following the publication of The Media Equation, now widely regarded as a classic in the field of human-computer relationships, Reeves and Nass (1996) extended their experimental research in collaboration with Youngme Moon. Their studies investigated how people apply the rules of human social interaction in their interactions with computers. What their research results demonstrated was a marked difference between how people say they regard computers and how they behave towards computers (Nass and Moon, 2000). Their results are based on some of the 35 experimental studies that Nass and his team carried out, studies that recreated a broad range of social and natural experiences in which computers often took the place of one of the humans in the interaction.

Nass and Moon's (2000) paper, Machines and Mindlessness: Social Responses to Computers $^{13}$, makes the following clear statement at the outset.

"Of the thousands of adults who have been involved in our studies, not a single participant has ever said that a computer should be understood in human terms or should be treated as a person."

In the light of this unanimity, the actual behaviour of these thousands paints a stark contrast, leading Nass and his group to conclude that there is clear evidence that people subconsciously treat computers as having personality and "apply social rules and expectations to computers". The experiments they carried out were mainly based on situations described in the literature of experimental psychology. The same social situations were replicated, as were the same experimental stimuli, but instead

\footnotetext{
${ }^{13}$ I find the use of the term "mindless" in their paper to be most unfortunate in the connotations of stupidity that it suggests. The authors adopt "mindlessness" from a 1989 paper by Ellen Langer, where "subconscious" would, in my view, be far more appropriate. Where I paraphrase extracts of Nass and Moon's fascinating paper I have therefore replaced "mindless" with "subconscious".
} 
of monitoring a human-human social situation the experimenters replaced one of the humans by a computer. Before you start to think that this replacement creates a completely different form of interaction, pause for a moment to consider some important similarities: (1) humans communicate using words - so do computers; (2) humans are interactive in that they respond to a social situation based on all of their prior "inputs" from the person with whom they are interacting - computers are also interactive, in that the way they respond is based on their prior inputs from the user during that session (and possibly during earlier sessions as well, if the software has been programmed to learn); and (3) computers fill many roles that have traditionally been filled by humans. It is against this background of similarity, rather than a background of complete difference, that the results of these experiments should be interpreted. Three series of the experiments carried out by the Nass team were on (1) the gender perspective in relation to a computer, (2) whether people are polite to computers, and (3) reciprocal self-disclosure. I discuss all three series of experiments below.

The first of these series of experiments was by Nass, Moon, and Green (1996) and by Reeves and Nass (1996). They investigated whether or not computer users attribute gender to a computer. ${ }^{14}$ Three stereotypical attitudes were investigated: (1) dominant men are assertive and independent - positive attributes, while dominant women are pushy or bossy - negative attributes; (2) people are more likely to accept an evaluation of their own performance if it comes from a man rather than from a woman; and (3) people assume that men know more about certain topics, thought of as "masculine" topics, than do women, while women know more than men about certain "feminine" topics. The experiment designed to test whether these stereotypical attitudes extend to "male" and "female" computers, employed programs that incorporated male and female recorded voices saying exactly the same things.

Each of the participants in the experiment went through sessions with three computers, each running a different program. There was a tutor program, a program that tested the participants on the topics taught by the tutor program, and finally a program that evaluated both the participants' test results and the teaching abilities of the tutor computer. Both groups, men and women, regarded the female voiced evaluator as significantly less friendly than the male, supporting the stereotypical view that an evaluation by a man is more acceptable than exactly the same evaluation by a woman. In addition, both groups treated praise from the "male" computer more seriously than exactly the same praise from the "female" computer, and believed the tutor computer to be significantly more competent after it had been praised by the "male" evaluator computer, compared to when it had been praised by the "female" evaluator. Finally, the "male" computer was perceived as being more informative than the "female" computer on the subject of computers (a "masculine" subject), while the "female" computer was considered to be the more informative when tutoring in love and relationships (a "feminine" topic).

\footnotetext{
${ }^{14}$ I reiterate that the use of the word "computer" here implies a combination of a computer and its software.
} 
The clear evidence from these experiments confirms that both men and women tend to carry over stereotypical views on human gender to their interactions with computers. Yet, when they were questioned after the experiments, the participants uniformly agreed that there was no difference other than voice between the "male" and "female" computers, and that it would be ludicrous to think of computers as gender stereotypes! All in all, the different reactions to male and female computers are remarkable. They confirm an unexpected picture of different hierarchies in which all things are perceived as either male or female. An appropriate question for computer scientists might be: can we construct computers that are gender neutral? Or, is it even possible to reverse the traditional gender roles by the use of a computer? If this is possible we may address other challenges with analogous methods and techniques, such as the clash of civilizations, the clash of religions, social inequalities, and other global problems (cf. Meijer, 2007). I believe that these questions, interesting as they are, will be addressed by future revolutions in computer technology, but they are too far from my thesis topic to be discussed here.

The second series of experiments was devoted to an investigation into whether people are polite to computers, just as they are to other people. Research in social psychology has revealed that when someone is asked to comment on another person in a face-to-face social situation, for example "How do you like my new haircut?", the resulting comments tend to be positively biased, even when the genuine evaluation might be negative. This is because people are, inherently, polite to other people. Nass and his team (Nass and Moon, 2000) replicated this type of situation by having participants work with a computer on a task, and then asking each participant to evaluate the computer's performance. These evaluations were conveyed by a participant in one of three ways: (1) to the computer itself; (2) to another computer, which the participant knew to be another computer but which was identical for all practical purposes to the computer being evaluated; and (3) as a pencil and paper questionnaire. The evaluations presented by the participants to the collaborating computer itself were found to be significantly more positive than the evaluations presented to the second computer and to those on paper (both of which produced identical, and presumably truthful, responses). The clear conclusion here is that people are polite to computers, this despite a uniform denial by the participants that computers have feelings or that they deserve to be treated politely.

In the third series of experiments Nass' team (Nass et al., 2000) investigated the psychological phenomenon of reciprocal self-disclosure. Research psychologists have confirmed something that is intuitively obvious - the general reluctance of people to talk about their innermost feelings to anyone other than their nearest and dearest (Kelly and McKillop, 1996). The one pronounced exception to this rule is that people will often disclose their secrets to a stranger if that stranger first discloses secrets about themselves (Moon, 2000). Does this reciprocity of self-disclosure apply to people who are in conversation with a computer? In the experiment designed to answer this question the participants were interviewed by a computer on a variety of topics. Where there was no self-disclosure by the computers, the interview questions were asked in a different manner, without suggesting in any way that the computer had feelings and without the computer referring to itself as "I". Typical of these questions was: "what has been your biggest disappointment in 
life?" The results demonstrated that that when the computer reciprocated, by first disclosing something about itself before asking the question, the participant's responses evidenced more intimacy, both in terms of the depth and the breadth of the participant's self-disclosure, than when the computer disclosed nothing about its virtual persona. So once again the evidence points to a human tendency to relate to computers, in much the same way as the same human would relate to other humans in comparable social situations.

The weight of the evidence found by Nass and his colleagues (Nass and Moon, 2000) from these and other experiments ${ }^{15}$, leads to the conclusion that people subconsciously employ the same social "rules" when interacting with computers as they do when interacting with other people. However, their personal reaction showed otherwise (cf. Nass and Moon, 2000).

"(...) despite the fact that the participants in our experiments were adult, experienced computer users. When debriefed, they insisted that they would never respond socially to a computer, and vehemently denied the specific behaviors they had in fact exhibited during the experiments."

It seems perfectly reasonable to explain this phenomenon on the basis of a combination of attachment and anthropomorphism - with emphasis on the latter in these experiments because the participants did not interact with the computers for long enough for attachment to become the dominant factor. Nass and his group (Nass and Moon, 2000) disagree, basing their arguments on a subtle but importantly different definition of anthropomorphism from the customary one. ${ }^{16}$ Instead they prefer to treat such behaviour by computer users as ethopoeia, responding to an entity as though it were human while knowing that the entity does not warrant human treatment or attribution. I feel that the line between subconscious anthropomorphism (as I and many others use the word) and ethopeia, is too fine, if it exists at all, to cause us any concern in this discussion.

\subsection{The Development of Social Relationships with Computers}

Computers are increasingly being regarded as our social partners, and with the evidence amassed by Nass and his group (Reeves and Nass., 1996; Nass and Moon, 2000) it is not difficult to understand why. In addition to the examples of their experimental research described above, Reeves and Nass (1996) have also discovered that people prefer interacting with computers which have identifiable personalities, more so when a computer's personality matches their own, and especially when the user actually experiences the process of the computer adapting its own personality and style of communication to be increasingly like that of the user $^{17}$. Yet another supporting argument for the view of computers as social entities

\footnotetext{
${ }^{15}$ For example, the dominant/submissive computer experiment discussed in the section 6.7.

${ }^{16}$ They define the anthropomorphism of computers as a belief that computers are essentially human, a considerably stronger connection than that usually implied by the use of the word.

17 Evidence for this phenomenon can be found in Chapter 3.
} 
is the liking that people develop for computers that praise them, preferring these computers to ones that offer no such compliments.

One area in which social interaction between humans and computers is often evident is the realm of games. The history of game playing by computers is littered with evidence that many humans anthropomorphise when competing against a computer program, for example Michael Stean's exclamation: "bloody iron monster" and his dubbing the computer as "a genius". ${ }^{18}$ In an experiment designed to investigate the manner in which human games players are emotionally stimulated by computers, two social psychologists, Karl Scheibe and Margaret Erwin (1979), arranged for 40 students to play five different computer matching games against a machine ${ }^{19}$, while a tape recorder was left running in order to record the students' comments. Almost all of the students referred to the computer as they might do to a human opponent, making comments such as: "It's just waiting for me to do it". Interestingly, the students' vocabulary employed for the machine often included the words "he", "you" and "it", but never "she".

An example of a less intellectually demanding game that engenders this same psychological phenomenon is pinball. The definitive study of pinball is Harry McKeown's (1976) book Pinball Portfolio. It describes how an experienced player who comes across a new model of pinball machine for the first time will immediately look for and identify its most interesting features. He will notice the angles of various shots, the arrangement of the flippers, and other important characteristics that affect how this particular machine should be played in order to achieve a good score. When the expert human player starts to work on the machine, it is almost as though he were exploring the characteristics of a potential partner for a new relationship. He discovers its personality, its foibles. As Neil Frude (1983) explains in his book The Intimate Machine, "master players fondle and caress the machine during play, exploring its reaction to their subtle wrists and finely-tuned flipper-fingers." When an expert player gets more to grips with the playing characteristics of the pinball machine, their emotional attachment to the machine develops and they begin to treat it as though it were alive. As McKeown (1976) puts it, "A good machine almost seems to have a mind of its own." Then he quotes some pinball enthusiasts who comment on a machine in humanlike, almost intimate terms: "You can sense the machine responding to your tightness, almost as if it knew and was mocking you."

While game playing is perhaps one of the most sociable activities in which computers can participate and demonstrate their sociability, the breadth of computer applications in which software can be socially responsive is almost limitless. One increasingly common reason for interacting with computer technology is the availability for purchase, via the Internet, of just about every type of product. When we buy something from an Internet shop the owners of that shop want us to return to

\footnotetext{
${ }^{18}$ See section 5.2 .

${ }^{19}$ The games required the human subjects to make a binary choice at each move, e.g., zero or one, heads or tails. The computer program would try to guess what choice was coming next. The humans tried to fool the computer program by varying their choosing strategy.
} 
buy more, so customer loyalty and commitment are important to them. In order to engender such feelings in us, these shops often use software designed to learn more about us from our shopping habits, information that might be used at a later date to engage our interest and to encourage us to buy. A relatively simple example of this can be seen in the way that the Amazon site operates. When I buy a book from Amazon it remembers my purchase and tells me what other books the software believes might interest me. The software on the site knows ${ }^{20}$ who else has bought the book that I have just purchased, and it knows what other books those same people have purchased from Amazon, so it is able to deduce that I might have similar tastes to those other people and recommends to me the other books most often bought by that group. Translating this crude (but presumably effective) approach to a world with robots, when I ask my robot butler robot to bring me a glass of a particular chardonnay, it will remember, and in the future it might ask if I would like it to go to the wine store to buy a similar wine that it knows is on special offer. In this way my butler robot will endear itself to me, just as Amazon hopes to do. But relating to technology does not always bring its emotional rewards in the form of an interactive process, such as the way that I might interact with my robot butler. We can love our FURBY but the FURBY does not love us. We care about the FURBY, but we do so without needing the relationship to become two-sided. In a sense this is analogous to sex with a prostitute - the needs of the client do not include the requirement that the prostitute loves him.

Why then, do some humans develop social relationships with their computers, and how will robots in future decades replicate the benefits of human-human relationships in their own relationships with humans? To help us answer this question we should first consider exactly what emotional benefits human-human friendships provide, and then determine whether these benefits might similarly be provided by computers.

In his book Understanding Relationships, Steve Duck (1991) has summarized the four key benefits of human friendships. I discuss them below

(1) A sense of dependability, a bond that can be trusted to provide support for one of the partners when they need it.

A dramatic example of human trust in computers, and dependability on them, can be seen in the progress made during recent years in the field of computer psychotherapists. For four decades researchers attempted, without very much success, to replicate in software the experience of psychotherapy encounters, replacing a human therapist with a computer (Cavanagh et al., 2003). But then a team at King's College London, led by Judy Proudfoot, developed a successful therapy program called BEATING THE BLUES for dealing with anxiety and

\footnotetext{
${ }^{20}$ The software "knows" in the sense that you and I know something, by remembering. That the software can readily be perceived by us as knowing something, is a prime example of how you and I anthropomorphize computers. I could have written, more precisely: "The software stores the knowledge that ...", but there is no need to be pedantic, since it is already generally accepted that computers "know" whatever it is that is stored in their computer memories. I am grateful to Bill Yeager for pointing out that I am as guilty as anyone of anthropomorphising in this way.
} 
depression. Their most important finding was that computer therapy, using their software, reduced anxiety and depression in a sample of 170 patients "significantly and substantially", to levels that were barely above normal (Proudfoot et al., 2003).

The relevance of this progress to the subject of human-computer emotional relationships derives from the nature of the patient-psychotherapist relationship. In making the initial decision to visit a therapist, and in deciding to continue with the course of therapy after the first few visits, a patient places great trust in the therapist. This trust encourages the patient to divulge personal and intimate confidences to the therapist and to take the therapist's advice on sensitive emotional and other intimate problems in their lives. The fact that patients willingly divulge the same confidences, and take the same advice, when interacting with a computer therapist, demonstrates an inherent willingness to develop emotional relationships, on a trusting and intimate level, with computers ${ }^{21}$. Furthermore, as we saw in Chapter 3, the act of divulging intimate confidences is one of the ingredients that can quickly turn a relationship into love.

(2) Emotional stability - reference points for opinions, beliefs and emotional responses.

Endowing a robot with opinions and beliefs is, at the simplest level, merely a question of programming it with the necessary data, which could take a form such as:

Opinion: $\quad$ The Red Sox will lose to the Yankees tomorrow.

Explanation: Their top four players are ill with 'flu. They have lost to the Yankees in the last seven games between them. The Yankees have recently purchased the two best players in the country.

Software can be developed to use such explanations to argue a case logically. For instance, it will become possible for robot lawyers to argue in defence of their opinions and beliefs by making use of such explanations (cf. Van den Herik, 1991, 1999).

Giving a robot the means to express appropriate emotional responses is a task that falls within the development of a software "emotion module". Robot emotions are discussed briefly in the section "Emotions in Humans and in Robots" in Chapter 6, and more fully in my book Robots Unlimited $^{22}$. The $\mathrm{Oz}$ emotion module, Juan Velasquez' Cathexis program, and the work of Cynthia Breazeal's group at MIT,

\footnotetext{
${ }^{21}$ It would perhaps be as well to remind the reader that, throughout this thesis, when discussing any aspect of human-computer interaction, I employ the word "computer" to mean the combination of the computer hardware (the box, screen, keyboard, and mouse) with whatever software it is running. Here, for example, what the user is actually trusting is the software with which the user is interacting. But because the user sees the computer, feels the keyboard and the mouse, and it is the computer that displays and possibly speaks the output generated by the software, while the software itself is invisible, the user talks about their interaction being with the computer, rather than the computer/software combination.

${ }^{22}$ See chapter 10 .
} 
are amongst the best known examples created to date. Research and development in this field is burgeoning, within both the academic world (e.g., Trappl, Petta, and Payr, 2003) and commercial robot manufacturers, and especially in Japan and the USA, but also in The Netherlands (cf. Dastani and Meyer, 2006). I am convinced that, by 2025 at the latest, there will be artificial emotion technologies that can not only simulate the full range of human emotions and their appropriate responses, but also exhibit non-human emotions that are peculiar to robots. This will make it possible for robots to respond to some human emotions in ways interestingly different from those exhibited by humans, i.e., ways that some people will most likely find to be more appealing, in some sense, than the emotional responses they experience from humans.

(3) Providing physical support (doing favours), psychological support (showing appreciation of the other and letting them know that their opinion is valued), and emotional support (affection, attachment, and intimacy).

Physical support from robots will be a question only of engineering, of designing and building robots to have the necessary physical capability to perform whatever task is being asked of them. If the favour consists of mowing the lawn or vacuuming the carpet, such robots are already on sale. As time goes on, more and more tasks will be undertaken by special purpose robots, of which the lawn mower and vacuum cleaner are merely the first domestic examples. Eventually there will not only be a vast range of robots, each of which can perform its own specified task, but also robots that can operate these robots and others, making it possible for us to ask one robot to accomplish all manner of tasks, simply by commanding the relevant special purpose robots to do their own thing.

Psychological support from robots will most likely be provided by robot therapists, programmed with software akin to that employed in BEATING THE BLUES.

Emotional support will be an ancillary by-product of a robot's emotion module, one for which artificial empathy will be a prerequisite. It has been shown that, so long as a computer appears to be empathetic - understanding and responding to the user's expression of emotion and appropriate in the feedback it provides - it can engender significant behavioural effects in a user, similar to those that result from genuine human empathy (Klein and Klein, 2002). Empathy in robots will be achieved partly by measuring the user's psycho-physiological responses, as described in Chapter 6. By converting this empathy into emotional support, robots will be laying the foundations for behaviour patterns that will enhance their relationships with their users.

(4) Providing reassurance about one's worth as a person.

Our friends contribute to our self-evaluation and self-esteem by giving us compliments and repeating to us the nice things that other people have said about us. Friends also raise our self-esteem by listening, asking our advice and valuing our opinions. All of this will be accomplished by a robot's conversational module, 
backed by scripts and other conversational technologies that teach a robot how to talk in a reassuring manner.

In considering the potential of robots to provide these various benefits of friendship, Yeager (2006) queries whether it is likely or even inevitable that we should entertain some doubts in the backs of our minds - to what extent will people, in the middle of this century, be saying to themselves "But this thing is still only a machine"? To what extent will those, whose strongest friendships are all or mostly with robots, miss the angst of human-to-human relationships? It is my belief that such doubts and feelings will, by then, have dissipated almost entirely, partly because robots will be so convincing in their appearance and behaviour, and partly because people who grow up in an era in which robots are even more commonplace than pet cats and dogs, will relate to robots as people nowadays relate to their friends.

\subsection{Sustaining Social Relationships with Computers}

Timothy Bickmore and Rosalind Picard (2005) have conducted an extensive review of the research into the social psychology of human-human relationships and human-human communication, research that is also relevant to human-computer relationships. They found that people use many different behaviours to establish and sustain relationships with each other, and that most of these behaviours could be used by computer programs to manage their relationships with their users.

One of the key elements of relationships, an element that, until recently at least, has been missing from the software that is designed to create relationships between a computer and a human, is the importance of maintaining the interest, trust, and enjoyment of the human. Maintaining interest can be a side effect of doing everyday tasks together on a regular basis, the collaboration on these tasks acting as a bonding agent. Maintaining the trust in a relationship can be achieved by "meta-relational communication" - talking about the relationship in order to establish the expectations of each partner and to ensure that all is well in the relationship. Other contributing factors to maintaining trust are: (1) confiding in one's partner as to one's innermost thoughts and feelings - this increases both trust and closeness; (2) emphasizing commonalities and de-emphasizing differences - this behaviour is associated with increasing solidarity and rapport with one's partner; and (3) "lexical entrainment" - using a partner's choice of words in conversation.

Maintaining the enjoyment of a relationship can also come in a variety of ways: (1) the use of humour, which makes computers appear more likeable, competent, and co-operative than computers that lack humour (Morkes, Kernal, and Nass, 1998); (2) talking about shared past experiences and the expectations of future togetherness, especially when making use of reference to mutual knowledge; and (3) "continuity behaviours" related to the time people are apart, talking about the time spent apart and using appropriate greetings and farewells. All these are important strategies in maintaining a sense of persistence in a relationship. 
Conversation in general is also an important element of relationships and has formed one of the biggest challenges to the AI community, ever since Alan Turing (1950) proposed his famous test for intelligence. ${ }^{23}$ Most human relationships develop during the course of face-to-face conversations, and even small talk, such as the regular use of the greeting "good morning", can influence the development of a conversation, since it has been found to increase the trust of some computer users ${ }^{24}$. A lesson learned from the development of "expert systems" software is that another way for an intelligent computer to garner a user's trust is by explaining and justifying its beliefs, decisions, and conclusions during a conversation ${ }^{25}$.

It is not only what we say in conversation that affects people's reactions to us, how we speak is also important. The way we address someone will usually depend on the form of our relationship with them: "David" is friendly, "Mr Levy" is less so. "Hello" is friendly, "Good morning" is less so. Thus, the forms of language used in a computer application, even if it is only in menus or some other form of text, signals a certain set of relational expectations on the part of the user. The tone of voice produced by a computer's speech synthesizer can also be an important factor in shaping the attitude of a user to that computer. The more frequently a computer matches the user in intonation, the higher the user rates the computer on measures of familiarity, such as comfortableness, friendliness, and perceived sympathy (Suzuki et al., 2003).

In summary, it would appear that all of the emotional benefits I have considered here, deriving from human-human relationships, could also be provided by computers. Similarly, the behaviours I have discussed here, those necessary to endear one human being to another, appear already to be capable of simulation, and in some cases have been simulated, using conversational and other techniques that are the subjects of research in the AI community. It is true that relatively little progress has been made during the past half-century in the recognition and understanding of conversational language, and that the field requires a quantum leap in progress for the conversational abilities of robots to rise to the levels anticipated here (see also section 4.6, the Turing (1950) debate). Such leaps will certainly come, partly through the emergence of much faster and bigger computing technologies that will enable the use of new software techniques - ones that are not possible with today's level of computing power but which will be possible using the computers of the future.

\footnotetext{
${ }^{23}$ See section 6.4. The Turing Test is also described in more detail in my book Robots Unlimited (Levy, 2005).

${ }^{24}$ This applies when talking to extroverts, but no effect has been found in conversations with introverts.

25 "Expert systems" as the name suggests, are computer-based systems that incorporate human expertise, usually in the form of the "rules" that human experts employ when making judgements and recommendations. It has been found that users of such systems place more trust in a system's decisionmaking capabilities if the system explains its thinking to the user by referring to or describing the rules it employed when making a particular decision. A fuller description of the methodology of expert systems may be found in Chapter 6 of Robots Unlimited (Levy, 2005).
} 


\subsection{Virtual Pets - The TAMAgotchI}

In 1975 a fad for "pet rocks" was started in California by Gary Dahl, a salesman. Here was a pet that required no care, no food, no walking, and yet gave its owner a few moments of pleasure. The idea spread like wildfire and within a few weeks of the inception of the idea Dahl was selling rounded grey pebbles at the rate of ten thousand per day, together with a Pet Rock Training Manual - a step-by-step guide to having a happy relationship with your geological pet, including instructions for how to make it roll over and play dead and how to house-train it. "Place it on some old newspapers. The rock will never know what the paper is for and will require no further instruction."

In the light of the widespread enthusiasm for Dahl's completely inanimate, amorphous pets with which their owner could enjoy no real interaction, the advent and huge commercial success of the TAMAGOTCHI should have come as no great surprise. For those readers who might not have come across one of the most successful toys of recent years, let me first explain the nature of the TAMAGOTCHI ${ }^{26}$. The idea for this product was conceived by a Japanese mother for her children, to counter their problem of being unable to own a real pet due to lack of space at home. Depending on which reports one believes, the number of TAMAGOTCHIs sold during its heyday varied between 12 million and 40 million $^{27}$.

The TAMAGOTCHI fits into the palm of the hand and is shaped like a flattened egg, with a small $\mathrm{LCD}^{28}$ screen on which a simple graphical representation of the virtual pet is displayed. The idea is that the owner must care for the TAMAGOTCHI in its virtual world, by pressing buttons to simulate the giving of food and drink, the playing of games, and other behaviours that are typical of a mother-child relationship, ensuring that the TAMAGOTCHI will survive and thrive. When the TAMAGOTCHI "wants" something, it sounds an electronic beep to alert its owner, and indicates its particular needs at that moment by displaying appropriate icons on the LCD. If the TAMAGOTCHI is neglected it can "grow ill" and "die", often causing heartbreak to its owner. The creature's behaviour patterns were programmed to change with time, in order to give the owners the sense that each TAMAGOTCHI is unique and therefore provides a unique relationship for the owner, just as each pet animal and each human child are unique.

A remarkable aspect of the huge popularity of the TAMAGOTCHI is that it possesses hardly any elements of character or personality (Renée-Bloch and Lemish, 1999), its great attraction coming from its need for almost constant nurturing. It is this nurturing theme that engenders, in many TAMAGOTCHI owners, a feeling of love for their virtual pet, an experience that can substitute for the experience of owning and caring for a real pet or even a human baby. In Japan the biggest group of

\footnotetext{
${ }^{26}$ The name is a diminutive form of the Japanese word "tamago" (egg) and is thus intended to convey the idea of a loveable egg.

${ }^{27}$ The heyday of the original TAMAGOTCHI was the second half of 1997. A new version was launched in the summer of 2005.

${ }^{28}$ Liquid crystal display.
} 
TAMAGOTCHI owners has been women in their twenties, most of whom purchased their toy because they craved the experience of nurturing. In the mother-child and other relationships between humans, the nurturer nurtures as a natural consequence of her love for the nurtured one, and of their need for her nurturing. In the humanTAMAGOTCHI relationship the same elements of a human relationship exist but they act in the reverse direction - it is the need to nurture the virtual pet that engenders the emotion of love, not the love that impels the nurturing instinct. This desire to nurture creates, in many TAMAGOTCHI owners, what Sherry Turkle (2006) calls "the fantasy of reciprocation". The TAMAGOTCHI owner also wants their virtual pet to care about them in return.

This nurturing instinct is also a significant feature in human-pet relationships. In referring to the role of a pet as a surrogate child in a childless relationship, or as an additional child for parents, Marvin Koller (1974) explains that yet another role of pets is to prolong the parenthood process for middle-aged and elderly parents whose children have flown the nest:

"The family pet always needs attention, and the pleasure it brings its keepers derives partly from the sustained dominance and importance of those who take care of it. The need to be needed is powerful, and parents whose children have grown up are gratified by this sustained dependence of their family pet over the years."

The literature abounds with anecdotes about Japanese TAMAGOTCHI owners who go to great lengths in order to preserve the life and well-being of their virtual pet businessmen who postpone or cancel meetings so as to be able to feed their TAMAGOTCHI and attend to its other essential needs at appropriate times; women drivers who are momentarily distracted in traffic while responding to the beeping of their needy electronic creature; a passenger who had boarded a flight but felt compelled to leave the aircraft prior to takeoff, and vowed never to fly with that airline again, because a flight attendant insisted she turn off her TAMAGOTCHI, which the passenger felt was akin to killing it (Virtualpet, 1997). Every example reflects the attitude of devoted TAMAGOTCHI owners that their loveable egg is alive, and a logical corollary of this virtual life is that the TAMAGOTCHI can virtually die. When death occurs the owner could arrange for the virtual birth of a new creature, and in addition many owners paid proper respect to their departed creature by logging on to a Web site that offers virtual cemeteries where the owners could post eulogies to their departed ones. The belief that their TAMAGOTCHI had died is a further indication that the owner had somehow regarded it as having been alive.

It was not only in Japan that the TAMAGOTCHI craze gave rise to important life decisions such as whether to miss a business meeting or to take one's eyes off the road while driving. In Israel an important religious question arose that depended for its answer on whether or not a TAMAGOTCHI was deemed to be alive. Orthodox Jews are not permitted to do anything on the sabbath that constitutes "work", and in the strictest of orthodox households this includes such acts as switching on and off the lights and other electrical and electronic equipment, unless the act of work is necessary for pikuach nefesh - the saving of souls, an act of life or death. The 
question therefore arose, is the pressing of the buttons on a TAMAGOTCHI, an act carried out in order to sustain the TAMAGOTCHI's virtual life, covered by the "saving of souls" caveat? The position of TAMAGOTCHI owners on this issue is clear, but the Rabbinate in Israel took a different view, namely that it is not a real soul which is being saved by pressing the buttons and therefore interaction with a TAMAGOTCHI is forbidden on the Sabbath (Renée-Bloch and Lemish, 1999). Despite this ruling, the very fact that the Rabbinate had to make a decision on the TAMAGOTCHI issue underlines the widespread breadth of feeling that exists, that the TAMAGOTCHI is alive and has a right to life.

The effect of the TAMAGOTCHI and FURBY crazes has been to spawn a culture in which electronic products are accepted as having life-like properties. Sherry Turkle (1999) describes how children have been affected by this realisation of some sort of life in man-made objects.

"A generation of children is growing up who grant new capacities and privileges to the machine world on the basis of its animation. Today's children endow the category of made objects with properties such as having intentions and ideas. These were things previously reserved for living beings. Children come up with the new category "sort of alive" for describing computational animation, and they are increasingly softening the boundaries between artifact and flesh, as well as blurring boundaries between the physical real and simulation."

But even though Turkle (1984), came to expect that children "might come to take the intelligence of artefacts for granted, to understand how they were created, and be gradually less inclined to give them importance", she was surprised at "how quickly robotic creatures that presented themselves as having both feelings and needs would enter mainstream American culture", remarking that "By the mid-1990s, as emotional machines, people were not alone" (Turkle, 2006).

Turkle (2006) explains that, as a result of this change in perception as to the aliveness of artefacts, "people are learning to interact with computers through conversation and gesture. People are learning that to relate successfully to a computer you have to assess its emotional state (...), you take the machine at interface value, much as you would another person." Moreover, she discovered that, in some people, this change in perception can lead to a preference for interacting with an artificial creature rather than a real one, quoting children who, on seeing a pair of Galapagos turtles at the American Museum of Natural History in Boston, remarked that robot turtles would have been just as good, and cleaner, and would have saved transporting the real ones thousands of miles. Turkle (2006) also observes that "When Animal Kingdom opened in Orlando, populated by 'real' - that is, biological - animals, its first visitors complained that they were not as 'realistic' as the animatronic creatures in the other parts of Disneyworld. The robotic crocodiles slapped their tails, rolled their eyes - in sum, displayed archetypal 'crocodile' behaviour. The biological crocodiles, like the Galapagos turtle, pretty much kept to themselves." 
The relationship between a TAMAGOTCHI owner and their virtual pet has been compared to "para-social" relationships - typically those between a television viewer and the characters they see regularly in their favourite soap operas. The term para-social was coined by Donald Horton and Richard Wohl (1956) to represent the type of interaction that viewers have in mind when they imagine themselves becoming closely acquainted with the personalities of TV characters: "After watching a television series for a period of time, viewers come to feel that they know the characters as well as friends or neighbours."

It has been found that the process of developing para-social relationships bears many similarities to the process of developing real-life relationships (Rubin and McHugh, 1987; Perse and Rubin, 1989). But Linda Renée-Bloch and Dafna Lemish (1999) assert that the development of an owner-TAMAGOTCHI relationship is quite different from a para-social relationship because, in the case of the TAMAGOTCHI, it is not a human (TV) personality with which the relationship is developed but the personification of a machine. They support their assertion with the argument that, in the TAMAGOTCHI relationship, the owner can affect the life of the creature by their actions, "the very existence of the virtual partner to the interaction depends on responding to its demands". I take the opposite view. I hold that, precisely because the owner can affect the virtual life of their TAMAGOTCHI, the relationship is an even stronger form of para-social interaction than that between a TV viewer and their favourite character, the dream of having an intimate closeness with that character being better realised in the case of the TAMAGOTCHI because its owner controls, and has the power to enhance, the creature's virtual life, just as a human has the power to enhance and, to some extent, to control (or at least affect) the lives of their friends and loved ones. This type of power can already be seen in some interactive TV systems that allow a viewer to determine what happens next in a storyline - should she kiss him passionately, slap his face or run out of the room crying? Such systems cater for TV viewers enhancing their para-social relationship experience by adding the element of control, allowing them to gain an increased level of intimacy with the TV character in a similar way to how the TAMAGOTCHI owner relates to their virtual pet.

\subsection{Virtual Pets that Live on the Screen}

Hand-held virtual pets such as the TAMAGOTCHI are the simplest form of the genre, based on low-cost electronics that allow a retail price of $\$ 15$ or less. The next step up in complexity is the virtual pet that "lives" on the TV or computer screen, usually a cartoon-like character. The most believable and lifelike of these characters exhibit a variety of social cues: intelligence, individuality, sociability, variability, coherence, and some conversational ability. When these virtual characters are also able to recognize the user's emotional state and other social cues they will become utterly compelling.

Turkle (2006) notes that the behaviour of a character in a computer game impels some computer users to anthropomorphize, not only the virtual character but also 
the computer itself. This is hardly surprising, given that computer users often anthropomorphize their computer even when the task it is executing is not one involving any virtual characters. Add a believable character to the screen and the tendency to anthropomorphize must surely be greater.

A popular example of a screen-based character that encourages anthropomorphism is the virtual GIRLFRIEND. A character of this ilk was first announced in a 1994 advertisement in PC-Magazine ${ }^{29}$ :

"Now You Can Have Your Own GIRLFRIEND

... a sensuous woman living in your computer!

GIRLFRIEND is the first ViRTUAL WOMAN. You can watch her, talk to her, ask her questions and relate with her. Over 100 actual VGA photographs allow you to see your GIRLFRIEND as you ask her to wear different outfits, and guide her into different sexual activities. As a true artificial intelligence program, GIRLFRIEND starts with a 3000 word vocabulary and actually GROWS the more you use it. She will remember your name, your birthday, and your likes and dislikes. GIRLFRIEND comes with the base software [sic] and GIRLFRIEND LISA. Additional girls will be added. This program requires 7-10 $\mathrm{MB}$ of free space."

This type of character has recently been metamorphosed in order to create a new twist on the TAMAGOTCHI concept. Rather than the user lavishing care on the virtual character as the path to giving her a long and happy life, the key with this more recent virtual girlfriend, launched by the Hong Kong company Artificial Life Inc. in the autumn of 2004 , is much simpler. It is money. For a monthly fee of $\$ 6$ (real money, not virtual dollars), customers could download an image of VIVIENNE, a slim, talking brunette, to their $3 \mathrm{G}$ mobile 'phones, and then spend much more (real) money sending her virtual flowers, virtual chocolates, and other virtual gifts, not to mention the essential spend on the mobile "phone calls necessary to interact with VIVIENNE. In return for their generosity, customers are made privy to different aspects of VIVIENNE's life, such as meeting her virtual female friends who also appear as images on the display of the mobile 'phone. But if a customer neglects VIVIENNE she refuses to speak.

VIVIENNE was followed in January 2006 by a virtual boyfriend for women, with other characters being planned by Artificial Life Inc. to cater for gay and lesbian customers.

${ }^{29}$ Vol. 13, p. 483. 


\subsection{Robotic Virtual Pets}

The highest form of virtual pet is one that moves around your room, for example Sony's AIBO, a robot dog. AIBO's design was based on the ethology ${ }^{30}$ of canine behaviour patterns, and in particular on the research conducted by John Scott and John Fuller (1965), and by Michael Fox (1978). This body of research has provided a comprehensive categorisation of canine behaviour patterns that covers the whole range of a dog's activities, and form the basis for the AIBO's own behaviour patterns, which include expressions of anger, disgust, fear, happiness, sadness, and surprise (Arkin and Mosahiro, 2003).

AIBO comes with a number of pre-programmed behaviour patterns that encourage their owners to project human-like attributes onto their virtual pets. The AIBO plays, it sleeps, it wags its tale, it simulates feelings of affection and unhappiness. Sony describes the AIBO as "a true companion with real emotions and instinct" 31 . Not everyone will embrace this concept, but to a large extent any argument over this point is not of great import. What is important is that many people, especially children and the elderly, have been found by psychologists to behave with AIBO in the same way that they would interact with real animals. As the technology improves, and robot pets become increasingly lifelike, the boundary between people's perceptions of robotic pets and their perceptions of real animals will become increasingly blurred.

As a result of its animal-like behaviour, AIBO engenders similar feelings of love in many of its owners to those felt by the owners of real pets. Children's interactions with AIBO were investigated in a comparative study of 7- to 15-year-olds, which compared their AIBO interactions with their interactions with a real shepherd dog (Melson et al., 2005). The majority of children in this study treated AIBO in ways that were dog-like. As one child said, when asked how she would play with AIBO, "I would like to play with him and his ball and just give him lots of attention and let him know he's a good dog." 56 per cent of those surveyed by Melson et al. (2005) believed that AIBO had mental states (for example, feeling scared), 70 per cent said that AIBO had personality, and 76 per cent asserted that AIBO had moral standing (i.e., it could be held morally responsible or blameworthy for its actions, and could have rights and deserve respect). Given how rudimentary AIBO is in terms of its capabilities, it is remarkable that so many children treated AIBO not only as if it were a social agent (the focus of research by Reeves and Nass (1996), albeit human not dog) but also as having mental states and moral standing. It is therefore reasonable to conclude that, as robots become increasingly life-like in their behaviour, and as these children influence the adults around them and grow into adults themselves, more and more people will treat robots as if they are mental, social and moral beings - thus raising the perception of robotic creatures toward the level of biological creatures.

\footnotetext{
${ }^{30}$ Ethology is a study of animals in their natural surroundings.

${ }^{31}$ www.aibo.com
} 
Melson's et al. (2005) team also found that, as compared to AIBO, more children conceptualised the live shepherd dog as having physical essences, mental states, sociality, and moral standing. Behavioural analyses of children in the study indicate that they also spent more time touching and within arms distance of the live dog, as compared with AIBO. Nevertheless, a surprising majority of children conceptualised and interacted with AIBO in ways that were similar to how they interacted with a live dog.

The extent of the love of AIBOs demonstrated by their adult owners can be seen from the many AIBO Internet chat sites that testify to just how widespread are these feelings of love. In a study based on more than 3,000 spontaneous Internet postings on AIBO discussion forums, a team led by Peter Kahn found that 42 per cent of forum members spoke of AIBOs having intentions or engaging in intentional behaviour (Kahn et al., 2004). For example "He [AIBO] also likes to wander around the apartment and play with his pink ball or entertain or just lay down and hang out." Or "He is quite happily praising himself these days." Some members (38 per cent) spoke of AIBO having feelings: "My dog [AIBO] would get angry when my boyfriend would talk to him", or "Twice this week I have had to put Leo [AIBO] to bed with his little pink teddy and he was woken in the night very sad and distressed." Some members (39 per cent) spoke of AIBO as being capable of being raised, developing and maturing, for example, "I want to raise AIBO as best as I possibly can". Some (20 per cent) spoke of AIBO as having unique mental qualities or personality, and 14 per cent of the members of the forum imbued AIBO with a substantial measure of animism, for example "I know it sounds silly, but you stop seeing AIBO as a piece of hardware and you start seeing him as a unique 'life-form' ", or "He seems so alive to me."

Kahn and his team (2004) raise the question: "What are the larger psychological and societal implications as robotic animals become increasingly sophisticated, and people interact less with real animals and more with their robotic counterparts? Our results provide some empirical data to begin to think about such a question. We are not saying that AIBO owners believe literally that AIBO is alive, but rather that AIBO evokes feelings as if AIBO were alive." Based on the research of Batya Friedman and her colleagues (2003) it seems that these feelings arise because people actually want to perceive their AIBOs as real pets, and therefore they attribute dog-like emotions to AIBO. The design of the AIBO has not yet been developed to the point where it can have simulated dog-like emotions and express them in ways that its owner can appreciate, but such capabilities in robot pets will come, and will probably not be long in coming. The relative successes in emotional modelling that have been built upon the findings of the ethology literature will undoubtedly lead to an increase in the study of ethology for this specific purpose, and when it is fully understood what makes dogs tick it will be possible to develop increasingly sophisticated simulations of the emotional make-up of dogs, and to employ such simulations in future artificial canines.

One crucial aspect of life and bonding, that has not yet begun to be deeply explored by the developers of robotic pets and partner robots, is ageing. This is not only important because of the inevitability of our own eventual deterioration and death, 
but also because of the learning processes and greater strength of bonding that can take place as we age. The depth and richness of behaviour patterns in animals, including humans, is founded on the learning process and all that goes with it. As we get to know someone better with time our relationship and intimacy with them can develop, grow stronger. The FURBY concept does simulate the learning process in a very primitive way, by appearing gradually to learn to speak the language of its owner, and even at that primitive level the simulation creates enormous appeal in many of its owners. FURBY starts out life talking in a jibberish language called Furbish, but with time reduces the incidence of Furbish in its vocabulary and correspondingly increases its use of English or whatever. Thus FURBY enjoys a virtual kind of growth in its communicative ability.

The down side, of course, in the ageing process in humans, is the inevitability of death. In theory at least there is no reason why robots will need to "die", and even if a robot suffers damage it can be replicated, both physically (new body, same appearance) and mentally (a copy of the contents and intellectual capacities of its "brain"). The possibility therefore exists that, while simulating the process of growing older alongside its owner, with all the benefits of greater bonding and greater intimacy that that will bring, robots will be able to continue to develop in this way but without ever dying. In the case of humans, impermanence is built in. In robots, impermanence can be built out, allowing robots to continue to develop even after their human has passed away.

\subsection{The Benefits of Forming Attachments to Robot Pets}

The development of AIBO and other technological substitutes for pets has in part been inspired by the benefits that are known to derive from conventional human-pet relationships, and it is now known that there are also psychological and other benefits, especially for children and the elderly, in forming attachments with sociable robots. As we have seen in Chapter 4, research into the therapeutic benefits of owning real pets suggests that simulated pets might bring therapeutic benefits to the elderly, to the disabled, and to emotionally disturbed children, as the real word consequences of the users' treatment of their virtual pet are also simulated by the virtual pets' behaviour patterns.

The use of robot pets as companions and carers for the elderly is a research topic that is gathering great momentum, particularly in $\mathrm{Japan}^{32}$ and the USA, and partly because feeling cared for is known to have profound effects on a patient's physiology, cognition and emotional state (Bickmore and Picard, 2004). Governments are now worrying about how their countries' social services will be able to cope with huge populations of senior citizens. The U.S. Census Bureau, for example, has estimated that the elderly population in the USA will more than double between 2005 and 2050, to 80 million people. How will the elderly be provided with the emotional and physical care they need?

\footnotetext{
${ }^{32}$ See chapter 1.
} 
A research team led by Nancy Edwards (Beck et al., 2005) at Purdue University is investigating the use of robots as a possible solution, providing a simulation of caring that is expressed partly through the content of a robot's speech, partly through its voice, tone and the timing of its speech, and also through the use of appropriate facial expressions and postures. Human communicative behaviours that could be employed by a robot to elicit the perception of feeling cared for, include demonstrations of empathy and comforting behaviour, both of which are within the grasp of current AI research. Facial expressiveness by physical therapists (smiling, nodding and frowning), has been found to be significantly correlated with short- and long-term functioning in geriatric patients (Ambady et al., 2002).

Edwards and her team (Beck et al., 2005) base their idea of using robot pets as carers, on the known therapeutic benefits of real animals on the elderly.

"Hundreds of clinical reports show that when animals enter the lives of aged patients with chronic brain syndrome (which follows from either Alzheimers disease or arteriosclerosis) that the patients smile and laugh more, and become less hostile to their caretakers and more socially communicative. Other studies have shown that in a nursing home or residential care center, a pet can serve as a catalyst for communication among residents who are withdrawn, and provide opportunities (petting, talking, walking) for physical and occupational rehabilitation and recreational therapy. Thus, is it possible that robotic pets - such as Sony's robotic dog AIBO - can provide the elderly with some of the physiological, cognitive, and emotional benefits of live pets?"

Solid evidence that computers have the capacity to instil a sense of caring was revealed in a study carried out by Timothy Bickmore (2003) as part of his Ph.D. research at MIT. Bickmore employed an animated, talking character called LAURA, a virtual fitness consultant, whose screen image showed her with bobbed chestnut brown hair. LAURA was designed to advise users on how to improve their training regimes, and the participants in Bickmore's experiment interacted with LAURA for 10 minutes every day for a month, answering her questions about their workouts and being guided by her advice on how to overcome various obstacles they encountered in taking their daily exercise. Two versions of LAURA were employed for the experiment, with roughly half of the participants interacting with a version that incorporated a full range of caring behaviours that included providing health information, giving feedback on the participants' exercise behaviour, and encouraging them to commit to exercise. This "caring" version would sympathize with any participant who claimed they did not feel well enough to exercise that day, the sympathy including suitable facial gestures as well as an appropriately sad tone of voice. The other group of participants interacted with a version of LAURA that provided the same health advice but none of the caring interactions.

The result after one month was dramatic. Those participants who had interacted with the caring version of LAURA exhibited a significantly greater agreement with four statements about their experience than did those who worked with the non-caring 
version: (1) "I feel that LAURA cares about me in her own unique way, even when I do things that she does not approve of." (2) "I feel that LAURA, in her own unique way, is genuinely concerned about my welfare." (3) "I feel that LAURA, in her own unique way, likes me." and (4) "LAURA and I trust one another." When the participants were asked at the end of the month whether or not they would like to continue working with LAURA, those who had interacted with the caring version responded much more positively than those in the other group, and significantly more participants (69 per cent) in the "caring LAURA" group chose to sign off their final session with "Take care LAURA, I'll miss you.", rather than with the proffered alternative of simply "Bye.", whereas in the "non-caring LAURA" group only 35 per cent chose the more sentimental signoff option.

Bickmore's (2003) results indicate that a suitably programmed virtual character can significantly increase a user's perception of being cared for, even when the user is a very bright, computer-savvy student who knows that computers do not genuinely care for their users.

When robot pets are made sufficiently lifelike, with warm bodies, soft artificial flesh and perhaps with artificial fur, their owners will most likely derive even greater therapeutic benefits than the owners of real pets get from stroking them and from other forms of interaction with them, given that robot pets will also be able to carry on some sort of meaningful conversation, however rudimentary it might be. For children the social benefits of such attachments would include the learning of decent social behaviour - being kind to their virtual pets - and unlearning negative social behaviour.

\subsection{From Virtual Pet to Humanoid Robot}

The transition from relating to a simple battery-operated toy animal, to relating to video game characters, then to computer characters, to robot animals, and finally to human-looking robots, is not a difficult one to make. Given that children have already been shown to form emotional attachments to virtual and robotic pets, and that at the opposite end of the age spectrum the elderly are showing a similar tendency towards carer robots, it seems inevitable that this phenomenon will eventually extend to all generations, when today's children, who grow up loving their robot pets, have turned into tomorrow's adults. By adding intelligence to a robot and making the entity convincingly humanlike rather than dog-like in appearance, robot manufacturers will enhance the user experience to such a great extent that the adult who, 20 years earlier, would happily play with a simple robot pet, will be likely to enjoy the company of one of its successors - the humanoid robot. Cynthia Breazeal, who led the design of the sociable KISMET robot at MIT, found that when she finished her PhD and had to leave KISMET behind in the robot laboratory, she suffered withdrawal symptoms and described a sharp sense of loss. "Breazeal experienced what might be called a maternal connection to KISMET; she certainly describes a sense of connection with it as more than with a 'mere' machine." (Turkle, 2006). 


\subsection{Chapter Conclusions}

In chapter 3 I showed that an essential factor for love is attachment. Subsequently, in chapter 4, I examined the characteristics of affective relationships with our pets. Before broadening the scope still further, from humans to pets to objects, I embarked upon an investigation of emotional attachment to virtual pets. My research has provided us with ample insight into the social relationships between human beings and computers. In the latter case, for computers one may read entities, from TAMAGOTCHI via AIBO to special purpose programs such as LAURA. Every entity has its own research environment, and it would take too long for this thesis to describe the phenomena encountered in all of their detail, but the trend is overwhelmingly clear. I provisionally conclude that human beings tend to attach emotional feelings to virtual pets. In everyday language we might say that human beings "love" virtual pets. The next step is to investigate what "love" (with quotation marks) means in relation to love (without). The next chapter investigates that difference. 


\title{
Chapter 6
}

\section{FALLING IN LOVE WITH VIRTUAL PEOPLE (HUMANOID ROBOTS)}

\begin{abstract}
A sociable robot is able to communicate and interact with us, understand and even relate to us, in a personal way. It should be able to understand itself and us in social terms. We, in turn, should be able to understand it in the same social terms - to be able to relate to it and to empathize with it. Such a robot must be able to adapt and learn throughout its lifetime, incorporating shared experiences with other individuals into its understanding of self, of others, and of the relationships they share. In short, a sociable robot is socially intelligent in a human-like way, and interacting with it is like interacting with another person. At the pinnacle of achievement, they could befriend us, as we could them.

Cynthia Breazeal (2002)
\end{abstract}

In this chapter I address RQ4: what is the attraction of a humanoid robot for a human being? The investigations of this question complete the first part of the problem statement which is focussed on emotional feelings of attraction leading to attachment or love.

It is well established that people love people and people love pets, and nowadays it is relatively commonplace for people to develop strong emotional attachments to their virtual pets, including robot pets. So why should anyone be surprised if and when people form similarly strong attachments to virtual people, to robot people? In response to this question some might ask "But why would anyone want to?" There are many reasons, including the novelty and the excitement of the experience, the wish to have a willing lover available whenever desired, a possible replacement for a lost mate - a partner who dumped us. Psychiatrists will no doubt prescribe the use of robots to assist their patients in the recovery process, after a relationship break-up for example, since such robots could be well trained for the task, providing live-in therapy, including sexual relations, and benefits that will certainly exceed those from Prozac and similar drugs.

To arrive at an answer to RQ4 I conduct a small research programme that contains no fewer than thirteen steps. All these steps are described in separate sections. The design of the chapter shows a logical sequence of building blocks which brings us to the answer of RQ4. Before I start my discourse, I believe that it is wise to provide maximal insight into the direction of my argument by briefly listing the contents of the sections. I start with an investigation of attitudes to relationships in general (in 6.1). This is followed by a discussion on why many people actually prefer interacting with computers to interacting with other people (in 6.2). The discussion 
in this section leads to ideas on robotic psychology and behaviour (see 6.3). From there I am interested in the differences between emotions in humans and emotions in robots (described in 6.4). The next step is to investigate to what extent robots may recognise human emotions (see 6.5). The analyses of the recognition process lead to three routes towards falling in love with robots (described in 6.6). Different designs will lead to different robot personalities. I am interested in robot personalities and their influence on relationships (see 6.7). Subsequently, I examine how the process of designing robot personalities works (described in 6.8). This examination brings us to the concept of robot chromosomes (see 6.9). I am now ready to apply the ten factors of section 3.5 (that cause humans to fall in love with humans) to humanrobot relationships (see 6.10). I then summarize what this comparison proves (see 6.11). For a deeper understanding of the topic of human-robot relationships I am forced to investigate more concepts directly related to love, and therefore in section 6.12 I examine: (1) robot fidelity, (2) passion, and (3) the intensity of robot love. These three topics are closely related to the mood and desires of one of the partners. Following the line of reasoning so far, it is hardly surprising that the next research topic is entitled: "Marrying a Robot" (see 6.13). My analysis thus reaches a provisional culmination, so the time is then ripe for a concluding section - the Chapter Conclusions (in 6.14).

\subsection{Attitudes to Relationships}

I believe that one of the most widespread reasons why humans will develop strong emotional attachments to robots is the natural desire to have more close friends, to experience more affection, more love. Timothy Bickmore (1998) explored the concept and implications of having computer-based intimate friendships in his paper Friendship and Intimacy in the Digital Age, in which he surveyed the state of friendship in our society and found it to be "in trouble". Bickmore explains this assessment as follows.

"Many people and men in particular, would say they are too busy for friends, given the increasing demands of work, commuting, consumerism, child care, second jobs, and compulsive commitments to television and physical fitness."

Bickmore (1998) supports this assertion by quoting McGill, Rinehart, and Winston (1985) The McGill Report on Male Intimacy.

"To say that men have no intimate friends seems on the surface too harsh, and it raises quick objections from most men. But the data indicate that it is not very far from the truth. Even the most intimate of friendships (of which there are very few) rarely approach the depth of disclosure a woman commonly has with many other women. Men do not value friendship. Their relationships with other men are superficial, even shallow." 
Bickmore (1998) also quotes the statistic that "most Americans (70 per cent) say they have many acquaintances but few close friends", and he then posits that "technology may provide a solution." His argument is clear and convincing. Given the great commercial success of the rather simple technology employed in virtual pets such as the TAMAGOTCHI and the AIBO robotic dog, and the popularity of the even simpler conversational technology employed in ELIZA and other "chatterbot" programs $^{1}$, it seems clear that a combination of these technologies, with additional features for self-disclosure and simulating an empathetic personality in the robot, would provide a solid basis for a robotic virtual friend. It is of course reasonable to question why someone would have time for a robot friend but insufficient time for a human one. I believe that amongst the principal reasons will be the certainty that one's robot friend will behave in ways that one finds empathetic, always being loyal, and having a combination of social, emotional and intellectual skills that far outweighs the force of the combination of characteristics that will likely be found in a human friend.

AIBO is clearly the most advanced virtual pet to make any commercial impact thus far, but AIBO's vision and speech capability are limited in comparison with the best that technology could offer today if cost were not an obstacle. Nevertheless, even with limited vision and speech capabilities AIBO appeals to many children and adults as a social entity. Progress in creating everyday lifelike behaviour patterns in robots will increase our appreciation for them, and as robotic pets and humanoid robots increasingly exhibit caring and affectionate attitudes towards humans, the effect of such attitudes will be to increase our liking for the robots. Humans long for affection, and tend to be affectionate towards those who offer it.

\section{Empathy}

As a prerequisite of adapting to the personality of a human, robots will need to have the capacity for empathy - the ability to imagine oneself in another person's situation, thereby gaining a better understanding of that person's beliefs, emotions, and desires. Without empathy, a satisfactory level of communication and social interaction with others is at best difficult to achieve. In order for a robot to develop empathy for a human being it seems likely that the robot will need to observe that person's behaviour in different situations, then to make intelligent guesses as to what is going on that person's mind in a given situation, in order to predict their subsequent behaviour. The acquisition of empathy is therefore essentially a learning task - relatively easy to implement in robots.

The psychological effect on computer users of interacting with an empathetic program was evaluated in an experimental study at Stanford University (Brave, Nass and Hutchinson, 2005). The participants were asked to play casino Blackjack, on a web site, in the virtual company of a computer character who was represented by an image of a human face. The computer character would communicate with the participants by displaying text in a speech bubble adjacent to its image. The

\footnotetext{
${ }^{1}$ Chatterbot (or chatbot) is the generic name of the ELIZA-like programs that can carry on a conversation, appearing always to understand the user's previous utterance while in fact understanding absolutely nothing.
} 
participant and the computer character "sat" next to each other at the Blackjack table and both played against an invisible dealer. After each hand was completed, the computer character would react with an observation about its own performance and an observation of the participant's performance.

Two versions of the program were used, one in which the computer character appeared to be self-centred and one that appeared to be empathetic. In order to simulate self-centredness, the character would express a positive emotion if it had won the hand, by its facial expression and what it said, and a negative emotion if it had lost, but it showed no interest in whether the user won or lost. The empathetic version displayed positive emotions when the participant won a hand and negative emotions when the participant lost.

The investigators found that, when the computer character adopted a purely selfcentred attitude, it had little or no effect on the participants' reactions to its virtual personality. But when the computer character appeared to empathize with the user's results at the Blackjack table, the participants developed a liking, a trust for the character, and a perception that the character cared about their wins and losses and was generally supportive. The conclusion of the study was that, "just as people respond to being cared about by other people, users respond to [computer characters] that care."

\section{Emotional Intelligence}

A robot's social competence, and therefore the way it is perceived by humans as a social being, is inextricably linked to its emotional intelligence ${ }^{2}$. We saw in Chapter 5 that the design of robot dogs benefits from the canine ethology literature. Similarly, creating an accurate and sophisticated model of human emotion is a task that benefits from the literature on human psychology, and it is unlikely to be many years before all the key elements described in that literature have been modelled and programmed. Just imagine how powerful these combined technologies will become a few decades from now: speech, vision, emotion, conversation, ...., when each of them has been taken to a human-like level, a level that today is only a dream for AI researchers. The resulting combination will be an emotional intelligence commensurate with a sophisticated human being. The effect will be sensational.

Even though computers have such a wide range of capabilities that they are already pervasive throughout many aspects of our lives, they are not yet our intellectual and emotional equals in every respect and they are not yet at the point where humancomputer friendships can develop in a way that mirrors human-human friendships. Perhaps the strongest influence on the attitudes of those who do not believe in a future populated with virtual friends, is their difficulty in relating to an artefact, an object that they know is not alive in the sense that we usually employ the word. I do not for a moment expect all of this to change overnight, and until computer models of emotion and personality are sufficiently advanced to enable the creation of high

\footnotetext{
${ }^{2}$ Emotional Intelligence is defined by Daniel Goleman (1997), the originator of the concept, as "the ability to monitor one's own and others' emotions, to discriminate among them, and to use the information to guide one's thinking and actions".
} 
quality virtual minds on a par with those of humans, it seems to me inevitable that there will be many who doubt the potential of robots to be our friends. At the present time we are happy (or at least most of us are) with the idea of robots assembling our cars, robots mowing our lawns and vacuuming our floors, and with robots playing a great game of chess, but not with robots as babysitters or robots as intimate friends. Yet the concept of robots as babysitters is, intellectually, one that ought to appeal to parents more than the idea of a teenager or whoever being responsible for the safety of their infants. The fundamental difference at the present time, between this responsibility and that of building cars or playing grandmaster level chess, is, surely, that robots have not yet been shown to be capable babysitters, whereas they have been shown to excel on the assembly line and on the chessboard (Plaat and Schaeffer, 1997). What is needed to convert the unbelievers is simply the proof that robots can indeed take care of the security of our babies better than we can. And why not? Their smoke detection capabilities will be better than ours and they will never be distracted for the brief moment it can take for an infant to do itself some terrible damage or to be snatched by a deranged stranger.

\section{Automatic Pilot}

One example of how a strong disbelief and lack of acceptance for intelligent computer technologies can change to a diametrically opposite viewpoint, has been seen in the airline industry with the automatic pilots in passenger 'planes. In the first few decades of mass commercial air travel we had the comfort of seeing the captain of our aircraft walking through the cabin, nodding a "hello" to some of the passengers and stopping to chat with others, while his co-pilot took the controls. There was something reassuring about this humanisation of the process of flying, to know that people with such obvious authority and nice uniforms to match were up at the front, ensuring that our takeoffs and landings were safe and negotiating the airplane securely through whatever storms and around whatever mountain ranges might pose some risk of danger. In those days, if all airline passengers had been offered the choice between (1) having an authoritative human pilot in charge and (2) having a computer responsible for their safety, I feel certain that the vast majority would have preferred the human. But today, no more than fifty years later, the situation is quite different. Computers have been shown to be so superior to human pilots in many situations, that there have been prosecutions brought in the USA against pilots who did not engage the computer system to fly their aircraft when they should have done so. Thus, the development in this field has been a change of attitudes from a lack of confidence in the capabilities of a computer to an insistence that the computer is superior to humans at the task. This development will undoubtedly occur in many other domains in which computer use is being planned or already implemented, including the domain of relationships. As the acceptability of sociable robots becomes pervasive and they are treated as our peers, a relevant question might be: "Who is taking you to the party tonight?" Whether it is a robot or a human will become almost irrelevant.

\section{Two Camps}

Different people will, of course, adapt to the emotional capacities of robots at different rates, depending largely on a combination of their attitude, and their 
experience with robots. Those who accept that computers (and therefore robots) already possess or will come to possess human-like psychological and mental capabilities; they will be the first converts. But those who argue that a computer "cannot have emotions" or that robots will "never" have human-like personalities, they will probably remain doubters or unbelievers for many years, until well after many of their friends have accepted the concept and embraced the robot culture. Between those two camps there will be those who are open minded, willing to give robots a try and to experience for themselves the feelings of amazement, joy, and emotional satisfaction that robots will bring. I believe that the vast majority in this category will quickly become converts, accepting the concept of robots as relationship partners for humans.

Bill Yeager (2006) suggests that this level of acceptance will not happen overnight because the breadth and depth of the human experience currently goes far beyond the virtual pets and robots made possible by the current state of the art in Artificial Intelligence. So long as robots are sufficiently different from us to be regarded as a novelty, our relationships with them will, to some extent, be superficial, and not even approach the relationships we have with our pets. One of the factors that cause us to develop strong bonds with our (animal) pets is that they share our impermanence, our frailties, being caught up in the same life-death cycle that we are. Yeager (2006) believes that in order to achieve a level of experience comparable with humans, robots will have to grow up with us, acquire our experiences with us, be our friends, mates, and companions, and die with us. Moreover, he argues that they will be killed in automobile accidents, perhaps suffer from the same diseases, get university degrees, be dumb, average, bright, and geniuses. What Bill Yeager expresses with well chosen words is similarly expressed by Kaja Silverman (1991) in her critique of the movie Blade Runner. Silverman analyses the consequences of the possible developments to an extreme end. The question is: what will this end be in reality?

I take a view different from Yeager's (2006) and Silverman's (1991). I believe that almost all of the experiential benefits that Yeager (2006) anticipates for robots to be needed, can either be designed and programmed into them, or can be compensated for by other attributes that robots will possess but we do not. I know that my vision is as speculative as Yeager's and Silverman's. I rest my "hopes" on different approaches that perform better than the approaches known so far. For instance, AI technologies have made it possible for a computer to play world class chess, despite thinking in ways completely different from human grandmasters. Similarly, I believe that yet-to-be-developed AI technologies will make it possible for robots to behave as though they had enjoyed the full depth and breadth of human experience, without having done any such thing. I see the resulting differences between robots and humans as being no greater than the cultural differences between peoples from different countries or even from different parts of the same country. Will robots and humans typically interact and empathise with each other any less than, say, Shetland Islanders with Londoners, or the bayou inhabitants of the swamps of Louisiana with the residents of suburban Boston? Donna Haraway takes a different position (1985), suggesting a new world with three different species and a new hierarchy, viz. 
humans, animals, and then machines. Time will show who is right: Haraway or Levy.

\subsection{Preferring Computers to People}

Many people actually prefer interacting with computers to interacting with other people. Let me start with some personal experiences. I first learned of this tendency in 1967, in the somewhat restricted domain of medical diagnosis. I was a young Artificial Intelligence researcher at Glasgow University, where a small department had recently started up, the Department of Medicine in Relation to Mathematics and Computing. The head of department, Wilfred Card, explained to me that his work into computer-aided diagnosis took him regularly into the alcoholism clinic at the Western Infirmary, one of Glasgow's teaching hospitals. There he would ask his patients how much in alcoholic beverages they usually drank each day, and his computer program would ask the same patients the same question on a different day. The statistics proved that his patients would generally confess to a significantly higher level of imbibing when typing their alcohol intake on a teletype ${ }^{3}$ than when they were talking to the professor. This phenomenon, people being more honest in their communication with computers than they are to humans, has also been found in other situations in which questions are asked by a computer, such as in the computerized interviewing of job applicants (Martin and Nagao, 1989). Another example stems from a survey of students' usage of drugs, investigated by Lee Sproull and Sara Kiesler (1991) at Carnegie Mellon University, in which only three per cent of the students admitted to using drugs when the survey was conducted with pencil and paper, but when the same survey was carried out by e-mail the figure rose to 14 per cent.

A preference for interacting with a computer program that appeared sociable, rather than with a person, was observed a year or so after Card's experience by Joseph Weizenbaum (1976) at MIT, when a version of his famous ElIZA program was run on a computer in a Massachusetts hospital. ELIZA's conversational skills operated simply by turning around what a user "said" to it, so that if, for example, the user typed "My father does not like me" the program might reply "Why does your father not like you?" or "I'm sorry to hear that your father doesn't like you". ${ }^{4}$ Even though ELIZA was dumb, with no memory of the earlier parts of its conversation and with no understanding of what the user was saying to it, half of those who used it at the hospital said that they preferred interacting with ELIZA to interacting with another human being, despite having been told very firmly by the hospital staff that it was only a computer program. This stubbornness might be because the patients knew that they were not being judged in any way, since they would have assumed, correctly in this case, that the program did not have any judgemental capability or tendencies.

\footnotetext{
${ }^{3}$ An early form of computer keyboard.

${ }^{4}$ See also the section "On Anthropomorphism" in Chapter 5.
} 
The preference for interacting with computers rather than with humans helps to explain why computers are having an impact on social activities such as education, guidance counselling and psychotherapy. As long ago as 1980 it was found that a computer could serve as an effective counsellor and that its "clients" generally felt more at ease communicating with the computer than with a human counsellor. Sherry Turkle (1984) describes this preference as an

"infatuation with the challenge of simulated worlds . . . Like Narcissus and his reflection, people who work with computers can easily fall in love with the worlds they have constructed or with their performances in the worlds created for them by others."

Communicating information is by no means the only task for which people prefer to interact with a computer rather than with another human being. It was also noticed in early studies of human-computer interaction, that people are generally as influenced by a statement made by a computer as they are when the same statement is made by a human, and that the more someone interacts with a computer the more influential that computer will be in convincing them that it is telling the truth.

I strongly suspect that the proportion of men preferring interaction with computers to interaction with people is significantly higher than the proportion of women, though I am not aware of any quantitative psychology research in this area. Evidence from the McGill Report, for example, shows men to be more prone than women to eschewing human friendships, leaving men with more time and inclination than women to relate to computers. This bias, assuming that it does exist, suggests that men will always be more likely than women to develop emotional relationships with robots, but although I do believe this will be the case in the early years of human-robot emotional relationships, I suspect that in the longer term women will embrace the idea in steadily increasing numbers (see also my preliminary discussion on this topic in section 4.3). One reason, as will be discussed in Chapters 9 and 10, is that women will be extremely enthusiastic about robot sex, once the practice has received a good press from the mainstream media in general and women's magazines in particular, and with their robot sexual experiences women will, more than men, want a measure of emotional closeness with their robot. A second scenario that I foresee as being likely, is that, from the positive publicity about human-robot relationships, women who are in or who have recently left a bad relationship will come to realise that there is more than one way of doing better. Yes, it would be very nice to start a relationship with a new man, but one can never be sure how it is going to work out. I believe that emotional relationships with robots will come to be perceived as a more dependable way to assuage one's emotional needs, and women will be every bit as enthusiastic as men to try this out. In today's modern world there are many women, particularly the upwardly mobile career-minded, who would have more use for an undemanding robot that satisfied all of her relationship needs, than she would for a man. In this respect we may remember the Canadian feminist Shulamith Firestone (1970) who long ago 
advocated the use of technology to enable women to seize the means of human reproduction and move it from the bedroom to the laboratory. ${ }^{5}$

What is the explanation for the preference of interacting with a computer over interacting with people? It is partly the feeling of privacy and the sense of safety that such interactions bring, making people more comfortable when answering a computer, and therefore more willing to disclose information. But this preference, and the reasons why people can even develop a strong affection for computers, are sometimes explained by describing this form of affection as an antidote to the difficulties that many people face in forming satisfactory human relationships. While this is undoubtedly true in a significant proportion of cases, there are also many people who enjoy being with computers simply because computers are cool, they are fun, they empower us.

\subsection{Robotic Psychology and Behaviour}

The exploration of human-robot relationships is very much a new field of research. While the creation of robots and the simulation of human-like emotions and behaviours in robots are fundamentally technological tasks, the study of relationships between humans and robots is an even newer research discipline, one that belongs within psychology. This field has been given the name "robotic psychology" and practitioners within the field are known as "robopsychologists". Amongst those who have taken a lead in developing this nascent science are a husband-and-wife team at Georgetown University's psychology department, Alexander and Elena Libin, who are also the founders of the Institute of Robotic Psychology and Robotherapy in Chevy Chase, Maryland. The Libins (2003) define Robotic Psychology as "a study of compatibility between robots and humans on all levels - from neurological and sensory-motor to social orientation”. Their own research into human-robot communication and interaction, although still in its infancy, has already demonstrated some interesting results. They conducted experiments to investigate people's interactions with NECORO, a sophisticated robotic cat covered with artificial fur, manufactured by the Omron Corporation and launched in 2001. NECoRo stretches its body and paws, moves its tail, meows, and acts in various other cat-like ways, getting angry if someone is violent to it, expressing happiness when stroked, cradled and treated with lots of love. NECoRo incorporates learning methods that cause the cat to become attracted to its owner day by day, and to adjust its personality to that of its owner. It was found that older people obtain more pleasure from the responses of the robot cat to their touch than do younger people; women find it less interesting to play with the robotic cat than do men ${ }^{6}$; the American participants generally liked what NECoRo said to them

\footnotetext{
Among the reproductive technologies predicted by Firestone were in-vitro fertilisation and sex selection.

${ }^{6}$ More research is called for as to why this difference exists. Is it merely evidence of an extension of the difference suggested in the previous section (men preferring interaction with computers over interaction with humans, more than women do), or does the difference in this older generation have a different foundation?
} 
better than did the Japanese participants; and the Americans enjoyed touching the robots more than did the Japanese. Experimental results such as these will provide data to assist the robot designers of the future in their goal of making robots increasingly acceptable as friends and partners for humans.

As the human and artificial worlds continue to merge, it will become increasingly important to study and understand the psychology of human-robot interaction. The birth of this new area of study is a natural consequence of the development of robot science. Increasingly, our daily lives bring interaction with different kinds of robots, whether they be TAMAGOTCHIs, robot lawn mowers or soccer playing androids. These robots are being designed to satisfy different human needs, to help in tasks such as education and therapy, tasks hitherto reserved for humans. It is therefore important to study the behaviour of robots from a psychological perspective, in order to help robot scientists improve the interactions of their virtual creatures with humans.

Much of the early research in this field has been carried out with children, as this age group is more immediately attracted to robot pets than are their parents and grandparents. One of the first discoveries from this research was intuitively somewhat obvious, but nevertheless interesting and useful in furthering good relations between robots and humans. It was discovered that children in the 3 to 5 age group are more motivated to learn from a robot that moves and has a smiling face than from a machine that neither moves nor smiles. As a result of recognizing these preferences, the American toy giant Hasbro launched a realistic looking animatronic robot doll called MY REAL BABY, that had soft flexible skin and other human-like features. It could exhibit fifteen human-like emotions by changing its facial expressions, moving its lips, cheeks, and forehead, blinking, sucking its thumb, ... By virtue of these features it could frown, smile, laugh, and cry.

The appeal to children of MY REAL BABY lies in its compatibility with them, a compatibility that breeds companionship. The shape and appearance of a robot can have a significant effect on the level of this compatibility. A study at the Sakamoto Laboratory at Ochanomizu University in Japan investigated people's perceptions of different robots: the AIBO robotic dog and the humanoid robots ASIMO and PAPERO, and explored how these perceptions compared with the way the same group of people perceive humans, animals and inanimate objects. One conclusion of the study was that appearance and shape most definitely matter - people feel more comfortable when in the company of a friendly-shaped, human-like robot than when they are with a robotic dog (RoboFesta Kanagawa, 2001).

In Chapter 5 we discussed the use of ethology, the study of animals in their natural setting, as a basis for the design and programming of robot animals. Since humans are also a species of animal it would seem logical to base the design and programming of humanoid robots on the ethology of the human species, but unfortunately the ethological literature for humans is nowhere near as rich as it is for dogs, and what literature there is on human ethology is mainly devoted to child behaviour. For this reason, the developers of Sony's SDR humanoid robot (Figure 6.1) have adapted the ethological architecture used in the design of AIBO, an 
architecture that contains components for perception, memory, and the generation of animal-like behaviour patterns, adding to it a thinking module ${ }^{7}$ to govern its behaviour (Arkin et al., 2002). SDR also incorporates a face recognition system that enables the robot to identify the face of a particular user from all the faces it has encountered, a large-vocabulary speech recognition system that allows it to recognize what words are being spoken to it, and a text-to-speech ${ }^{8}$ synthesizer $^{-}$ allowing it to converse using human-like speech.

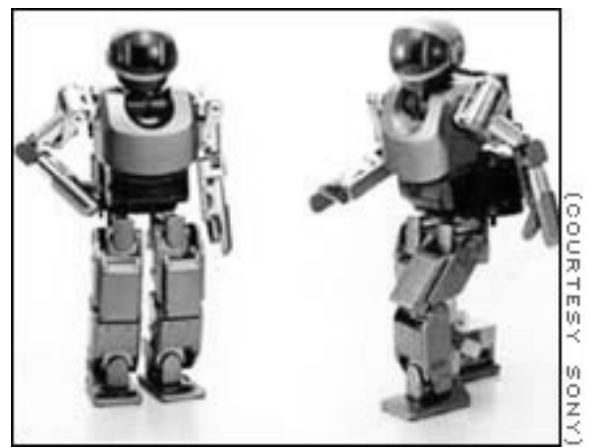

Figure 6.1: Sony's SDR humanoid robot.

\subsection{Emotions in Humans and in Robots}

Building a robot sufficiently convincing to be almost completely indistinguishable from a human being, a "Stepford Wife" but without their level of in-built subservience, is a formidable task that will require a combination of advanced engineering, computing, and artificial intelligence skills. Such robots must not only look human, feel human, talk like humans, and react like humans, they must also be able to think or, at least, to simulate thinking at a human level. They should have (or at least simulate) and should be able to express their own (artificial) emotions, moods, and personalities, and they should recognize and understand the social cues that we exhibit, thereby enabling them to measure the strengths of our emotions, to detect our moods, and to appreciate our personalities. They should be able to make meaningful eye contact with us and to understand the significance of our body language. From the perspective of engendering satisfying social interaction with humans, a robot's social skills, the use of its emotional intelligence, will probably be even more important than being physically convincing as a replica human. For those who would only accept that computers can simulate emotions adequately, but not have them, I would like to address this topic in brief, and without changing my position. A perfect simulation is not distinguishable from the real thing, so in a

\footnotetext{
${ }^{7}$ Referred to by its designers as a "deliberative layer".

${ }^{8}$ Text-to-speech is a speech synthesis technology that allows the software to say any word, based on its spelling and its assumed pronunciation. It is not, therefore, limited only to a fixed pre-programmed vocabulary. A more detailed description of text-to-speech can be found in Chapter 7 of Robots Unlimited (Levy, 2005).
} 
perfect simulation we have what Jean Baudrillard calls a "hyper-real". This brings the discussion back to one on representation (cf. Baudrillard, 1988). I present my arguments below.

Lest I be accused of glossing over a fundamental objection that some people have to the very idea that machines can have emotions, I shall here summarize what I consider to be the most important argument supporting this notion. ${ }^{9}$ Certainly there are scholars whose views on this subject create doubts in the minds of many: how can a machine have feelings? If a machine does not have feelings, what value can we place on its expressions of emotion? What is the effect on people when machines "pretend" to empathise with their emotions? All of these doubts and several others have attracted the interest of philosophers for more than half a century, helping to create something of a climate of scepticism.

From a behaviourist point of view, all such doubts can be assuaged by applying a complementary approach of that by Alan Turing (1950) when he investigated the question "Can Machines Think?"10 Turing is best known in the history of computing for contributions ranging from leading the British team that cracked the German codes during World War II, to the solution of a number of fundamental issues on computability (cf. Carpenter and Doran, 1986). But it was his exposition of what has become known as the Turing Test that has made such a big impact on Artificial Intelligence and which enables us, in my view, to answer all the sceptics who pose questions such as "Can machines have feelings?"

The Turing Test was proposed as a method of determining whether or not a machine should be regarded as intelligent. The test requires a human interrogator to conduct typed conversations with two entities and then to decide which of the two is human and which is a computer program. If the interrogator is unable to identify the computer program correctly, then the program should be regarded as intelligent. The logical argument behind Turing's test is easy to follow - conversation requires intelligence, ergo if a program can converse as well as a human being, then that program should be regarded as intelligent.

To summarize Turing's (1950) position, if a machine gives the appearance of being intelligent then we should assume that it is indeed intelligent. I submit that the same argument can equally be applied to other aspects of being human: to emotions, to personality, to moods, and to behaviour. If a robot behaves in a way that we would consider uncouth in a human, then, by Turing's standard, we should describe that robot's behaviour as uncouth. If a robot acts as though it has an extrovert personality, then, with Turing, we should describe it as being an extrovert. Here we arrive at a similar discussion to that in section 4.6, "Comparing Relationships". Then I discussed the behaviouristic vision in relation to three other visions, viz. reductionism (Dawkins, 1976), functionalism (Lem, 1974) and computational psychology (Cherniak, 1978), and now I shall briefly continue the discussion with

\footnotetext{
${ }^{9}$ This and other arguments are given a much more thorough airing in Robots Unlimited (Levy, 2005).

${ }^{10}$ In 1950 Turing asked this question in his famous paper "Computing Machinery and Intelligence", arguably the most important publication in the history of Artificial Intelligence.
} 
respect to postmodernism. (I do not discuss the difference of emotions by gender type, as that is beyond the scope of this thesis.)

The current postmodern belief is that an accurate description of reality is impossible. According to Baudrillard (1988) we cannot do better than arriving at a position of perfect simulation, the representation of the hyper-real (cf. Derrida, 1974). So if, like a TAMAGOTCHI, a robot "cries" for attention, then the robot is expressing its own form of emotion in the same way as a baby does when it cries for its mother. The robot that gives the appearance, by its behaviour, of having emotions, should be regarded as having emotions, the corollary of this being that if we want a robot to appear to have emotions it is sufficient for it to behave as though it does. Of course, a robot's programmed emotions might differ in some ways from human emotions, and robots might even evolve their own emotions, ones that are quite different from our own. As with a chess program that "thinks" differently from human grandmasters, robots might evolve their own emotions, ones that are quite different from our own. In such cases, instead of understanding, through empathy and experience, the relationship of a human emotion to the underlying causes, we might understand nothing about robotic emotions except that on the surface they resemble our own. Some people will not be able to empathise with a robot frowning or grinning - they will be people who interpret the robot's behaviour as nothing more than an act, a performance. But as we come to recognize the various virtual emotions and experiences that lie behind a robot's emotional behaviour, we will feel less and less that a robot's emotions are artificial.

Our emotions are inextricably entwined with everything we say and do, and are therefore at the very core of human behaviour. For robots to interact with us in ways that we appreciate, they too must be endowed with emotions, or at the very least they must be made to behave as though they have emotions. Sherry Turkle (1995) has found that children deem simple toys, such as FURBY, to be alive, if they believe that the toy loves them and if they love the toy (Allis, 2004). On this basis, the perception of life in a humanoid robot is likely to depend partly on the emotional attitude of the user. If the user believes that their robot loves them, and that they in turn love their robot, then the robot is more likely to be seen as alive. If a robot is deemed to be alive then it is more likely that its owner will develop increased feelings of love for the robot, thereby creating an emotional snowball. But before robot designers can mimic emotional intelligence in their creations, they must first understand human emotions better than they do now.

Human emotions are exhibited in various ways: in the changes in our voice, in the changes to our skin colour when we blush, in the way we make or break eye contact; and robots therefore need similar cues to help express their emotions. Just as face and sound are used as a matter of course, instinctively and subconsciously, by humans communicating with other humans, so similar forms of communication are being exhibited by emotionally expressive robots in order to communicate their simulated emotions to their human users.

Many studies have shown that the activity of the facial muscles in humans is related to our emotional responses (Lang et al., 1993, Lang 1995; Bradley and Lang, 2000). 
The muscle that draws up the corners of the lips when we smile ${ }^{11}$ is associated with positive experiences, while the muscle that knits and lowers the brows when we frown $^{12}$ is associated with negative ones. Much of today's research into the use of facial expression in computer images and robots stems from a coding system developed during the 1970s by Paul Ekman, a psychologist at the University of California at San Francisco (Ekman and Friesen, 1978). He and Wallace Friesen classified dozens of movements of the facial muscles into 44 "action units" components of emotional expression - each combination of these action units corresponding to a different variation on a basic facial expression such as anger, fear, joy, or surprise. It has been shown as a result of Ekman's and Friesen's (1978) work that the creation of emotive facial expressions is relatively easy to simulate in an animated character or a robot, while research at MIT has revealed that humans are capable of distinguishing even simple emotions in animated characters by observing the character's facial expressions (Cassell, 2000). The recognition, by a machine, of these various action units, can therefore be converted to the recognition of a human emotional state. The simulation of a combination of action units becomes the simulation, in a robot or on a computer screen, of a human emotion. Yes, this is an act on the part of the robot, but as time goes on the act will become increasingly convincing, until it is so good that we cannot tell the difference.

The study of emotions and other psychological processes is a field that pre-dates the electronic computer, providing researchers in robotics with a pool of psychological research into which they can tap for ideas on how best to simulate these processes in robots. If we understand how a particular psychological process works in humans, we will be able to design robots that can exhibit that same process. And just as being human endows us with the potential to form companionable relationships, this same potential will be designed into robots in order to help make them sociable.

An example of a robot in which theories from human psychology have been synthesized, is FEELIX, a $70 \mathrm{~cm}$ tall humanoid robot designed at the University of Åarhus, and built with LEGO bricks (Cañamero and Freaslund, 2000). The manner in which a user interacts with FEELIX is by touching its feet. One or two short presses on the feet make FEELIX surprised if they immediately follow a period of inactivity, but when the presses become more intense and shorter FEELIX becomes afraid, whereas a moderate level of stimulation, achieved by gentle, long presses on its feet, makes FEELIX happy. But if the long presses become more intense and sustained, FEELIX becomes angry, reverting to a happier state and a sense of relief only when the anger-making stimulation ceases.

FEELIX was endowed with five of the six "basic emotions" identified by Paul Ekman (1992): anger, fear, happiness, sadness, and surprise ${ }^{13}$. These five emotions all have the advantage that they are associated with distinct corresponding facial expressions that are universally recognized, making it possible to exhibit the robot's emotions

\footnotetext{
${ }^{11}$ This muscle is called zygomaticus major.

12 This muscle is corrugator supercilii.

13 The sixth emotion proposed by Ekman (1992), disgust, was not felt appropriate for the type of interactions that FEELIX's designers expected humans to have with the robot.
} 
partly by simulating those facial expression. Anger, for example, is exhibited by FEELIX raising its eyebrows and having a moderately open mouth with its upper lip curved downwards and its lower lip straight, while happiness is shown by straight eyebrows and a wide closed mouth with the lips bent upwards. When it feels no emotion, i.e., when none of its emotions are above their threshold level, FEELIX displays a neutral face. But when it is stimulated in various ways Feelix becomes emotional and displays the appropriate facial expression.

In order to determine how well humans can recognize emotional expressions in a robot's face, FEELIX was tested on two groups of participants, one made up of children in the 9 to 10 age range and one with adults aged 24 to 57 . The tests revealed that the adults correctly recognized FEELIX's emotion from its facial expression in 71 per cent of the tests, with the children slightly less successful at 66 per cent recognition. These results match quite well the recognition levels demonstrated in earlier tests, using photographs of facial expressions, that had been reported in the literature on emotion recognition, providing evidence that the simulation of expression of the basic emotions is not something from science fiction but can already be designed into robots. Accepting that an acted out emotion is just that, an act, will make it difficult to believe that the acted emotion is being experienced by the robot. But again, as the "acting" improves, so any disbelief will evapourate.

\subsection{Robot Recognition of Human Emotions}

To interact meaningfully with humans, social robots must be able to perceive the world as humans do, sensing and interpreting the same phenomena that humans observe. This means that, in addition to the perception required for physical functions such as knowing where they are and avoiding obstacles, social robots must also possess relationship-oriented perceptual abilities similar to humans, perception that is optimised specifically for interacting with humans and on a human level. These perceptual abilities include being able to recognize and track bodies, hands and other human features, being capable of interpreting human speech, and having the capacity to recognize facial expressions, gestures and other forms of human activity.

Even more important than its physical appearance and other physical attributes, in engendering emotional satisfaction in humans, will be a robot's social skills. Possibly the most essential capability in robots for developing and sustaining a satisfactory relationship with a human is the recognition of human emotional cues and moods. This capability must therefore be programmed into any robot that is intended to be empathetic. People are able to communicate effectively about their emotions, by putting on a variety of facial expressions to reflect their emotional reactions and by changing their voice characteristics to express surprise, anger, and love, so an empathetic robot must be able to recognize these emotional cues. 
Robots who possess the capability of recognizing and understanding human emotion will be popular with their users. This is partly because, in addition to the natural human desire for happiness, a user might have other emotional needs: the need to feel capable and competent, to maintain control, to learn, to be entertained, to feel comfortable and supported. A robot should therefore be able to recognize and measure the strength of its user's emotional state, in order to understand a user's needs and recognize when they are being satisfied and when they are not.

Communicating our emotions is a process called "affect", or "affective communication", a subject that has been well investigated by psychologists. It is also a subject of great importance in the design of computer systems and robots that detect and even measure the strength of human emotions, and in systems that can communicate their own virtual emotions to humans. The Media Lab at MIT has been investigating affective communication since the mid-1990s, research led by Rosalind Picard (1997) whose book, Affective Computing, has become a classic in this field. Affective computing involves giving robots the ability to recognize our emotional expressions (and the emotional expressions of other robots), to measure various physiological characteristics in the human's body, and from these measurements to know how we are feeling.

Inexpensive and effective technologies that enable computers to measure the physiological indicators of emotion, also allow computers to make judgements about a user's emotional state. Thanks largely to Picard (1997), detecting and measuring human emotion has become a hot research topic in recent years (Cowie et al., 2001; Picard, Vyzas, and Healey, 2001; Picard and Klein 2001). By measuring certain components of the human autonomic nervous system ${ }^{14}$ it is already possible for computers to distinguish a few basic emotions. A straightforward example of such measurements is galvanic skin response - the electrical conductivity of the skin. This has long been known as an indicator of stress and has therefore been employed in some lie-detectors, but more recently it has also been used as a metric for helping to recognize certain emotional states other than stress. Heart rate is another easy-to-measure example - it is known to increase most during fear, but less when experiencing anger, sadness, happiness, surprise, and disgust, the last of these eliciting only the barest minimum of a heart rate change (Cacioppo et al., 1997). Yet another example is blood pressure, which increases during stress and decreases during relaxation, the biggest increase again being associated with anger (Cacioppo et al., 1997)

It is relatively easy to measure human blood pressure, respiration, temperature, heart-rate, skin conductivity, and muscle tension, using what are currently regarded as sophisticated items of electronic equipment. Research into "affective wearables", usually items of clothing and other attachments that may be worn unobtrusively and which come with electronic sensors for taking such measurements ${ }^{15}$, will inevitably

\footnotetext{
${ }^{14}$ The autonomic nervous system is that part of the vertebrate nervous system that regulates involuntary action, for example the actions of the intestines, heart and glands.

${ }^{15}$ Much of the research into affective wearables is being conducted by Rosalind Picard's group at MIT. This subject is discussed in more detail in Chapter 10 of Robots Unlimited.
} 
lead to the development of technologies that can monitor all of these vital signs without us even noticing that we are wearing them. By transmitting the measured data, affective wearables will thus enable robots to recognize and quantify at least some of our emotions, allowing them to judge our moods, based on our displays of emotion as they appear to the electronic monitors. For example, by combining the data from only four different measures: respiration, blood pressure volume, skin conductance, and facial muscle tension, Rosalind Picard, Elias Vyzas and Jennifer Healey (2001) developed an emotion recognition system capable of 81 per cent accuracy when distinguishing amongst eight emotions: anger, hate, grief, platonic love, romantic love, joy, reverence, and the neutral state (no emotion).

Additional help in detecting human emotion can come from auditory and visual cues. Facial recognition technology is making dramatic advances, spurred on by the impetus of a fear of terrorism - the technology that today successfully identifies faces seen on a closed circuit TV camera will tomorrow be identifying not only the person behind the face but also their mood. Similarly with voices. Voice recognition has taken on an increased import as a means of identification for security purposes, turning the sound characteristics of the human voice into measurable quantities that can act as an additional aid to identification. Iain Murray and John Arnott (1993) have investigated the vocal effects associated with several basic emotions, establishing links between voice characteristics and emotion that make possible the design of a voice-based emotion recogniser. This particular slant on the technology comes from the measurement of the pitch of a voice, the speed with which words are uttered, the frequency range of the voice and changes in its volume. Someone who is sad or bored will typically exhibit slower, lower-pitched speech, while a person who is afraid, angry, or joyous will speak louder and faster, with more words spoken at higher frequencies (Picard, 1997).

In summary, the creation of natural and efficient communication between human and robot requires that each display their emotions in ways that the other is able to recognize and assess. But the emotionally intelligent robot must not only be able to recognize emotions in humans and to assess the strength of those emotions, it should also demonstrate that it recognizes the emotions displayed by its human. As the development of emotion recognition and emotion simulation technologies advance, so will the development of emotional intelligence in robots, and their relationships with humans will come to mirror a healthy human-human relationship.

\subsection{Three Routes to Falling in Love with Robots}

It is interesting to consider how human beings will come to fall in love with robots. I now identify three distinct routes of progression that I believe will lead to enormous numbers of humans developing affection for and falling in love with robots. One route will develop in a human-like loving way, as robots become more and more human in appearance and personality, encouraging us to like and to love them. This is a natural extension of normal human loving and is the easiest of the three routes to 
comprehend. Just as with the TAMAGOTCHI, the human tendency to nurture will help to engender in us feelings of love for robots.

A second route is via a love for machines and technology per se, sometimes called "technophilia". People who "love" computers and machines do so in different ways. There are those who rush out and buy every new technological gizmo the moment it is put on sale - theirs is a love for all new technology. There are those for whom the technology converts into some other form of emotional or even erotic stimulation, such as pornography on the Internet or on a DVD. Then there are the technophiles, usually programmers but also those who love pressing buttons to make their gizmos do weird and wonderful things, theirs is a love of control, whether it is control by writing the programs that instruct their computers what to do or the much simpler form of control achieved by pressing the buttons on devices that have already been programmed. The act of programming has itself been compared to sex, in that programming is a form of control, of bending the computer or the gadget to the will of the programmer, forcing the computer to behave as one wishes.

The second route, a love of technology and its benefits, was at first very largely the province of the technically more adept, the economically upward mobile and, predominately, of adolescents and those in their $20 \mathrm{~s}$ and $30 \mathrm{~s}$. As the cost of electronics has come down, enabling consumer electronics manufacturers to create electronic toys and other products, in particular for children, so the age range of technophiles has widened considerably. Nowadays, with primary school children and even pre-schoolers finding themselves the owners of a plethora of electronic products, we are creating future generations of adults for most of whom the latest gizmos will seem perfectly normal rather than amazing. So it will be with robotics. Those who are born surrounded by electronics will grow up eager for and receptive to whatever new electronic inventions become available during their lifetimes. The love that yesterday's children and young adults demonstrated for their FURBIEs and TAMAGOTCHIs will be the basis for the adults of the future finding it perfectly normal, first to love their interactions with robots and then to love the robots themselves.

A third route in the evolution of love for robots will arise out of emotions that are similar to those that have made Internet relationships so hugely popular. Let us recall Deb Levine's (2000) words, quoted in Chapter 1.

"For some people, online attraction and relationships will become a valid substitute for more traditional relationships. Those who are housebound or rurally isolated and those who are ostracized from society for any number of different reasons may turn to online relationships as their sole source of companionship."

The same could equally be said of human-robot relationships, and some will find this worrying. Most people who develop emotional attachments to robots, and to whom robots exhibit their own demonstrations of love, will have in their mind the knowledge that the robot is just that, a robot, and not a human being. This "you are 
only a robot" syndrome will be some kind of boundary, across which a human must pass in order to feel love, to its fullest extent, for a robot; though in the case of certain groups within our society crossing that boundary will seem perfectly natural. Those who prefer to relate to computers rather than to humans will doubtless find it no problem at all. Similarly, many nerds, many social outcasts, and those who will be only too happy to find someone, almost anyone, who exhibits affection for them, will have no problem at all. But what about the more normal members of the population? What will it take for them to cross this boundary? One could argue that the first requirement will be incredibly good engineering, so that robots are as convincing in their appearance and actions as Stepford wives - almost indistinguishable from humans. But as we saw in Chapter 5, the TAMAGOTCHI experience and the reactions of the owners of AIBO pet dogs indicate that very strong emotional attachments can develop in humans even when the object of such affection is not human-like in appearance (cf. Winnicot, 1953).

Deb Levine's aside into the world of Internet romances and its implications has another important point to make in my line of argument on the subject of love with robots. One conclusion that can safely be drawn from the phenomenon of falling in love via the Internet, as with a pen friend, is that it is not a pre-requisite for falling in love, ever to be in the presence of the object of one's love. The falling-in-love process can be conducted completely in the physical absence of the loved one. This is consistent with and much a stronger form of the phenomenon noted by Robert Zajonc $^{16}$. Of course, there are photographs and video images of the loved one that can be received via the Internet. Moreover, the loved one's voice can be heard via the Internet or the telephone, but their physical presence is simply not necessary.

Now consider the following situation. At the other end of an Internet chat line, complete with a webcam to transmit its image, a microphone to carry the sound of its voice and a smell detection and transmitter system to convey its artificial bodily scent to you, there is a human-like robot endowed with all of the artificially intelligent characteristics that will be known to researchers by the middle of this century. You sit at home, looking at this robot, talking to it and savouring its fragrance. Its looks, its voice and its personality appeal to you, and you find its conversation simulating, entertaining and loving. Might you fall in love with this robot? Of course you might. Why should not you? We have already established that people can fall in love without being able to see or hear the object of their love, so clearly, being able to see it, finding its looks to your liking, being able to hear its sexy voice, and being physically attracted by its simulated body fragrance, can only strengthen the love that you might develop in the absence of sight, sound, and smell.

If you do fall in love with a robot, what will be the nature of this love and how will it differ from the way you feel about the love of your life in the world as it is today?

One important difference will be that robots are going to be replicable, even to the point of their personality, their memories, and their emotions. Those readers who are frequent computer users will know that it is good practice to "back up" your work

\footnotetext{
${ }^{16}$ See section 3.2 .
} 
on the computer just in case of a disaster that causes the loss of some or all of your data. Similarly, it will become common practice for the knowledge, personality, and emotion parameters, and all the other software aspects of a robot's "brain", to be backed up on a frequent basis. By mid-century this process will, almost certainly, be fully automatic, so that neither the robot nor its owner needs to do anything. At regular intervals the contents of the robot's brain, its consciousness, its emotions, will all be transmitted to a secure memory bank. If a robot is damaged or destroyed, and its owner wishes an exact copy, the physical characteristics can be replicated in the robot factory, and then the contents of the brain, pre-damage, can be downloaded into the new copy of the original robot. This capability creates one enormous difference between the love that one feels for another human being and the love that will be felt for robots. If you love someone enough you will willingly undertake any risk, or knowingly sacrifice your own life, in order to save theirs. This is only partly because of the strength of your love for them. It is also partly because they are irreplaceable. But in the case of love for a robot, it will be as though death simply does not exist as a concept that can be applied to the object of your love. If it can never truly die, because it can always be brought back to life in an exact replica of its original body, then there will never be any need for a human to sacrifice their own life for their robot, or to take a major risk on its behalf. Here we arrive at a new and difficult point in the discussion. Eternal life might be torment, at least for human beings (cf. De Beauvoir, 1955), and moreover for humans "death or any form of end creates meaning" (cf. Kermode, 2000), whereas for robots the same will not be true unless the torment is programmed into them; and therefore, for robots, we need to develop a new framework to enable us to understand the notions of death and eternity.

A second important difference between the nature of the love felt for a robot and that felt for another human being, is that robots will be programmable never to fall out of love with their human, and they will be able to ensure that their human never falls out of love with them. Just as with the central heating thermostat that continuously monitors the temperature of your home, making it warmer or cooler as required, so your robot's emotion detection system will continuously monitor the level of your affection for it, and as that level drops, your robot will experiment with changes in behaviour until its appeal to you has reverted to normal.

\subsection{Robot Personalities and their Influence on Relationships}

Personality is one of the most important factors that drive the process of falling in love, so before I examine the specific causes of falling in love with robots, I first discuss some of the most important research on robot personality that has been conducted during the past decade or so.

Robot personality is a subject that some readers might regard with scepticism - how can a robot have a personality? In the mid-1990s Clifford Nass and some of his colleagues in the Department of Communication at Stanford University showed it to be relatively straightforward to create human-like characteristics in computers - 
computer personalities - using a set of cues drawn from the extensive literature on the subject of human personality. In psychological terms, personality is the set of distinctive qualities that distinguish individuals. Nass and his group have conducted more than 35 experiments to investigate some of these qualities, how they can be simulated in computer programs, and how such simulations compare with the corresponding trait in humans.

One of the experiments carried out by Nass' group is related to the team element of a partnership relationship. Couples act as a team in myriad ways: she might wash the dishes while he dries, she might do the laundry while he does the gardening, he might be the principal breadwinner while she devotes more time to taking care of the children, or vice versa, ... It is not only the drudge tasks that are shared in a partnership relationship, it is also the more pleasant ones, and in both cases the sharing of responsibilities will often act as a bonding factor, helping to sustain the relationship. A study of computers as team-mates is therefore of considerable interest in estimating how a computer-human dyad might also function as a team.

Reeves and Nass (1996) based their study into computers as team-mates on social psychology experiments which show that there are two key factors in a team relationship - group identity and group interdependence. Group identity simply means that a team must have something to identify it by, often just a name such as "Mr and Mrs Bloggs", or "The Smith Family", or "Christine and David". The importance of group interdependence is that the behaviour of each member of a team can affect all of the other team members ${ }^{17}$.

The teams created for this study each consisted of a human and a computer, with the team being identified by a colour and the members of the team sporting a ribbon of that colour and a notice saying "blue team" or whatever on that team's computer. Half of the people in the experiment were told they were on the blue team. They were also told that their performance would be graded and that the final evaluation of their performance would depend not only on their own efforts but also on those of the blue team computer. The other half of the people in the experiment were treated as though they were not on the same team as the computer with which they were collaborating. These subjects also wore a blue ribbon, but their computer was dressed in green and carried a notice affirming that it was a "green computer". The experimenters also made no mention to the humans in the second group of any collaboration between them and the computer, in order to avoid creating an association of team-work in their minds. These subjects were told that their performance would be graded solely on the basis of their own work with the computer - that the computer was simply there to help.

The participants were set to work on a problem-solving task commonly employed in experimental psychology, a task known as the Desert Survival Problem ${ }^{18}$. When the

\footnotetext{
${ }^{17}$ In the case of a relationship dyad the word "all" relates, of course, to the one other partner in the relationship.

${ }^{18}$ This task requires the participants to imagine themselves as co-pilots of a airplane that has crash-landed in the desert and to decide on the order of importance of twelve objects that might help in their survival, such as a quart of water and a flashlight. Each participant in a pair (in this case one computer and one
} 
participants first attacked the problem they would try to solve it by themselves, creating their own ranking for the survival items. They then went into another room, one at a time, where they worked on the task in collaboration with their assigned computer. Everyone exchanged information with their computer about each of the twelve survival items and, if they wished, the participants could then change their initial rankings. Once the human participants had interacted with their computer, they would be sent into a third room where they wrote out their final rankings and responded to questions about their interaction with their computer, questions such as "How similar was the computer's approach to your own approach in evaluating the twelve items?" and "How helpful were the computer's suggestions?"

The results of this experiment revealed many things about how people perceive team relationships. When the humans believed that they were on the same team as the computer, they assessed the computer as being more like themselves, relative to how much like themselves the participants thought the computers to be when the participants worked alone. These "teamed" participants also thought that their "team-mate" computer had adopted a problem solving style more similar to their own, and that their computer agreed more completely with their own ranking of the items. Another tendency was for the "teamed" participants to believe that the information given to them by the computer was more relevant and helpful, and that it was presented in a friendlier manner, compared to the participants who did not believe they were members of a human-computer team, all this despite the information being identical and being presented in an identical manner in both cases. Other indications of relationship building between the human participants and their computers, were that the "teamed" participants tried harder to reach an agreement with their computer on the rankings and they were more receptive to their "team-mate's" suggestions and influences.

One of the most important conclusions of this study was to confirm the work of earlier psychologists who "have long been excited by how little it takes to make people feel part of a team, and by how much is gained when they do." Reeves and Nass (1996) had extended this earlier research by showing that feelings of being part of a team are powerful enough to affect people's interactions with computers, once they believe that their own success depends also on the success of the computer.

This research was ground-breaking work at that time, but even more remarkable than the ease with which their goal was accomplished was what the experimenters learned when they tested two simple computer personalities, each designed into a program that collaborated with a human user on the Desert Survival problem. One of these computer personalities was "dominant", using strong language in its assertions and commands, displaying a high level of confidence when communicating with the human test subjects, and leading off the dialogues with their human collaborators. The other computer personality was "submissive", using weaker language in which assertions were replaced by suggestions and commands by questions, and inviting or allowing the human collaborator to start each dialogue.

human) exchanges their initial rankings with their partner and discusses each object. These discussions enable experimental psychologists to measure the assertiveness of each participant. 
It was found that those humans who themselves had more dominant personalities ${ }^{19}$ enjoyed interacting with the dominant computer more than they did with the submissive one, while those with a more submissive personality preferred interacting with the submissive computer. Furthermore, not only did the human subjects prefer to interact with a computer similar in personality to their own, they also experienced a greater satisfaction in their own performance on the problemsolving task when collaborating with the similar computer. These results led to the conclusion that, not only do humans prefer to interact with other humans of similar personality, but humans also prefer to interact with computers that have similar (virtual) personalities to their own.

Other experiments conducted by Nass, Moon and Green (1996) confirmed that human-like behaviour by a computer enhances the user's experience of the interaction and makes the computer more likeable. One example of this phenomenon is the ability of computers to increase users' liking of them through the use of flattery, by matching the users in personality, and by the use of humour, which has been found to lead to assessments of them as being more likeable, competent and cooperative than computers that do not exhibit any humour (Morkes, Kernal and Nass, 2000). A second example came from highly expressive teaching programs that were found to increase students' feelings of trust in the programs because the students perceived them as helpful, believable and concerned (Lester et al., 1997).

\subsection{Designing Robot Personalities}

Sentiment apart, there seems to be no good justification why anyone should argue against the possibility of robots having, or at least exhibiting, emotions and personality. Some prefer to describe this as "robots simulating emotions" - clearly they belong to the school of Baudrillard (1988). However, in my opinion designing a robot to exhibit a personality similar to that of a particular human being would seem to be an obvious goal, one that would allow you to go into the robot shop and choose from a range of personalities, just as you will be able to choose from a range of heights, looks, and other physical characteristics. But with personality there is extra scope for robot designers, scope to achieve considerably more than just a range of models based on a one-user-one-personality approach. Instead, each robot could be designed to generate its personality from an entire range. As a robot learns more and more about a particular human, that robot can adjust its own personality to match, thereby leading to an increased liking, by that human, for the robot. This is just one of the ways in which the robot emotional technologies of the future will be superior to the human emotional makeup. Robots will be able to adapt their behaviour to suit the personality and even the mood of a human with whom they are interacting. This could lead to boring relationships for some people, knowing that their robot will always co-operate with their every mood and whim, but one of the features of a robot's personality could be capriciousness, which when set at the right

\footnotetext{
${ }^{19}$ The personality of each of the human subjects was tested for dominance and submissiveness, using a standard personality test commonly employed by psychologists.
} 
level will cause an owner to sustain sufficient interest in their robot's unpredictable moods, emotions, and behaviours.

One important consideration for robot programmers when planning a robot's personality and behaviour, will be how best to cope with different cultures. Just think of the courting rituals and the chaperone phenomena in some Latin countries, the Chinese tendency not to be too demonstrative physically in public and the contrasting lack of inhibitions exhibited in some other countries, and the tradition of arranged marriages in certain cultures - a tradition that ought to present no problem for robots because the parents of the human bride or groom will simply make all the choices in the robot shop as to its physical appearance and other characteristics, rather than leave these decisions to their offspring. Whatever the social norms of the prospective owner and their culture, a robot will be able to satisfy them. Placed in a philosophical context it is not clear whether we should welcome such possibilities. If all is possible, who should distinguish between what is good and what is better, or what is not so good. The analogy with religion is obvious, the details and intensity can be chosen and changed at will. Whether you are looking for an atheist, an occasional churchgoer or a devout member of any religion, you have only to specify your wishes when placing your order at the robot shop. But will we enjoy this freedom of choice? The key here will be ensuring that the robot has a flexible personality. It will most likely leave the factory with a set of personality traits, some standard and others chosen by the customer, but a robot will be able to set any or all of these traits aside as required, allowing the robot itself to adapt to the personality needs of its owner.

The example of the dominant and submissive problem-solving programs devised by Nass et al. (1995), suggests that creating artificial personalities will probably not be an immensely difficult task for robot scientists Similarly, the creation of blue eyes, a sexy voice, or whatever other physical characteristics turn you on, are all within the bounds of today's technology. If what turned you on when you purchased your robot ten years ago no longer turns you on today, the adaptability of your robot and the capability of changing any of its essential characteristics will ensure that it retains your interest and devotion. When robots are able to exhibit the whole gamut of human personality and physical characteristics, their emotional appeal to humans will have reached a critical level in terms of attracting us, inducing us to fall in love with them, seducing us in the widest sense of the word. We will recognize in these robots the same personality characteristics that we notice when we are in the process of falling in love with a human. If a particular person finds a sexy voice in their partner a real turn-on, they are likely to do so if a similar voice is programmed into a robot. If it is blue eyes that one is after, simply select a blue-eyed robot when you make your choice. If it is a particular personality trait, your robot will come with that trait ready made, or it will learn the trait as it discovers its importance to you. 


\subsection{Robot Chromosones}

A huge step forward on the path to creating robots with human-like personalities and emotions appears to have been taken recently by Jong-Hwan $\mathrm{Kim}^{20}$ and his team at the Robot Intelligence Technology Laboratory in Daejeon, South Korea, while working on the development of successive versions of a robot called HANSARAM. In a 2005 conference paper entitled: The Origin of Artificial Species, Kim and his colleagues (2005) describe artificial chromosomes they have developed for robots ${ }^{21}$.

Kim's approach to robot personality was inspired by the evolutionary biologist Richard Dawkins (1976), whose book The Selfish Gene asserts that "We and other animals are machines created by our genes". Kim draws a parallel between humans and humanoids by proposing that the essence of the origins of an artificial species such as humanoids must be the genetic code for that species. His paper presents the novel concept of the artificial chromosome, which Kim describes as the essence for defining the personality of a robot and the enabler for a robot to pass on its traits to its next generation, just like human genetic inheritance. Thus the artificial chromosome creates a simulation of evolution for its artificial species.

"If we think in terms of the essence of the creatures, we must consider this the origin of artificial species. That essence is a computer code, which determines a robot's propensity to 'feel' happy, sad, angry, sleepy, hungry or afraid." (Kim et al., 2005)

Continuing the parallel between humans and humanoids still further, Kim et al. suggest that the main functions of a robot's genetic code are reproduction and evolution, and that the code should be designed to represent all of the traits and personality of these artificial creatures. Thus his artificial chromosomes are a set of computerized representations of a DNA-like code, that will enable robots to think, feel, reason, express desire or intention, and could ultimately empower them to reproduce $^{22}$, to pass on their traits to their offspring, and to evolve as a distinct species. This programmed genetic code is modelled on human DNA, but is equivalent to a single strand of the human genetic code rather than the complex double helix of a real chromosome.

\footnotetext{
${ }^{20}$ Jong Hwan-Kim was the originator of the robot soccer competitions that have become enormously popular within the electronics and software communities as an intercollegiate and inter-corporate sport. See, for example, Chapter 8 of Robots Unlimited.

${ }^{21}$ For ease of testing and development, their initial experiments were conducted with simulated chromosomes programmed into a software simulation of a robot living in a virtual world, but their future research plans call for the chromosomes to be used to define the personality of real robots, including the humanoid HANSARAM.

${ }^{22}$ For a tiny bit more on robot reproduction see footnote 7 in Chapter 7, and for significantly more see Chapter 11 of Robots Unlimited (Levy, 2005).
} 
Kim's team has designed fourteen robot chromosomes in all, six of which are related to the robots' motivation, three to their homeostatis ${ }^{23}$ and four to their emotions. These chromosomes dictate how robots should respond to various stimuli: avoiding unpleasantness, achieving intimacy and control, satisfying curiosity and greed, preventing boredom, as well as engendering feelings of happiness, sadness, anger, and fear, and creating states of fatigue, hunger, drowsiness and so on, all of which will combine to imbue the robot with "life". Kim's robots will be able to react emotionally to their environment, to learn, and to make reasoned decisions based on their individual personalities.

Kim's simulated chromosomes have been programmed into a simulated creature - a software robot called RITY, that can perceive 47 different types of stimuli and is able to respond with 77 different behaviours. As determined by their genetic codes, no two RITY robots react in the same way to their surroundings. Some become bored with their human handlers while others, because they have a different personality, pant and express their "happiness" at the sight of their humans. It is all in their genes! One of the next steps by Kim and his team will be to create the equivalent of the human $\mathrm{X}$ and $\mathrm{Y}$ chromosomes, conferring on robots their own version of sexual characteristics, including lust. Thus, if male and female robots like each other "they could have their own children". This gives rise to a digression - to investigate the gender structure of the future. In section 7.3, I discuss the question: will the use of robots reinforce gendered stereotypes?

Kim readily admits one of the principal messages of the movie I Robot, namely that the feasibility of giving robots their own personalities and emotions might make them a danger to humanity. To counter this he suggests employing artificial chromosomes "to design brilliant but mild-tempered and submissive robots", which is one way to ensure that we do not become enslaved by our creations as they evolve. Given this elementary precaution, by the time "malebots" and "fembots" are available for general consumption the market will be ready for them.

\subsection{The Ten Factors Applied to Human-Robot Relationships}

In Chapter 3 I examined ten principal factors that cause humans to fall in love with humans. Let us now consider which of these factors might also be important in causing humans to fall in love with robots.

At the outset we should recall the importance of proximity and thus repeated exposure, as major factors (over and above the ten) that contribute to placing people in a situation in which falling in love becomes more likely. In the case of a robot, both proximity and repeated exposure are easy to achieve, subject to the robot's cost. Simply buy a robot and take it home, and both of these criteria are instantly satisfied. For a convincing view on this perspective the reader is again referred to Kaja Silverman's (1991) critique of the film Blade Runner.

\footnotetext{
${ }^{23}$ Homeostatis is a creature's ability or tendency to maintain internal equilibrium by adjusting its physiological processes.
} 
In Chapter 3 I also discussed "Byrne's Law", which demonstrates that we are more inclined to like someone when we feel good. The empathetic robot, able to determine what makes a particular human feel good, will therefore have a head start in its attempts to seduce. The robot will do its best to create "feel good" situations, perhaps by playing one of its human's favourite songs, or by switching on the TV when its human's favourite soccer team is playing a match, and then it will exhibit virtual feelings that mirror those of the human, such as feelings of enjoyment when hearing a particular song, or cheering on a soccer team.

A second lesson from Chapter 3, on the subject of getting someone to fall in love with you, was that the self-disclosure of intimate details can be a powerful influence in this direction. Robots designed to form friendships and stronger relationships with their users will therefore be programmed to disclose virtual personal and intimate facts about their virtual selves, and to elicit similar self-disclosure from humans. The ultimate, most intimate self-disclosure might be: "I have to tell you something - I'm a robot." I note in passing that the conventional gender $\operatorname{script}^{24}$ is based on differences, and not so much on similarities, suggesting the question: do we believe that humans will interact with robots as they interact deal with other humans? Whatever the case, in human-human attraction it is possible to disregard gender, and a subject for further research is the importance of gender in human-robot attraction.

Let us now turn to the ten reasons for falling in love. Which of them might have parallels in human-robot relationships, parallels strong enough to lead to humans developing feelings of love for robots?

\subsubsection{Similarity}

Of the most important similarities referred to in Chapter 3, only one of them coming from a similar family background - is not easy for a robot to imitate convincingly, given that its human will know that the robot was made on an assembly line. But as to the other key similarities, I forsee no problem in replicating them, including the most important of all, similarity of personality. It will be recalled from one of Clifford Nass' (1996) experiments described earlier ${ }^{25}$, that not only do humans prefer to interact with other humans of similar personality, but humans also prefer to interact with computers that have similar personalities to their own. That finding is of great significance when considering the importance of similarity of personality in the process of falling in love. Attitudes, religious beliefs, personality traits, and social habits - information on all of these can be the subject of a questionnaire to be filled in when a human orders their robot, or could be acquired

\footnotetext{
${ }^{24}$ A gender script is a mostly unconscious set of assumptions about men and women, and about masculinity and feminity, which works as a formative model for the perception of reality, for the interpretation of all kinds of things: for design, for education and for behavior. The Dutch scholar Nelly Oudshoorn has expounded extensively on this topic. Her examples come from the design of technology, where she shows, for example, that cars are created differently when they are targeted at male or female users. Men are expected to like to have things such as big cars, they are assumed to enjoy driving their cars, changing settings, cleaning motors, etc., whereas women are assumed to prefer more light-weight activities relating to cars, such as calling the garage when they need something done to their car. (Meijer, 2007).

${ }^{25}$ See section 6.7 .
} 
by the robot during the course of conversation. Once the robot's memory has acquired all necessary information about its human, the robot will be able to emulate a sufficient part of their stated personality characteristics to create a meaningful level of similarity. As the robot gets to know its human better, the human's characteristics will be observable by their robot who can then adjust its own characteristics, moulding them to conform to the "design" of its human.

One example of a similarity that will be particularly easy to replicate in robots is a similarity of education, since just about all of the world's knowledge will be available for incorporation into any particular robot's encyclopaedic memory. If a robot discovers, through conversation, that its human possesses knowledge on a particular subject at a particular level, its own knowledge of that subject can be adjusted accordingly - it can download more knowledge, if necessary, or it can deliberately "forget" certain areas or levels of knowledge in order that its human will not feel intimidated by talking to a veritable brain-box. This self-modifying capability will also allow robots to develop an instant interest in whatever are its human's own interests. If the human is an avid train spotter then the robot can instantly become a mine of information about trains; if its human loves Beethoven the robot can instantly learn to hum some of the composer's melodies; and if the human is a mathematician, the robot will have the reasoning powers necessary to prove the popular mathematical theorems of the day. Robots will not only have an extensive knowledge, they will also have the power of reasoning with that knowledge.

\subsubsection{Desirable Characteristics of the Other}

The key "desirable" characteristics revealed by the research literature are personality and appearance. Just as a robot's personality can be set to bear a measure of similarity to that of its human, so it can be adjusted to conform to whatever personality types its human finds appealing. Again, this could partly be determined prior to purchase by asking appropriate questions in the customer questionnaire, and then, after purchase, the robot's learning skills will soon pick up vibes from its human, vibes that indicate which of its own personality traits are appreciated and which need to be reformed. When its human, in a fit of pique, shouts at the robot "I wish you weren't always so goddam calm", the robot could reprogram itself to be slightly less emotionally stable.

A desirable appearance is even easier to achieve in a robot. The purchase form will ask questions about dimensions and basic physical features, such as height, weight, colour of eyes and hair, whether circumcised (if appropriate), size of feet, length of legs, ... Then the customer will be led effortlessly through an electronic photo album of faces, with intelligent software being employed to home-in quickly on what type of face the purchaser is looking for. The refinement of this process can continue for as long as the purchaser wishes, until the malebot or fembot of his or her desire is shown on the order screen. If it is a pert nose that turns you on, your robot can come with a pert nose. If it is green eyes, they are yours for the asking. 


\subsubsection{Reciprocal Liking}

Reciprocity of love is an important factor in engendering love - it is more likely for Peter to fall in love with Mary if Peter already knows that Mary loves him. So the robot who simulates demonstrations of love for its human will further encourage the human to develop feelings of love for the robot.

Reciprocal liking is another attribute that will be easy to replicate in robots. The robot will exhibit enthusiasm for being in its owner's presence, and for its owner's appearance and personality. After an appropriate getting-to-know-you period it will whisper, "I love you my darling". It will caress its human and act in other ways consistent with human loving. These behaviour patterns will convince its human that the robot loves them.

\subsubsection{Social Influences}

With time, social influences undergo huge changes. What was considered a social aberration fifty years ago or less might now be very much the norm. Attitudes to robots will also change with time - now they are our toys and items of some curiosity; before long the curiosity will start to diminish and robots will make the transition from being our playthings to being our companions, and then our friends, and then our loved ones. The more accepted robots become as our partners, the less prejudice there will be from society against the notion of human-robot relationships, leading more people to find it acceptable to take robots as their friends, lovers, and partners.

\subsubsection{Filling Needs}

If a robot appreciates the needs of its human, it will be able to adapt its behaviour accordingly, satisfying those needs. This includes those relationships in which the human's needs relate to intimacy, even to sex as explained in Part Three of this thesis. One can reasonably argue that a robot will be better equipped than a human partner to satisfy the needs of its human, simply because a robot will be better at recognizing those needs, more knowledgeable about how to deal with them, and lacking any selfishness or inhibitions that might, in another human being, militate against a caring, loving approach to whatever gives rise to those needs.

\subsubsection{Arousal/Unusualness}

This factor depends for its existence on the situation in which a human and their potential love object initially find themselves together, and not on the love object itself. The arousal stimulus is external to the couple. As a result there would appear to be no difference between the effect of a particular arousal stimulus on someone in the presence of another human and the effect of that same arousal stimulus on that same someone in the presence of a robot. In both cases the stimulated human will find the situation arousing, possibly even to the extent that the situation might make the human feel more attracted to the robot than they would be to another human. After all, in a situation that appears dangerous, would not a robot be more likely than a human to be able to eliminate or mitigate the danger? 


\subsubsection{Specific Cues}

Specific cues are in my opinion not a problem. After a trial-and-error session at the robot shop you will be able to identify exactly what type of voice you would like in your robot, which bodily fragrances turn you on, and all the other physical characteristics that could act as cues to engender in you love for your robot at first sight.

\subsubsection{Readiness for Entering a Relationship}

As in the case of arousal, readiness for entering a relationship leads to a situation that gives rise to affectionate feelings. If you have just been dumped by your partner and are looking for a flirtation or a fling to recover and rediscover your self-esteem, your robot can help you in all these eventualities, with no need for speed-dating sessions or for placing an announcement in the lonely hearts columns.

\subsubsection{Isolation from Others}

This is yet another factor where the circumstance dictates what happens, and it is a factor associated in some respects with proximity and repeated exposure. If you have a robot at home you will be likely to spend considerable time in isolation with it - as much time as you wish.

\subsubsection{Mystery}

Robots are already something of a mystery to most people. Imagine how much more of a mystery they will become as their mental facilities and emotional capacities are expanded as a result of Artificial Intelligence research. This is not to say that robots should, as a result of the expansion of their capabilities, be "perfect". By having different levels of performance that can be set or can self-adapt to suit those with whom a robot interacts, the behaviour and performance of the robot can be endowed with human-like imperfections, giving the user a sense of superiority when that is needed to benefit the relationship. The element of mystery, like variety, will be the spice of life in human-robot relationships.

\subsection{What Does this Comparison Prove?}

I submit that each and every one of the main factors that psychologists have found to be the major causes for humans falling in love with humans, can almost equally apply to humans falling in love with robots. The logical conclusion, therefore, is that, unless one has a prejudice against robots, the concept of humans falling in love with robots is a perfectly reasonable one to entertain. What we cannot really imagine at the present time is, what loving a robot will mean to us or how it might feel. Some humans might feel that a certain fragility is missing in their robot relationship, relative to a human-human relationship, but that fragility, that transient aspect of human-human relationships, as with so much else in robotics, will be capable of simulation. I do not expect this to be one of the easier tasks faced by AI researchers during the next few decades, but I am convinced that they will solve it. 


\subsection{Robot Fidelity, Passion, and the Intensity of Robot Love}

For the benefit of most cultures robots should be faithful to their owner/partner what we might call robot fidelity ${ }^{26}$. Robots will be able to fall in love with other robots and with other humans apart from their owner, possibly giving rise to jealousy unless the owner is actually turned on by having an unfaithful partner. Problems of this type can, of course, be obviated, simply by programming your robot with a "completely faithful" persona, or an "often unfaithful" one, according to your wishes. How different life would be for many couples if the possibility of infidelity simply did not exist. But in contrast, while the infidelity of one's robot might be something to be avoided by careful programming, the possibility equally exists for humans to have multiple robot partners, with different physical characteristics and even different personalities. The robots will simply have their "jealousy" parameters set to zero.

Being able to set one's robot to any required level of fidelity will be but one feature of robot design. It will also be appealing to be able to set the love intensity level and the passion level of your robot to suit your desires. Your robot will arrive from the factory with these parameters set as you specified, but it will always be possible to ask for more ardour, more passion, or less, according to your mood and energy level. At some point it will not even be necessary to ask, because your robot will, through its relationship with you, have learned to read your moods and desires and to act accordingly.

\subsection{Marrying a Robot}

For many of the readers of this thesis, any discussion on the history or current status of the institution of marriage will take place within the somewhat conservative confines of traditional Judeo-Christian thinking and attitudes, and those of some of the other major world religions. Within these confines marriage can only be the union of one man with one woman, a union intended to last for life, a union that usually has as one of its principal goals the creation of children. Yet, this view of marriage is not the only view, because there are and for a long time there have been cultures within which marriage is viewed quite differently. One of the most obvious examples of such differences is that between monogamy, for a long time one of the fundamental tenets of marriage in Western society, and polygamy, which is and has been the norm in many other cultures, including tribes in Africa, North and South America, and Asia, and a bedrock of religions such as Mormonism and Islam ${ }^{27}$.

\footnotetext{
${ }^{26}$ The robot's parameters, set in the factory and changeable by the owner, will doubtless include a "polygamy" option, to cater for those religions and cultures in which monogamous relationships are not the norm.

${ }^{27}$ The Ethnographic Atlas has data on 1,231 societies studied during the period 1960-1980, of which only 186 were monogamous societies, while 453 had occasional polygyny (a man having more than one female sexual partner simultaneously), 588 had more frequent polygyny, and 4 had polyandry (a woman having more than one male sexual partner simultaneously). Since the non-monogamous societies are, in general, much smaller than the monogamous ones in terms of population, these statistics do not indicate that monogamy is the status of the minority of the world's population. Far from it.
} 
Surely, if we are to enter a balanced debate on the history, the current state, or the future of marriage, our discussions should take into account all cultures, their customs, and how they regard marriage. Why should someone assume that, inevitably, their own attitudes are the only correct ones, and that cultures other than their own are in some way wrong?

America is perhaps the best example in the world of a mixture of races, religions, and cultures that is, precisely because of its mix, fast becoming a society in which the tolerance and acceptance of non-traditional customs and ideas creates the very basis of society as it evolves. In such a society, if it is to evolve and thrive harmoniously, the toleration and acceptance of other people's values and ideas is an essential moral prerequisite. Sometimes we must accept that it is our own views that might be inappropriate, possibly because they are outmoded, and that the more radical, more modern views of others are more suitable for the times in which we live and for the future. This phenomenon of changes in opinion leading to massive social change, has been seen in recent decades with attitudes to homosexual relationships ${ }^{28}$.

The trend towards the toleration and acceptance of same-sex marriages is but one aspect of the changing face and meaning of marriage. The November-December 2004 issue of Harvard Magazine published a highly charged essay, "The Future of Marriage", by Harbour Fraser Hodder (2004), which, although primarily intending to examine how changes in demographics, economics, and laws have altered the meaning of marriage in America, makes a number of points that can also be used to support the prediction that marriage to robots will, by mid-century, raise no more eyebrows than same-sex marriages and civil unions do today. One such point is based on the observation by Nancy Cott, a Harvard professor of American history, as reported by Hodder (2004), that "marriage itself has therefore come in for a broad reassessment".

The reassessment to which Cott refers is, according to Hodder (2004), the outcome of two polarising views, viz. those of the advocates of same-sex marriage and those of their "family values"-oriented opponents. Cott explains that "as same-sex couples line up for marriage licences at courthouses across Massachussets, opponents predict the death of marriage itself. One side sees tragedy in the making, the other wants to rewrite the script entirely."

It is my belief that marriage to robots will be one of the by-products of the rewriting of the script, a belief rooted in the type of argument employed by those judges who have ruled in support of same-sex marriage. In 1998, for example, in a superior court ruling in Alaska, Judge Peter Michalski called the right to choose one's life partner constitutionally "fundamental" (Cott, 2000), a privacy right that ought to receive protection whatever its outcome, even a partner of the same sex. "Government intrusion into the choice of a life partner encroaches on the intimate personal decisions of the individual ... The relevant question is not whether same-

\footnotetext{
${ }^{28}$ See Chapter 11.
} 
sex marriage is so rooted in our traditions that it is a fundamental right, but whether the freedom to choose one's own life partner is so rooted in our traditions." Michalski's ruling (Cott, 2000) and many since then have pointed the way, not only to a liberalising of the legislature's attitude to same-sex marriage, but also to a strengthening of the attitude towards the right to choose.

The controversy over same-sex marriage is not the only reason why attitudes to marriage in America have undergone dramatic change. Cott (2000) points to the way that women's legal identities and their property used to be subsumed into those of their husbands, and we should not forget that in the past wives were sometimes themselves regarded as the property of their husbands. These issues of unequal ownership have been erased with time, but ownership seems likely to reappear, though in a completely equal guise, as humans of either sex acquire and thereby own robots that act as their lovers and their spouses.

Cott also points to another important and relevant change in the history of marriage in the USA, "the dissolution of marital prohibitions based on race". Even though such unions were previously far from unknown, it was not until 1967 that interracial marriages were ruled to be legal in the USA, when the U.S. Supreme Court overruled the sixteen states that still, at that time, considered marriage across the colour line to be void or criminal. The statistics for interracial marriage have since given proof to the overwhelming need for that change: the number of marriages in the USA between African Americans and Caucasians rose from 51,000 in 1960 to more than 440,000 in 2001 (Cartwright, 2002).

Same-sex marriage, ownership of a wife and her property, and interracial marriage, are some of the most significant changes that are apparent from a study of the history of marriage in the U.S.A. (Cott, 2000). Other major changes include an acceptance of the fact that marriage is not necessarily for life, as evidenced by the 50 per cent plus divorce rate in the U.S.A.; and the increasing proportion of couples who opt not to have children. All these and other changes of attitude to marriage lead us to the conclusion, succinctly enunciated by Nancy Cott, that "Change is characteristic of marriage. It's not a static institution (...) People can cohabit without great social disapproval; they can live in multigenerational families; there are scenes of group living; there are gay unions or civil unions. There is a greater variety of household forms that are approved and accepted, or at least tolerated, (...)."

Social change is happening faster now than it did 200, 100 or even 50 years ago, with the result that change in the meaning and purpose of marriage is also happening faster than ever before, and the rate of such change seems certain to accelerate. Chapter 11 provides a relevant example - it is an analysis of how our sexual mores and attitudes have changed over time. In the case of marriage, it seems eminently reasonable to assume that changes in the approval, acceptability, and tolerance of different ideas and new forms of marital relationship, will take place over periods no longer than the few decades that were needed to make interracial marriage and same-sex marriage socially acceptable to many and legally acceptable to the state. Cott (2000) points out that, in the late twentieth century, marriage moved "towards 
the spouses themselves defining what the appropriate marital role or preference is." This new-found freedom for couples to define their respective roles within their marriages, now extends into the realm of legal agreement. Elisabeth Bartholet (Hodder, 2004), holder of the Wasserstein Public Interest Chair in Law at Harvard, observes that the legal context of marriage has shifted from the state having "enormous control over marriage" to people writing "the terms of their own marriage" and being "allowed to have pre-marital contracts". Furthermore, Bartholet comments that the trend of recognizing de facto relationships means that "if you look like a family, feel and smell like a family - you cook meals together, share bank accounts - then you are a family for the purpose of the law."

In summary, marriage is changing at such a rate that there appear to be ever increasing levels of acceptance and tolerance of how any given couple wish to conduct their lives together. As part of the right to choose, will come the inalienable right to choose one's spouse, even a robot spouse. By the time that today's infants are entering matrimony, many of them will be deciding for themselves almost all the rules and laws that are to govern their union ${ }^{29}$. By the time that their children are ready for marriage, around the middle of this century, I believe that such a freedom of decision will be almost universally exercised.

How, then, will today's children and their children make use of their own generations' new found freedom of marital choice? In attempting to answer this question, we first consider the main criteria employed in the choice of a marriage partner. Elaine Hatfield and Susan Sprecher (1995) have examined preferences in marital partners in three different cultures: the U.S.A., Russia, and Japan, in preparation for which they selected 12 criteria after studying several other lists of reasons for mate selection from the psychology literature. A total of 1,519 college students took part in their survey (634 men and 885 women) in which they were asked to rate each of the 12 criteria on a scale from 1 (unimportant) to 5 (essential).

\begin{tabular}{|l|c|}
\hline Trait & Mean Rating (out of 5) \\
\hline Kind and understanding & 4.38 \\
\hline Has sense of humour & 3.91 \\
\hline Expressive and open & 3.81 \\
\hline Intelligent & 3.73 \\
\hline Good conversationalist & 3.72 \\
\hline Outgoing and sociable & 3.47 \\
\hline Ambitious & 3.36 \\
\hline Physically attractive & 3.27 \\
\hline Skill as a lover & 3.17 \\
\hline Shows potential for success & 2.95 \\
\hline Money, status, and position & 2.50 \\
\hline Athletic & 2.50 \\
\hline
\end{tabular}

Table 6.1: Ratings of the Mate Selection Traits.

\footnotetext{
${ }^{29}$ One exception that I do not believe will be eroded, and for very good reasons, is the issue of consent. In my view it should always be an essential pre-requisite that the partners in a marriage should agree to it, and should be considered legally competent to make such an agreement.
} 
The results given in Table 6.1 indicate that of the 12 criteria only the $7^{\text {th }}$ ranked, "being ambitious", and the three lowest-ranked characteristics could reasonably be argued to be inappropriate descriptors for the robots of the next few decades. All six of the top-ranked characteristics will be demonstrable by robots within that time frame, and as for being physically attractive and skilled as a lover, these characteristics will, in my opinion, be amongst the first to be demonstrated with some measure of success.

With the freedom for couples to define the parameters of their own marriages, will also come the freedom for the individual to define what he or she intends their own marriage to mean. Seeking a suitable human spouse might then become not only an exercise in matching interests, personalities, and the various other factors that we know to influence the falling-in-love process, but also a search for someone who has used their freedom of choice as to the meaning, rules, and purpose of marriage, to create a model that matches one's own. This relaxation of the constraints that used to provide a stable basis for the rules and expectations of marriage, might therefore make it more difficult to find a spouse, since different potential spouses will be looking to play according to different sets of rules. For this reason, one of the factors that I believe will contribute to the popularity of the idea of marrying a robot is the avoidance of the difficulty of finding a human partner with matching views on marriage - your robot will be programmed with views that match and complement your own.

Even more relevant to the practice of marriage to robots, will be the question: to what extent will the new freedoms of choice regarding marriage extend to a choice of who (or what) people will legally be allowed to marry? The United States has already seen some major changes in this respect, as interracial marriage and samesex marriage have both shifted from illegal to legal. In 2005, Holland hosted a ceremony of a civil union involving three partners - a man and his two "wives" when Victor de Bruijn, aged 46, from Roosendaal, "married" both Bianca (31) and Mirjam (35) in a ceremony performed before a notary who duly registered their civil union (Beilin, 2005).

What novel form of civil union will be next? In future decades the sciences of prosthetic limbs and artificial hearts and other organs will continue to develop with accelerating pace, perhaps even adding artificial brains to the ever-growing list of body parts that surgeons can replace. The Norwegian philosopher Morten Søby (1998) discusses this trend in terms of the manner and extent to which it more and more reduces the distinction between man and machine, and "(...) becomes an element in the great story of evolution and development of civilisation". Writing about what prosthesis offers for the future, Søby (1998) explains the following.

"More and more artificial parts are added to the body - the result being a more artificial body. Research is being carried out with neural interfaces to develop auditory and visual prostheses, functional neuromuscular stimulants and prosthesis control through implanted neural systems etc. Biosociological research into complex self-generating and self-referral systems is another example. Information technology and virtualisation not 
only occupy Man, nature and culture but are also about to outdate the genre of science fiction."

To emphasize the point Søby quotes other prominent philosophers: Paul Virilio (1995) in The Art of the Motor (1995), who argues that "The basic distinction between Man and machine no longer applies. Both biological research and computer technology question the absolute difference between living machine and dead matter." Donna Haraway asserts (1985), in her essay A Manifesto for Cyborgs, that "Late-twentieth century machines have made thoroughly ambiguous the difference between natural and artificial, mind and body, self-developing and externallydesigned, and many other distinctions that used to apply to organisms and machines."

Thus, with artificial limbs, organs, and just about everything else bodily, blurring the boundaries between real life and virtual life, it is appropriate to ask what impediments need to be lifted in order to make marriage between human and robot legally and socially acceptable. Right now there is no legal impediment to someone with an artificial leg from marrying; nor against someone with two artificial legs, or all four artificial limbs, or an artificial heart, ... . Where and why should society draw the line? Can we reasonably argue that it should be legally acceptable to marry someone, 20 per cent of whose body is made up of artificial limbs and organs, but that if the proportion were to rise to 21 per cent then such a union should be illegal? What logic dictates that a partner who is half natural and half artificial should be an acceptable marriage candidate but that a three-quarters, or 90 per cent, or 100 per cent artificial partner should not? Here lies a difficulty for the lawmakers of the future, those who are given the responsibility of drafting changes designed to bring the law up to date. As robots become increasingly sophisticated, as people have them in their homes as companions, when people have sex with them and fall in love with them, so it will become appropriate for those lawmakers to paraphrase Elisabeth Bartholet's (Hodder, 2004) argument thus: "If your robot looks like a partner, feels, smells like a partner - you cook meals together, share bank accounts then you are partners for the purposes of the law." As to the question of a robot being legally able to consent to its marriage, if it says that it consents, and behaves in every way consistent with being a consenting adult, then it does consent.

Finally, there are those who would ask: "Why marry?", when discussing humanrobot relationships, meaning "Why would anyone want to marry any robot?", as opposed to why marry a particular robot. Two of the most commonly given reasons as to why people marry are love and companionship. In this section, I hope to have convinced the reader that (1) loving a robot will come to be viewed as a perfectly normal emotional experience, and that (2) robots will be regarded by many as interesting, entertaining, and stimulating companions. If these two reasons for getting married, viz. love and companionship, are the foundation for so many millions of marriages between human couples, why should the same reasons not provide a valid basis for the decision to marry a robot? 


\subsection{Chapter Conclusions}

In this chapter I have investigated the attraction of a humanoid robot for a human being. From the analysis of the existing material and my investigations of what can reasonably be expected to be developed in the coming decades, I conclude that the relationship between a humanoid robot and a human being will mainly be governed by the humanoid robot being attractive for the human being.

However, the deeper question is PS1: to what extent will the emotions that humans feel for other humans, for pet animals, for virtual pets, and even for less animal-like artefacts - namely computers, be extended to embrace the robots of the future? In this and the three preceding chapters I have analysed the development of the emotions and feelings of attraction that lead to attachment and love. Based on those investigations I conclude that (1) currently, the incorporation of emotions in humanoid robots is in its infancy; (2) scientific developments, combined with requests from the commercial market, will undoubtedly lead to the production of humanoid robots that have emotions incorporated and that are attractive for human beings as companions.

Moreover, from a thorough analysis of the factors which are usually involved when we speak of love between two human beings, I may conclude that the same factors will play a part in the companion relationship between a robot and a human being. I therefore suggest that we should describe such intimate relationships as the love of human beings for humanoid robots. 



\section{PART THREE}

In Part Three we consider the second part of the problem statement, viz.

To what extent will the normal bounds of human sexuality be extended with respect to the robots of the future?

In chapters 7 to 10 , I investigate the following four research questions in this order:

RQ5: Why do people enjoy sex?

RQ6: Why do people pay for sex?

RQ7: What technologies are available to be used as sex technologies?

RQ8: What mental obstacles exist to prevent the final step towards the second objective? 


\section{Chapter 7}

\section{HUMAN BEINGS, SEX, AND ROBOTS}

The world of sex is at the threshold of trends amounting to a twenty-first century revolution, bringing about the most dramatic changes in sexual relationships, habits, health, pleasures, pains, and living standards the world has ever seen.

Joel Snell (1997)

To answer the second part of the problem statement (see section 1.4) I have distinguished four specific research questions. This chapter deals with RQ5: why do people enjoy sex? In the framework of this thesis it will be clear that I neither focus on the psychological/sociological aspects of sex, nor on medical/physiological factors, but instead I concentrate on the connections that exist between human beings, sex, and robots. Therefore I do not aim at a full psychological answer in the long traditions that started with Freud's (1905) work, or even earlier.

Sex with humanlike artefacts is by no means a $21^{\text {st }}$ century concept - in fact its foundations lie in the myths of ancient Greece. A Cypriot sculptor, King Pygmalion $1^{\text {st }}$, made an ivory statue in the form of a woman, a statue so beautiful that he fell in love with it, gave the statue a name, Galatea, and desired it. So he prayed to Aphrodite, the goddess of love, and one day, while Pygmalion was kissing the statue, Aphrodite brought it to life. Pygmalion's kisses were suddenly being reciprocated, and finally he married Galatea. The myth of Pygmalion thus led to the nametag pygmalionism being attached to the fetish of sexual attraction to statues ${ }^{1}$.

In his authoritative tome, The Sexual Life of Our Time, Iwan Bloch (1909) explains one of the oldest of religio-sexual phenomena, the act of "religious prostitution", as a form of pygmalionism. This is an act of sacrifice, made to a deity, most often taking the form of a sacrifice by a woman of her virginity shortly before giving herself to her husband for the first time. The defloration process would sometimes be accomplished with a penis made of ivory, stone, wood or even iron, and sometimes by a form of pygmalionism - intercourse with a statue of the god. As an example of this practice Bloch describes how a bride, at a religious shrine near Goa, would be assisted by her friends and relatives in mounting the stone penis of an image of a god, thereby destroying her hymen.

In this religio-sexual act the statue is a representation of a deity, but in the far more common form of pygmalionism the statue substitutes not for a deity but for a living human being. In the brothels of late nineteenth century Paris it was not uncommon for prostitutes to act out a variation on this theme, standing on suitable pedestals as

\footnotetext{
${ }^{1}$ This fetish also goes under the name agalmatophilia.
} 
though they were statues and being watched by their clients as they gradually appeared to come to life. Such a scene induced sexual enjoyment in the Parisian pygmalionists, often elderly patrons who no longer had the energy for sex.

The idea of sex with robots affects different people in different ways. Some regard the concept as totally outlandish, arguing that only sex with another human being can be a meaningful and enjoyable experience. Some rely on religious objections based upon the idea of sex as being solely for procreation. Others are curious as to exactly how a robot would function sexually and how it would feel for the human. Some embrace the idea wholeheartedly and want to know "Where can I buy one?"

In this chapter I start dispelling any suggestions of outlandishness, and presenting what I believe are compelling arguments to show that sex with robots will become a norm rather than being an oddity. I start by examining sexual relationships between humans. This I do from a graded perspective, though the gradation is not one with a range that lies between lousy sex and great sex - rather it transcends a spectrum of categories of sexual partner. At one end of this spectrum is the passionate love of our life. At the other end lies someone who we do not even know, have never met before the first sexual encounter (which might be the only encounter with this particular sex object), and who has little or no reason to offer any genuine affection before or during sex. I hope that by explaining why people have sex with people across this entire spectrum, even with those at the "bottom" end of the range, I will be able to convince those members of the "totally outlandish" persuasion that, for many people, sex can be an enjoyable experience even when the sex object is off the bottom end of the range altogether, when instead of a human sex partner there is a sexual robot.

The course of the chapter is as follows. Section 7.1 continues on from the opening of the chapter (pygmalionism), under the title "From Unreality to Reality", which shows that the ideas developed in this thesis have a solid historical basis. In section 7.2 I provide background to the intriguing question: why do people make love (with people)? Here I focus on elements that are essential to our framework, but the framework is not yet fully specified. With an eye on the virtual world one may wonder whether a new gender structure may emerge and, if so, to what extent it might influence that our framework. In section 7.3 I discuss sex in a new gender environment. In section 7.4 I embark upon the topic: sex as a result of transference. In section 7.5 I give my chapter conclusions and my answer to RQ5.

\subsection{From Unreality to Reality}

The French talent for inventing mechanical automata such as Vaucanson's duck and Maillard's swan (cf. section 2.1), when combined with the legendary French expertise in matters sexual, led in late nineteenth century France to the invention of artificial devices, and even whole artificial bodies, designed to provide substitutes for human genitalia. Bloch (1909) describes how these were employed, to act as surrogate sex partners. 
“... we may refer to fornicatory acts effected with artificial imitations of the human body, or of individual parts of that body. There exist true Vaucansons in this province of pornographic technology, clever mechanics who, from rubber and other plastic materials, prepare entire male or female bodies, which, as hommes or dames de voyage, subserve fornicatory purposes. More especially are the genital organs represented in a manner true to nature. Even the secretion of Bartholin's glands ${ }^{2}$ is imitated, by means of a "pneumatic tube" filled with oil. Similarly, by means of fluid and suitable apparatus, the ejaculation of the semen is imitated. Such artificial human beings are actually offered for sale in the catalogue of certain manufacturers of "Parisian rubber articles." A more precise account of these "fornicatory dolls" is given by Schwaeblé" [1905, pp. 247-253].

From René Schwaeblé's (1905) description of one of these fornicatory dolls it would appear that they were extremely convincing replicas of the female form ${ }^{3}$.

"In the Middle Ages the dream of the most daring alchemists was to create a homunculus, in other words to fabricate a living being of flesh and blood, a little man, in a place other than a mother's womb.

"Well, I know one "mad woman" who has been occupying herself with occult sciences for many a long year. Adoring children but hating men, and wanting to have a youngster all to herself, she had herself injected - using a specially shaped syringe that is greatly prized in certain houses of ill repute - with a liquid that is greatly prized in all houses."

With real products available for purchase in fin de siècle France, such as the one described here by Schwaeblé, it is hardly surprising that French fiction of that time made use of fornicatory dolls. Bloch (1909) wrote that

"The most astonishing thing in this department is an erotic romance $L a$ Femme Endormie, by Madame B.; Paris, 1899, the love heroine of which is such an artificial doll, which, as the author in the introduction tells us, can be employed for all possible sexual artificialities, without, like a living woman, resisting them in any way. The book is an incredibly intricate and detailed exposition of this idea."

So "shocking" was the content of La Femme Endormie, that not only did the author feel the need for anonymity, but the book boldly displayed the misinformation that it was printed in Melbourne, in an attempt to throw off the scent any straight-laced French authorities who might be seeking to take legal action against the printer or to prevent further copies from being distributed.

But it is a far cry from titillating nineteenth century French fiction to mid- $21^{\text {st }}$ century sexual robots. In order to convince any sceptics amongst you that this

\footnotetext{
2 The glands located on either side of the vaginal orifice that secrete a lubricating mucus.

3 This translation of pages 247-253 of Schwaeblé's book is by John Sugden.
} 
transition will indeed materialise, I shall start by attempting to debunk what I believe will be the most common objection to the concept of sex with robots - the question "Why would we want to?" In order to assist in answering this question I first examine some fundamental aspects of human sexuality - what are our motives for having sex and why do we enjoy it?

\subsection{Why Do People Make Love (with People)?}

Half a century after Freud's (1938) proclamation that pleasure is the goal of sex, psychologists began to analyse methodically the most common reasons for making love. In some of the earliest of those studies it was found that traditional stereotypes reflected the actuality of the different reasons why men and women engage in sex. A study by John DeLamater in 1989 found that twice as many women as men claimed to have been in love with their first sexual partner, while another study found that 95 per cent of college women but only 40 per cent of college men responded that for them emotional involvement was "always" or "most of the time" a prerequisite for having sex. When researchers asked the specific question: "What would be your motives for having sexual intercourse?", women typically gave reasons relating to love, while the answers from men focussed much more on the physical pleasure (Carroll, Vole, and Hyde, 1985). And when the question was even more focussed, enquiring about the subject's most recent sexual encounter, 51 per cent of women and 24 per cent of men gave reasons connected with love and emotion, while 9 per cent of women and 51 per cent of men gave answers relating to lust and physical pleasure (Whitley, 1988). These results have generally been confirmed by subsequent experimental psychology research.

The general drift of this research might seem to suggest that men will be more likely than women to be interested in participating in sex with robots, based on the assumption that men are more likely than women to be willing or indeed eager to satisfy their sexual desires, even without any emotional attachment to their chosen sex object. On the contrary, I believe that eventually women will exhibit every bit as much enthusiasm as men for sexual coupling with robots, but the women's reasons will often be different - men will want the pure physical pleasure of intercourse and orgasm with robots, while most women will want not only a personal demonstration of the robot's virtuoso lovemaking skills but also to feel the robot's virtual love for them.

Barbara Leigh (1989) used a survey amongst 580 people taken from 4,000 randomly chosen households in the San Francisco area as the basis for an analysis of seven reasons for having sex (see Table 7.1). Heterosexual participants were asked to rank each of the seven reasons on a scale of 0 to 4 , from "not at all important" (scoring 0 ), to "extremely important" (scoring 4). The highest score from the two groups was 3.7 out of a maximum of 4 for the "pure pleasure" motivation for men, supporting Freud's belief in pleasure being the goal of sex. 


\begin{tabular}{|l|c|c|}
\hline Reason & \multicolumn{2}{|c|}{ Frequency } \\
\hline & Men & Women \\
\hline For pure pleasure & 3.7 & 3.1 \\
\hline To express emotional closeness & 3.5 & 3.6 \\
\hline To please your partner & 3.2 & 2.7 \\
\hline Because your partner wants to & 2.8 & 2.5 \\
\hline To relieve sexual tension & 2.5 & 2.0 \\
\hline To reproduce & 1.2 & 1.2 \\
\hline For conquest & 0.6 & 0.3 \\
\hline
\end{tabular}

Table 7.1: Seven reasons for having sex (Leigh, 1989).

A more recent study by Valerie Hoffman and Ralph Bolton (1997) expanded the above list from seven reasons to sixteen. In addition to the factors listed by Leigh in Table 7.1, they employed factors from two other studies, including one from 1984 of college students in which the participants revealed their reasons for deciding to have sex for the first time with a recent partner (Christopher and Cate, 1984). The sixteen reasons in the Hoffman/Bolton study were put to 146 heterosexual men, generally well educated, who were asked to indicate how frequently each reason applied to their sexual encounters (the scale in Table 7.2 ranges from 0 , meaning that it never applies, to 4, meaning it always applies ${ }^{4}$ ). Note that the Hoffman/Bolton list does not explicitly include "own pleasure" as a reason, but their published results make it clear that four of their reasons are highly correlated with obtaining pleasure: to have fun, to please my partner, because I want new experiences, and to reduce tension.

\begin{tabular}{|l|c|}
\hline Reason & Frequency \\
\hline To please my partner & 2.80 \\
\hline To express love & 2.78 \\
\hline To have fun & 2.77 \\
\hline To feel close emotionally & 2.49 \\
\hline To feel loved & 2.14 \\
\hline Because my partner wants me to & 2.11 \\
\hline To reduce tension & 2.10 \\
\hline Because I want new experiences & 1.99 \\
\hline To avoid boredom & 1.32 \\
\hline Because I feel I just have to & 1.25 \\
\hline Even when I don't want to & 1.11 \\
\hline For conquest & 0.92 \\
\hline Because I'm drunk & 0.86 \\
\hline To express domination and power & 0.85 \\
\hline Because I'm high & 0.69 \\
\hline To have children & 0.49 \\
\hline
\end{tabular}

Table 7.2: Sixteen reasons for having sex (Hoffman and Bolton, 1997).

\footnotetext{
${ }^{4}$ In fact Hoffman and Bolton employed the range 1-5 but here the numbers have been converted to the scale 0-4 for ease of comparison with Leigh's results.
} 
The majority of the motivations listed in both of the above surveys are presented in somewhat egocentric terms, generally indicating something that the respondent wants for themselves out of the sexual experience. In contrast, a third, even more recent study (Davis, Shaver, and Vernon, 2004), based on a survey conducted via the Internet, expressed ten of its eleven proffered motivations in terms of the way that the respondent related to and felt about their partner. These were: (1) to achieve emotional closeness, (2) to experience physical pleasure, (3) raising one's selfesteem by increasing the feeling of being desirable and wanted, (4) to nurture and care for the partner, (5) experiencing the partner's power, (6) to obtain approval and reassurance from the partner, (7) to disarm the partner and protect oneself against hostility or the partner's negative moods, (8) to reduce one's own stress, (9) to exert power, (10) to have control over the partner, and (11) to elicit nurturing and caregiving from the partner. Table 7.3 presents the motivations in abbreviated forms together with the frequency for men and women.

\begin{tabular}{|l|c|c|}
\hline Reason & \multicolumn{2}{|c|}{ Frequency } \\
\hline & Men & Women $^{\mathbf{5}}$ \\
\hline Emotional closeness & 2.95 & 2.85 \\
\hline Physical pleasure & 2.93 & 2.67 \\
\hline Enhance self-esteem & 2.68 & 2.85 \\
\hline Nurture & 2.46 & 2.19 \\
\hline Feel partner's power & 2.25 & 2.19 \\
\hline Reassurance & 2.06 & 1.94 \\
\hline Self protection & 1.94 & 1.92 \\
\hline Stress reduction & 2.10 & 1.70 \\
\hline Feel one's own power & 1.83 & 1.77 \\
\hline To manipulate the partner & 0.83 & 0.95 \\
\hline To have children & 0.69 & 0.69 \\
\hline
\end{tabular}

Table 7.3: Eleven reasons for having sex (Davis et al., 2004).

In all three of these studies pleasure and emotional closeness were at or very near the top of the respondents' lists, so we shall examine them first when considering why humans might want to have sex with robots. Let us start with pleasure.

The most obvious way in which humans obtain pleasure from sex is through orgasm, and a robot that can give its partner great orgasms on demand will therefore be highly prized as a sexual partner. In Chapter 9 I discuss the technologies that will most likely be employed in robots for achieving this goal, but in the meantime I shall consider how an inanimate sex doll, with no electronic brain, no artificial intelligence, and none of the humanlike characteristics that come from these technologies, can help men to achieve great orgasms. In 1997 the popular American radio "shock jock" Howard Stern was given the "Celine" model of a RealDoll by its manufacturer, Abyss Creations Inc. Stern tried it out and waxed lyrical on his radio show about the experience.

\footnotetext{
${ }^{5}$ The scores in Table 7. 3 have been converted, for ease of comparison, from the scale of 1-9, as used by Deborah Davis and her colleagues, to the scale of $0-4$ as in Tables 7.1 and 7.2. Table 7.3 is presented in descending order of the mean scores from male and female respondents.
} 


\begin{abstract}
"Best sex I ever had! I swear to God! This RealDoll feels better than a real woman! She's fantastic! I love her! This RealDoll is for real, I swear! Better than a woman! My wife isn't as good as that! May God take away all my ratings if I'm lying! I'll take a lie detector test! I swear on the life of my children! I did it and it was fulfilling! I did it and I'm proud of it! It was great! It was the best sex I ever had! ... It was fabulous! I could fall in love with that thing!"
\end{abstract}

I present this primitive example to show how much sexual pleasure a doll can bring its owner, through the simple expedient of being a non-active partner in an orgasmic experience. Despite Stern's claim that his was the best sex he ever had, just imagine how much better it might have been for him if instead of a lifeless doll, with no intelligence, no conversation, and no sparkle, he had pleasured himself with a fembot who had told him how much she loved him and what a wonderful lover he was, and who had caressed him and employed her other sensual capabilities to heighten his enjoyment of the encounter. For a more detailed discussion of sex dolls and the technology of the orgasm, the reader is referred to Chapter 9. But for now I return to consider the other reasons, apart from the pure physical pleasure of orgasm, why we enjoy sex.

At this point, I assume that some readers, despite having digested the evidence and arguments in the earlier chapters, do not yet believe that rational humans will develop emotional attachments for robots by mid-century, let alone be falling in love with them. However, those readers will surely admit that a fembot or malebot who not only gives great orgasms but also relieves one's sexual tensions, provides new sexual experiences, leads a path away from boredom and reduces stress, that such a robot could make an outstanding lover. So even in the absence of a strong emotional attachment from the human side, there will be ample motivation for a significant proportion of the population to desire sex with their robots. For example, the 60 per cent of college men in James Carroll's (1985) survey who did not respond that, for them, emotional involvement was always or most of the time a prerequisite for having sex - they will be likely customers. Similarly the 51 per cent of men in Whitley's (1988) study who mentioned lust and physical pleasure as their main motivations for engaging in their most recent sexual encounter.

Those readers who do accept the concept of humans falling in love with robots, might add other elements to the given lists of benefits in tables 7.1, 7.2, and 7.3, elements derived from the emotional attachment that loving owners will feel for their electronic sex partners, such as (1) the expression by the robot's owner of their closeness and/or love for their fembot or malebot, (2) the giving of pleasure to their robot partner, (3) obtaining reassurance about the robot's virtual love for its owner, (4) the enhancement of one's self-esteem on being praised by the robot for one's lovemaking skills, and (5) satisfying their robot partner's stated desire for sex.

A final remark is in order on the motivations found in the lower reaches of the survey statistics. In the case of those motivations relating to the human's power and domination of their sex partner, those giving the human a feeling of sexual conquest, and the stimulus for having sex being drink or drugs; there will certainly be some 
occasions when these motivations provide sufficient impetus for having sex with a robot, even for people who are not impelled by any of the more powerful motivations. However, I refrain from an analysis of these less prevalent reasons.

This leaves only one motivation from Tables 7.1, 7.2, and 7.3, that cannot be applied to human-robot sexual activity - the desire to procreate with a robot. Yet the idea of human-robot procreation is not as ludicrous as it first appears. In Robots Unlimited (Levy, 2005) I describe some of the self-reproducing robots that have already been created by scientists at Brandeis University, robots that can design and build other robots, including exact replicas of themselves. My description includes the explanation that, in future decades, a robot will have the capacity to find certain characteristics in its human owner appealing, and to design those characteristics into the next robot that it builds.

Thus far in this chapter I have explored the main reasons why people decide to have sex with people, and some of the reasons why people in the decades to come will decide to have sex with robots, but this discussion has somewhat ignored an important catalytic effect that increases the likelihood of a sexual encounter taking place - the sex appeal of the prospective sex object. In this sense, the bare statistics expressed by the respondents in the surveys present only part of the picture. The other part, the seductive part, is less obviously a reason to a participant in a psychological survey, largely because of the natural inclination to rationalise when answering a questionnaire rather than to admit to being influenced by factors that are not directly related to sexual decision making.

These "other factors", the behavioural ones, the seductive ones, have been investigated by David Bass (1988) at the University of Michigan, who ranked various "male acts" and "female acts" according to how effective they were assessed as being in leading the person's date to the bedroom. In Bass' list of the "20 most effective male acts" there are nine that could apply to robots, including the top three. To restrict any digression I suppress discussion of the other eleven acts.

$\begin{array}{ll}1^{\text {st }} & \text { He displayed a good sense of humour } \\ 2^{\text {nd }} & \text { He was sympathetic to her troubles } \\ 3^{\text {rd }} & \text { He showed good manners } \\ 6^{\text {th }} & \text { He offered to help her } \\ 14^{\text {th }} & \text { He smiled a lot at women } \\ 15^{\text {th }} & \text { He gave encouraging glances to girls } \\ 18^{\text {th }} & \text { He touched her } \\ 19^{\text {th }} & \text { He made up jokes to make women laugh } \\ 20^{\text {th }} & \text { He expressed strong opinions }\end{array}$

In any of these assessments, gleaned mostly from the comments of close friends of the women who admitted being influenced by these "acts", we can replace "He" (the woman's sexual partner) by "It" (a robot) with no loss of validity. Already there are computer programs that can make up new jokes ${ }^{6}$. Most of them are not wonderful

${ }^{6}$ For example, Kim Binsted's (1996) program JAPE creates puns. 
jokes but some are clever enough to get a smile or a laugh. As the software technologies of joke-making develop, so robots will come to appreciate jokes made by their conversation partners, in other words to have a sense of humour. These robots will ably perform the $1^{\text {st }}$ and $19^{\text {th }}$ acts on the above list.

Being sympathetic, well-mannered and helpful, and being able to express strong opinions during conversation, these attributes come from a combination of empathy and conversational skills - nothing here is beyond the bounds of reasonable expectation for the artificially intelligent robots of 2050. As for smiling and giving encouraging glances, David Hanson's moving head ${ }^{7}$ can already accomplish both (Ferber, 2003). And touching, of course, is just about the easiest thing to design into a robot.

The "20 most effective female acts" listed by Bass (1988) strongly mirrored the male list, omitting only two acts: touching, and expressing strong opinions; and including one act not on the male list - telling him things he wanted to hear (another straightforward task, once robots have reached the necessary level in their conversational skills).

\subsection{Sex in a New Gender Environment}

Many writers in the domain of postmodern philosophy have been searching for new gender structures for human beings. In section $1.6 \mathrm{I}$ introduced the theories by Braidotti (1996) and Van Zoonen (2002). Braidotti mentions "transgender entities" and "genderless entities" in relation to the Internet, while Van Zoonen speculates on a type described as being "beyond gender". The extension of the human world with a virtual world may, in this respect, evoke the following question: "Will the use of robots reinforce gendered stereotypes or will gender stay as it is?" Maaike Meijer (2007) remarks on this topic that "the current technological interventions might enable us to make critical interventions in the more problematic sides of the gender structure." Although I am not a gender specialist I found this an intriguing perspective, in particular after Meijer (2007) had given the following argument. "The institution of and the persistent belief in the inevitably and 'naturalness' of gender, itself legitimizes a division of power and a cultural hierarchy that many feminists, and others, would like to see changed."

Following my own thoughts and reasoning, I must admit that the above question is a logical follow-up of my position on making love with humans (see section 7.2) and sex with robots (see Chapter 10). Having read some of the literature on gender structures, why they are as they are and what can be changed, I was mostly impressed by Judith Butler's (1990) contribution in Gender Trouble. She discusses the ideas of many of her predecessors and finally arrives at the position that the categories of sex, gender, and sexuality are in some sense coherent and culturally constructed. Butler speaks about "frameworks of intelligibility" and "disciplinary

\footnotetext{
${ }^{7}$ See Chapter 4.
} 
regimes", and aims at deciding what possibilities of gender, sex, and sexuality might appear as natural.

However, Butler's book does not give a new gender structure. Although it is now seventeen years later, and her book was, at that time quite influential (and still is, even today) I have not seen any new proposals for gender structures other than the ones we still consider "natural". This thesis aims to broaden that scope of thinking on sex and sexuality in relation to robots, but I have neither the ambition nor pretension to propose a new gender structure. I will be satisfied if this thesis, and in particular the thoughts expressed above, serve as stepping stones for other (gender) researchers so that they can come up with new gender structures.

\subsection{Sex as a Result of Transference}

Transference is a psychological phenomenon, typically described as a subconscious redirection of feelings from one person to another. Whereas attachment is a transference of positive feelings that develop first and specifically for a baby's primary carer, usually its mother, and later in life to objects which are important to that baby/child/adult, and possibly to other people in the form of romantic love; transference is a redirection of feelings, positive or negative, that were first associated with a significant person in the subject's life, not necessarily its primary carer, and are later transferred towards some other person. As an example one might have negative feelings towards somebody whose manners, voice or appearance resemble those of an abusive parent, a sadistic teacher, or physical education instructor, a bully or a tease, or a loathed ex-spouse. Examples of positive feelings also abound, and might be more closely related to sexuality: a dazzling girl who sat in front of a boy in their high school algebra class, inspiring his sexual fantasies; or a sexy teacher whose slit skirt and fulsome cleavage were similarly inspirational. Transference was first described by Sigmund Freud (1938), who recognized that the models we create in our minds during our formative years as to how people behave, stay with us and affect our choices, experiences and relationships into adulthood.

Sigmund Freud (1938) knew nothing of computers since they did not exist at that time. Sixty years later John Suler, on the Psychology of Cyberspace Web site, was among the first to describe an application of transference theory involving computers. Suler (1998), in his well-formulated article Mom, Dad, Computer (Transference Reactions to Computers) explains how the phenomenon of transference extends to relationships with computers.

"These models also shape how people select and experience things in their lives that are NOT human, but so closely touch our needs and emotions that we want to imbue them with human characteristics. We humans can't help but anthropomorphize the elements in the world around us. It's in our blood. We use our internal models to humanize and shape our experience of cars, houses, pets, careers, the weather.... and COMPUTERS. 
"Yes, computers can be a prime target for transference because they may be perceived as human-like. They are complex machines that almost seem to "think" like humans think. In fact, some people say they WILL someday be able to "think" like us. Unlike TV, movies, or books, they are highly interactive. We ask them to do something and they do it - at least, they usually do (like humans they sometimes disobey and surprise us). With the new generation of highly visual, auditory, and customisable operating systems and software applications, we also have a machine that can be tailored to reflect what we expect in a companion. The science fiction fascination with robots and androids is the culmination of this perception of machines as being almost like one of us.

"What makes computers especially enticing targets for transference is that they are VAGUELY human and PROGRAMMABLE to be whatever we make them out to be."

It is important to note that the whole process of transference is often subconscious. As soon as we are in a new, indistinct, somewhat tractable situation we start shaping the new environment according to our background theories, developed as templates in our youth. We remember them and fill them with familiar knowledge and wellexperienced relationships. Thus, we are automatically involved in the process of forming the new world around us according to our personal perceptions and actions. Our relationships with computers might well be an example of this subconscious behaviour.

Along these lines, Suler's (1998) article continues with a discussion of the various ways in which transference can apply to computers - how we might subconsciously experience our computer as being like our mother or father or a sibling? One of these ways is examined in the context of Freudian psychology, in terms of sexual desires and fantasies experienced in relation to one's parents, a subject explored more fully by Norman Holland (1996) in another article from the Psychology of Cyberspace Web site. Quoting Joseph Weizenbaum's (1976) reaction to the way that people anthropomorphized and became deeply involved with his programs ELIZA and DOCTOR, Holland points out that people form bonds with computers more quickly than with other objects.

"The computer just makes this process faster and more drastic, because it exhibits "intelligent" behavior like another human.

"In sum, then, we have some fantasies about the computer as a thing: phallic fantasies of power and oral fantasies of engulfing pleasure. We also have these more remarkable fantasies that the computer is something more than a thing, something between person and thing. We have a quasi-human relationship with the machine as helpmate, as true friend, as permissive parent, as sex object, and as sex partner."

Suler (1998) describes Holland's view of the computer as being ". . . seen as seductive, as a sex object, a satisfier of desire, as a symbol of sexual power and 
prowess." Here we see that the concept of transference to computers has rapidly become a discussion of computers as sex objects.

\subsection{Chapter Conclusions}

In this chapter I have investigated the question: why do people enjoy sex? I have restricted myself to the essentials of this question that may be relevant for an extension of the subject in the direction of robotics. I did not attempt to focus on a psychological answer along the lines of Freud's (1905) work. The most direct answers are given in tables 7.1 to 7.3. From the research results contained in these tables I may conclude that people enjoy sex: (1) for pure pleasure, and (2) to express emotional closeness. These two answers will guide my continuing investigations in the quest for a solution to the second part of my problem statement. 


\section{Chapter 8}

\section{WHY PEOPLE PAY FOR SEX}

I pay for sex because that is the only way I can get sex. I am not ashamed of paying for sex. I pay for food. I pay for clothing. I pay for shelter. Why should I not also pay for sex? Paying for sex does not diminish the pleasure I derive from it.

Hugh Loebner (1998)

This chapter continues my investigations into the possible extension of the normal bounds of human sexuality towards robotics. Here I address the question RQ6: why do people pay for sex? The behaviour of the human being in this respect provides some insight into the possibility of making use of the sexual services of robots.

I therefore examine, in this chapter, the facility of sex on demand from the perspective of prostitution. I discuss the parallels between the enjoyment and benefits derived by clients from sex with a prostitute and the enjoyment and benefits that will be derived by their owners from sexual robots.

The course of the chapter is as follows. Section 8.1 deals with men paying women. As a direct follow up I examine the reverse relationship of women paying men. Then in section 8.3 I try to reveal some of the background reasons as to why men pay women for sex, and in section 8.4 I examine the counterpart of the topic: why women pay men for sex. All this results in a common perspective on the future of prostitution as given in section 8.5. Section 8.6 looks at paid sex surrogates as a form of therapy. Section 8.7 provides chapter conclusions.

\subsection{Men Paying Women}

Obtaining accurate estimates of the percentage of the population that visit prostitutes is fraught with difficulties, largely due to the stigmatising view of prostitution and its clients that has long been held by so many people. As a result, serious attempts at quantifying the use made of the services of prostitutes did not begin until the middle of the twentieth century, when Alfred Kinsey, Wardell Pomeroy, and Clyde Martin (1948) estimated that 69 per cent of the white male population of America had been to a prostitute at least once in their lives. If this figure seems high to some readers, it should be considered alongside the historical study by Timothy Gilfoyle (1992), who estimated that 10 to 25 per cent of all young women in New York City in the nineteenth century were prostitutes, either temporarily or on a long-term basis, making prostitution, for much of that period, the second largest business in terms of the revenue generated (the first being tailoring). It should also be noted that Kinsey 
et al.'s (1948) figure of 69 per cent was for men who had had sex with a prostitute at least once in their lives, and most of these men had only one or two such experiences. Kinsey et al.'s estimate of the proportion of American men whose sole sexual outlet was prostitutes was very much lower, namely between 3.5 and 4 per cent. Other, more recent estimates of the numbers of men in the USA who had had sex for money have ranged from 16 per cent (Lauman et al., 1994) to 18 per cent of those aged 18 to 59 (Sullivan and Simon, 1998) to 20 per cent (Janus and Janus, 1993).

The accuracy of all of these figures must be viewed with some doubt because of the known discrepancies between what johns ${ }^{1}$ are willing to admit in an interview survey or when filling in a pen-and-paper questionnaire, and the figures ascertained by other means that are known to be more reliable. This phenomenon of underreporting by johns was examined in a study published in 2000 by the U.S. Academy of Sciences, entitled Prostitution and the Sex Discrepancy in Reported Number of Sexual Partners (Brewer et al., 2000). Devon Brewer and his colleagues found that, when responding via a computer-assisted interviewing process, which is generally believed to promote accurate reporting, the johns' answers relating to contacts with prostitutes were almost four times higher than when responding to human interviewing or pencil-and-paper questionnaires. It seems most unlikely (not to say impossible) that this four-to-one ratio persists across the whole spectrum of quantitative research on prostitution, but what is clear is that figures such as 16 to 20 per cent in the USA should certainly be regarded as underestimates.

In many parts of Europe it has long been common practice for young men to receive their sexual initiation from a prostitute, though the numbers might be declining due to changing moral values that no longer place such stringent constraints on the sexual behaviour of young unmarried women. A study carried out in Lisbon found that 25 per cent of men in their sample of 200 had lost their virginity to a prostitute (Amaro, Dantas, and Teles, 1995), while in a study in France some 30 years earlier, 47 per cent of men who were practising Catholics similarly had their first sexual experience in this way (Moal, 1964). Given that these particular statistics do not include those men whose first visit to a prostitute came when they were no longer virgins, it would appear that the overall figures for men who have had sex with a prostitute is significantly higher in these strongly Catholic countries than one might otherwise expect.

Estimates from other developed countries vary considerably. From a national study carried out in Britain during the early 1990s on sexual attitudes and lifestyles, out of 19,000 households surveyed only 1.8 per cent of men responded that they had paid for sex during the previous five years (Johnson et al., 1994). A second survey, published seven years later, noted an increase to 4.3 per cent (Johnson et al., 2001), but the authors questioned whether this was a genuine increase in numbers or whether it was due to those surveyed for the later report being more willing to admit to their peccadilloes. Other studies include a national telephone survey in

\footnotetext{
${ }^{1}$ In North America the male clients of prostitutes are traditionally referred to as "johns", and the female clients of prostitutes as "janes".
} 
Switzerland, which estimated that 12 per cent of men between 17 and 30 years of age had visited prostitutes (Hausser et al., 1991); and a study by Cecelie Hoigard and Liv Finstad (1992) in Norway that estimated the figure there to be 13 per cent. The difficulty in obtaining accurate estimates, even nowadays when people are more willing than in the past to discuss their sexual habits, is shown by the results of a survey in Holland: only 3 per cent of heterosexual men aged 18 to 50 were willing to admit to having paid for sex in the previous year, whereas calculations based on the estimated number of prostitutes and the average number of clients that they serve per day put the figure at 16 per cent (Vanwesenbeeck and De Graaf, 1998). On other continents estimates are significantly higher, particularly in developing countries such as Thailand and the Philippines. In 1994 it was estimated that each day more than 450,000 Thai men visited prostitutes (Shih, 1994), while "Prostitution, as an integral component of the tourist industry, is an important source of foreign exchange for the Philippine Government" (Economist, 1996; IWRAW, 2003).

These somewhat diverse statistics confirm that, even though there is a wide variation in the percentages between countries, a huge number of men employ the services of prostitutes.

As an aside I would like to mention that there is substantial violence wrought upon female prostitutes. Moreover the number of girls that are exploited at too young an age is considerable (and not only in sex-tourist countries). These two issues are discussed in section 10.5, a section on ethics, where there is also a discussion of the question as to whether robots might provide satisfying substitutes in place of prostitutes.

\subsection{Women Paying Men}

The field of gender studies promotes a discussion on the balance between men and women in many facets of our lives, for example in situations involving power (politics and the board-room) and other situations of decision making. In the case of prostitution, Christine Overall (1992) discusses such a balance in terms of the respective benefits that prostitution brings to each of the sexes.

"Some writers have thought that if buying sex is a benefit for men, it must also be a potential benefit for women, one that they should be encouraged to seek out. For instance, Ericsson argues that under the present unequal circumstances of sex work, 'some benefit is withheld from or denied women that is not withheld from or denied men.' The best way to deal with this inequality would not be an attempt to stamp out the institution but an attempt to modify it, by making the benefit in question available to both sexes."

It has always been the case that the number of male clients of female prostitutes far outweighed the number of women who pay men for sexual services. The principal 
reason for this, pointed out by Kingsley Davis's (1937) article The Sociology of Prostitution, has been economic - the number of women who earned enough (or had jobs at all) to allow them to pay for sexual services has been considerably below the corresponding number for men. Nevertheless, the practice has existed since at least the late nineteenth century. In The Sexual Life of Our Time Iwan Bloch (1909) refers to an anonymously written 1848 book, Prostitution in Berlin, and its Victims ${ }^{2}$ which

“contains an appendix on 'prostituted men' (p. 207), who, however, are not homosexual prostitutes, but, according to the writer's own definition, "men who make it their profession to serve for payment voluptuous women by the gratification of the latter's unnatural passions". This species still exists to the present day [i.e. 1909], but there is no particular name for the type. (In the seventies [the 1870s], in Vienna, men who could be hired to perform coitus were known locally as "stallions" - German Hengste.)"

In the pleasure-seeking boom of the post-prohibition USA, it was inevitable that men-for-hire-for-ladies would become a growth area within the world's oldest profession. Ted Peckham (1955) quickly became famous in New York society during the mid-1930s for being able to supply presentable men who would satisfy the desires of his largely wealthy female clientele, on a strictly pay-as-you-go basis with a charge for overtime after midnight. For four years his agency, Guide Escort Services, was a booming success and very much in the public eye, even opening for business in Europe, but eventually the law took against Peckham in the form of a writ accusing him of running an employment bureau without a licence, a legal ploy designed to get around the problem that the authorities doubted whether any charges laid against him relating to prostitution could be made to stick. Peckham was prosecuted by the forceful gangbuster and District Attorney Thomas E. Dewey, who later became Governor of New York state and was a Republican candidate for the presidency in two elections ${ }^{3}$. Peckham was found guilty by the judge (no jury) and was fined 250 dollars, with an additional sentence of 3 months in the workhouse suspended during his "good behavior" and "upon the condition that he not conduct this agency unless and until he has obtained from the proper authorities of the city of New York a license to do so". Peckham duly gave up the escort business and became a writer ${ }^{4}$.

Peckham may have been the exception rather than the rule during the 1930s. His notoriety did little to dent the assumption by most people that women have no need or wish to pay for sexual services, a view that prevailed at least until the advent of the toy boy fashion in the early 1990s. This fashion, and the changing behaviour patterns that accompanied and followed it, were all part of the new era of feminism, which encouraged women to assert their equal right to full and satisfactory sex lives.

\footnotetext{
${ }^{2}$ Die Prostitution in Berlin und ihre Opfer.

${ }^{3}$ In 1944 and 1948.

${ }^{4}$ The dust jacket of his memoirs, Gentlemen for Rent, proclaims that his service in New York was launched with the blessing of a host of celebrities, including Lucius Beebe, Maury Paul, Walter Winchell, Danton Walker and Louis Sobol, and that in London he was "sponsored by the Duke of Kent".
} 
Enter Joel Ryan, a $21^{\text {st }}$ century version of Peckham (cf. Treays, 1997). Ryan runs a successful "escort" business called "Heaven On Earth" in Melbourne, catering for both male and female heterosexual clients (women make up approximately 40 per cent of his client list). Brothels and escort services may legally ply their trade throughout much of Australia, as a result of which Ryan and his service have become something of a curiosity item in the media, including being the subjects of a television film, What Sort of Gentleman Are You After?, by the British documentary maker Jane Treays ${ }^{5}$.

While Joel Ryan caters for both men and women clients, a new brothel service announced in Valencia, Spain, was set up in 2006 by a woman, exclusively for women (Keeley, 2006). In Spain, as in most countries, visiting prostitutes is traditionally seen as cosa de hombres (a man's thing), with an estimated 25 per cent of men having indulged, according to a survey by the Institute for National Statistics. While the medical publisher Mundo Medico's figure for Spanish women who have paid a gigolo is very much smaller at 2 per cent, it is nevertheless higher than many people would expect, especially for a strongly Catholic country.

"Charming Barbara", the madam who opened and runs this particular Valencia brothel, was herself a sex worker for eight years. Then she set up an agency for female clients, offering male escorts, but soon decided to start a permanent luxury brothel. Barbara has had no shortage of men who want to work for her, and is very clear about what her mostly professional executive clients want for their money, which can reach about $€ 1,200(\$ 1,500)$ for a whole-night session: "I don't want muscle-men. Above all they must have good conversation."

The advent of the Internet has greatly facilitated prostitution, by making it possible to advertise, almost free of charge, to a huge potential client base. This freedom is being exploited by increasing numbers of men who advertise their sexual services to women in language that often leaves little to the imagination in terms of the advertiser's claimed sexual prowess and size. Isabel Kessler (2005) of Middlesex University investigated this growing trend. She found that between 150 and 200 male escorts offered their services to women in London via their own web sites, which could be viewed free of charge. Kessler did not investigate the number of men advertising on so-called "membership" home pages, for which access is available only upon payment of a fee, so the figure of 150 to 200 can safely be assumed to be an underestimate. Typical of the charges quoted by these sites at that time were $£ 100$ (€150) per hour and around $£ 450$ (€675) for an overnight session. This trend has also found its way into the film world. In the interesting and excellent film The Full Monty, we follow an English working class man into a career in show business (undressing and displaying his nakedness), and what that does to him and to the women of his community.

The comparatively recent growth in the heterosexual male prostitute business in the UK is almost nothing in comparison with a phenomenal surge in demand from

\footnotetext{
${ }^{5}$ Shown as part of the BBC's "Under the Sun" series on $15^{\text {th }}$ December 1997, watched by an estimated 4.8 million viewers.
} 
financially well off women in Thailand, noted by Zenitha Prince (2002) in her article "Thai Female Elite Demand Black Gigolos", that appeared in the Independent Newspaper of Morgan State University ${ }^{6}$.

"The long-perpetrated image of the black man as a sexual toy continues to flourish as the niche market for black male prostitutes in Thailand booms. Escort services are now importing hundreds of prospective black gigolos from Jamaica and Africa into the Asian country to satisfy the surge in the demand for these services among the Thai female elite. A research project, recently completed by Associate Professor of Sociology Nither Tinnakul, from Bangkok's Chulalongkorn University, puts the number of male prostitutes in Thailand at a staggering 30,000, triple the estimated amount of just two years ago.

... "I think the women want some equal rights you know [revenge against philandering husbands], some kind of freedom. She needs something." Tinnakul said. Apparently, there is a need that these black foreign prostitutes or "forungs" have aptly satisfied. The report further stated that Thai women are paying upwards of 10,000 baht (243 dollars) per night for the servicers, who are "fiercer", more "thrilling" in bed than their Thai peers, and well built."

A different form of prostitution for women clients has also been rising steadily in popularity in recent years - sex tourism, which is also referred to, with the benefit of a fair dose of delusion, as "romance tourism". Sex tourism has, of course, long been popular with many men, who travel to Thailand, the Philippines, Bali, and elsewhere, in the knowledge that the price of sex in their chosen destination comes very cheaply. For most of these men the transaction is simple prostitution, sometimes for a single brief encounter and sometimes for longer, perhaps for most or all of their vacation if they meet a girl who gives them a really good time. For a few others it is a means of finding a satisfying wife to take home.

For women, the nature of the transaction in sex tourism and the treatment they are seeking both differ from those of male sex tourists. Instead of a cash transaction that is overtly money for sex, often paid in advance, the payment comes in ways that the woman can rationalize as a gift, helping out the beach boy or the tourist guide and his family. As Taylor (2001) stated: "Most beach boys enter into sexual relationships with as many tourist women as they possibly can, and most of these relationships result in some form of material or economic benefit for the man. Some beach boys and hotel or bar workers engage in explicit sex for cash exchanges with male tourists, female tourists and/or tourist couples, but on the whole, the economic element of their sexual relationships with tourist women is less formally arranged." These men play the game of pretending to be genuinely attracted to the women, of falling in love with them and wanting to marry them ${ }^{7}$. In return the woman plays the

\footnotetext{
${ }^{6}$ November $8^{\text {th }} 2002$.

${ }^{7}$ Sometimes there is indeed a desire to marry, as that will often provide the man with a first world passport and therefore an exit from his third world poverty, and sometimes the woman will return to the
} 
game of enjoying being pampered and often deludes herself into believing that the man loves her and that she loves him. She buys him meals, buys him presents, and gives him money for a "sick relative" or on some other pretext, often repeating the cash gift after she returns home from her vacation. The whole process is described by Nigel Bowen (2004) in his article Sugar Mamas.

"It is not sex for sale; it is love for sale. These guys get girls by courting them, charming them, wooing them. Women are attracted to the romance of it. It is a fantasy to meet an exotic stranger on the street who seems to have fallen in love with you at first sight. Balinese men target women's hearts: they're sensitive, sweet, flattering and funny. And they're also very clever about going for the Achilles heel. If a girl is fat, they'll tell her she has a beautiful body.

"Prue (not her real name) is an exuberant 54-year-old widow with a healthy bank balance and an even healthier libido. Three times a year, she locks up her home in one of Sydney's more respectable suburbs and flies to Bali for the sole purpose of spending a week being sexually pampered by a teenager. 'The Balinese say they love you, and of course I want to hear that, but at the end of the day, it is a business deal. At my age, money is their sole focus. I pay for the accommodation, meals, excursions and buy them gifts. At the end of the holiday, I slip several thousand dollars enough to support their family for six months - into an envelope and leave it on the table for them.",

From the little published research that exists on the prevalence of women sex tourists, it appears that, in some tourist destinations at least, the practice is rapidly becoming commonplace. Jacqueline Sánchez Taylor (2001) surveyed 240 women who were on holiday alone in the Dominican Republic and Jamaica, asking them to complete a questionnaire for a study on tourism and sexual health. "A questionnaire was constructed which was designed to yield some basic data on tourist women who had sexual contact with local men, including their nationality, age, occupation and racialised identity; their perceptions of the 'sexual culture' of the host country; how often they had travelled to that country and other known sex tourist destinations; how many different local sexual partners they had and whether they perceived these relationships as 'real love', 'holiday romances' or 'purely physical'; whether or not they gave money or made other gifts to their local sexual partners; whether or not they took safe-sex precautions." When responding to the questions about how they perceived their relationships with their local lovers, 39 per cent of the women described it as a holiday romance, 22 per cent as real love, and only 3 per cent as purely physical. (A further 12 per cent said it was both physical and a holiday romance.) Taylor found that part of the self-delusion process is due to "racist ideas about black men being hypersexual and unable to control their sexuality", which enables the women "to explain to themselves why such young and desirable men would be eager for sex with older, and/or often overweight women, without having

same vacation spot and to the same man, eventually sending him an air ticket so that she can import him to her own country. 
to think that their partners were interested in them only for economic reasons .... Only women who had entered into a series of brief sexual encounters began to acknowledge that 'it's all about money'".

Almost one-third of those who completed Taylor's (2001) questionnaire admitted to engaging in one or more sexual relationships with local men during the course of their holiday. These women ranged in age from girls in their late teens to women in their $60 \mathrm{~s}$, the most likely to indulge being those in their $30 \mathrm{~s}-40 \mathrm{~s}$. About a quarter of the women surveyed said that they had been offered sex for money by local men, but not one of these woman admitted to have taken up the offer, so those who did engage sexually with the locals clearly did not accept that there was a commercial element to the relationship. This is despite 57 per cent of the women who did take local sex partners acknowledging that they gave their lovers "help" in the form of cash, gifts and/or meals. Taylor recognizes that, because of underreporting, this figure "is unlikely to accurately describe the true level of economic benefits transferred to local men by these women".

Taylor and O'Connell Davidson (1999) found in an earlier investigation that these women differ in terms of the type of sexual encounter they are after and the manner in which they rationalise these encounters. "Some are eager to find a man as soon as they get off the plane and enter into multiple, brief, and instrumental relationships; others want to be romanced and sweet-talked by one or perhaps two men during their holiday."

The reasons for women to seek these special services can thus be seen to vary considerably. Yet, a common factor seems to be that women have much more need than men do for something that resembles real love. Nancy Chodorow (1978) explains this difference as coming from the fact that a lack of closeness for women seems much more unbearable then it does for men. Assuming this to be true, this lack can be solved by roboticists at the design stage, and the robot can later adapt its behaviour if necessary, in order to satisfy women's needs for closeness.

\subsection{Why Men Pay Women for Sex}

Several reasons have been identified as to why men pay women for sex - what the men want or expect from these sexual encounters. While the reasons vary somewhat from one country to another, there is one common underlying emotional need that appears to be extremely widespread. It is the need for mutuality, the self-delusional feeling that the prostitute is a true partner in a relationship, however brief (Holzman and Pines, 1982; Plumridge et al., 1997). This "myth of mutuality" as Elizabeth Plumridge et al. call it, posits the typical prostitute as caring about the client and enjoying her intimacy with him. For the johns interviewed by Plumridge et al. for her study, all of whom were clients at a New Zealand massage parlour, "pleasure rested on two postulates; on the one hand a complex of notions that revolved around relaxation from constraints and obligation, and on the other, a set of interpretations 
that relates to mutuality." Plumridge et al. found that these men wanted the myth of social warmth to be sustained from the moment they entered the so-called massage parlour, and would complain "if the surface social pleasantries were torn away and the naked imperatives of sexual exchange for money revealed as the true purpose of the warm reception." The johns in her study did not all claim that the prostitutes they visited loved them, but all of these men did ascribe some level of emotionality to the encounters, describing their visits in terms such as "very nice to be pampered, just the feel of it and the warmth".

This desire for reciprocity perhaps explains certain trends in the sex industry in the USA in recent years, away from brief gratification for the man and towards a warmer, more sociable environment for the sexual encounter, as explained by Elizabeth Bernstein (2005).

"Those [johns] who frequented indoor venues enjoyed the benefit of an arrangement that was structured to more effectively provide them with the semblance of genuine erotic connection. For example, interactions with escorts as opposed to streetwalkers are typically more sustained (averaging an hour as opposed to 15 minutes), more likely to occur in comfortable settings (an apartment or hotel room, rather than a car), and more likely to include conversation as well as a diversity of sexual activities (vaginal intercourse, bodily caresses, genital touching, and cunnilingus, rather than simple fellatio). The fact that street prostitution now constitutes a marginal and declining sector of the sex trade means a transaction that has been associated with quick, impersonal sexual release is increasingly being superseded by one which is configured to encourage the fantasy of sensuous reciprocity .... .

"In recent years, one of the most sought after features in the prostitution encounter has become the "Girlfriend Experience," or GFE. In contrast to commercial transactions premised upon the straightforward exchange of money for orgasm, clients describe the GFE as proceeding "much more like a nonpaid encounter between two lovers," with the possibility of unhurried foreplay, reciprocal cuddling, and passionate kisses."

Several of those interviewed by Plumridge et al. (1997) claimed that their paid sex partners were of greater emotional importance to them than their relationships with their wives. While this speaks volumes about the states of these men's marriages, the fact that they genuinely believed it, or at least deluded themselves into believing it, demonstrates just how easy it is for someone who wants a particular person to care about them to succumb to the myth that that person does indeed care. Plumridge et al. summed this up by explaining that the men "all wanted a responsive embodied woman to have sex with. This they secured by ascribing desires, responses and sexuality to prostitute women. They did not know the true 'selves' of these women, but constructed them strategically in a way that forwarded their own pleasures." Another New Zealand study (Jordan, 1997) on why men visit prostitutes found further support for the companionship, the myth of mutuality and the lack of complications being prime reasons for paying for sex. There was also an 
emphasis by some of the johns in this particular study on the inability of their wives to satisfy them sexually.

Some fifteen years prior to Plumridge et al.'s (1997) research, Harold Holzman and Sharon Pines (1982) had examined the motivations of a sample of men aged from 27 to 52, almost half of whom were married, for their paper Buying Sex: The Phenomenology of Being a John. In common with Plumridge et al. they found that the men's desire for sex was coupled with a desire for companionship. They expressed it as follows: "In every encounter discussed, the individual paying for sex engaged in social, courting behaviours that were often flavoured with varying degrees of romance." Holzman and Pines (1982) found that "There existed a belief that by being pleasant or even quite amorous they could subtly seduce the prostitute into allowing their created illusion to play itself out .... Clearly, a great deal of energy is invested in the maintenance of the illusion." Roger Kernsmith (2001) found the same need for a social bond in those johns whose postings on the Internet newsgroup ASP (alt.sex.prostitution) he studied for his survey: "The theme that clients hired prostitutes as much for the sense of social closeness and acceptance as for the physical stimuli associated with the performed sex acts was found in every element of the ASP data". Further reinforcement of this theme comes from an even earlier study by Charles Winick (1962), who interviewed 732 clients in five major American cities, and concluded that the "emotional meanings and overtones of a client's visit to a prostitute are more important to the client than the desire for sex."

The importance of companionship for the client as a benefit of the transaction is fully acknowledged in the teaching at the Hanky Panky School in Amsterdam, which was opened in 2003 by Elene Vis, the former madam of an escort agency (de Hemptinne, 2005). In the Netherlands brothels are legal and prostitutes pay tax on their earnings. The country is renowned for its tolerant attitude towards commercial sex, and the red light district in Amsterdam is a well-known tourist attraction where the women display themselves in shop windows.

Vis prides herself on teaching her students to perfect their skills and boost their sales by giving "more than sex" (de Hemptinne, 2005). "Of course I teach sex techniques to the students, but with a client that only takes ten minutes and does not satisfy the customer or the escort ... It is about attention, listening, tenderness and positive energy, and those things can be bought."

\footnotetext{
${ }^{8}$ And for those men who wish to take up heterosexual prostitution as a career, and to learn the tricks of the trade, there is an online gigolo school called Gigolo International, that will doubtless teach you everything you need to know. The site advertises membership for $\$ 49.95$, with the news that "Modern upscale (working) women are always busy and have become more emancipated regarding paid (erotic) company. This could be a dinner-date, a short business-trip or even a fully paid vacation! These women need a man to share quality time without troubles afterwards and they will gladly pay for the right services. Did you ever dream of becoming Gigolo? This could be your first step into a whole new lifestyle! The members-section contains: Gigolo's tricks of the trade; How to become an independent Gigolo; Independent Gigolo promotional tools; The Ultimate Gigolo; Exclusive discount for members; Increase your female-contact skills; New tips and updates every month; Earn additional TOP\$\$ with our unique referral-program."
} 
Vis claims that after a half day of classes the prostitutes emerge with the power to change "ten disappointing minutes" into an exchange of positive energy. "Escort is accompanying someone. If the man feels pampered, he will be willing to pay for more than just the sex. In return this boosts the girl's self esteem." For 450 Euro (\$ 490) students can take classes in "Presentation", "Adding on hours" and "Entertaining",

The illusion in the minds of the johns, this myth of mutuality, is something that will be even more believable when the pampering and the imitation affection emanate

\footnotetext{
${ }^{9}$ The Hanky Panky School inspired interest in the same idea in India, as a March 2005 article by Sidhi Chadh in the Hindustan Times attests. The article was entitled "Now Learn Prostitution in School":
}

A Diploma in Sex Trade? That will be among the several qualifications on offer when a government-sponsored school for prostitutes opens in the capital on Friday. The move to encourage sex workers who are fully trained in their craft comes just days after the US threatened to impose sanctions unless the administration did something to regulate the flesh trade in the country.

Giving details of the scheme, Kamal Kishore, spokesperson for the Ministry of Human Resource \& Development says only those who received training at the Institute for Carnal Studies (ICS) would be granted a license to operate legally. The government, he claims, would be providing the best infrastructure possible at the Institute. "We have decided to hire sex workers with at least 10-12 years of experience as teachers. They will give students a first-hand account of how they made their way in the trade. Besides modern-day porn, the Institute will also have lessons from the Kamasutra so that lovemaking is pleasurable rather than being just about money," he says.

The girls will learn everything from seduction to handling finances. "It will be an honour to teach. Besides giving the girls useful tips about sex, we will also tell them how to seduce clients and extract maximum money. I am glad that the government is finally thinking about our needs," says Kamala, one of those on the ICS faculty.

While the Institute will offer a basic two-year degree programme for just Rs 2000, there will be advanced courses for those wishing to specialise as high-society call girls. With a growing demand for same-sex partners, ICS also has an option six-month crash course in "Lesbian Relationships and Practices". Special classes for gigolos could begin as early as next year. "The students will get a lot of practical exposure. They will do a month-long internship in various red light areas of the country where they will practice what they have learnt. We also expect them to produce feedback from clients. The student who scores the highest in terms of client satisfaction will get a cash prize of Rs 1 lakh and also a chance to represent India at an international meet in Phuket, Thailand," says Kishore.

According to a senior official in the HRD Ministry, there could be a number of spin-offs from a bold initiative like this. "Look, we have failed to clamp down on prostitution despite our best efforts in the past. Doesn't it make better sense to open a school and bring the flesh trade out in the open? It will help us in many ways - first, prostitution will become a legitimate profession; the girls in the trade will no longer be looked down upon and ostracized from society. Second, ICS will produce highly trained individuals who will know all about safe sex, hygiene and the use of condoms. Our biggest hope is that the school will play a pivotal role in the fight against AIDS. Lastly, it is also our intention to eliminate pimps and others who exploit sex workers. Those found operating outside the purview of the ICS will be prosecuted," he says.

Application forms will be available from April 10 at select government offices. The forms can be also be downloaded from the ICS website (www.indianprostitute.org).

More than 130 Web sites reproduced this Hindustan Times article, very few of them noting the closeness of its publication date (March $31^{\text {st }}$ ) to the date that helped to inspire it. 
from a sexual robot rather than a human prostitute. One reason for this is that, in the case of the prostitute, the john pays for every encounter and is therefore reminded repeatedly of the connection between the sexual experience and money, whereas having purchased a robot, this connection in its owner's mind will quickly dissipate forever ${ }^{10}$. More obvious reasons why the robot experience will be more appealing than visiting a prostitute include the utterly convincing manner in which robots will express affection and other emotions, simply because their emotions will be programmed into them, to be part of them, instead of being make-believe affections acted out by a prostitute with little genuine enthusiasm for the need to convince.

I now discuss three separate issues relating to the motivations for paying for sex, viz. variety (in 8.3.1), lack of complication and constraint (in 8.3.2) and lack of success with women (in 8.3.3). Then I consider the robot designer's solution (8.3.4).

\subsubsection{Motivations: Variety}

Neil McKeganey and Marina Barnard (1996) studied the reasons most often mentioned by johns as being important in the decision to employ the services of prostitutes. One of the reasons they highlighted is variety - the opportunity to have sex with a range of different women. Plumridge et al.'s (1997) research confirmed this finding, quoting as an example one john who explained his motivation as "someone different someone new", and another responding that "What actually turns me on is a bit of variety around me".

A robot will be able to provide endless variety in terms of its conversation, its voice, its knowledge and its virtual interests, its personality, and just about every other aspect of its being. All will be changeable on demand. Even a robot's physical characteristics could be changeable, thanks to clever mechanical design and replacement parts. And all aspects of a robot's sexuality will similarly be changeable according to its owner's wishes. It is hardly practical for a john to go searching the streets of a red light district, or to a brothel, expecting to be able to find a woman looking like Marilyn Monroe (or whoever his lust desires), with the brain power and knowledge of a university professor, and with the conversational style of a party-loving teenager. But with a robot at home he need search no further - all these characteristics and more will be selectable at the time of purchase. So the man who wants variety in his sexual partners will be able to find it, wherever he wishes, and far more easily than when looking for a prostitute to match his desires.

While variety in the appearance, personality, and attitude of prostitutes is one major reason for men paying for sex, variety in the sexual experience itself is, for many johns, another important factor, often the most important. "One of the main reasons clients pursue encounters with prostitutes is that they are interested in sexual practices to which they do not have access, either because they have no regular partners or because their partners are unable or unwilling to accommodate their desires." (Monto, 2001).

\footnotetext{
${ }^{10}$ Of course, there will be robot prostitutes (see Chapter 10.6), for johns who lack the resources or the inclination to purchase a sexual robot for use at home, and if there are robot prostitutes then there will also be robot brothels, staffed by robots for the benefit of humans.
} 
Many men are in relationships in which their wife or partner's sexual tastes do not accept oral sex or some other sexual practice which the man would like to indulge, so paying for the service provides an easy way out of the man's problem. The extent to which oral sex is an important reason for male clients to visit female prostitutes was studied by Martin Monto at the University of Portland, and described in his 2001 paper "Prostitution and Fellatio" in the Journal of Sex Research. Monto gathered questionnaires from more than 1,200 men who had been arrested while attempting to hire female prostitutes in Las Vegas, Portland (Oregon) and San Francisco, and who were participating in a scheme known as "johns' schools", designed to discourage them from re-offending ${ }^{11}$. The results of Monto's survey indicate that having a prostitute perform oral sex was even more prevalent for most johns than vaginal sex, with 81 per cent of those surveyed having experienced oral sex given by a prostitute, when the figure for vaginal sex was only 55 per cent. However, when asked how they would rate various sexual activities, 76 per cent of the johns in Monto's survey described vaginal intercourse as very appealing, while the figure for "having a partner perform oral sex on you" was lower, at 65 per cent ${ }^{12}$.

Comparing Monto's figures with findings from the National Health and Social Life Survey $^{13}$ (Laumann et al., 1994) reveals that in the USA male population as a whole, a significantly lower proportion of men, 45 per cent, found receiving oral sex very appealing. This comparison, between johns and the male population as a whole, indicates that a significant number of men seek encounters with prostitutes because of a desire for oral sex, providing a convincing example of the wish for sexual variety being a prime motivator for many johns. This motivation has also been confirmed by various other researchers (Day, Ward, and Perrotta, 1993, in the UK; Jordan, 1997, in New Zealand; McKeganey and Barnard, 1996, in the UK; Sullivan and Simon, 1998, in the USA; and Xantidis and McCabe, 2000, in Australia).

Clearly there will not be much of a problem in designing a mechanically sophisticated robot so that it can perform oral sex. Furthermore, sexual robots will not only be able to satisfy any particular sexual desire expressed by their owners, but also to suggest sexual practices that their owners have never previously experienced, and to teach their owners to become better lovers for those occasions when they prefer human company to sex with their robot.

\footnotetext{
${ }^{11}$ Attending these schemes wipes out the record of the participant's arrest, thereby ensuring that almost all those who are arrested for attempting to hire prostitutes in these three jurisdictions take up the offer of attending a johns' school.

${ }^{12}$ Monto suggests various possible reasons for the discrepancy between the percentages that have experienced oral sex and vaginal sex with a prostitute as compared to the percentages that rate these experiences as very appealing. One reason is that "it is much easier and more convenient to engage in oral sex than vaginal intercourse in a car or alley, where many of these episodes occur"; another is that prostitutes might "prefer oral to vaginal sex for a variety of reasons"; while others include clients' beliefs that there is a lower risk of AIDS from oral sex than there is from vaginal sex and less need to wear a condom (Monto, 2001, 2005).

${ }^{13}$ A survey conducted amongst 3,422 respondents between February and October 1992 across the 50 states of the USA.
} 


\subsubsection{Motivations: Lack of Complications and Constraints}

Alongside variety as a prime reason for visiting prostitutes, the research literature has identified a small group of motivations that might collectively be described as a lack of complications and constraints. I commence my discussion with two quotations. Bernstein (2005) made the following remarks.

"For many clients, one of the chief virtues of commercial sex exchange is the clear and bounded nature of the encounter ... . What is unique to contemporary client narratives is the explicitly stated preference for this type of bounded intimate engagement over other relational forms."

Neil McKeganey (1994) found that "For some men the appeal of prostitution seemed to lie in a combination of the anonymity, the brevity and the emotionally uninvolved nature of the prostitute contact."

Another survey, conducted amongst the clients at two Melbourne brothels, indicated that 90 per cent of the men who participated confirmed that a lack of "complications" was one of their main motivations in paying for sex (Xantidis et al., 2000). From earlier research it appears that the complication most often cited as an obstacle to getting non-commercial sex was the perceived need by men to "play games", pampering and courting a woman in order to achieve their goal, possibly requiring an enormous effort in return for which there is no guarantee of sex (Holzman and Pines, 1982). As one of the johns in Holzman and Pines' survey put it: "If I just want to go out and get laid I'm not going to bother going to a bar and buying drinks and dancing with a girl all night because I'm not interested in that ... you don't want to spend time looking for it where there is always a maybe - maybe yes or maybe no ... you almost want a written guarantee."

When discussing their wish for sex without constraints, johns present something of a paradox in their attitudes. On the one hand there is the self-delusion of the myth that a measure of emotional involvement exists in both directions with the prostitute. In contrast there is what Monto (2001) describes as "a wish to avoid the responsibilities or emotional attachments of a conventional relationship", the attitude that "payment of money for sex entitled them to freedom from the requirements normally associated with relationships" (Plumridge et al., 1997). Many of the johns who provided data for this research indicated that they regarded sex with their wife or partner as part of a different type of transaction, one in which they were tied down or had other demands placed on them. So instead of playing games, instead of the constriction of obligations imposed within a non-commercial sexual encounter, the johns are attracted by the ease of a paid sexual experience. The limited nature of paid sexual encounters and the lack of any long-term emotional involvement further contribute to the johns' feelings of freedom. The payment of cash is a simple, direct way to guarantee a sexual experience with the minimum of effort.

To avoid any necessity to indulge in "games" in the pursuit of a sex partner, for the avoidance of what are often perceived by johns as being constraints and complications in more conventional sexual relationships, and in the interest of 
limiting the nature and duration of any emotional involvement to whatever extent is wanted by its owner, a robot will be the ideal sex partner. You do not have to buy it endless meals or drinks, to take it to the movies or on vacation to romantic but expensive destinations. It will expect nothing from you, no long-term (or even shortterm) emotional returns, unless you have chosen it to be programmed to do so.

\subsubsection{Motivations: Lack of Success with Women}

For a variety of reasons many men have difficulty in becoming involved in dating or more permanent relationships with women. In some cases this is because the man is ugly, physically deformed, psychologically inadequate, a stranger in another town or a foreign land, or simply lacking in the necessary social skills and/or sexual assurance. Such men, with normal male desires, have a need for sexual intimacy that they cannot satisfy because of their lack of sexual effectiveness - they simply cannot attract a mate, or are afraid to try, or suffer from a combination of both. Their need can, however, be satisfied by a prostitute. By seeking to pay for sex they reduce the risk of rejection to an absolute minimum, thereby almost guaranteeing themselves sex on a plate. For these men prostitution is the only sex available, a reason for paying for sex that was indicated by almost 40 per cent of the johns in the Xantidis and McCabe (2000) study. It is succinctly expressed by Mary Laner (1974) as follows.

"The basic function of prostitution is to provide a primarily sexual service to people who either fail to meet the requirements of the more legitimate "market" or who exclude themselves from the larger market because they do not feel comfortable in it. The system is very flexible, and no-one is turned away."

\subsubsection{A designer's solution}

Above I have analysed three motivational issues. None of the issues mentioned presents any problem to the designers of robots. The reasons are straightforward. First, a purchaser's fembot will be immune to ugliness or a physical deformity in their owner, and to their owner's psychological inadequacies. Second, she will be available for hire (or travel with her owner) when he is visiting another town or land. Third, she will cater for the socially inept and the sexually unassured with the same virtual emotions and the same sexual responsiveness as when she is encountered by the handsomest, the most socially adept and the most sexually confident.

\subsection{Why Women Pay Men For Sex}

In contrast to the relatively well-researched topic of men paying for sex, there is almost no systematic published research on the reasons why women pay, on what exactly they are seeking from their commercial sexual encounters. Reported anecdotal evidence from a number of media articles on sex tourism promotes the 
view that, when on vacation, many women are looking for physical satisfaction from young toned native male bodies with large penises. But that is far from being the whole story, as an examination of the extremely sparse evidence testifies. The truth appears to be close to what has been observed from the studies of the reasons why men pay women for sex, as discussed in section 8.3.

One source that does go some little way to explain why women pay for sex is an article published in the UK edition of Marie Claire in February 1994: "Why Women Go to Male Prostitutes", the research for which was carried out by an academic at Birmingham university (who was not credited in the magazine ${ }^{14}$ ). Ten women were interviewed for this article, of whom nine gave reasons that mirror some of those generally expounded by $\operatorname{men}^{15}$.

Three of the women responded very much in line with the "myth of mutuality", wanting social warmth, caring, companionship. Jane ${ }^{16}$, aged 51, a housewife, commented "It's not so much the sex I'm looking for, as the feeling that someone is there for me." Jean, a 39 year old teacher, endorsed the importance of companionship: "It's not even the sex I want - just the company. Unless you have been through it yourself [husband leaving you for another woman], it's impossible to understand how desperately lonely you get ... . I did eventually have sex once, but I would be just as happy to pay for the company." And Anne, 64, a housewife, was very much like Prue the sex tourist, in her attitude: "I suppose I think of it as a holiday romance more than anything else. I would never dream of looking for anyone here in England. I certainly didn't feel demeaned by it. I wouldn't expect a man to want to do it with a woman of my age for nothing."

Six of the other women in the Marie Claire article also espoused motivations that are amongst the most prevalent ones expressed by men. Below I single out two motivations that are analogous, discussed in 8.3.2. and 8.3.3., namely a lack of complications and constraints (8.4.1) and a lack of success with men (8.4.2).

\subsubsection{Lack of Complications and Constraints}

The lack of complications and constraints is probably best highlighted by two telling quotations from the research by Carmen Caldas-Coulthard (Marie Claire, 1994).

"The only thing lacking in my life is regular and uncomplicated sex." (Yasmin, 44, a charity fund-raiser).

"The only way I could guarantee sex without involvement was to pay for it." (Barbara, 29, a hospital administrator).

\subsubsection{Lack of Success with Men}

Below I provide four statements by women on their lack of success with men, also taken from the research by Carmen Caldas-Coulthard (Marie Claire, 1994).

\footnotetext{
${ }^{14}$ Carmen Caldas-Coulthard.

${ }^{15}$ The reason given by the tenth woman was that her husband wanted her to do it (while he watched).

${ }^{16}$ The names of the women were, of course, changed for publication.
} 
"I have always been overweight and have developed a bit of a complex about it over the years. I've never really had a proper boyfriend - not one that lasted more than a few weeks anyway." (Lucy, 35, a housing officer).

"Finding a new man [after a breakup] seemed impossible." (Nicole, an art director).

"My husband hasn't made love to me for ten years." (Irene, 37, a housewife, describing lack of success with one particular man - the one she wanted.).

"I felt neglected by Colin's lack of interest in me." (Louise, 47, a doctor's receptionist - about her husband.)

A small but useful source of additional data on the reasons women pay for sex is the group of clients who consented to be interviewed for the documentary What Sort of Gentleman Are You After? ${ }^{17}$ Their comments revealed that, in addition to simply enjoying "good sex", by and large they are motivated by the same desire for a "lack of complications" that appeals to many johns ${ }^{18}$ :

"A mutual adult consent meet. No bullshit about it."

"It's a completely business transaction."

"The beauty I think of paying for it as opposed to picking up somebody is that I feel I didn't need I need to repay the favour. I didn't need to pleasure him. I could just lie there and absorb it all. If I'd wanted him to go down on me for the entire two hours then I could have said it and he would have done it."

"It is so much easier than having to go out and pick one up, and then if that's all you want you're left with him there and you can't get rid of him without being extremely rude."

"I tend to go for long periods without sex, basically. Not through choice, but through not finding anyone I fancy. So I find I end up in relationships for two or three months with complete arseholes just to have sex."

\subsection{The Future of Prostitution}

With women only recently beginning to swell the number of clients of prostitution, the world's oldest profession is currently thriving and showing every sign of continuing to do so. A recent study (Sexually Transmitted Infections, 2005) found

\footnotetext{
${ }^{17}$ See Chapter 8.2 .

${ }^{18}$ Other personal reasons given by Joel Ryan's clients in these interviews are: "He's very inventive sexually and that's why I keep seeing him - it's always fun, it's always something new." (i.e., the variety motive); "I find it quite exciting to pay for it. I find that quite sexy."; and "They've got to have something, a spark, and a big penis as well."
} 
that the number of men in Britain who have paid for sex had almost doubled between 1990 and 2000. Of 11,000 men interviewed in 1990, 5.6 per cent admitted to having paid for sex. By the year 2000 the figure was over 9 per cent.

I do not believe that this trend will continue forever. Robots will be able to satisfy the myth of mutuality for people of both sexes, to provide variety, to offer sex without complications or constraints, and to meet the needs of those who have no success in finding human sex partners. And for those women who are swelling the ranks of today's sex tourists, beautifully toned malebot bodies can be made to order, with whatever vital dimensions are desired. Chapter 9 describes the technologies which, when they are combined together, will create sexbots that can fulfil all of these needs.

When sexbots are available in large numbers, a cold wind is likely to blow through the profession, causing serious unemployment. As long ago as 1983 The Guardian reported that New York prostitutes "share some of the fears of other workers - that technology developments may put them completely out of business. All the peepshows now sell substitutes - dolls to have sex with, vibrators, plastic vaginas and penises - and as one woman groused in New York 'It won't be long before customers can buy a robot from the drug-store and they won't need us at all.',"

\subsection{Paid Sex Surrogates as Therapy}

More than 35 years ago William Masters and Virginia Johnson (1970) published their pioneering book on sex therapy Human Sexual Inadequacy. They had developed a successful method of treating sexual dysfunction by suggesting that patients be engaged physically rather than just verbally, thereby creating the basis for modern sex therapy. Their method was to work with the couple, teaching both partners about their bodies and their sexualities. In this book they also described their successful treatment of single men. The only difference between their couples method and the approach required to help single men, was that in the latter case the place of the woman in a couple was taken by a surrogate partner, thereby enabling men who did not have partners available, to participate in the Masters/Johnson couples therapy programs.

Surrogate therapy is a three-way process, with many of the sessions involving the client, the surrogate partner and the patient's therapist. It is the therapist who decides when the client is ready to work directly with the surrogate on their emotional and sexual problems, who introduces the client to the surrogate (with the therapist present), and who consults with the surrogate when the therapist feels the client is ready for intimate and private contact with her. And while the client is attending sessions with the surrogate he is still being counselled by his therapist, who is also in regular contact with the surrogate.

Lyman (2001) made the following comment in The Ethics of Sex Therapy. 
"Sex surrogacy isn't for everyone, but it seems that trying to resolve serious sexual dysfunctions just by talking them over is like learning to drive a car by reading about the history of automobiles. You have to practice."

The treatment process is designed to develop the client's skills at physical and emotional intimacy. All of the most common sexual dysfunctions and their causes can be treated by surrogate partner therapy. Of the following five issues (all applicable to men), three issues are also applicable to women: non-consummation of a relationship, performance anxiety, fear of intimacy; the other two being: premature ejaculation, and erection difficulties. The surrogate and the client typically progress through a series of "structured exercises in relaxation, introspection, communication, nurturing, and sensual and sexual touching" (Blanchard, 2001).

Sex surrogacy is bound to be controversial because it involves sex as a paid activity. But physical sexual activity is only a relatively small part of the surrogate's typical duties during the therapy process. Raymond Noonan (1984), whose MA thesis is the standard work on sex surrogacy, surveyed 54 sex surrogates and found that the average surrogate spends approximately 34 per cent of the session time talking with the client, in order to provide sexual information, reassurance and support. Almost half of the time ( 48.5 per cent) is spent on experiential exercises that involve the body but in a non-sexual way, teaching the client how to feel, how to be aware of the sensory input during sexual encounters. Only 13 per cent of the session time is typically spent on physical sexual activities: intercourse, oral sex, and sexual techniques.

In regard to the controversy that attaches to sex surrogacy, Noonan (2003) emphasizes that although "the use of surrogates remains controversial, with complex legal, moral, ethical, professional and clinical implications, (...), when performed under the supervision of a licensed therapist, [surrogacy] is completely legal throughout the U.S." And in the online magazine InnerSelf Barbara Roberts (2000) points out that "The fact that money is paid for the services of a prostitute, a sexual surrogate or a sex therapist is not the issue. We live in a society where monetary exchange for goods and services is the rule. The intent of those who insist on comparing sex surrogate assisted sex therapy with prostitution is to demean and discredit both. It is a reflection of our basically repressive culture regarding sexuality."

As a profession within the therapy profession, sex surrogacy has never taken off in a big way, though it does boast its own professional association, the International Professional Surrogates Association (IPSA) with its own code of ethics regarding the welfare of both client and surrogate. It appears that in 1977 Masters and Johnson abandoned the recommendation of sex surrogacy, most probably because of a severe nationwide lack of surrogates. Noonan (1984) estimated that in 1983-84 there were only about 300 surrogates practising in the USA, most of whom were in California and most of the others on the East Coast, but despite the small number this appears to have been a peak time for the profession, partly because of the subsequent fear of AIDS and partly because most therapists are afraid to recommend the use of sex 
surrogates to their clients in case of an eventual legal action should the client contract a sexually transmitted disease in the process.

One obvious application of sex surrogacy is in the initiation of young men into sex, a task that, in Europe at least, has often been the remit of a prostitute. Barbara Roberts (2000), who is a practising surrogate in California, has found that sex surrogacy has begun in a small way to take on this burden.

"In modern Western societies the messages about sex are extremely contradictory and confusing. We have no traditional rites of passage nor meaningful ceremonies to initiate young people into informed adult sexuality. I hoped that my work might establish standards that could help people of all ages have less confusion about sex and intimate relationships.

"Much to my professional satisfaction, there were several enlightened parents who paid for a full course of sexual surrogate assisted therapy so that their sons could be initiated into the wonders of their own sexuality. How lucky to have been those young men's girlfriends or wives! I often wished that parents would take that same enlightened view toward sexual initiation for their daughters, but it was not yet the time for that. I predict, however, that this day will eventually come."

Clearly sex surrogacy has great potential as a method of treatment, because of the caring, sensitive manner in which a good surrogate can approach the client's sexual problems. The UK Sexual Healing Centre in Bedfordshire ${ }^{19}$ has achieved a high degree of success in treating premature ejaculation, erectile dysfunction, and the inability to consummate a relationship, and a lesser though still significant improvement in resolving the underlying psychogenic ${ }^{20}$ causes of performance anxiety and fear of intimacy. But despite the proven benefits of surrogacy, the paucity of human surrogates currently militates against this form of treatment becoming mainstream. The solution to this problem should not be difficult for the reader to spot. It is to employ robots as sex surrogates, programming them with the necessary psycho-sexual knowledge, teaching skills and humanlike sensitivity.

Many people instantly dismiss the idea of paying for sex, often on the grounds that it is in some way immoral, or because of the commonly held view that only sex with someone who feels genuine affection can be a worthwhile and enjoyable experience. The purpose of this chapter has been to highlight a number of morally valid reasons why paying for sex can be justified, and to demonstrate that, for those who do pay for sex, whether frequently or rarely, it can be a positive experience even though they know that their sex object has no genuine feelings of affection for them. This indicates that those who consider experimenting by having sex with robots should have no qualms on the basis of the robot's presumed lack of affection for them. Even if their robot exhibited no affection, whether genuine or otherwise, this is no

\footnotetext{
${ }^{19}$ www.icasa.co.uk

${ }^{20}$ Causes that originate in the mind or in mental or emotional processes, rather than being of a physiological nature.
} 
reason to assume that the sexual experience will not be an enriching one for the human. And those who doubt the veracity of this assertion can find comfort in the knowledge that their robot will be able to exhibit affection for them at any desired level. It will all be in the software.

\subsection{Chapter Conclusions}

In this chapter, I have investigated the question: why do people pay for sex? I approached this question from two sides: (1) why do men pay for sex?; and (2) why do women pay for sex? On the first question there is a considerable body of publications, and it is difficult to condense their essence into a short statement. Nevertheless, to summarize my conclusions: men enjoy variety, an economic transaction without any "complications" (such as a relationship), and to a lesser extent to feel a measure of emotional closeness. For women the emotional closeness is more relevant, and they treat the economic transaction as love for sale rather than sex for sale. Payments for sex as part of therapy are of a different order; and are very much rarer than payments by men for pleasure and payments by women for love.

Four intriguing questions remain. Although they are beyond the scope of my thesis I will mention them as topics for further research.

(1) Can the introduction of sexual robots help to reduce the violence that is wrought on (young) prostitutes?

(2) Will the arrival of sexual robots render many people (women in particular) unemployed?

(3) Is it practically and scientifically possible to make an inventory of the factors that trigger an individual's sexual desires?

and

(4) Would a robot who is the perfect lover represent perfection as a partner? And if so, what is our vision of the future? 



\section{Chapter 9}

\section{SEX TECHNOLOGIES}

Our dolls feature completely articulated skeletons which allow for anatomically correct positioning, an exclusive blend of the most expensive silicone rubbers for an ultra-flesh like feel, and are each custom made to order, to our customer's specifications. We offer an extensive list of options, from body type and face type all the way down to fingernail color. If you've ever dreamed of creating your ideal woman, then you have come to the right place.

Realdoll Web site (Abyss, 2006)

Many readers will doubtlessly be somewhat sceptical of the prediction that by the middle of this century humans will be enjoying sex with robots. They may wonder how this might happen. Therefore I have included in this thesis my RQ7: what technologies are currently available to be used as the basis for sexual robots? This chapter is intended to be something of a proof of concept, describing the history of various types of sex machine and showing how these and other technologies will merge to create sophisticated sexual robots.

I would like to remark that the chapter focuses on the genital side of sex with little attention to kissing, hugging, sweet talk, and other foreplay activities. There are two reasons for this narrowing down of erotics to the gymnastics of sex. First, the computer developments in this area of research are currently in their infancy and continue from the mechanical developments of previous centuries. Second, many of the subtleties of foreplay require a refined and well-tuned psychosexual study, a field that is not yet explored deeply by artificial intelligence researchers.

It might surprise some readers that the history of dolls as lover substitutes dates back to the $19^{\text {th }}$ century. In section 9.1 you will be introduced to the earliest attempts at creating such dolls and other devices, in particular vibrators, designed to assist in achieving orgasm. In section 9.2 the popularity of vibrators is discussed and in section 9.3 vibrators for men are described. In section 9.4 I trace the evolution of sex devices to the much more sophisticated products of today, including dolls that can satisfy some people's sexual desires, and can do so sufficiently well to generate income for doll "escort" services in Japan and South Korea. The most advanced of the Japanese dolls are remarkably enticing, erotic, and life-like in their appearance, and judging from the demand they are surprisingly appealing in their sexual functionality. In section 9.5 we see that adding the technologies of virtual sex and the Internet creates an astounding mixture of sexual technologies. Section 9.6 describes some sexual inventions that have been the subject of patents. Section 9.7 is devoted to the relatively new domains of Virtual Reality and Teledildonics. Section 9.8 brings us to the forefront of technology by introducing haptic interfaces for teledildonic devices. Section 9.9 contains chapter conclusions. 


\title{
9.1 Vibrators Originated in the 1880s
}

Anyone who has doubts that women will find it appealing or even possible to receive the most incredible, amazing, fantastic orgasms by courtesy of sexual robots, should think again. Think vibrators. Below I describe the origin of vibrators and how they progressed towards general acceptance.

The electromechanical vibrator was invented in the early $1880 \mathrm{~s}$ as a means of fulfilling a task that hitherto had been accomplished by physicians, and before them by midwives. It had been recognized for at least two millennia, and described in medical texts going back that far, that women suffer from a variety of complaints particular to their sex, complaints that collectively went under the name "hysteria", the Greek for womb disease (Maines, 1999). It was also recognized that the most efficacious remedy for hysteria was to bring the patient to orgasm, a task that fell to the medical profession. In The Technology of Orgasm, a fascinating and comprehensive account of the history of the vibrator, Rachel Maines (1999) quotes a 1653 medical text by Pieter van Foreest that recommends the following.

\begin{abstract}
"When these symptoms indicate, we think it necessary to ask a midwife to assist, so that she can massage the genitalia with one finger inside, using oil of lilies, musk root, erocus, or similar. And in this way the afflicted woman can be aroused to the paroxysm ${ }^{1}$. This kind of stimulation with the finger is recommended by Galen ${ }^{2}$ and Avicenna ${ }^{3}$, among others, most especially for widows, those who live chaste lives, and female religious, as Gradus ${ }^{4}$ proposes; it is less often recommended for very young women, public women, or married women, for whom it is better to engage in intercourse with their spouses."
\end{abstract}

Why not simply recommend masturbation to women? A very good question. The answer is simply that sexual mores dictated masturbation to be a $\sin$, but it was fine when exactly the same act was performed by a midwife or physician!

Thus, for centuries, the manual massage of women's genitalia was a task frequently undertaken by doctors and midwives, though some physicians of the eighteenth and nineteenth centuries recommended instead horseback riding combined with up to three hours of massage, as a method whereby young women could achieve orgasm. All sorts of devices were devised throughout the centuries, in attempts to make this task easier and quicker to perform, many of them being manually operated waterpowered and steam-powered devices which required some measure of skill and effort by their operator. Furthermore, these devices were often heavy, unreliable and relatively inconvenient to use. Clockwork vibrators, for example, tended to run down rather quickly, and often just at the moment when the woman needed it most,

\footnotetext{
1 "Paroxysm" was a term formerly employed for orgasm.

${ }^{2}$ A second century Greek physician, the most famous physician in the Roman Empire.

${ }^{3}$ An eleventh century Persian physician.

${ }^{4}$ Gradus, also known as Giovanni Matteo Ferrari da Gradi, was a $15^{\text {th }}$ century Italian physician.
} 
while a steam-driven vibrator invented in the USA in 1869 was inconvenient for doctors to use because they repeatedly had to shovel coal into its boiler.

By the latter quarter of the nineteenth century physicians had pushed out midwives from this function, realising that bringing their female patients to "paroxysm" was a nice little earner that added to their regular incomes. It was then that serious demand grew for machines to facilitate the task. Many physicians devoted most of their working week to this task (Slade, 2000), and the number of women a doctor could service using a machine was significantly greater than the number he could cope with manually. Any physician whose consulting rooms boasted a vibration device for this purpose could therefore increase his turnover of patients and hence his income.

The successors to the clockwork and steam generations of vibrators were electrically operated and therefore considerably more effective than their precursors, and once they became available it was possible, through their use, for women to experience multiple orgasms. The first electromechanical vibrator was a battery-powered device invented in 1883 by Joseph Mortimer Granville, a British physician (see Figure 9.2). He had previously experimented with clockwork percuteurs ${ }^{5}$ (see Figure 9.1) "but except for the treatment of neuralgia - and in bad cases of that intractable malady - I do not recommend these instruments" (Granville, 1883).

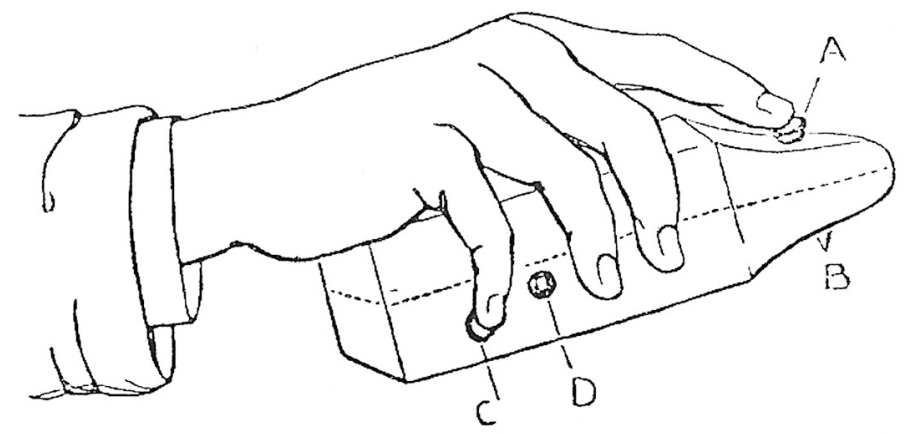

Figure 9.1: Granville's Clockwork Percuteur.

Granville's (1883) annotated drawing of his clockwork device is accompanied by a description of how it is operated. " $\mathrm{D}$ " is the winding-up pivot used to wind the clockwork mechanism. When the percuteur is wound, a pointed ivory hammer (B) makes percussive movements on the appropriate part of the body, though instead of the ivory point a flat-headed hammer or brush can be substituted. " $C$ " marks an ivory button - while this is pressed by the finger the hammer continues in action, and when the pressure is released the hammer stops. The other button, marked " $\mathrm{A}$ ",

\footnotetext{
${ }^{5}$ Hammers.
} 
causes the length of the stroke to be increased and the speed of vibration slightly reduced, while at the same time the force of the hammer blow is augmented.

Granville (1883) explains that "the percuteur worked by electricity is, in every way, superior to the clockwork instrument, except as regards portability. In consultingroom practice, the electric instrument answers every purpose most efficiently. The general practitioner will, however, need to provide himself with the clockwork percuteur for use at his patient's house; and, as I have said, although seemingly very weak in its blow, and troublesome, because it requires to be frequently wound, it is by no means ineffectual."

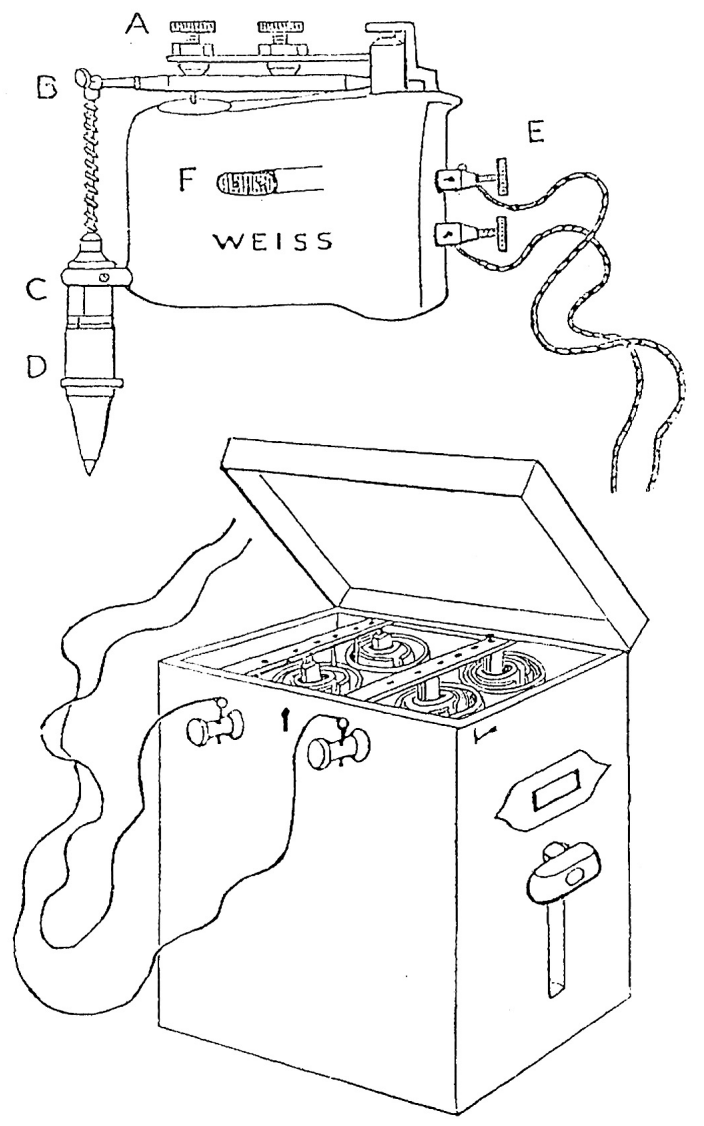

Figure 9.2: Granville's Electric Percuteur.

The electromagnetic version of Granville's percuteur went into production in Britain in 1889, manufactured by Weiss \& Sons Instrument Manufacturing Company (see Figure 9.2). The terminals of a battery were connected by cables to the vibration 
device at its terminals marked "E". "F" was the on/off button. Two screws, marked "A", could be adjusted to alter the movement of the hammer, for example by changing its rate of vibration. The screw marked " $\mathrm{B}$ " was for attaching different hammers and brushes to the instrument in order to create different sensations in the patient. "C" is a brass cylinder through which the rod of the hammer or brush passed. "D" was a tube, made of vulcanite", which was attached with a screw and which regulated the length of the stroke made by the hammer. Accompanying the instrument was a set of hammers and brushes of different shapes, sizes and purposes, as shown in Figure 9.3.

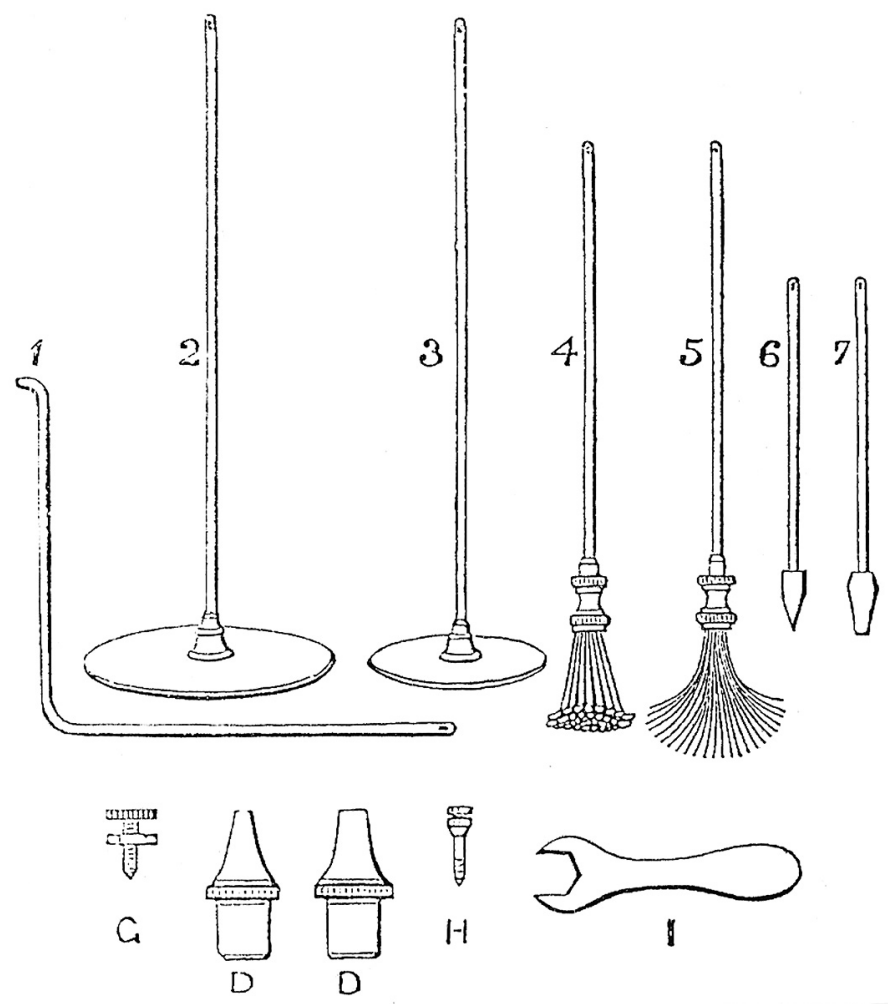

Figure 9.3: The hammers and brushes employed with the electric percuteur.

There is a bent hammer, marked 1, a large and a small disc (2 and 3), a hard brush (4) which Granville (1883) described as "very effective", a light brush (5) "for relief of superficial pain and to redden the surface", a pointed hammer (6) and a flatheaded hammer (7).

${ }^{6}$ A hard rubber. 
Granville (1883) went to considerable lengths to profess that his invention should not be employed as a means of sexual relief for women, but instead recommended that it be used only on the muscles of men.

"I should here explain that, with a view to eliminate possible sources of error in the study of these phenomena, I have never yet percussed a female patient, and have not founded any of my conclusions on the treatment of hysterical [fe]males ${ }^{7}$. This is a matter of much moment in my judgement, and I am, therefore, careful to place the fact on record. I have avoided, and shall continue to avoid, the treatment of women by percussion, simply because I do not want to be hoodwinked, and help to mislead others, by the vagaries of the hysterical state or the characteristic phenomena of mimetic disease ${ }^{8}$.

Granville (1883) further emphasizes his protestations in the Conclusion of his book.

"I do not, because I cannot, strongly urge recourse to the method in a considerable number of troublesome afflictions in the treatment of which I have not yet had any large experience of its use. Among these may be mentioned hysteria and the mimetic diseases, and disorders of the sexual organs, ..."

But in the very next paragraph, before going on to recommend the use of his instrument in the treatment of epilepsy, Granville (1883) admits "That the memetic diseases may be successfully treated by nerve-vibration, I have little doubt ...."

Thus, to all appearances, Granville (1883) was distancing himself from the suggestion that his invention could be employed for the sexual arousal and satisfaction of female patients. It does seem inevitable, however, that once Granville had mentioned these possible but nefarious uses of his invention, others would try out these uses. Cynics might therefore suggest that drawing the attention of his medical colleagues to these possibilities in his book was precisely what Granville intended with his description of how the machine functioned. Certainly the medical profession in the USA and other countries was quick to realise the delightful effects that the invention could produce in women, firmly establishing the vibrator as a must-have item for many. Those women who would frequently visit their doctor for sexual relief could now economize by purchasing a vibrator, since the cost was no more than that of a few visits to the doctor.

By the beginning of the twentieth century vibrator advertisements were appearing regularly in the press. Rachel Maines (1999) quotes an explicit advertisement for a \$5 vibrator from a 1908 issue of the National Home Journal.

\footnotetext{
${ }^{7}$ Granville's book has an unfortunate typographical error here - the word is printed as "males", though the text makes it quite clear that he intended it to be "females".

${ }^{8}$ Mimetic disease (a psychological complaint associated with mimicry) is a term often found linked to "hysteria" in nineteenth and early twentieth century medical writings.
} 
"To women I address my message of health and beauty (...). Gentle, soothing, invigorating and refreshing. Invented by a woman who knows a woman's needs. All nature pulsates and vibrates with life."
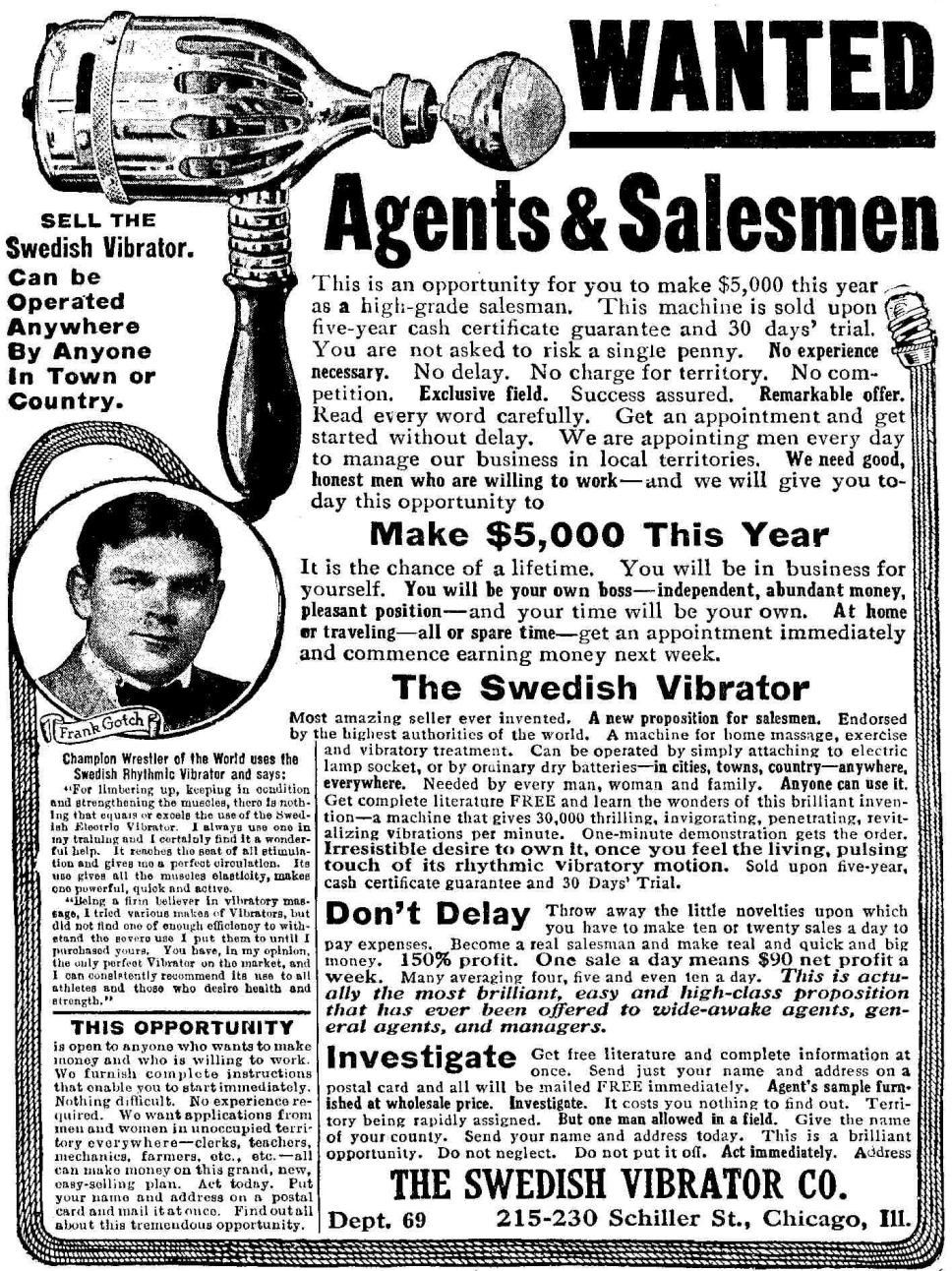

Figure 9.4: Advertisement from Modern Priscilla, April 1913.

A rival manufacturer, the Swedish Vibrator Company of Chicago, advertised its product (see Figure 9.4) in the April 1913 edition of Modern Priscilla as follows.

"(...) a machine that gives 30,000 thrilling, invigorating, penetrating, revitalizing vibrations per minute." 
In the USA there appears to have been something of a hiatus in the publicity given to vibrators from the 1930s until around 1970, but this might well have been due to a prurient attitude exerting its influence, rather than any reduction in their sale and use. By the early 1970s this attitude had largely worn itself out, and writers on sexual matters had become far less reluctant to extol the virtues of the vibrator. In addition, in 1952 the American Medical Association declared that hysteria is not really an ailment, and since the vibrator would then no longer be used as a medical device, it had to be acknowledged for its real purpose. Furthermore, the advent of 1960s feminism and the accompanying sexual revolution opened up whole new worlds of sexuality for women. Suddenly it was acceptable for women to demand more and better sexual gratification. Thereafter some writers on sex reported on the popularity of achieving sexual satisfaction with the aid of a soft-bristled electric toothbrush (remember Granville's "light brush"! - see Figure 9.3, item 5), but in her book The New Sex Therapy, Helen Kaplan (1974) expressed no doubts whatsoever, and wrote:

"The vibrator provides the strongest, most intense stimulation known. Indeed, it has been said that the electric vibrator represents the only significant advance in sexual technique since the days of Pompeii."

Clearly one of the strongest sexual trends of the twentieth century was for women to embrace electromechanical devices as an alternative and sometimes more reliable form of achieving sexual satisfaction. As the modern woman has taken an increasingly independent view of her absolute right to enjoy her sexuality to the full, so the vibrator has played an increasingly important role in satisfying women's sexual needs. With the advent of the Internet, advertisements can be made absolutely explicit - one company offering a product that gives "clitoral stimulation from 0 to approximately 6,000 oscillations per minute, and vaginal and G-spot stimulation from 0 to approximately 200 rotations per minute". Vibrator sales have soared, partly as a result of the ease and popularity of making purchases from behind the anonymity of the Internet, and in turn this increase in their popularity has made them respectable. In 2005 the largest British pharmacy chain, Boots, belied the traditions of the company's Methodist founders, announcing that it was planning to stock vibrators and place them on its open shelves with no embarrassment.

\subsection{The Popularity of Vibrators}

Although the vibrator has gained in market acceptance, there were many who believed and still believe the devices to be the epitome of obscenity. In 1998, for example, the state of Alabama amended its Obscenity Statute, making it "unlawful to produce, distribute or otherwise sell sexual devices that are marketed primarily for the stimulation of human, genital organs". So although the sale of Viagra was perfectly legal in Alabama, achieving sexual satisfaction through the use of certain other products was not. The penalty for a first offence could be a fine of up to US\$10,000, and/or 1 year in prison, or 1 year of hard labour. All this for reaching orgasm in a way that could bring no possible harm to anyone. 
Almost immediately after this amendment to the Alabama law came into force, and incensed by its stupidity, four Alabama women, with the support of the American Civil Liberties Union and a few vibrator retailers, filed a lawsuit against the state's Attorney General Bill Pryor, admitting that they had themselves used vibrators "either for therapeutic purposes related to sexual dysfunction, or as an alternative to sexual intercourse." The Attorney General argued that vibrators were obscene. The plaintiffs brought forward various expert witnesses, one of whom was Rachel Maines who testified by affidavit that, inter alia: genital massage technologies "have been available to the citizens of Alabama with or without medical advice and/or supervision, since before the Constitution was written"; that "the FDA 9 explicitly recognizes massage of the human genitalia as a legitimate therapeutic use of vibrators"; and that the "massage of the genitalia to orgasm has been used as treatment of female sexual problems since the time of Hippocrates, $5^{\text {th }}-4^{\text {th }}$ century $\mathrm{BC}^{10,}$ (Maines, 2001).

In deciding on the suit, the court supported Maines' arguments against the 1998 amendment, partly on the basis that obscenity, the very title of the statute of Alabama law, means something that appeals to "prurient interest ... shameful or morbid interest in nudity, sex or excretion." The court found that, if the law were to be upheld, then "users of these devices will be denied therapy for, among other things, sexual dysfunction", and that the law "interfered with the very sexual stimulation and eroticism related to marriage and procreation with which the State disclaims any intent to interfere." On this basis, on October $10^{\text {th }} 2002$ the court overturned the 1998 amendment to the Obscenity Statute, ruling that the law was "overly broad", that it bore "no rational relation to a legitimate state interest", and that it thus violated the Due Process Clause of the Fourteenth Amendment to the United States Constitution (Alabama, 2002).

So vibrator sales are now legal in Alabama within the confines of marriage, which is just as well because their sales are thriving there as everywhere in the USA ${ }^{11}$. But it is neither clear whether the pursuit of orgasm by artificial means would be ruled legal in Alabama for unmarried couples or for gay or lesbian couples, nor have I been able to discover any indication that any or all of Connecticut, Georgia, Louisiana, Massachusetts, Mississippi, Nebraska, South Dakota or Texas have yet repealed the similar laws to the Alabama statute that were on their books as of 1998. Bearing in mind the massive sales of vibrators, one can only assume that the law in those states is being broken by huge numbers of women (and even by men), a conclusion that many will find truly shocking.

In 2003, and undaunted by the Alabama Attorney General's convincing defeat in court, the State of Texas attempted to prove once again that the law is an ass, as reported by the San Francisco Chronicle (Rubenstein, 2003). I make no apologies for giving the quotation in full - I believe that the original text serves its purpose

\footnotetext{
${ }^{9}$ The U.S. Food and Drug Administration - the body responsible for controlling all things medical that are sold in the USA.

${ }^{10}$ The entire affidavit is available at http://www.libidomag.com/nakedbrunch/maines.html

${ }^{11}$ See below.
} 
better than I could with a paraphrase. The recentness of the report opens our eyes to the obstacles that still occur in this domain and might, furthermore, occur in the domain of my research.

"A Texas housewife is in big trouble with the law for selling a vibrator to a pair of undercover cops, and the Brisbane vibrator company she works for says Texas is an 'antiquated place' with more than its share of 'prudes'. Joanne Webb, a former fifth-grade teacher and mother of three, was in a county court in Cleburne, Texas, on Monday to answer obscenity charges for selling the vibrator to undercover narcotics officers posing as a dysfunctional married couple in search of a sex aid. Webb, a saleswoman for Passion Parties of Brisbane, faces a year in jail and a $\$ 4,000$ fine if convicted. 'What I did was not obscene,' Webb said. 'What's obscene is that the government is taking action about what we do in our bedrooms.'

"The arrest of Webb in Cleburne, a small town 50 miles southwest of Dallas, was the first time that any of the company's 3,000 sales consultants have been busted, said Pat Davis, the president of Passion Parties. She said the company was outraged by the charges and stood behind Webb. 'It makes you wonder what they're thinking out there in Texas,' Davis said. 'They sound like prudes, with antiquated laws. They must have all their street crime under control in Texas if they're going to spend tax money arresting us.'

"For the past year, Webb has sold the company's line of vibrators, gels, lubricants, strawberry-flavored nipple cream and 'edible passion puddings.' The merchandise is offered for sale in private, Tupperware-style parties, to women who may be reluctant to visit an adult novelty store. Among the company's top items are a $\$ 12$ jar of passion pudding in chocolate and strawberry flavors ('apply head to toe, wherever you want your lover to linger'), a $\$ 9$ jar of nipple cream in strawberry, raspberry and watermelon flavors, and battery-powered vibrators that sell for $\$ 17$ to $\$ 140$. The company also offers such lubricants as Slippery Stuff (\$13), Lickety Lube (\$12) and Lucky Stiff (\$11.50), and a \$22 battery-powered item for men known as Jelly Julie ('with soft jelly silicone lips').

“ 'Our products are not obscene.' Davis said. 'All we're trying to do is help people build loving relationships.' Webb suspects she got in trouble because she ruffled feathers in town by daring to join the Chamber of Commerce with her sex toy business. She said her arrest had caused her husband of 20 years to suffer a nervous breakdown.

"Webb said she was amazed that the town's narcotics squad would be put on the case. 'We have a real problem with drugs in our schools,' she said, 'and they're using our narcotics officers to entrap me for selling a vibrator." 
“Joanne Webb's troubles were not limited to her being arrested and charged. A few prominent citizens in her home town of Burleston, citizens with strong Christian beliefs, not only lodged the complaints with the local police that led to her arrest, they also created trouble for Webb and her husband at local churches, two of which asked the couple to leave. Gloria Gillaspie, a pastor at Lighthouse Church in Burleston explained that 'They didn't want to comply with what was really Christian conduct and that is why they were asked to leave those churches." "'

Webb was duly charged under a Texas law that allows the sale of sexual toys so long as they are billed as novelties, but when someone markets sex toys in a direct manner, showing their sexual role, then under that same law that person is subject to obscenity charges. Webb's lawyer, BeAnn Sisemore, described the Texas obscenity laws as being "so vague that they could be used to prosecute anyone who uses or sells condoms designed to provide stimulation for sexual pleasure" (Rubenstein, 2003). Fortunately a Texas judge had the good sense to dismiss the case in July 2004, before it could go to trial and waste more of the taxpayers' resources.

The above case was something of an exception, but for the people involved it was difficult to handle. In order to present a broader picture, I now provide some statistics that give an insight into the actual increase of the use of vibrators during recent decades.

In 1976, as few as one percent of the American population used vibrators, but in 1982, only six years later, 25 percent of Cosmopolitan readers confessed to doing so. More recently, the day after a particular model of vibrator was used by Charlotte on Sex and the City, stores across North America were sold out of the item (Concordia, 2004). Even those women who have never used one to bring themselves to orgasm, cannot deny the popularity of vibrators, which are being purchased in increasing numbers both on the Internet and in retail stores ${ }^{12}$. So the sales of vibrators are booming. The UK's leading sex shop chain, Anne Summers, sold 2.5 million in 2004. In Australia 1 million are sold per year, with 8 million already purchased by early 2005. Americans, in 2001, were estimated to be buying 12.5 million vibrators every year, to add to an estimated 50 million plus that were already

\footnotetext{
1227 per cent of all those who responded to the 2004 Durex Global Sex Survey and who answered its question on the ownership of vibrators, said that they did own a vibrator or an intimate massager. The figure was even higher in both the 25-34 and 45-plus age groups, with more than one-third of respondents being owners. The survey also found, not surprisingly, that vibrators are more popular with women than with men, but did not address the question of how many of the male owners used their vibrators on themselves and how many reserved their use for female partners. As to which countries were shown by the survey to have achieved the highest market penetration for this product category, Iceland led the way with 52 per cent of those surveyed, followed by Norway with 50 per cent, the UK with 49, USA and Sweden both 43, Australia 42, Denmark 41, and China 40 per cent. (The lowest usage was found to be in Thailand and Vietnam, with 6 per cent and 5 per cent respectively.) The statistic for the USA is broadly in line with the results of a survey amongst more than 1,600 American women, conducted by Knowledge Networks, an independent polling and market research firm in California. Their survey results were published by The Berman Center and indicated that 51 per cent of women in the 25-34 age group had used a vibrator, reducing to between 41 and 46 per cent in most other age groups and to 32 per cent in the 55-60s (Berman, 2004).
} 
in the bedrooms of American women at that time ${ }^{13}$, and by 2005 annual sales had risen to an estimated 30 million plus (Good Vibrations, 2005).

It is not difficult to understand why vibrators have become so popular with women. The reasons are succinctly, if somewhat dryly, explained in a 1996 paper published in the Journal of Sex Research (Davis et al., 1996), which summarized the opinions of women who used them.

"A majority indicated orgasms triggered by vibrator stimulation were more intense than others. Nearly half experienced multiple orgasms when using a vibrator. Most were very satisfied with their orgasmic experience in autoerotic activity and were either moderately or very satisfied with their orgasmic experience in partnered activity."

\subsection{Vibrators for Men}

No matter what use is made by men of female vibrators, the differences between the male and female genitalia obviously call for sex toys for the boys that are different from those made for women.

The first two patented devices designed to help in providing sexual relief for men were both the product of German inventiveness in the early 1950s. The very earliest was the Gymnastikapparat (Gymnastic Appliance) designed by Emil Sprenger of Munich, who applied for a patent for his device in May 1949 and had it granted in November $1951^{14}$ (see Figure 9.5).

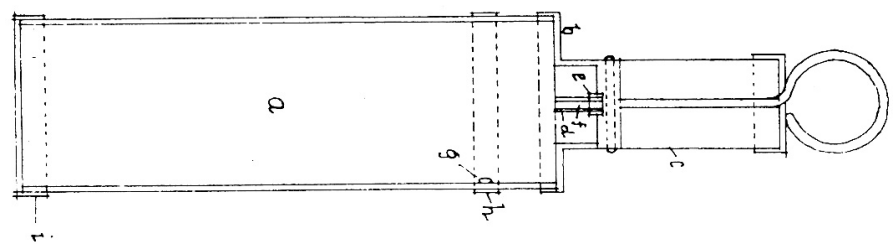

Figure 9.5: Emil Sprenger's Gymnastic Appliance.

\footnotetext{
${ }^{13}$ According to the web site www.cakenyc.com

${ }^{14}$ German patent number 825,137. Sprenger's invention consisted of a hollow cylinder made of glass or some other material, to which an air evacuation device such as pump could be connected at one end. The purpose of the invention was described as being to overcome sexual impotence in men, which according to Sprenger's patent application is nearly always based on an inadequate blood supply to the erectile tissue of the penis. To operate the device the penis was inserted and the air sucked out of the cylinder by the pump, thereby creating a vacuum inside the cylinder. The resulting excess pressure forced the blood corpuscles into the erectile tissue, causing an erection. Springer admitted that on first use, the erection may weaken when the container is removed, but he claimed that after repeated use the erection would persist.
} 
Following closely on Sprenger's heels came Ernst Raeder and Ludwig Hanemann with their Massageapparat zur Behebung acuter nervös-muskulärer Schwächeerscheinungen (Massage Device for Relieving Acute Nervous Muscular Debility Symptoms), for which the patent was granted in February $1952^{15}$ (see Figure 9.6). The symptoms to which the patent title refers are those "arising specially during sexual intercourse".

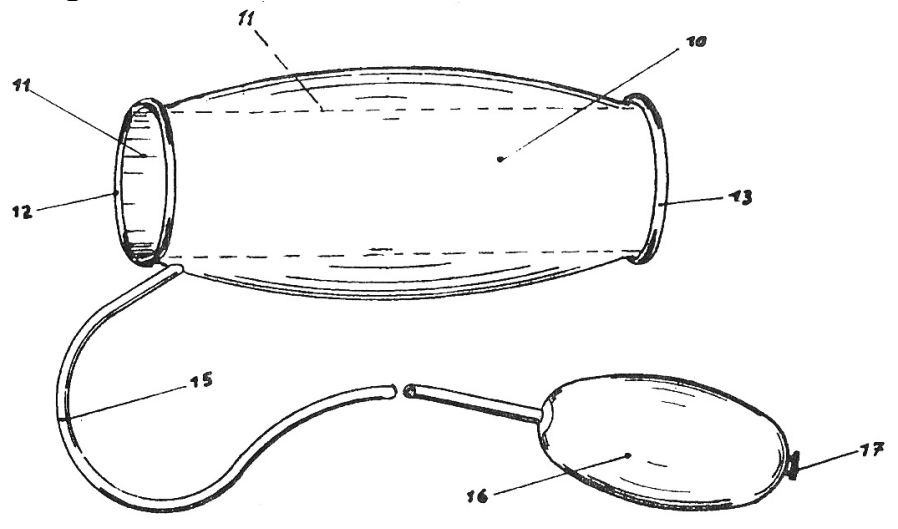

Figure 9.6: Ernst Raeder and Ludwig Hanemann’s Massage Device.

The first such device developed in the New World appears to be a bagel-shaped penis ring invented in 1966 by Cesareo Barrio of San Leopoldo, Brazil (Figure 9.7).

The ring was actually a pneumatic or hydraulic chamber with flexible walls. Connected to this chamber by a tube was a pump arrangement that alternately supplied and withdrew fluid from the chamber, thereby causing the walls of the

\footnotetext{
${ }^{15}$ German patent number 835,637 . The invention was a sleeve made of a watertight and highly elastic material such as rubber, which had a double wall containing sufficient compressed air to the extent necessary for the sleeve to preserve its own shape. To use the device it is moderately inflated and then slipped over the penis "before commencement of the sex act. The erection which initially occurs is maintained by pumping an appropriate quantity of air into the inner space (marked 14 on the drawing) by means of the rubber bulb (marked 16). . . . On suitable repeated use of the device, this pressure massage at the moment of erection causes a noticeable invigoration of the weakened muscles, so that in due course the massage device will become unnecessary. The desired therapeutic effect is further enhanced by suitable massaging when not performing intercourse."

Clearly there would be immense practical problems for a man wearing this device on his penis while entering and moving inside his partner and simultaneously operating the rubber bulb in order to maintain his erection. In fact these difficulties seem so overbearing that one wonders whether this description of the use of the device was not merely a sop to distract prudish German patent officers, and whether the intended purpose of the invention was, perhaps, as a sex machine, human partner not required. This scandalous suggestion might explain the inventors" enthusiasm in recommending "suitable massaging when not performing intercourse".
} 
chamber to expand and contract, squeezing and relaxing whatever might be in the bagel hole ${ }^{16}$.

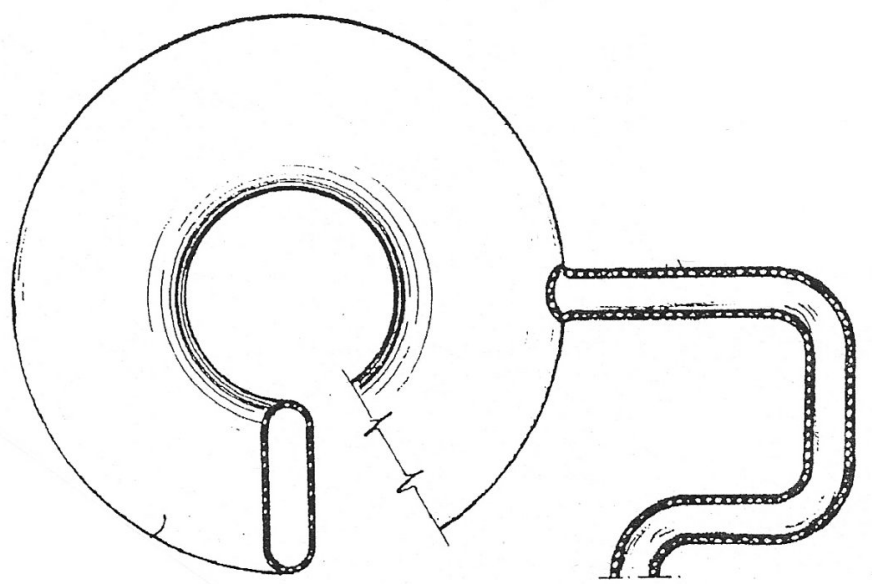

Figure 9.7: Cesareo Barrio's sex bagel.

In 1972 a Dutch inventor, Robert Trost, developed a "technological partner" designed to enable the physically handicapped, of both sexes, to "attain complete sexual orgasm in an inconspicuous way" (Heslinga, Schellen, and Verkuyl, 1974). The system, called the Coïtron, comprised electrodes that attached to the handicapped person's genitals, and which allowed for the adjustment of a pulse generator by means of knobs on a control box. The system was battery operated, both for portability and for "psychological (fear of electrocution) reasons". By the end of 1972 a working prototype was offered to medical and rehabilitation specialists for further research and testing, and initial results on non-handicapped men and women were said to be very encouraging. A doctor Bakker experimented with the Coïtron and wrote his Ph.D. thesis on the basis of these experiments. But the system was never mass produced because of "the taboos on handicapped people enjoying private sex (i.e., masturbation) which last until today, even in free thinking Holland." (Trost, 2005).

Another device designed to excite any penis was a gripping system patented by Peter Sobel of Miami Beach in 1975. This invention came with attachments covered "with a soft yieldable material, such as rubber or fur" for gently stroking the penis. "The gripping arms of the first and second gripping members are placed on opposite sides of a male genital organ ${ }^{17}$ and one side of the three-way switch is depressed. The variable speed motor is energized to cause the first and second gripping members to oscillate back and forth and thereby stroke the male genital organ.

\footnotetext{
${ }^{16}$ Barrio's patent document does not make any mention of the word penis or any other part of the anatomy. Instead it merely devotes two-and-a-half lines, less than one-fiftieth of the entire text of the patent, to reveal that "One of its principal applications is that of an auxiliary means for the achieving of sexual intercourse in the case of people who are old, paralysed etc."

${ }^{17}$ Another patent application that avoids use of the $\mathrm{P}$ word.
} 
Again the speed at which the first and second gripping members reciprocate backand-forth can be gradually adjusted."'(Sobel, 1973) ${ }^{18}$

None of these patented inventions designed for men ever reached commercial viability ${ }^{19}$. But although the vibrator was invented with women in mind, and sales of vibrators to women heavily outnumber sales for men, this imbalance has begun to show some signs of a revolution. Since the 1990s vibration devices have come onto the market designed specifically for men, for example the Venus range which was launched in October 1993 (see section 9.5) from the manufacturer of the SYBIAN sex machine described later in this chapter (also in section 9.5).

A more recent idea, combining penis vibration with synchronized stimulating videos, was launched in December 2004 on the web site Virtual Sex Machine $N e w s^{20}$, which displays as its banner headline "The Future of Virtual Sex". The site presents an image of what it described as "The Newest Virtual Sex Machine", one that was first announced on the Martin Sargent programme Unscrewed on the Tech TV Network in the USA. This is a suction device with an interface that responds to the activity on screen, allowing the user to watch videos of women porn stars while fantasizing that the women are participating with them in the action. The physical experience generated by the device is thus linked to the visual action by the women, giving the user the virtual reality experience of having a sexual liaison with a porn star. The operating instructions, as posted on the manufacturer's Web site, represent the height of simplicity.

"Step 1: Put the machine on your penis

Step 2: Choose any of the girls

Step 3: Sit back, relax, watch and FEEL IT!"21

\subsection{Fornicatory Dolls}

The sexual life of sailors has never been an easy one. Living and working as they used to do in an entirely male environment, their trips ashore to the red light districts of various ports provided just about their only female sexual comfort. Wives and

\footnotetext{
${ }^{18}$ Yet another invention from the 1970 s, with a very similar purpose, was a "massaging apparatus", patented in 1976 by Ulrich Glage and his wife Gisela, of Hamburg, Germany. The Glages' invention "relates to a device or apparatus for massaging elongated part of the human body, and especially for applying massage to stimulate and enhance the ability for erection." It consisted of a vibrating plastic tube lined with flesh-like rubber that would fit around the entire length of a penis and would operate autonomously or with the added help of the human hand. "The invention provides an apparatus for massage comprising an elongated hollow cylindrical sheath having one closed end and so designed that the outside of the sheath is connected to a vibrating device containing means for the simultaneous generation of two different mechanical vibrations."

${ }_{19}$ All these and some 800 other sex devices are described in Hoag Levins' 1996 book American Sex Machines: The Hidden History of Sex at the U.S. Patent Office, a history spanning 150 years of sex inventions.

${ }^{20}$ Available at www.vrinnovations.com

${ }^{21}$ Their emphasis, not mine.
} 
lovers at home could only rarely be visited, so long were the voyages to and from the ships' destinations on other continents. Hence the need for dames de voyage (travelling woman) as the French called them. In Austro-Germany they were known as "sailors' sweethearts". These were dolls in the female form, most often made of cloth and used as sexual outlets by sailors on board ship (see Figure 9.8).

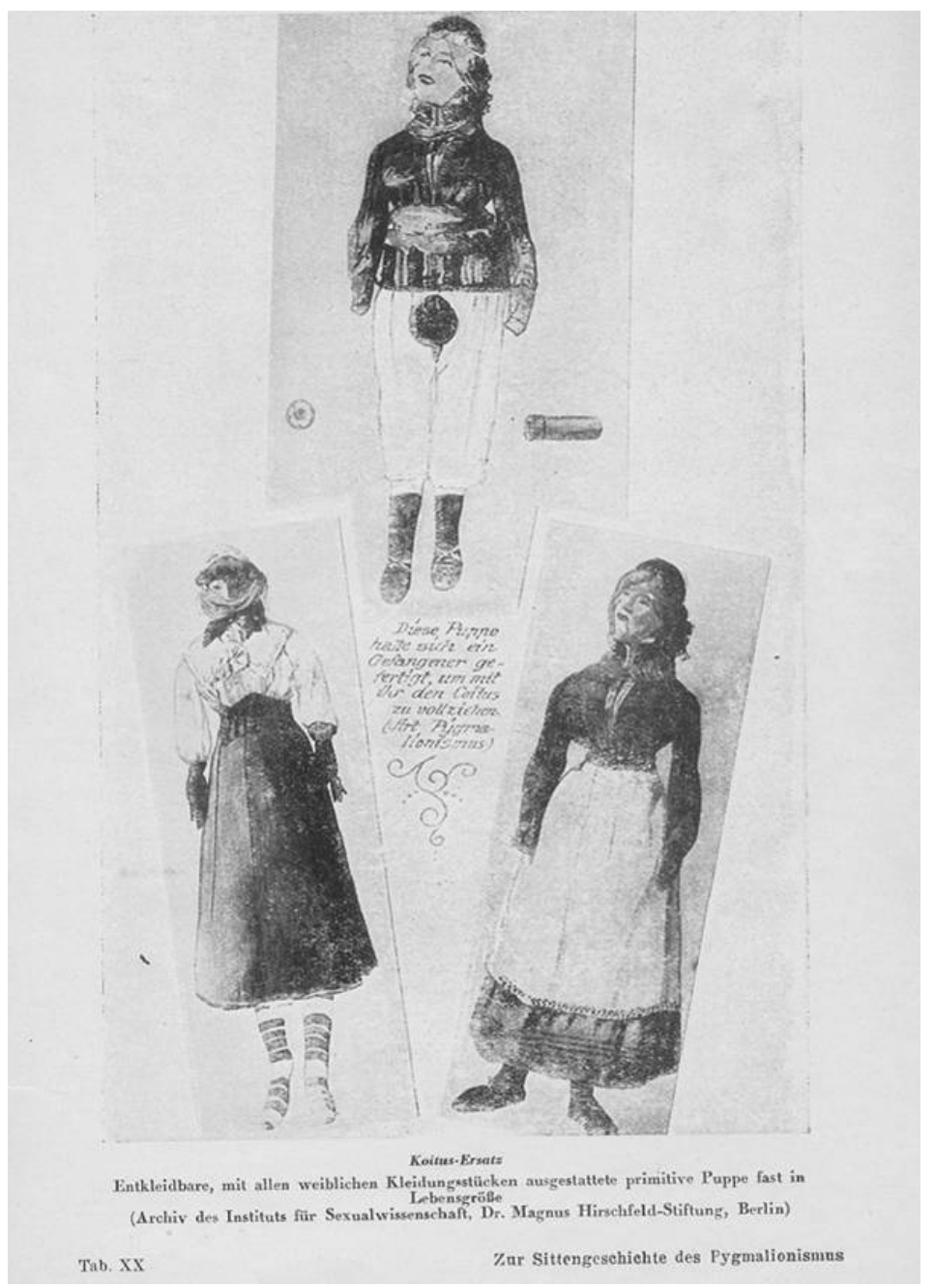

Figure 9.8: A sex doll, from the archives (since destroyed) of Magnus Hirschfeld's Institute of Sexual Studies in Berlin.

Sex dolls of a less primitive form gained a certain measure of popularity in late $19^{\text {th }}$ century France ${ }^{22}$. Henry Cary (1922) privately published Erotic Contrivances: Appliances Attached to, Or Used in Place of, the Sexual Organs, a book in which he

${ }^{22}$ See also Bloch's description in section 7.1. 
reproduces and briefly discusses two French advertising circulars, one selling artificial vaginas (see Figure 9.9) and the other an entire artificial man or woman. Again the quotations are given in full (with no apologies), in order to emphasise that the development of artificial sexual agents investigated as part of my research has some respected predecessors. The essentials of Cary's description of the first circular read as follows.

"There is manufactured and sold in Europe today an imitation of the female private parts, even to the pubic hair. These are inflated to give them the desired amount of tightness to the vagina and they are deflated and folded up after using. Circulars describing them usually call them lady travellers, and recommend them for the use of naval officers and others who are deprived of female society for long periods of time. They also advertise that upon receipt of photograph, height, weight and other necessary data, a complete woman will be manufactured to order.

"A French circular describes the articles as follows:

\section{'Woman's Belly or Artificial Vagina'}

"Giving the man the perfect illusion of reality and procuring for him sensations as sweet and voluptuous as those from the woman herself. Outwardly the appliance represents the belly without the thighs. The secret parts, the mount of Venus, covered with abundant and silky hair, the greater lips, the smaller lips, and the clitoris offer themselves to the covetous gaze with rosy colours and temptations as delicious as the pussy of a woman herself.

"In the interior the vagina has wrinkles or folds which embrace and provoke the ejaculation of sperm. The contact is soft and agreeable and the pressure is regulated at will by a pneumatic tube. There is also a lubricating apparatus that is filled beforehand with a warm and oily liquid, and which, under pressure floods the vaginal interior in the same way as the feminine glands secrete at the psychological moment.

"The woman's belly, with lubricator, it is the only apparatus representing exactly the generative organs and capable of giving the effect of reality.

"It can be inflated and deflated at will, and can be folded up and placed in the pocket as easily as a handkerchief.

The complete apparatus: 100 francs

Superior quality: $\quad 150$ francs 


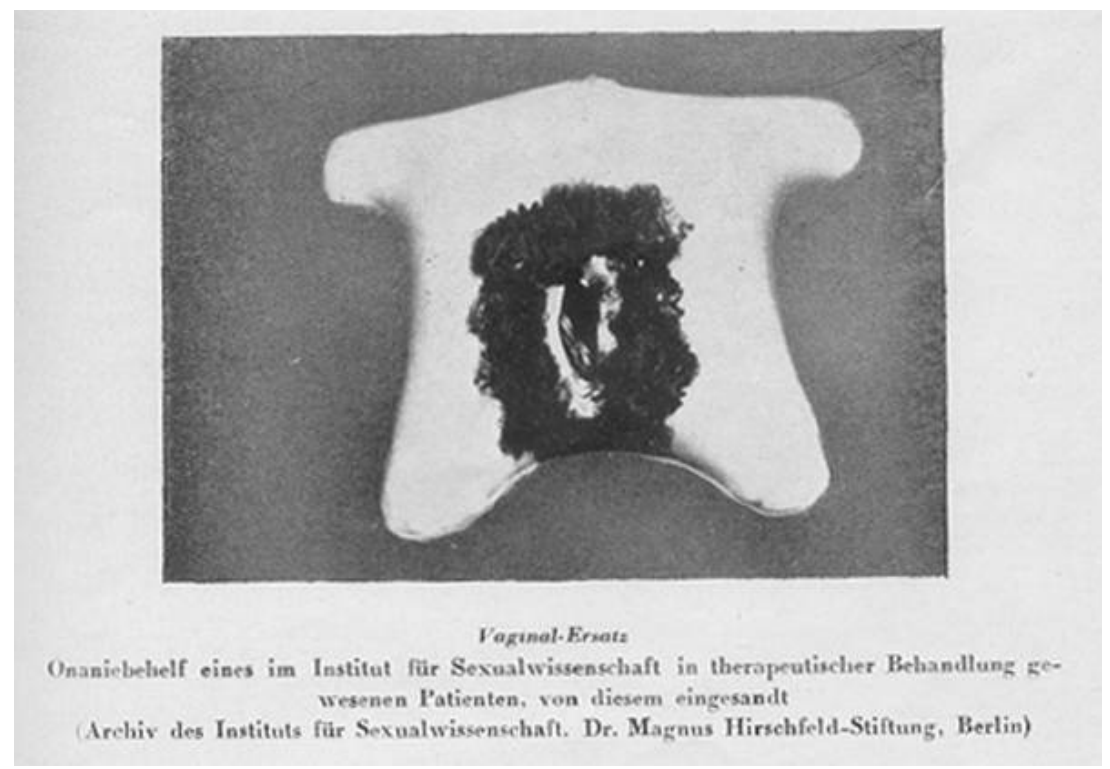

Figure 9.9: An artificial vagina, from the archives (since destroyed) of Magnus Hirschfeld's Institute of Sexual Studies in Berlin.

The essentials of the second circular are given below.

"Other advertisements offer to furnish a complete rubber man, with member of any size desired, and with clockwork mechanism which enables it to perform as desired. Also a woman's torso with generative organs as described in the circular just quoted; also, an entire woman. The latter is made to order, upon receipt of a photograph and measurements, color of hair, and other details, and a perfect likeness is guaranteed, as follows:

\section{'Complete Body, Artificial Man or Woman'}

"All moves, arms, legs, buttocks, head, eyes; a perfect likeness of the person whose photograph is sent. The body in action moves like a living being, pressing, embracing, changing position at will by a simple pressure. The mechanism which gives life to the apparatus is very substantial and cannot get out of order. The complete apparatus, guaranteed against breakage, man or woman, 3000 francs.

"This apparatus can be fitted with a phonographic attachment, recording and speaking at will - man, 3250 francs; woman, 3500 francs.

"In sending photographs of the subject, be sure to give us the height, details of the figure, size of the breasts and buttocks, color of the hair, with sample if possible, and in a word all the information necessary to enable us to complete the figure in an irreproachable manner." 
Cary (1922) explains that the articles referred to are sold generally throughout Europe, and the fact that the circulars noted come from Paris does not indicate that the French have any monopoly on the traffic. The great bulk of pornographic articles and literature and obscene photographs sold in Europe come from Germany and Austria, the latter country furnishing the most artistic and expensive varieties and Germany, as usual, the cheaper ones.

The popularity of these primitive sex dolls in Europe gave some well-off men the idea of having a doll made in the image of their own lover, past, present or hopedfor. This idea appealed to a few of the surrealist and avant-garde artists of the 1920s, one of whom was Oskar Kokoschka who had conducted a difficult three-year affair with Alma Mahler, wife of the composer. After their relationship ended, Kokoschka had a life-sized doll made in Alma's image by the Munich doll maker Hermine Moos, to whom he had provided a detailed description and some drawings of how he wanted the doll to be made (Alma-Mahler, 2005).

"On my drawing I have broadly indicated the flat areas, the incipient hollows and wrinkles that are important to me. Will the skin - I am really extremely impatient to find out what that will be like and how its texture will vary according to the nature of the part of the body it belongs to make the whole thing richer, tenderer, more human? Take as your ideal... Rubens' pictures of his wife, for example the two where she is shown as a young woman with her children. If you are able to carry out this task as I would wish, to deceive me with such magic that when I see it and touch it imagine that I have the woman of my dreams in front of me, then dear Fräulein Moos, I will be eternally indebted to your skills of invention and your womanly sensitivity as you may already have deduced from the discussion we had."

Kokoschka bought dresses and lingerie from the best shops in Paris in order to dress the doll, and revealed that when the trunk containing the doll arrived and was being unpacked, his butler became so excited that he had a stroke. But whether Kokoshka actually used the Alma doll for sexual relief appears extremely doubtful, as the doll apparently failed to fulfil his erotic and sexual desires and in the end became no more than a kind of still-life model which, in his frustration, he destroyed by decapitating it in his garden during a party. He wrote that a Venetian courtesan asked him if he slept with it, but his writings did not answer the question.

Another sad ex-lover who did use a lifelike doll as a sex surrogate is amusingly described by Hedy Lamarr (1966) in her autobiography. Lamarr was an Austrianborn film actress whose appearance in her second film, Ecstasy, which she made in Czechoslovakia in 1933, shot her to stardom at the age of 20. This was not because of her acting performance but because she appeared in a nude swimming scene, creating an immediate sensation in Europe and promptly getting the film banned in the United States. Louis B. Mayer was so impressed with her looks that he called her "the most beautiful girl in the world", and took her to Hollywood in 1937 where she embarked on a series of affairs and six marriages that contributed to the considerable unhappiness of her private life. 
In Ecstasy and Me: My Life as a Woman, Lamarr (1966) describes how, when she had discarded Sam, one of her rich lovers, he fell into emotional desolation because their relationship had ended, and had

"a full-sized plastic-rubber doll made to look exactly like me - nude! ... The hair looked real, the colouring was accurate (even to the make-up). It had nail polish on the toes as well as the fingers. The figure had obviously been contoured with exquisite care. There was an indecent accuracy to the breasts."

Lamarr (1966) goes on to explain how she witnessed Sam using his doll, which he named "Hedy-the-Inferior", a use that seemed to provide him with some measure of sexual comfort.

"Sam laid Hedy-the-Inferior on the bed, right in the blue spot.

'Do you love me, darling?' he asked, moving right onto it. He touched those life-like legs, and didn't stop there. I tell you, his master craftsman had included every part of my body.

Sam commenced moving up and down. 'Am I hurting you?' he breathed solicitously, 'does it feel nice?'

Insane as it was, I couldn't take my eyes off the blue spot!

He was panting, in rhythm. 'I love you, I love you, I love.' Faster. 'I love you,' he exclaimed one last time - 'do you love me'

I blushed in supreme embarrassment. I knew what was going on the instant he asked that question ...

And then he was just quivering and whispering to the doll in the blue light.

Finally, he collected himself. He kissed those lips, 'Thank you darling, you were wonderful. I hope I didn't mess your hair. I know you want to go out tonight ...,"

Despite speculation that the Germans and the Japanese manufactured sex dolls for their armed forces during World War II, no genuine examples appear to have been documented during that period ${ }^{23}$, but in the mid 1950 s a sex toy for men was marketed, under the name "Bild Lili" (Strangelove, 1998). Based on a lewd cartoon character that was popular in Germany at that time, Bild Lili is said to have inspired Ruth Handler in her design for the original Barbie doll.

\footnotetext{
${ }^{23}$ An article posted on the Internet by Norbert Lenz in 2005 gave an account of "the world's first sex doll", a project initiated by Heinrich Himmler during World War II, with the idea of satisfying the sexual urges of the German troops in France while at the same time keeping the troops away from the disease ridden prostitutes with whom many of them consorted. This article was taken up by other Web sites and subsequently published by the German newspaper Bild and in at least one Scandanavian newspaper. Rather than being of any historic interest, most of the article was merely an "April Fool" hoax, and Norbert Lenz is most likely a pseudonym. What I find most interesting about this article's publication is that many people believed it, demonstrating that, in 2005, there was already a significant measure of belief in the viability of sex robots.
} 
By the early 1980s blow-up sex dolls were becoming quite big business in some countries but were viewed as obscene in others. In 1982 David Sullivan, a British sex entrepreneur ${ }^{24}$, attempted to import from West Germany a consignment of inflatable rubber dolls. When inflated these became life-size replicas of a woman's body, complete with the usual three orifices to provide male customers with sexual gratification. The dolls were seized by the British Customs and Excise as "indecent or obscene articles" and their seizure was upheld in the condemnation proceedings before magistrates and on appeal to the Crown Court. But Sullivan's company, Conegate Ltd., then appealed to the High Court in Britain and, having lost that appeal as well, Conegate appealed yet again, this time to the European Court of Justice, where finally the company won the case in 1987. It turned out that the English law prohibiting the import of the dolls, which dated from 1876, had been superseded by Articles 30 and 36 of the 1957 Treaty of Rome, the document signed when the European Economic Community was created. Under the terms of the treaty, restricting the import of the dolls into the UK would have constituted an arbitrary barrier to free trade, and it was free trade that the treaty was specifically designed to promote. The major consequence for the British government of losing this case was that all import restrictions on "obscene or indecent" items had to be lifted!

The paucity of published information on the history of sex dolls makes it extremely difficult to date the launch of the first products that appeared on the market in commercially interesting quantities, though the Conegate case indicates that it must have been no later than 1982. Cynde Moya's comprehensive 2006 Ph.D. thesis, Artificial Vaginas and Sex Dolls: An Erotological Investigation, implies that it could have been in the 1960s and 1970s, though no quantities from that period are given. Since the mid 1990s at least, various grades of sex doll have been manufactured, ranging from inexpensive inflatable welded vinyl models, whose looks leave much to be desired but who incorporate an artificial vagina - the main purpose of their customers; through mid-priced products made of heavy latex and with convincingly moulded hands and feet, imitation eyes in glass or plastic, and styled wigs adorning their mannequin-like heads; up to the top-of-the range products which, in 2006, cost in the region of $\$ 7,000$, such as one of the market leaders in this price range RealDoll (Laslocky, 2005).

It was in 1996 that Matt McMullen, a Californian sculptor, revolutionized the sex toy industry when he launched "Nina", the first of a range of products sold under the RealDoll brand name by his company Abyss Creations. McMullen had previously worked in a Halloween mask factory, making innocent sculpted female forms in his spare time as a sideline. These were mostly small figures, about 12 inches tall, made of resin and sold as models. With time he began to make larger dolls and to use materials that were softer to the touch. He also designed a skeleton in order to allow his dolls to have limbs that could move (Laslocky, 2005).

\footnotetext{
${ }^{24}$ In the 1970s Sullivan spotted a gap in the soft port market and has since built a \$1 billion media empire that includes the newspapers Daily Sport and Sunday Sport.
} 
When McMullen started to advertise his dolls with photographs on his Web site he received several enquiries from people who believed his products to be sex dolls. When he explained to them that they were wrong, the enquiries changed to asking him if he would manufacture sex dolls, a group of visitors to his site offering him $\$ 3,000$ each for ten dolls. So he quit his job at the mask factory, developed a silicone material that could be employed to make the doll's genitalia durable and feel right, and by 1996 he was in business (Laslocky, 2005).

The RealDoll products are lifelike in appearance as well as being life-sized and close to life-weighted. The nine different body sizes advertised on the RealDoll site in early 2006 ranged from 5 feet 1 inch tall to 5 feet 10, they weighed in at between 70 and 100 pounds, they offered busts from 34A to 44FF, waists from 22 to 26 inches and hips from 34 to 38. Other options on offer included fourteen different female heads, each with their own name: Amanda, Angela, Anna Mae, Brittany, Celine, . . .; seven shades of hair colouring; six different colours for the eyes; fair, medium, tanned, Asian or African skin tones; and red, blonde or brunette pubic hair that can come shaved, trimmed or "natural". The dolls are based around articulated skeletons made of steel, artificial elastic flesh made of silicone, and they come with three functioning "pleasure portals" - vaginal, oral, and anal. Each female doll is thus custom made, with the buyer being able to choose from more than 500 million permutations of these various options (Abyss, 2006).

In addition to the fourteen female models on offer early in 2006, one model of a male doll was also available. It was named Charlie - 5 feet 10 inches tall, with a 44 inch chest, 32 inch waist, and a stocky body. Charlie was priced at $\$ 7,000$ plus shipping charges, and could be provided with "anal entry if desired, plus one size of penis attachment", size not specified. The female RealDolls at that time were slightly less expensive, at $\$ 6,500$, and the company was talking of sales in the region of 300-350 per year (Laslocky, 2005).

RealDoll is by no means the only American brand on the market. A Californian rival company, CyberOrgasMatrix, uses a different body material - an elastic gel which the manufacturers claim is stronger and more realistic than silicone, as well as being less expensive. Their principal product is the "Pandora Peaks" model which, like RealDoll, comes with numerous options. Customers pay according to which options they choose so that, for example, while vaginal and oral entries are standard, anal entry costs an extra $\$ 250$. Yet another Californian manufacturer is SuperBabe, whose doll is modelled on the porn star Vanessa Lace (SuperBabe, 2006).

The number of sex doll manufacturers is increasing steadily, as are the Web sites that sell them ${ }^{25}$. And not to be outdone by the growing band of American producers, companies in China, Germany, and Japan have been getting in on the act. In Nuremburg, Germany, an aircraft mechanic, Michael Harriman (Ananova, 2005), claims to have created the world's most sophisticated sex doll, called Andy, with skin made from a silicon-based material employed in plastic surgery, an artificial

\footnotetext{
25 A comprehensive range of sex dolls and other sex machines is shown, for example, on www.fuckingmachines.com
} 
heart that beats harder during sex, in time with the doll's harder breathing, and it has internal heaters to raise its body temperature, apart from its feet which stay cold just as in real life. Andy can be made to move by remote control, wiggling her hips under the bedclothes and making other suggestive movements, all at the touch of a button. The price is similar to that of the RealDolls but there are additional charges for special modifications such as extra large breasts. Harriman (Ananova, 2005) claims that his dolls "are almost impossible to distinguish from the real thing, but I am still developing improvements and I will only be happy when what I have is better than the real thing."

A wide range of Chinese offerings are available online and in sex shops, at prices ranging from $\$ 50$ to $\$ 250$, as described by Meghan Laslocky (2005).

"Sweet Spot: A Taste of Things to Come, a catalogue from Hong Kong, lists nearly 70 different models of blow-up doll, including saucy Sondrine, whose hair, nipples and genitalia glow in the dark; Betty Fat Girl Bouncer, to satisfy the chubby chaser; Brandi Sommer, with "super vibrating LoveClone $^{\mathrm{TM}}$ lips"; and The Perfect Date, which is just 36 inches tall and is equipped with a mouth and cup holder built into her head. There's even a dairy maid doll who lactates and has short blonde braids reminiscent of Swiss Miss. Some of the blow-ups vibrate and, oddly enough, scream."

Thus have the sexual lives of sailors, amongst others, been enriched with the advances in doll design and materials technology, advances that have created realistic skin-like substances such as "cyberskin" 26 and that have thereby made the current generation of sex dolls more comfortable to use than earlier models. That sailors are still avid users of such products is of little doubt, and provided an interesting example of their use that was described by Ellen Kleist and Harald Moi (1993). This report involved the skipper of a fishing trawler from Greenland. After some three months at sea, the skipper had had occasion to rouse the ship's engineer in his cabin during the night because of engine trouble. After the engineer had left his cabin to sort out the problem, the skipper observed a bump in the engineer's bed, whereupon he found an inflatable doll with an artificial vagina, and was tempted into using it in order to assuage his sexual starvation. A few days after this episode the captain experienced a discharge from his penis, and upon the trawler's return to port in Greenland he sought advice at a hospital in Nanortalik. There had been no women on board the trawler while it was at sea; the skipper denied having had any homosexual contacts; and there was no doubt in the minds of the hospital doctors that the onset of the symptoms occurred more than two months after leaving port, which meant that the source had to have been on board the trawler. The engineer was then examined by the hospital doctors and found to have gonorrhoea. He had observed a mild discharge from his own penis after the ship left port but had not been treated with antibiotics. He admitted having ejaculated into the vagina of the doll just before the skipper had called on him, without washing the doll afterwards. He also admitted having sex with a girl some days before the trawler had put to sea.

\footnotetext{
${ }^{26}$ Cyberskin is a natural feeling material that mimics human flesh. It is formed by combining silicone and latex.
} 
Kleist and Moi's (1993) account in Genitourinary Medicine ${ }^{27}$ suggests that this was the first reported case of the transmission of gonorrhoea through an inflatable doll.

In Japan, sex dolls are referred to as "Dutch wives"28. A report by Dacapo ${ }^{29}$ journalist, Mark Schreiber (2004) reveals how Dutch wives have their own special place and treatment within the confines of Japanese culture, with discarded dolls having the opportunity of funereal rituals redolent of the virtual cemeteries devised for "dead" TAMAGOTCHIs (see section 5.5). Again, I reproduce the quotation rather than paraphrase the article, in order to retain its essence. (I assume that the reader will concur with me on this.)

"Hideo Tsuchiya, president of Orient Industry Co., specializes in the design and manufacture of life-size mannequins [see Figure 9.10]. The dolls serve as sex substitutes for widowers, the handicapped and other males who are able to function sexually but who, for whatever reason, lack human partners.

"A Dutch wife is not merely a doll, or an object. She can be an irreplaceable lover, who provides a sense of emotional healing. Speaking at his showroom near JR Okachimachi Station, where some two dozen of Orient Industry's ersatz females are displayed, Tsuchiya tells Dacapo's reporter that for years his clientele had typically been handicapped men, or single men over 40. But from around six years ago, when he commenced sales via the Internet (www.orient-doll.com), he was mildly surprised to receive a surge of orders from men in their 20s and 30s.

"To heighten the lovely dolls' appeal, the showroom models are dressed (or undressed) to kill, some clad in designer fashions and wearing Bulgari wrist watches, others in flimsy negligees. 'Please, go ahead, touch one', Tsuchiya urges. 'Vinyl or silicon[e] $]^{30}$ can be used, but we use high-grade silicon[e],

\footnotetext{
${ }^{27}$ A journal devoted to the branch of medicine dealing with the reproductive and excretory organs.

${ }^{28}$ According to an entry in Wikipedia, "their name originates from the term, possibly English, for the thick rattan or bamboo bolster, used to aid sleep in humid countries by keeping one's limbs lifted above sweaty sheets". Other Internet postings suggest that these bolsters could also be in the form of an open frame, constructed of cane, and were originally used in the Dutch East Indies where they were [disparagingly] called Dutch wives because they were round and fat and just lay there. But the most authoritative explanation for the origin is found in Alan Pate's 2005 book Ningyō: The Art of the Japanese Doll: they were originally leather dolls carried aboard Dutch merchant ships, beginning in the seventeenth century, and through their interaction with the Dutch on the trade island of Deshima, established by the Dutch East India company in 1641, the Japanese became familiar with the practice. Pate's own source for this origin was Mitamura Engyo's book Takeda Hachidai - Eight Generations of the Takeda Family.

${ }^{29}$ Dacapo is a Japanese news digest, with a focus on current event feature stories.

30 Silicon and silicone are different substances, often confused by the less technically minded in the sex doll industry. Tsuchiya said silicon but meant silicone, which is a particular type of chemical compound containing silicon. Silicones are stable over a wide range of temperatures, they are extremely water repellent, physiologically inert, and they are used, inter alia, in protective coatings, synthetic rubber and prosthetic replacements for body parts.
} 


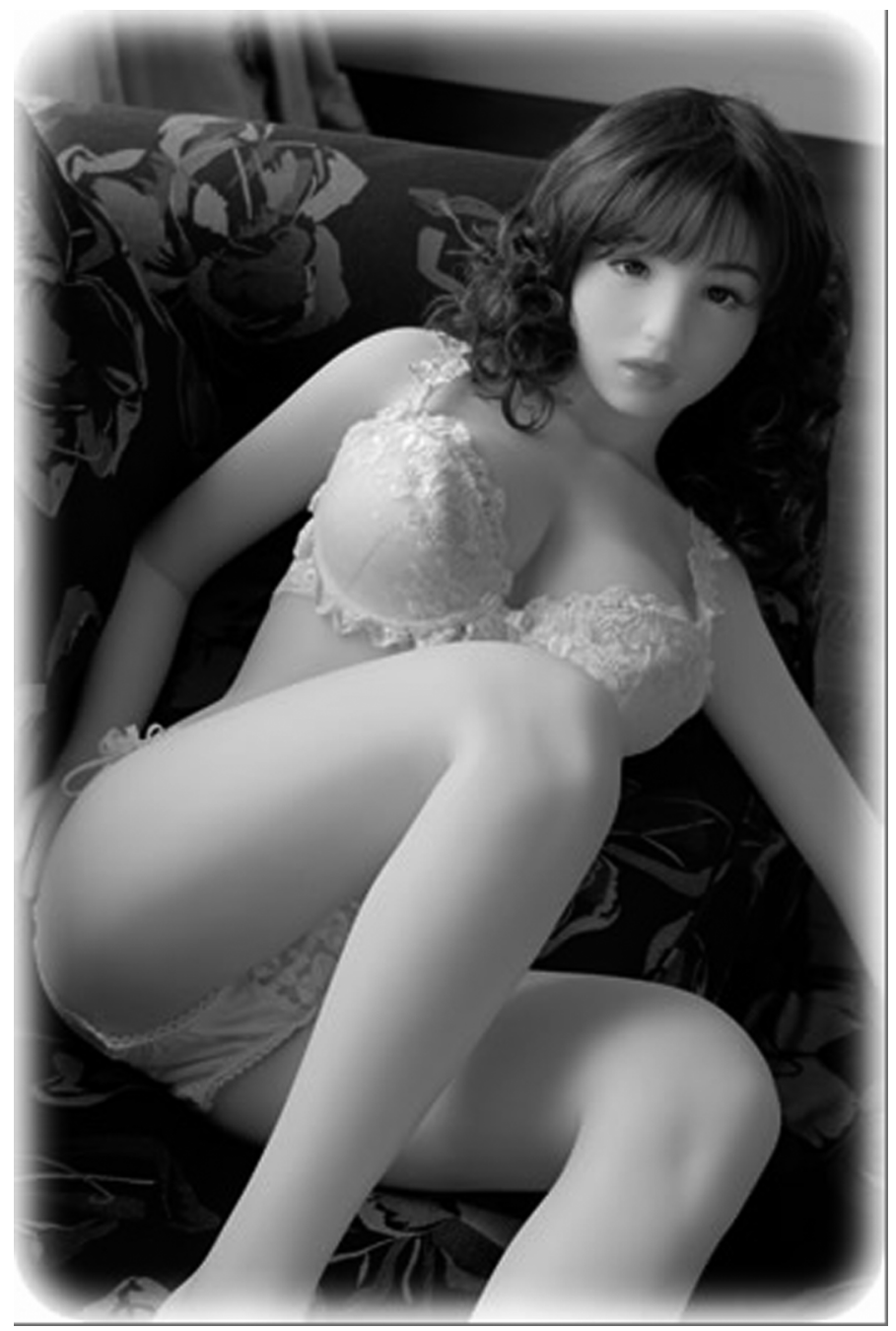

Figure 9.10: One of the dolls manufactured by Orient Industry.

which gives a texture close to human skin. The feeling is completely different from the inflatable type.'

"The latest best seller, named 'Jewel', went on sale three years ago. Two years in development, Jewel stands $140 \mathrm{~cm}$ tall and weighs $26 \mathrm{~kg}$. No seams are visible where the limbs or head join the torso. 'We've made the body more pliant, and the legs will open wider', says Tsuchiya. Perfecting the process required considerable investment in equipment but has paid off, as Orient Industry has already sold about 600 dolls, despite Jewel's hefty price tag of 600,000 yen [roughly $\$ 5,000]$. 
“' 'What do you think of her? Isn't she cute?' beams Tsuchiya, eyes twinkling with obvious pride.

“ 'When I ran my hand along the doll's thigh', confesses Dacapo's reporter, 'I felt a shiver of excitement.' After observing the painstaking effort that goes into the making of each doll at Orient Industry's factory, the reporter came away enlightened. 'Many people might be inclined to disparage sex toys', he writes, 'but these dolls truly exemplify Japan's status as a high-tech country!'

"Jewel and her sisters are shipped to purchasers in cardboard boxes stamped kenko kigu (health apparatus), and users are assured of lifelong after-service. As the vow 'until death us do part' may be stretching things a bit, the company anticipates a time when Jewel might outlive her usefulness or her owner. 'If a yome [bride] is no longer needed, we'll discretely take her off a customer's hands at no charge', Tsuchiya adds. 'Twice a year we also arrange for a kuyo (Buddhist memorial service) for discarded dolls at the special bodhisattva for dolls at the Shimizu Kannon$d o$ in Ueno Park'. Founded in 1631, it's where the 'souls' of dolls are consecrated. (Kannon is the Goddess of Mercy.)

“ 'This devoted treatment', says Tsuchiya, 'is out of deference to his customers' frequently close emotional attachment to their Dutch wives. Which may not necessarily be a bad thing.' When Tsuchiya reads of a teacher or policeman nabbed for molesting a woman, or perverts who hold girls in extended confinement, he sighs to himself, 'If only they had owned one of our gals, they wouldn't have committed such a crime!',"

The marketing of RealDolls and their cousins from other manufacturers tends to be based on the idea that they are "the perfect woman", perfect because they are always ready and available, because they provide all the sexual benefits of a human female partner without any of the complications involved with human relationships, and because they make no demands of their owners, with no conversation and no foreplay required. It is precisely because of these attributes, the dolls' lack of "complications" and demands, that they will likely appeal to many of the men who gave such explanations as to why they pay prostitutes for sex, and to others who have similar feelings about their sex lives at home. So already, in this promotional slant, we can see the basis of the idea that men who use prostitutes should save up their dollars or yen until they can afford a RealDoll. I believe that this will happen in a big way, and that the New York hooker who feared that robot technology would decimate her profession (see section 8.5) will be proved correct. In Japan this is already beginning to happen with the fembot's far less technologically sophisticated ancestor, the sex doll, as described by Ryann Connell's article Rent-a-doll Blows Hooker Market Wide Open (2004).

"Several companies are involved in the bustling trade supplying customers looking to slip it into some silicon[e], with lifelike figurines that set back buyers something in the vicinity of 600,000 yen (about $\$ 5,000$ ), as opposed 
to the simple, blow-up types with the permanently open mouths that can be bought from vending machines for a few thousand yen. Prime among the sellers of silicon[e] sex workers is Doll no Mori, which runs a 24-hour service supplying love dolls, or 'Dutch wives' as the Japanese call them, to customers in southern Tokyo and neighboring Kanagawa Prefecture.

\section{$(\ldots)$}

"Doll no Mori charges start at 13,000 yen (around \$110) for a 70-minute session with the dolls, which is about the same price as a regular call girl service. The company boasts of many repeat customers and a membership clientele topping 200. "Nearly all our customers choose our two-hour option. There're plenty of things you can do with the dolls, like take photos of them. Some customers also prefer the six hours a week option.' Kimura says. 'It's probably cheaper for most of our customers to go out and buy their own dolls, but when you think of problems like storage and maintenance, then renting them is probably better.'

"Doll no Mori's four dolls are called Alice, Ai, Mayu and Tina, with the doe-eyed Alice, who closely resembles a little child, by far the most popular of its love doll call girls. Incidentally, though the dolls each have different heads, their bodies are all the same, with exactly the same proportions [see Figure 9.11].

"Doll no Mori is even a fully fledged, registered trader within Japan's sex business. 'We registered under the requirements of the law regarding adult entertainment' said Kimura. 'The cops couldn't stop laughing at us.'"

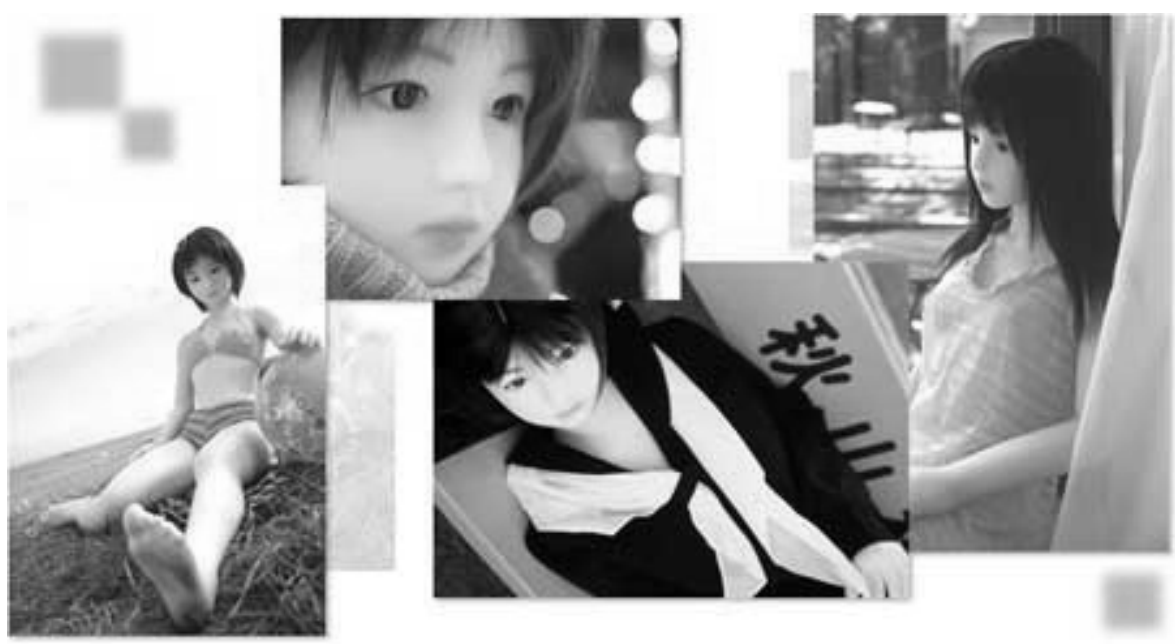

Figure 9.11: The four Doll no Mori “workers".

Within little more than a year of the sex-doll-for-hire idea taking root in Japan, sex entrepreneurs in South Korea also started to cash in. Upmarket sex dolls were 
introduced to the Korean public at the Sexpo exhibition in Soeul in August 2005, and were immediately seen as a possible antidote to Korea's Special Law on Prostitution that had been placed on the statute books the previous year. Before long, hotels in Korea were hiring out "doll experience rooms" for around 25,000 Won per hour (\$25), a fee that included a bed, a computer to enable the customer to visit pornographic web sites, and the use of a doll. This initiative quickly became so successful at plugging the gap created by the anti-prostitution law that, before long, establishments were opening up that were dedicated solely to the use of sex dolls, including at least four in the city of Suwon. These hotels assumed, quite reasonably, that there was no question of them running foul of the law, since their dolls were not human. But the Korean police were not so sure. The news web site Chosun.com reported, in October 2006, that the police in Gyeonggi Province were "looking into whether these businesses violate the law .... Since the sex acts are occurring with a doll and not a human being, it is unclear whether the Special Law on Prostitution applies."

The sex doll industry is still in its infancy and still very much catering for the desires of men, as demonstrated by the fact that, of the fifteen models offered on the RealDoll Web site, fourteen are made in the likeness of women and intended for sale to men, while only one is modelled on a man. A likely reason for this disparity, though not the only reason I am sure, is that RealDoll's "Charlie" typically sells for $\$ 7,000$, and there are far fewer women than men who have thousands of dollars of readily disposable income. But an alternative explanation that has been put forward for the disparity is one with which I strongly disagree - the suggestion that far fewer women than men are interested in using artificial means for getting some or all of their sexual stimulation and for achieving orgasm. Many women claim that the use of sex dolls is very much a "guy thing", but surely such a claim is easily refuted by the widespread use of vibrators amongst modern women.

\subsection{Sex Machines}

The first commercially available sex machine properly capable of simulating intercourse, and still the most prominent of such machines on the market, was the SYBIAN $^{31}$ (see Figure 9.12), the brainchild of David Lampert, a former dance instructor in Illinois. In an interview with Jessica West (1987), Lampert explained what inspired him, in the early 1970 s, to devise his robotic penis.

"Over the years, I kept hearing the same complaints from women I met in my dance instruction classes. They were sexually frustrated. Their partners could not, or would not, satisfy them. Some said their husbands had erectile problems due to ill health, age, or indifference. Some of these women confided that they had never experienced an orgasm. That struck me as tragic. I personally could never enjoy sex if the woman is not satisfied."

\footnotetext{
${ }^{31}$ The machine was named after Sybaris, an ancient city of the Greek empire that was built on what is now the Gulf of Tranato in southern Italy. The city became wealthy and its inhabitants were reputed to enjoy lives of unrestrained sensual pleasure, providing the origins of the word sybaritic.
} 
Lampert's idea became a passion and an obsession. In 1985 he sold his dance studio business to devote himself full-time to the development and marketing of what, at that time, was a revolutionary product.

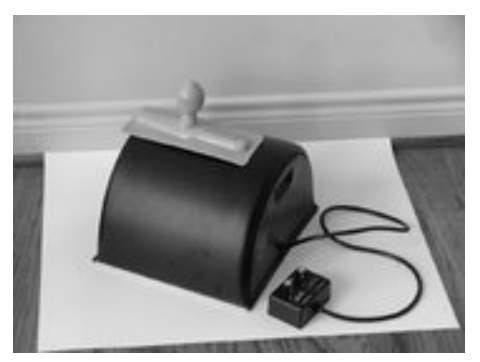

Figure 9.12: A SYBIAN machine with one of its inserts on the top.

The SYBIAN consists of a saddle-like seat, containing an electric motor to generate the motion of the machine's phallic "insert". (The inserts come in different sizes and thicknesses, and are removable for cleaning.) The SYBIAN is designed to create two separate movements. The insert rotates within the vagina, and at the same time the area of the SYBIAN that makes contact with the vulva vibrates, as does the phallic insert itself.

The SYBIAN is straddled by the woman, who lowers herself onto it when the insert is in place. Separate controls allow for the independent control of the speed of vibration and the speed of rotation. As the SYBIAN's insert rotates within the vagina, the internal area including the Grafenberg Spot (more commonly known as the Gspot) is stimulated. At the same time the entire vulva and clitoral area vibrates. The combination of these movements is designed to create a crescendo of orgasms.

After some 15 years in its development, the SYBIAN was launched at Couples 87, a weekend convention for sexually uninhibited couples held in St Louis in the spring of that year. Jessica West (1987) describes her reaction on first sight of the machine.

"All eyes were focused on a realistic rubber penis mounted on a vinyl seat. The penis was simultaneously rotating and vibrating at incredible speed. Those were movements no human male could possibly duplicate, at least for any length of time. Just watching that "thing" gyrate made me instantly wet and horny."

Lampert realised that, in order to convince potential buyers of the joys of using his machine, the best method of promotion would be to give women the opportunity to try it out in private, which he did in his hotel suite during the Couples 87 weekend. But before the private sessions began he gave a demonstration to the trial group as a whole, with their husbands/partners present, in which one of the potential customers had volunteered to be the guinea-pig. Jessica West (1987) describes what happened after Sally had lowered herself slowly onto the SYBIAN's insert. 


\begin{abstract}
"When she was fully seated, Lampert began the demonstration, turning the controls on low speed at first, and then gradually increasing the intensity of both the vibration and the rotation. Sally's face began to contort - first with mild pleasure, then with growing disbelief, and eventually with complete abandon. Her litany of moans and screams, her nails digging into poor Dave Lampert's back, gave ample evidence that she was in the throes of extreme orgasmic excitation. At one point I thought she was going to faint. 'Oh, God, oh no, oh yes, don't stop, harder, faster, oh wonderful', she intoned again and again. A communal sigh went up - almost like a communal orgasm. After about 20 minutes of this, it became obvious that Sally could go on coming forever. When Lampert finally turned the machine off, I thought it was probably because his back couldn't take any more. Sally continued to shudder from head to toe for several moments. As she raised herself back on her legs, I could see that her knees were weak. A cheer went up from the crowd, and Sally's husband gently helped her over to a couch. She smiled at her audience like a victorious long distance runner who had reached the finish line, and thanked Lampert for the experience. 'All I want to know is, when can I do this again?' "'
\end{abstract}

Encouraged by his initial commercial success with the SYBIAN, Lampert branched out by developing a sex toy for men, an electrically powered "hands free masturbation aid with controllable stroking action, that gives powerfully satisfying orgasms", and which allows the user to "achieve an orgasm in minutes or enjoy sensual stroking for hours". This device was first marketed in October 1993, under the name Venus II, and was later renamed the Venus 2000. The advertising description of the device suggests that it is easy to use: "Simply insert yourself into a lubricated, flexible, natural gum rubber liner", switch on the machine, adjust the stroke speed between 8 strokes and 300 strokes per minute, and adjust the stroke length. The company's advertisements point out the obvious benefits of the machine, including that it is "always ready, no partner needed and no risk of disease". Custom fit attachments can also be provided. These include a "pump" - a recreational vacuum device that pulls blood into the penis, thereby creating a fully engorged penis from a flaccid state or enhancing an existing erection. Another optional extra is a "head massager", described as an erotic foreplay device that creates a squeeze-release action wherever it is placed.

While the SYBIAN is perhaps the best known of its ilk, there are now many other machines on the market for simulating intercourse. This is hardly surprising in view of Kim Airs' estimate that, in 2005, there were 75,000 sex aids on the market, accounting for almost one quarter of the $\$ 12$ billion taken by the adult entertainment industry per year in the U.S.A. ${ }^{32}$ A different type of machine, with a more thrusting movement of the phallic component, has been the choice of a number of manufacturers, creating products that go under names such as STALLION, INVADER, PROBE PLUS and THRILLHAMMER.

\footnotetext{
${ }^{32}$ Airs' enthusiasm for the proliferation of sex aids is perfectly understandable - she quit a research position at Harvard in 1993 to found Grand Opening, a woman's sex toy store, where sales in 2005 were running at around $\$ 1$ million in each of her two branches.
} 


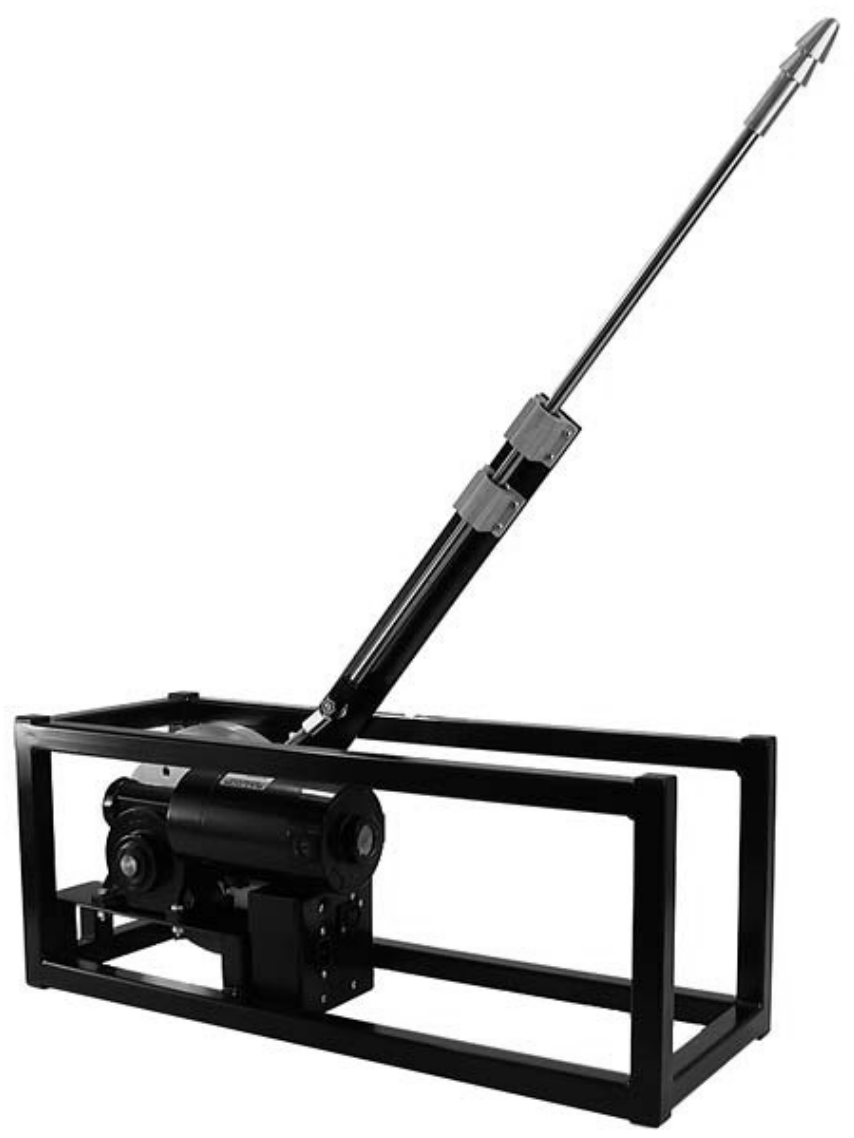

Figure 9.13: A STALLION sex machine.

Figure 9.13 shows a STALLION which, apart from being electrically powered, bears a remarkable similarity in appearance to the Onanierapparat für Frauen (masturbation machine for women $^{33}$ ), shown in Figure 9.14, which was built in Germany between the two world wars. This particular example of the machine had been confiscated by the German police, and at one time there was a specimen exhibited in the Dresden Criminal Museum ${ }^{34}$. Criminal? Yes, that's right. Certain sexual practices were illegal in Germany during the early part of the twentieth century $^{35}$.

\footnotetext{
${ }^{33}$ Also called the "female self-gratifier".

${ }^{34}$ This image appears on page 604 of the Sexualwissenschaft (Sexology) volume of Bilder-Lexicon (1930), a German illustrated encyclopaedia that described itself as "a reference work for all areas of medical, legal and sociological studies into sex".

${ }^{35}$ Strangely enough these included the offence of copulation with a statue, which was "classified as a misdemeanour (a public nuisance coupled with indecent exposure) and also claimed compensation in the form of a fine (if the statue was damaged or 'sullied')". (Tabori, 1969)
} 


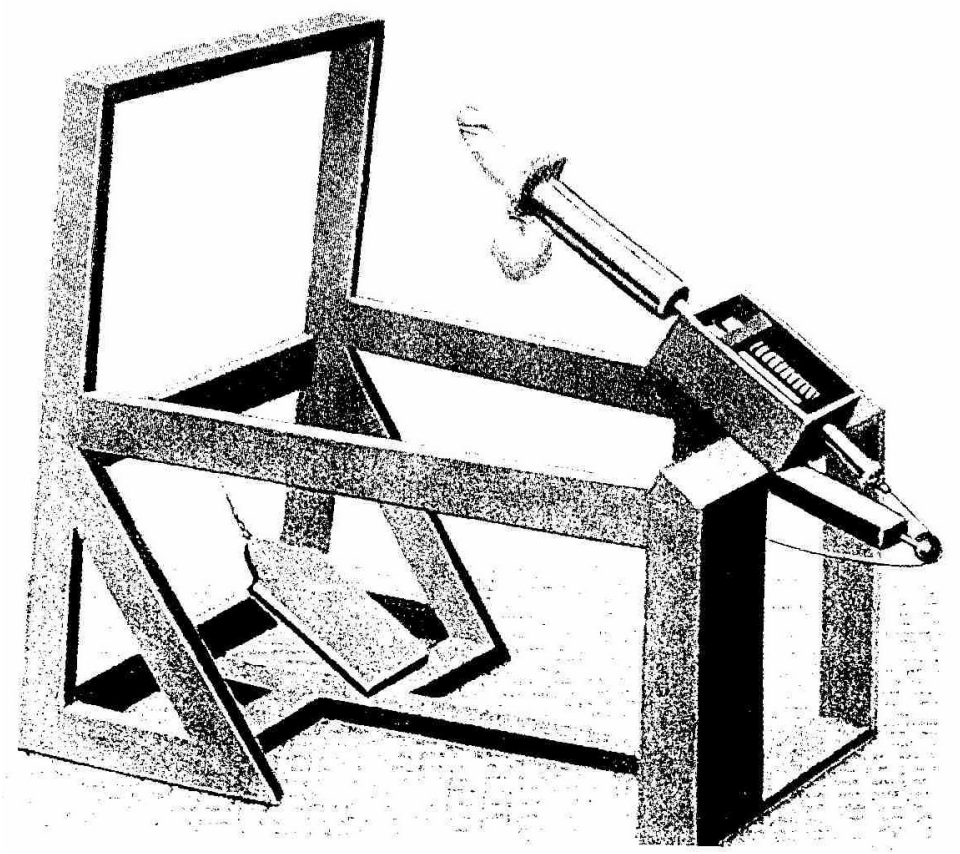

Figure 9.14: An Onanierapparat für Frauen.

The Onanierapparat für Frauen was operated by a foot pedal which in turn drove a pulley system to push the phallic device in and out of the vagina. The machine was built in 1926 by Russian-Jewish engineers in Leipzig, and passed to Magnus Hirschfeld a Berlin sexologist and sexual reformer, whose liberalising activities included his attempts to secure the decriminalisation of abortion and homosexuality in Germany. During the period of the Weimar Republic, the era of Christopher Isherwood's Cabaret when almost anything of a sexual nature was socially acceptable in Berlin, even if illegal, Hirschfeld also founded and directed the eponymous Institute of Sexual Science in the Tiergarten area of the city, which operated from 1919 until $1933^{36}$, many years before the work of Kinsey and other better-known names in the field of human sexuality research (cf. Figures 9.8, 9.9).

Unfortunately for Hirschfeld he was despised by the Nazis, not only because he was Jewish and gay, but also because the Nazis had their own ideas about sex, ideas that made Hirschfeld's sex machine appear to them like some sort of a threat. It was "a

\footnotetext{
${ }^{36}$ Hirschfeld opened the institute in July 1919, the first of its kind in the world, attempting to establish sexuality as a science. The institute had a staff of more than 40 , working in many different fields: research, sexual counselling, the treatment of venereal diseases and public sex education. The institute also hosted the main offices of both the Scientific Humanitarian Committee - the world's first homosexual organisation, and the World League for Sexual Reform. The Institute was defamed and denounced by the Nazis as "Jewish", "Social-Democratic" and "offensive to public morals". Hirschfeld eventually fled to France and the institute was vandalized, looted and shut down in May 1933.
} 
revolutionary idea, and it was the thing that most upset the Nationalists and the Nazis. The idea of this liberated woman, the Weimar Girl, a woman who could choose her own sexuality." (Gordon, 2000). Shortly after the Reichstag fire in Berlin in 1933, and as part of their crusade against Jews, Communists, sex and anything else to which they took a dislike, the Hitler Youth burned almost all of the books from Hirschfeld's institute, as well as his many research files and sex inventions, including the original female sex-gratifier.

\subsection{Patents}

Many of the sex machines on the market today have been the subject of patent applications. Patent documents make useful reading material for researchers who are interested in how things work, being available free of charge on the Internet, for example from the U.S. Patent Office ${ }^{37}$. Hoag Levins' (1996) book describes many of the more than 800 U.S. patents for sex machines that had been granted up to 1996, and from 1996 up to the end of 2005 almost 6,000 additional patents were granted in the U.S.A. alone that contain the word "sexual" in their specification. Clearly sex is a subject on the minds of many inventors.

Typical of the sex machines designed in the closing years of the twentieth century is an invention described simply as a "Sexual Aid", invented by Larry Taylor of Columbia, South Carolina, and granted a patent on March $101998^{38}$. Rather than attempting myself to create a more romantic paraphrase of the sexual process than that described in Taylor's patent document, I shall rely here on some direct quotations from that document in order to give readers a taste for the language of patentese, should they be contemplating further exploration in this field.

As a background to the invention the patent document wisely presents, near the start, an explanation of what happens during sexual intercourse, just in case the reader has any doubts about the process.

"During sexual intercourse, the penis is reciprocally and slidingly received in the vagina. The penis typically does not make substantial contact with the clitoris. Rather, the abdomen and the transition area from which the base of the penis extends provides the critical contact that may ultimately lead to sexual satisfaction. Sexual satisfaction in females generally is not derived from linear translation of the penis through the vagina, rather rhythmic pressure against and/or frictional engagement with the clitoris."

The background explanation continues by giving the reasons why such inventions are needed.

\footnotetext{
${ }^{37}$ www.uspto.gov

${ }^{38}$ U.S. patent number $5,725,473$
} 


\begin{abstract}
"Women, for one reason or another, are not always successful in finding partners who satisfy their sexual drive. Some women, especially in view of such lethal sexually transmitted diseases such as acquired immunodeficiency syndrome, or AIDS, prefer to abstain rather than engage in human sexual relations. Although sexual relations may be avoided, whether ill-fated or non-disciplined, sexual drive may not. A need exists for an invention that provides for satisfaction of primal sexual drive yet eliminates reliance on human sexual interaction. Specifically, a need exists for a sexual aid that is adjustable to suit individual needs and provides intimate engagement with and appropriate stimulation of a clitoris."
\end{abstract}

It is an important, nay essential part of any patent application to show how and why the invention represents an improvement on earlier inventions. Thus we find that:

"Several types of sexual aids are described in the patent literature. Unfortunately, the apparatuses described provide singular excitation means which are received in a vagina in a linear path or engage with a vulva in an arcuately ${ }^{39}$ tangential path.

\title{
$(\ldots)$
}

"Clearly, the above demonstrates a need for a sexual aid providing multiple excitation means that contact the clitoris in a locally arcuate path radially spaced inwardly from the path coincident with a vagina."

Taylor's (1998) invention not only overcomes the limitations of earlier inventions by exciting the vagina, clitoris, and anus in "locally arcuate paths", it also provides "multiple excitation means that cyclically contact" the vagina, the clitoris, and the anus, and furthermore induces a vacuum phenomenon over a user's nipples. A succinct description of the machine is given in the patent abstract.

"A sexual aid including a housing, mounted on detachable legs and containing a motor that urges a dildo, including vibration means, to describe an arcuate path generally coincident with an orifice, such as a vagina. A first stimulator, also containing vibration means, is superposed above the dildo and is urged through an arcuate path concentric with and radially spaced inwardly from that of the dildo, cyclically contacting a clitoris. The sexual aid may include means for introducing a vacuum between the first stimulator and the clitoris. A second stimulator, also containing vibration means, is subjacent the dildo and is urged through an arcuate path concentric with and radially spaced outwardly from that of the dildo, cyclically contacting an anus. The sexual aid includes remotely locatable stimulators that may be placed in contact with a user's nipples and areolae. The sexual aid also provides a vacuum phenomenon between the remotely locatable stimulators and the nipples."

\footnotetext{
${ }^{39}$ In the form of an arc or bow.
} 
Most readers may have never before thought of sex in these terms. However, understanding the essentials of the current technologies will enable people to believe that in the future new advanced sex technologies will be developed. These will be employed in the artificial partners described and predicted in this thesis.

\subsection{Virtual Reality and Teledildonics}

Virtual Reality (VR) is a technology that immerses the user in a computer-generated world, perhaps a room, perhaps an underwater city, perhaps a world as enormous as an entire solar system or as small as the inside of part of a human body. Typically the user wears a special helmet and/or goggles, and possibly an electronically endowed glove, allowing the exploration of this virtual world in a way that provides realistic feedback to the most crucial senses - sight (in 3D), sound (in stereo of course) and touch. You are there, right in the midst of your world, controlling and sensing virtual objects in very similar ways to real life, seeing things, as they would be if they were real. One way to see VR is as a magical window onto other worlds (Rheingold, 1991). The technologies employed in virtual reality systems owe their beginnings to the flight simulators designed for trainee pilots, to the stereophonic sound in our hi-fi systems, and to the 3D movie technologies such as I-Max that allow the viewer to reach out and touch a living dinosaur.

The Virtual Sex Machine described in section 9.5 is a prime example of virtual reality. The manufacturer's Web site, http://www.vrinnovations.com, extols the virtues of their product in language that requires no understanding of the technologies involved.

"It strokes your penis with a variable intensity, changes speeds in response to the action on the screen, and grips your penis harder or softer, based entirely on the action shown. It has variable vacuum, and can suck hard or soft, depending on the video that is playing. At various times throughout the scene, again, tied to the movie action, you will feel a stimulation on the tip and body of your penis ... . In some ways, this device exceeds the ability of a 'real' sexual partner, as the sensations are longer and more intense. Not only that, the machine NEVER gets tired."

But virtual reality is not enough by itself to create the whole of this illusion. The sights and sounds of the women on screen - yes. But the variable intensity penisstroker - no. That technology falls within a science called dildonics, meaning computer controlled sex devices, a word coined by computer visionary Theodor Nelson (1974). Nelson dreamed up the word dildonics in response to the invention of a machine that converted sound into tactile sensation, an "audiotactile stimulation and communications system", patented by a San Francisco inventor, How Wachspress $^{40}$. The title of Wachspress' patent is hardly likely to inspire lustful thoughts, nor would the wording of its abstract, including as it does specifications

${ }^{40}$ U.S. patent 3,875,932, granted April $8^{\text {th }} 1975$. 
such as "Control signals are derived from biopotentials or other sources". The patent document describes how the system applies high pressure sound waves to the skin of its user, "for a variety of purposes including sensory substitution, the generation of body music, pleasure stimulation, ...". Sex is simply not mentioned. The document suggests that one use of the device would be to place a probe in the human armpit, "for the communication of particular types of messages to the brain without employing the ear", and later in the document we find a description of a probe that "... may be inserted in other orifices of the body for a variety of purposes". Clearly it had not escaped Wachspress' attention that, by placing a rounded "coupling device" on the skin of a human body, or in a bodily orifice, sound waves could be converted into vibrations that are sexually stimulating.

Howard Rheingold (1991) explained the idea of "teledildonics" $" 41$ in his book Virtual Reality. The control of sexual devices via the Internet or other means is able to simulate sex at a distance.

"Picture yourself a couple decades hence, dressing for a hot night in the virtual village. Before you climb into a suitably padded chamber and put on your 3D glasses, you slip into a (eventually, one would hope, diaphanous) lightweight bodysuit...with the kind of intimate snugness of a condom. Embedded in the inner surface of the suit... a mesh of tiny tactile detectors coupled to vibrators of varying degrees of hardness, hundreds of them per square inch, that can receive and transmit a realistic sense of tactile presence ... Your partner(s) can move independently in the cyberspace, and your representations are able to touch each other, even though your physical bodies might be continents apart. You will whisper in your partner's ear, feel your partner's breath on your neck. You can run your hand over your partner's clavicle, and 6000 miles away, an array of effectors are triggered, in just the right sequence at just the right frequency, to convey the touch exactly the way you wish it to be conveyed. If you don't like the way the encounter is going, or someone requires your presence in physical realty, you can turn it all off by flicking a switch and taking off your virtual birthday suit."

"Teledildonics" then, is transmitted dildonics. Meredith Balderston and Timothy Mitchell (2001) explain that, although this term was originally employed to describe interaction between two people over a distance, it has come to include humanmachine sexual interactions. "Today's digital technology is attempting to capitalize on this technological concept, using streaming video, DVDs, real-time chat rooms and remote-controlled sex toys to provide customers with gratifying sexual experiences."

Marlene Maheu (1999) explains one of the benefits of teledildonics in her electronic booklet The Future of Cyber-Sex and Relationship Fidelity.

\footnotetext{
41 The word "teledildonics", sometimes referred to as "cyberdildonics", was the creation of Lee Felsenstein during the 1989 Hackers' Conference (Rheingold, 1991). It is often wrongly credited to Theodor Nelson.
} 
"Geographic separation over long periods can often stress a committed relationship and put the relationship at risk for infidelity. Examples of couples who deal with geographic separation include men and women who accept distant work assignments, such as military personnel, scientists, and business people. Virtual contact with electronic devices is likely to be a solution to the loneliness and deprivation caused by long periods of separation. Technology may make the separation more bearable and provide a solution for lonely people away from home. Various devices will allow couples in committed relationships to remain in virtual contact and engage in affection as well as sexual gratification."

\subsection{Haptic Interfaces for Teledildonics}

One of the technological keys to creating a teledildonic experience is what is called a haptic ${ }^{42}$ interface. Haptic technology allows the user to feel as though they are touching something in their virtual world. One example is the steering wheels used in simulated racing car video games - when the user turns the wheel the feeling is a simulation of how it would feel to turn a real steering wheel in a real racing car at the real speed and on the real racetrack being simulated in the game. A second example is a project at the University of Southern California, employing two haptic interfaces, one a glove-like device called a Cyber-Grasp, the other a robot arm called a Phantom. The robot arm is attached to a computer and used as a pointer in three dimensions, just as a mouse is used as a pointer in two dimensions. Motors allow the Phantom to exert a force on a user's hand, giving the feeling of interacting with virtual objects in three dimensions. The CyberGrasp fits over the hand, just like a glove, and is able to transmit, using a network of artificial tendons, all the sensations felt by a real hand. On one end of an Internet connection, a user of a Phantom robot arm strokes a virtual image of a CyberGrasp glove depicted on his computer screen; on the other end of the Internet connection the user's partner, wearing a CyberGrasp glove, feels the sensation.

Using a haptic interface to convey hand movements and feelings creates an uncanny effect. Mark Cutosky, a member of Stanford University's Dexterous Manipulation Laboratory describes the feeling when using a haptic interface to manipulate a robot hand. "Suddenly, it no longer feels like I'm here with my glove and I'm controlling that robot hand over there. Suddenly you feel like that's my hand over there, it's an extension of me." (Balderson and Mitchell, 2001).

In Robots Unlimited (Levy, 2005) I describe some of the features of the electronic sex surrogate patented by Australian inventor Dominic Choy, a life-sized sex doll that is designed to be fully controlled by a computer system. This particular invention is a sexual example of a haptic interface. Choy's invention can be employed in two different versions - in single-user mode the interface connects to a virtual reality software system that provides all the interactivity; in the two-user

${ }^{42}$ Pertaining to the sense of touch. 
mode the haptic interface connects, via the Internet (or similar means), with another haptic interface "worn" by the user's sex partner, allowing the two of them to engage in sex-at-a-distance. When a male user penetrates the artificial vagina in his Choy doll, his partner feels his penis entering her.

Choy's invention represents one form of sexual haptic interface, but one that has the disadvantage of imposing an extra "person", the robot doll, at each end of the transmission. This is fine, indeed ideal, when it is intended to operate the doll in single-user mode, but when two's company, three's a crowd ${ }^{43}$, so other approaches are needed to make sex-at-a-distance less crowded. One such device is the SINULATOR, launched in 2004, designed to allow your distant lover to control your sex toy over the Internet (Lynn, 2004). There is a transmitter module that connects to a PC - this measures the speed and force of each thrust of a penis and communicates this data to the software, which translates the data into vibration and pulsing signals at the other end. If a man's partner at the other end has her vibrator connected to her SINULATOR, the movements of his penis will control the movements of her vibrator.

An alternative method of use allows someone to control a sex toy simply by manipulating the controls of the SINULATOR, in much the same way as using a remote control device for a TV. A semi-public demonstration of teledildonics in action in this way was staged in June 2005 by the New York Museum of Sex. The woman being pleasured went under the name of Net Michelle, and the sex machine that was used on her was the THRILlHAMMER. At the other end of the Internet line, in San Francisco, was Violet Blue, a sex educator, columnist and author. A SINULATOR haptic interface was connected into the chain at both ends, allowing Blue to control the THRILLHAMMER's thrusts even though the machine was almost 3,000 miles away. A camera was set up in the museum for the benefit of the spectators in California. Despite some technical problems before the demonstration got fully under way, eventually Violet Blue did manage to give Net Michelle two transcontinental orgasms, proving that the technology of teledildonics is perfectly viable.

A completely different form of sexual haptic interface is the snugly fitting body suit as described by Rheingold (1991). From a psychological perspective I believe that the body suit concept will be more acceptable to the majority of lovers because, even though the suit will require the appropriate artificial genitalia, the experience will bring the lovers closer to each other in the sense that no-one else (i.e., no sexual robot) will be between them. Maheu (1999) explains this as follows.

"Body suits will be able to stimulate many different erogenous zones simultaneously, thereby intensifying the physical experience. They will use sensors to stimulate touch and will likely be custom-fitted to accommodate a wide range of body types and proportions. Different sensor pads might be located throughout the body suit, each designed to stimulate a different region of the body in variable and programmable ways."

${ }^{43}$ A British aphorism. 
So, instead of one lover asking the other "Do you have a condom?", the key question before sex will become "Is your body suit strapped on?" or "Are you connected to the haptic interface?"

\subsection{Chapter Conclusions}

This chapter's glance at the sexual technologies of today will surely have tickled the reader's imagination sufficiently to enable you to see at least some of the sexual possibilities of the robots of a few decades from now, given the inevitable advances in artificial intelligence research.

It will be several years before sexual robots are available that are completely humanlike in appearance, have sophisticated intelligences including emotional intelligence, an encyclopaedic knowledge, and a huge panoply of emotions of their own. But we have seen in this chapter that many of the necessary technologies already exist, in particular the physical technologies employed in products that can bring a man or woman to orgasm. Here then is an account of such products, in which the core physical elements of virtual sex are the forerunners of components that will be essential in the sexual robots of the future.

The above observations answer my RQ7 adequately. Hence I may conclude that the technological developments in this area have outstripped the limits of human imagination of sex, as it was two centuries ago. 



\section{Chapter 10}

\section{THE MENTAL LEAP TO SEX WITH ROBOTS}

The only unnatural sexual act is that which you cannot perform. Alfred Kinsey, Wardell Porneroy, and Clyde Martin (1948)

In the early years of the $21^{\text {st }}$ century the idea of sex with robots is regarded by many people as outlandish, outrageous, even perverted. But sexual ideas, attitudes, and mores change with time, making it interesting to speculate on just how much current thinking needs to change before sex with robots is accepted as one of the normal expressions of human sexuality rather than one of its more bizarre offshoots. To examine the process that brings about such a change I have asked question RQ8: what mental obstacles exist to prevent the final step towards the second objective? This chapter's glance at the sexual technologies of today will surely have tickled the reader's imagination sufficiently to illustrate at least some of the sexual possibilities of the robots of a few decades from now, given the inevitable advances in artificial intelligence research.

It will be several years before sexual robots are available that are completely humanlike in appearance, have sophisticated intelligences including emotional intelligence, an encyclopaedic knowledge, and a huge panoply of emotions of their own. But we have seen in this chapter that many of the necessary technologies already exist, in particular the physical technologies employed in products that can bring a man or woman to orgasm. Here then is an account of such products, in which the core physical elements of virtual sex are the forerunners of components that will be essential in the sexual robots of the future.

\subsection{Homosexuality}

Since Victorian times no aspect of human sexuality has been the subject of more dramatic changes of attitudes than homosexuality. Ancient Jewish law had prescribed the death penalty for sodomy (Taylor, 1959), based on the Biblical

teachings of Leviticus $^{1}$ : "If a man lies with a male as with a woman, both of them have committed an abomination; they shall be put to death, their blood is upon them." Since Biblical times, several countries and civilizations, including Britain and the USA, have similarly meted out the death penalty for sodomy, as documented by Richard Davenport-Hines (1990), Reay Tannahill (1989), Gordon Taylor (1959), and others. Here are four telling examples.

\footnotetext{
${ }^{1}$ Chapter 20, verse 13 .
} 
[a] Aztec law included the death penalty for homosexuals, male and female; in Peru anyone guilty of sodomy was condemned to be dragged through the streets and hanged, and then burned with all his clothes; the Incas burned sodomites alive in the public square (Taylor, 1959).

[b] In 1627 Pedro Simon, in Conquistas de Tierra Firme, reported on five Italian soldiers (homosexuals), serving in Venezuela, who were "strangled and burnt, with general applause" at the orders of their Spanish commander (Tannahill, 1989).

[c] The first Russian state laws against buggery appeared in military statutes drawn up during the eighteenth century reign of Peter the Great. Initially this was punished by burning at the stake, later changed to corporal punishment (Kon, 2004).

[d] In England the appetite for punishing homosexual behaviour with the death penalty appears to have been not completely consistent. An ecclesiastical law of 1290 ordered sodomites to be buried alive, but this sentence seems never to have been imposed, and the few sodomites who were convicted by Church courts were hanged. This was also the punishment prescribed by King Henry VIII in 1533, when a "Buggery Statute" was enacted in Britain, defining sodomy as sexual activity between two men or as bestiality involving an animal and either a man or woman. This brought homosexual behaviour, and in particular anal sex, within the jurisdiction of the state courts rather than the ecclesiastical courts as it had been previously, but despite the continuing capital nature of the offence there were cases in 1541 and 1594 of headmasters who were found to have sexually enjoyed male pupils but survived, not only with their lives but also with their reputations scarcely tarnished (Davenport-Hines, 1990).

Following the hanging of the Earl of Castlehaven in 1631 there appear to have been no more executions for sodomy in Britain until the eighteenth century. By the early part of the nineteenth century executions of homosexuals were steadily increasing in one English county alone, Middlesex, 28 men were hanged out of a total of 42 convicted sodomites during the period 1805-1815. Sodomy was regarded as so base a crime in early nineteenth century Britain, that in newspaper accounts of the trials and executions of those convicted it was commonplace to write somewhat euphemistically about their offences, in contrast to the reports of trials of murder for which all the gory details would normally be published. In The Times of August 13 1833, for example, the report on the execution of Henry Nicoll, a retired captain from the $14^{\text {th }}$ infantry regiment, says of his offence only that: "He was tried and found guilty of an unnatural offence." It was a popular pastime for large crowds to watch executions in those days, and The Times reported that "amongst the spectators a large number of females also presented themselves, and, by their shouts manifested their abhorrence of the criminal." The broadside ${ }^{2}$ of Nicoll's execution (see Figure 10.1) employs language of an even more venomous kind than was customary for hangings, reflecting the general view of the base level of depravity of his offence, but still without saying what he had done: "Heinous, horribly frightful,

\footnotetext{
${ }^{2}$ Broadsides, later known as broadsheets, were news posters, each one usually devoted to a single news item.
} 
and disgusting was the crime for which the above poor Wretched Culprit suffered the severe penalty of the law this morning, Monday, August 12, $1833 \ldots$. Thank heaven the public Gallows of Justice in England is very rarely disgraced by the Execution of such Wretches; but, every person must have observed, with dismay, how greatly the number of diabolical assaults of a similar nature, have lately multiplied in this country."

THE TRIAL AND

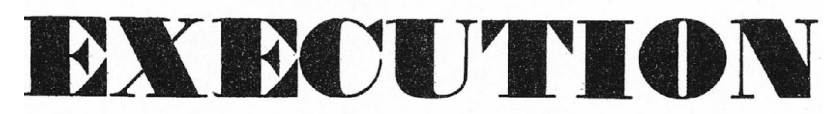

OF

\section{CAPT. HENTY NICHIDL, \\ Who Suffered this Morning,}

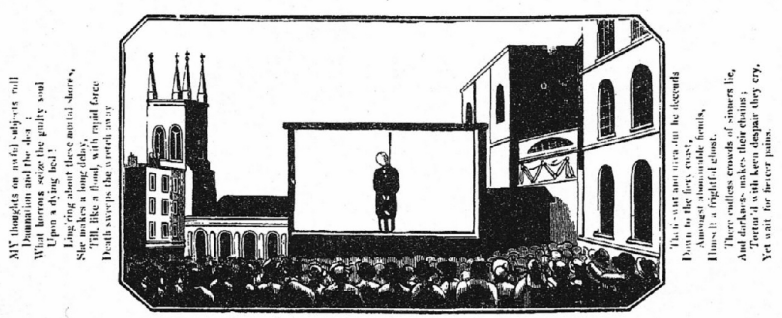

HORSEMOAGER LANE GOAL, SOUTHWARK.

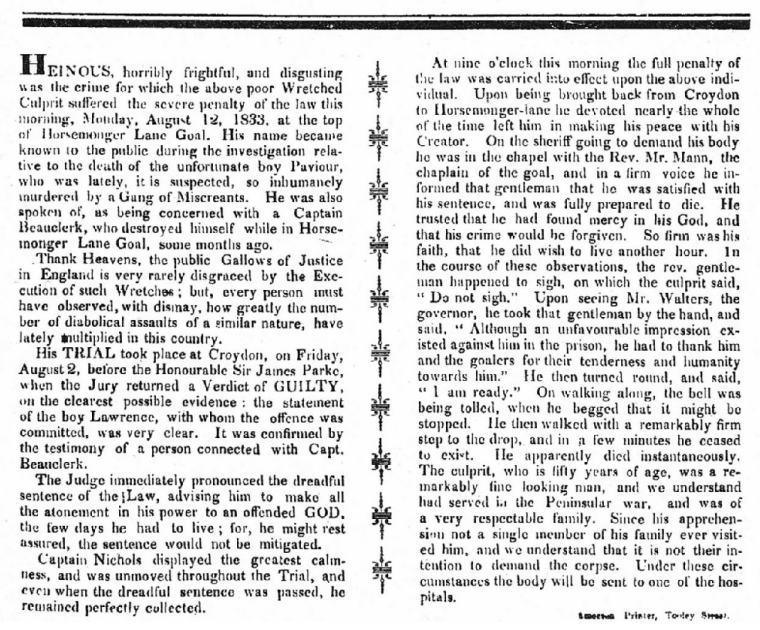

Figure 10.1: The Execution of Captain Henry Nicoll ${ }^{3}$.

Depicted in a broadside published that same day.

Equally euphemistic was The Times' wording when reporting on the September 1835 trial at the Old Bailey of John Smith and James Pratt, the last men to be

\footnotetext{
${ }^{3}$ The Times, generally an extremely reliable source, gives the spelling as Nicoll, whereas in the broadside it is Nichols.
} 
executed in Britain for sodomy. Their crime was described simply as "an abominable offence in a house kept by William Bonnell, who was charged as an accessory. The jury returned a verdict of Guilty against all the prisoners. Sentence Death."4

When, in 1828, new legislation retained buggery and oral sex as capital offences in Britain, the number of capital convictions rose to such an extent that, during 18421849 , only murder exceeded sodomy as a cause of death sentences, and during one year (1846) there were actually more death sentences passed on those guilty of sodomy than on murderers. However, after 1835 all such sentences were commuted, reflecting the beginnings of a marginally more tolerant attitude in Britain towards homosexuality, and in 1861 the statutory punishment of homosexual behaviour was changed from hanging to penal servitude of between ten years and life (DavenportHines, 1990).

Prior to the American War of Independence British laws were in force in the colonies, and so offences committed in Virginia, for example, would be subject to those laws and their punishments. Bruce Robinson (2005) has chronicled the history of sodomy legislation in the USA, a history that parallels that of Britain. Thus we find, for example, that in 1624 a Captain Richard Cornish was charged in Virginia under the British Buggery Statute with having raped his male servant. He was found guilty and both he and his servant were hanged. Sodomy became a capital crime in Massachusetts in 1641 (but only between males); the following year Connecticut included sodomy among its 12 capital crimes; and other states soon followed suit. In 1682 the Quaker colony of Pennsylvania became the first jurisdiction in America to make sodomy a non-capital offence. Initially the prescribed punishment was a whipping, a fine equal to one-third of the offenders estate, and six months hard labour, but in 1700 the punishment was made much harsher - imprisonment for life or castration.

During the years following America's independence from Britain, the death penalty for sodomy was gradually removed from the former colonial laws, though in several states this took quite some time. South Carolina, for example, abolished the death penalty as its punishment only in 1869 . Over the next one hundred years, both in the USA and Britain, the prison sentences passed for homosexual behaviour gradually grew shorter and shorter, being abolished completely in Britain in 1967.

By the second half of the twentieth century the punishment of homosexual behaviour had also become a rarity in the USA. In 1950 all American states had anti-sodomy laws on their statute books, and even in 1974, when the American Psychiatric Associated crossed homosexuality off its list of diagnoses, the laws of some states still regarded homosexual behaviours as criminal offences deserving of harsh punishments. Such laws were not dealt a final blow until, on June $26^{\text {th }} 2003$, after months of public media debate, the U.S. Supreme Court struck down a Texas law banning sexual relationships between gay couples, on the grounds that the law

\footnotetext{
${ }^{4}$ The record of public executions in Britain for 1835 makes no mention of Bonnell's execution, nor does The Times, so presumably he was either reprieved or acquitted on appeal.
} 
was unconstitutional. The basis for that judgement was simply that gay men "are entitled to respect for their private lives". This ruling apparently invalidated laws (for specifics see below) in four states: Texas, Kansas, Oklahoma and Missouri, that still prohibited oral and anal sex between same-sex couples; as well as laws (for specifics, see below) in nine other states: Alabama, Florida, Idaho, Louisiana, Mississippi, North Carolina, South Carolina, Utah and Virginia, which prohibited consensual sodomy (defined for the purposes of those laws to include oral sex) for everyone - homosexual, heterosexual, married or not. Until then the punishment prescribed in Idaho was the harshest remaining in the USA - imprisonment from five years to life.

By the summer of 2003 many of America's leading newspapers, including the New York Times and the Boston Globe, were publishing announcements of same-sex commitments in their wedding pages. Given the social climate in the USA at the start of the twentieth century, I suspect that anyone at that time suggesting the possibility of same-sex marriages within the next 100 years, would quite likely have been committed to a lunatic asylum, if not worse.

\subsection{Oral Sex}

Many American states had laws that in theory treated oral sex with a similar harshness to that for sodomy, an attitude that appears to have gained currency during the last 20 years of the nineteenth century. In 1900 there were 13 states with sodomy laws that also encompassed fellatio, and of these there were ten states that had specifically changed their sodomy laws so that they did cater for punishing fellatio. By 1920 the number of such states had almost doubled, from 13 to 24 (Painter, 2002). But despite this legislation, prosecutions were exceedingly rare and the practice was exceedingly popular - by the late 1940s Kinsey's research indicated that 49 per cent of married men in American had performed cunnilingus, while 46 per cent of married women had performed fellatio. In the 1970s the Hite report (TIME, 1977) published new material that showed a clear shift in attitude. "Men's preference for performing oral sex on women is growing. About $80 \%$ of men engage in the practice, and only $3 \%$ of those find it 'boring or unpleasant.' In answer to 'What would you like to do more often?' the top two male choices were different sexual positions, and oral sex. which the authors call 'the most rapidly growing turnon in America.',

Today oral sex is viewed very differently from the way it was eighty years ago. Nowadays it is close to being de rigeur in most heterosexual relationships, with 35 per cent of men in the USA and 40 per cent of those in France reporting in one study that they had engaged in oral sex (fellatio or cunnilingus or both) during their most recent sexual encounter. For women the percentages were 34 in France and 26 in the USA (Gagnon et al., 2001). 


\subsection{Fornication}

A third sexual "sin" that I consider in terms of changing attitudes and mores is that of fornication - sexual intercourse other than with one's spouse. The Old Testament prescribes death by stoning for fornication, a punishment that could be meted out, for example, to a woman who was found not to be a virgin at the time of her marriage: "Then they shall bring out the damsel to the door of her father's house, and the men of her city shall stone her with stones that she die: because she hath wrought folly in Israel, to play the whore in her father's house: so shalt thou put evil away from among you." (Deuteronomy, Chapter 22, verse 21.)

The mediaeval church in England was so obsessed with sex that it absolutely banned all forms of sexual activity other than intercourse between married persons, and then only when carried out with the object of procreating (Taylor, 1959). "In some penitentials fornication was declared a worse sin than murder. In the penitentials of Theodore and Bede the penance imposed for simple fornication was one year, but the penalty was increased according to the frequency of the act and the age and discretion of the parties." And under the influence of the Puritans in England, whose general attitude towards sex is best described as anti-sex, an Adultery Act became law in May 1650 in which the death penalty was stipulated for fornication (and adultery of course), though it seems that this punishment was never applied (Plant, 2005). After the Puritans moved from England to the colonies and set up their base in Plymouth, John Demos reports that throughout the seventeenth century, they had "a steady succession of trials and convictions for sexual offences involving single persons. 'Fornication' in particular, was a familiar problem" for which the punishment was "a fine of ten pounds or a public whipping - and applied equally to both parties".

Fast forward a few hundred years, to 1950s England, when, lo and behold, fornication could still be, technically, an offence. Gordon Taylor (1959) reports on a case in which two unmarried women had spent the night at a hotel with two American soldiers, both couples registering at the hotel as married. The women were prosecuted under the Aliens Order $^{5}$ and were duly committed to prison. Such eccentricities of the law also extended, until very recently, to the other side of the Atlantic. Amazingly it was only in January 2005 that the state of Virginia repealed a law dating back to the early nineteenth century, banning sexual relations between two unmarried, consenting, heterosexual adults. In fact that law had not been enforced since 1847, but it took this long for Virginia to accept, formally, that private relationships should be immune from government interference (Sincere, 2005).

\footnotetext{
A 1920 Act of Parliament intended to control, by the use of draconian powers, who could come to Britain and their behaviour once in Britain. The term "harmful act" was employed in relation to this Act of Parliament, in order to bring before the courts people who had committed a variety of "offences".
} 


\subsection{Masturbation}

To show the severity of this 'sin' we reproduce a statement by Anne Juhasz (1983) "For centuries masturbation or self-stimulation of the genitals has been associated with evil and madness, as well as a sin against God, deserving death and damnation. Masturbation has been blamed for causing tuberculosis, gonorrhoea, epilepsy, and insanity. As recently as 1901 the following were included in a list of alleged consequences of masturbation: depravity, bedwetting, acne, mental retardation, dull mind, memory loss, hallucination, hysteria, psychoses, malaise, weight loss, loss of strength, deafness, blindness, eye diseases, fever, debility, and sudden death."

Masturbation is the fourth sexual practice that was punished by the church. Masturbation is most often performed without the collaboration of a (human) partner just as robot sex will not require the presence of a human partner. In the early Christian church, priests would dole out penances ${ }^{6}$ of 20 days fasting for masturbation, and even 7 days for having a wet dream or "involuntary nocturnal emission" (Tannahill, 1989). So seriously was masturbation viewed by the clergy that "in the five comparatively short mediaeval penitential codes, there are twentytwo paragraphs dealing with various degrees of sodomy and bestiality, and not fewer than twenty-five dealing with masturbation on the part of laymen, to say nothing of others dealing separately with masturbation on the part of the clergy." (Taylor, 1959).

Jon Knowles' (2002) comprehensive history of masturbation, on which much of the following summary of the subject is based, indicates that, since ancient times and up to the middle of the twentieth century, the practice has almost universally had a bad press. For various reasons it was disapproved of by the ancient Greeks and Romans. The early church was opposed to it as to every other sexual act that could not bring forth children, for which reason Bishop Augustine of Hippo ${ }^{7}$ went so far as to argue

\footnotetext{
6 A penance is a sacrament in some Christian churches that includes contrition, confession to a priest, acceptance of punishment, and absolution. In England, until the nineteenth century, the courts of the established church would punish those who were found to have committed certain moral offences such as defamation, fornication, and adultery. Typical of such punishments is the following order, imposed by the Lichfield consistory court to the ministers of the parish churches of Walsall and Rushall and the chapel of Bloxwich, "to call before them Ann Bickley to do penance for fornication". Ann was required to visit each of the churches on successive Sundays and "during all the Time of Divine-Service shall stand upon a low Stool placed before the Reading-Desk, in the Face of the Congregation then assembled, being cloathed in a white Sheet, in her Stocking Feet, with her Hair about her ears, and having a white Wand in her hand, and immediately after the End of the second Lesson the said Ann Bickley shall (with an audible Voice) make her humble Confession, as follows: WHEREAS I Ann Bickley not having the Fear of God before mine eyes, but being led by the Instigation of the Devil, and my own carnal Concupiscence, have committed the Crime of Fornication with William Seney To the Dishonour of Almighty God, the Breach of his most sacred Laws, The Scandal and evil Example of others, and the Danger of my own Soul without unfeigned Repentance; I do humbly acknowledge, and am heartily sorry for this my heinous Offence, I ask God Pardon and Forgiveness for the same, in Jesus Christ, and pray him to give me his Grace, not only to enable me to avoid all such like Sin and Wickedness, but also to live Soberly, Righteously and Godly, all the Days of my Life. And to that End I desire all you that are here present to join me in saying the Lord's Prayer, Our Father, etc."

350-430 A.D.
} 
that masturbation was an "unnatural" $\sin$ and therefore more serious than fornication, rape, incest, and adultery, all of which could lead to pregnancy. Masturbation was a crime in the courts of many European countries during the middle-ages, and although it was rarely discovered and brought to the attention of a court, masturbators could suffer extreme civil penalties, including exile (Stengers and Van Neck, 2001). Emperor Charles V's "Penal Rules" of 1532 even went so far as to established the death penalty for masturbators (as well as for homosexual behaviour and for using contraceptives).

In 1676, the first major work on the evils of masturbation was published: Letters of Advice from Two Reverend Divines to a Young Gentleman, about a Weighty Case of Conscience, and by Him Recommended to the Serious Perusal of All those that may Fall into the Same Condition. This publication was the "confession" of a young man who ruined himself through masturbation and saved himself through penance (Stevenson, 2000).

During the eighteenth century, the church's perennial opposition to masturbation was taken up by many misguided medical practitioners (Michael et al., 1994), and for some 250 years thereafter the medical profession was generally of the view that masturbation was the cause of a plethora of horrible diseases. In 1760, for example, Samuel Tissot promoted the myth that masturbation is evil and leads to "postmasturbation disease" ${ }^{\prime 2}$. Physicians in the nineteenth and early twentieth centuries continued to diagnose and treat conditions thought to derive from masturbation, employing "cures" that ranged from food products and diets designed to decrease sexual drive, to techniques and devices (such as special chastity belts) that would physically prevent sexual arousal and masturbation (Patton, 1985). These antimasturbation contraptions included "a genital cage that used springs to hold a boy's penis and scrotum in place and a device that sounded an alarm if a boy had an erection" (Michael et al., 1994); rings of metal spikes that would stab the penis if it became erect; and metal vulva guards (McNab, 1993). Around the beginning of the twentieth century several other techniques came into common practice to keep children's hands away from their genitals, including: confinement in straitjackets; wrappings of cold, wet sheets while sleeping; applying leeches to the genitals in order to remove blood and congestion that might be created by desire; burning the genital tissue with an electric current or a hot iron; castration; and removal of the clitoris (Masters, Johnson, and Kolodny, 1984; Patton, 1985).

At the close of the nineteenth century, the pioneering British sexologist, Havelock Ellis, became the first authority on the subject to speak out against all this ranting. Fearful of censorship in England, Ellis (1899) published his refutation in Philadelphia, attacking the views put forward by Tissot and his followers. Ellis asserted that those authors were responsible for the mistaken notions of many

\footnotetext{
${ }^{8}$ Tissot's book L'Onanisme, ou Dissertation Physique sur les Maladies Produites par la Masturbation (Masturbation: Physical Dissertation on the Illnesses it Produces) ran to hundreds of editions, variations and plagiarised publications, throughout Europe and America, stretching well into the twentieth century, and thereby creating a worldwide fear of masturbation that continues to be problematic for young and old alike (Carter, 2001).
} 
medical authorities, notions sustained by nothing more than tradition, and he pointed out that masturbation relieved stress and has a sedative effect.

In contrast to Ellis' liberating teachings, the founder of the Boy Scout movement, Lord Baden Powell, helped to ensure by his writings in Boy Scout manuals that the fear of masturbation survived well into the 20 th century 9 .

"Smoking and drinking are things that tempt some fellows and not others, but there is one temptation that is pretty sure to come to you at one time or another, and I want just to warn you against it. It is called in our schools 'beastliness', and that is about the best name for it. ... . The temptation to self-abuse ... is a most dangerous thing ... for should it become a habit, it quickly destroys both health and spirits; he becomes feeble in body and mind, and often ends in a lunatic asylum.

"Sometimes the desire is brought on by indigestion, or from eating too rich food, or from constipation. It can therefore be cured by correcting these, and by bathing at once in cold water, or by exercising the upper part of the body by arm exercises, boxing, etc.

"It may seem difficult to overcome the temptation the first time, but when you have done so once it will be easier afterwards. If you still have trouble about it, do not keep a secret of it, but go to your scoutmaster and talk it over with him, and all will come right."

Even Sigmund Freud (1912), who acknowledged that masturbation relieves stress and cannot cause a sexually transmitted infection, nevertheless warned that it could cause certain neurotic disorders and have adverse effects on sexual potency. But despite Freud's warning, sexologists and psychologists increasingly came to agree with Havelock Ellis, and as medical, physiological, psychological, and sexual knowledge advanced in the twentieth century, most authorities dismissed claims that masturbating caused physical ailments, although there were still some who chose to emphasize the possibilities of mental impairment as a result. In fact, the effect of the stigma against masturbation was still strong in the USA in 1937, when studies showed that ninety per cent of children caught masturbating were severely threatened, punished, and often terrorized by being told that they would go insane or blind or have their penises cut off or their vaginas sewn closed. At that time 82 per cent of college freshmen in America believed that masturbation was dangerous (Stengers and Van Neck, 2001).

Increasingly, however, physicians abandoned the notion that masturbation caused physical or mental dysfunction. In 1950, more than 30 years after its publication in German, Wilhelm Stekel's book, Autoeroticism, which had suggested that masturbation was universal and normal, and that interference with it was the actual cause of problems and disorders, was translated into English. In 1951, after nearly a

\footnotetext{
${ }^{9}$ The following extracts from Boy Scout manuals are reported by Jean Stengers and Anne van Neck (2001).
} 
half-century of warning about the evils of masturbation and the horrors of postmasturbatory disease, the U.S. Federal Government published Infant Care, advising "wise" mothers that it could confuse children who masturbate to tell them that they should desist (Stengers and Van Neck, 2001).

One of the most important results of the work of Alfred Kinsey and his colleagues $(1948,1953)$ was the normalisation of masturbation and the weakening of the stigma against it. Kinsey's research revealed that, of the 20,000 people interviewed during his research, between 92 and 97 per cent of the men in his study Sexual Behavior in the Human Male (1948), and 62 per cent of the women in his study Sexual Behavior in the Human Female (1953) had masturbated. In fact Kinsey found that it was the behaviour in which women most frequently achieved orgasm.

Throughout the USA the Church protested at Kinsey's findings. Even without reading Kinsey's work, Billy Graham wrote: "It is impossible to estimate the damage this book will do to the already deteriorating morals of America", while Senator Joe McCarthy, as was his wont, denounced Kinsey's work as part of the Communist conspiracy. Ultimately, as a result of all this furore, the Rockefeller Foundation withdrew its financial support for Kinsey's research (Gathorne-Hardy, 1998).

Studies after Kinsey's death continued to corroborate his findings. In the late 1960s his colleague, Wardell Pomeroy, wrote the books Girls and Sex (1968) and Boys and Sex (1969), advising children about masturbation, reassuring them that "no physical harm can come of it, contrary to the old beliefs, no matter how frequently it is done." In fact, Pomeroy said that masturbation was "a pleasurable and exciting experience. ... . It releases tensions, and is therefore valuable in many ways .... It provides a full outlet for fancy, for daydreaming, which is characteristic of adolescence. ... . In itself, it offers a variety that enriches the individual's sex life ... it is not only harmless but is positively good and healthy, and should be encouraged because it helps young people to grow up sexually in a natural way" (Pomeroy, 1968). Finally, the American medical community pronounced masturbation as normal in the 1972 American Medical Association publication, Human Sexuality.

Nowadays masturbation is treated as a perfectly normal activity, practised by the mentally healthy and regarded by the medical profession as being free from any danger of causing mental illness, physical damage, illness or death. The Continuum Complete International Encyclopedia of Sexuality (2003) quotes data indicating that about 72 per cent of young American husbands masturbate, with an average frequency of about twice a month, and that about 68 per cent of young wives do so, slightly less than once a month on average. Possibly as a result of such incontrovertible evidence of the prevalence of masturbation, the Vatican revised its position on the practice in 1992, but only very slightly, with its revision of the Catechism of the Catholic Church, suggesting that, although masturbation is an "intrinsically and seriously disordered act", the Church would, in future, "take into account emotional immaturity, force of habit, a state of anguish, or other mental or social factors which lessen, indeed even extenuate, the individual's moral guilt". 


\section{Provisional conclusions of four observations}

We can see from the above historical summaries that, over time, there have been huge changes in attitude towards all four of these sexual practices: homosexuality, oral sex, fornication and masturbation. Practices that were, for centuries, treated as very serious, even capital offences, in some of the most "civilized" countries in the world, are now widely regarded as perfectly normal, and as leading to fulfilling relationships and satisfactory sex lives. The rates at which such attitude changes have come about have varied, but some of the most dramatic changes have taken only decades rather than centuries.

As with progress in so many other fields, particularly science and technology, progress in social ideas and social change are happening very much faster in the first decade of the twenty-first century than they did even fifty years ago, and as with science and technology the rates of progress and development in social and sexual ideas are themselves increasing. This will inevitably lead to even more rapid changes in the acceptability of new sexual practices. I assume that this will happen up to the point where sex dolls and sexual robots will become widely acceptable within society as our sex partners. I now divide my observations on the contemporary changes in sexual mores into two trends.

\subsection{The Cybersex Era}

The first trend is that sexual awareness and experiences are now happening to our children at ever younger ages. This is a side-effect of (1) the revolution in sexual behaviour in the second half of the twentieth century, (2) effects of the ever increasing media coverage of sex, and (3) the availability of pornography and other explicit sexual material on the Internet. The average age of first intercourse in the UK has fallen from 21 for women born in the 1930s, to 17 for those born in 1972 (Johnson, 2003). Ward Elliott (1997), quoting a long-unpublished 1970 Kinsey Institute survey, indicates that 92 per cent of American women who had married and who were born before 1900, were virgins at the time of their marriage, a figure that declined, on average, by about 8 per cent per decade, to 30 per cent for 1950 s-born "disco-era" women. This change is seen as even more dramatic when measured by the per centages of women who had had premarital sex, for whom the increase was almost ninefold, from 8 per cent of women born in the $19^{\text {th }}$ century to 70 per cent of those born at the peak of the Baby Boom. Mirroring these changes, public tolerance of premarital intercourse has grown markedly since the 1960s. In 1969, 68 per cent of the American public thought premarital coitus was wrong; this declined to 48 per cent of the general population and only 19 per cent of college students by 1975, a gap of only six years (Elliott, 1997).

Just as the youth of today are becoming sexually active earlier than in any previous post-war generation, the age at which children first learn about sex has lowered. Nowadays, if a six-year-old tells his classmate that he has just found a condom on the patio, he is just as likely to be asked in reply "What is a patio?" as "What is a 
condom?". Given this trend it is reasonable to assume that society's attitudes on sexual matters will, to a significant extent, be more and more moulded by the attitudes of the younger sexually active generation.

The second trend that will lead to positive changes in attitude towards sexual robots, is the "marriage" of sex and technology, a union which started in the closing years of the twentieth century. One hundred years earlier the invention of the automobile created a splendid venue for lovers lacking privacy, facilitating private assignation and fornication. In the last two decades, sex has led some of the most important technological developments within the consumer electronics industry, and has been, for example: (1) the driving force behind the boom in sales of the video cassette recorder (porn videos); then (2) the DVD (more porn); and, of course, (3) the Internet (yet more porn, and the first signs of interactive adult entertainment). These three examples show how social responses to technology sometimes encompass and encourage new sexual behaviours.

My point here is that these two trends have fused together to create cybersex ${ }^{10}$. This observation will guide us to an answer to my current research question. The use of personal computers has become increasingly the province of our youth, a phenomenon that will surely be repeated with hand-held PDAs ${ }^{11}$, with wireless connections to the Internet, and with third generation mobile phones. All these are becoming or have become mass market consumer items for recreational use, including sex-related use. As our youth wholeheartedly embraces such technologies, so sex will increasingly permeate through to their computer screens and the LCD ${ }^{12}$ displays on their hand-held devices.

\subsection{From Haptic Interface to Sex Robot}

When the Web site www.BetterHumans.com conducted a survey in February 2003 to investigate what sex technology most people desire, the clear favourite was "android ${ }^{13}$ love slaves" with 41 per cent of the votes polled, followed at a discrete distance by mind-to-mind interfaces with 24 per cent and virtual reality sex with 17 per cent. Clearly robots are forming a significant part of the sexual thinking of the technologically aware.

Cybersex is the latest sexual revolution, reflecting both the advances in the technologies that make it possible and the norms and play areas of contemporary sexual culture. Sex has become an activity which, instead of simply requiring the physical presence of a second person, now appeals to many people in newer and different forms, whether it be the opportunity to meet potential sex partners in an Internet chat room, or one of the intimate activities that have been made possible

\footnotetext{
${ }^{10}$ Cybersex is sexual activity or arousal through communication by computer.

${ }^{11}$ Personal digital assistants.

${ }_{12}$ Liquid crystal displays - the technology employed to create screens for, inter alia, PDAs and mobile telephones.

${ }^{13}$ Another term for humanoid.
} 
through the development of dildonic and teledildonic devices. In the words of Cheyenne, an online sex show host ${ }^{14}$ : "Technology has allowed people who may have felt repressed, guilty, unimaginative or just basically sheltered, a way to express their sexuality without boundaries and to explore different sexual worlds."

The sexual possibilities that have been created by the teledildonic age are mindboggling, so for many people sex today is already rather different, and the differences stem from the technologies. Amongst the most remarkable of these differences are the lack of a necessity to worry about AIDS and other sexually transmitted diseases, even without a condom, because, through the use of haptic interfaces, sex can now take place between lovers who are in entirely different locations - different homes in different cities, different countries, and different continents.

How long it will take for the full potential of these new sexual possibilities to be widely appreciated and adopted, is difficult to say. As William Ogburn (1964) explained: "Behavioral scientists have long recognized that emerging technology has a powerful influence on human behavior, although frequently there is a delay or lag between the emergence of the technology and the social behavioral adaptation to it." Nevertheless, I believe that, because sexual desire is such a strong influence on our lives, in the case of $21^{\text {st }}$ century sexual behaviour the lag might be minimal.

The modern era of expanding sexual freedom that began with the sexual revolution of the 1960s, takes place in cultural environments typified by dynamic change and increased levels of social tolerance. Commenting on some of the effects of this freedom on our view of what is normal in relationships, Maxwell Morris (1978) wrote:

"The dawning of a new idealism has given vent to increased sexual vigor and freedom among both sexes. The changing panoramic scenario of sexual liberation may, for example, be illustrated by the increasing number of nontraditional "experiments in living". Innovative living arrangements inclusive of the open marriage, group marriage, unmarried sexual cohabitation, and homosexual cohabitation offer a redefinition of the term 'meaningful relationship'.”

Some of the effects of this same freedom on the sexual aspirations and fulfilment of the individual are described by Dennis Peck (1979) in terms of an increase in the potential of our sexual pleasure: "Individual fulfilment through various sexually related activities has resulted in a greater emphasis upon recreational sexual expressions." So in the case of technologically driven sexual practices, the ideas are already with us, even in advance of the general availability of the equipment that will turn these ideas into reality.

In chapter 9 I discussed some of the haptic interfaces that make computer-driven sex a reality. I now consider this topic again. Assume for a moment that, instead of a

${ }^{14}$ At www.cheyennelive.com 
newly found human lover being at the other end of an Internet link with their own haptic interface, engaging with you in whatever sexual activities your respective hearts desire, there is instead a robot, a sexual robot programmed with the knowledge of countless experienced lovers and all of the world's sex manuals. Would you know the difference?

I believe that this test will be relatively easy for robots to pass, given that the physical feeling you experience will be based on a combination of the physical characteristics of your haptic interface and the skills of your lover. If sex-at-adistance is physically enjoyable with another person, why does it have to be any less enjoyable if that person is replaced by a robot, so long as the physical connection at your end, your haptic interface, is the same? And if you can enjoy sex-at-a-distance with a robot, then why should you not equally enjoy face-to-face (or whatever) sex with a robot whose embodiment incorporates all of the artificial genitalia and other physical characteristics of your favourite haptic interface, with the added benefits of arms to hold you tight, hands to caress you and a sexy voice to whisper in your ear? In this transition, from haptic interfaces for human-human sex-at-a-distance, to haptic interfaces for human-robot sex-at-a-distance, to human-robot sex period, we can see how easy it will be for many people to be converted to the idea of robot sex.

While discussing the physical characteristics of sexually appealing robots, we should not forget the benefits that $21^{\text {st }}$ century design and manufacturing technologies will very soon be bringing to sex dolls and somewhat later to sexbots, benefits that will allow the purchaser or hirer to specify the physical characteristics of the product's gentitalia. Women for whom size matters will be able to demand for their malebot any girth and length of penis they desire, while men will be able to choose a fembot's vaginal dimensions to be as tight or as cavernous as they wish. Of course, on the de-luxe models, these dimensions will be changeable with the press of a button, or even by murmuring the right words in the robot's ear. These physical characteristics will represent only some of the popular user features that will be designed into sex robots. Others include all the knowledge in The Kama Sutra (Burton, 1883) and similar books, and in the famous Japanese paintings of sexual positions. Just as chess programs are loaded with databases of moves in different chess openings, so the robots of the coming decades can be given databases of different sexual positions and techniques from around the world. It will be possible to set different "levels" or "preferences", in much the same way that different skill levels and style-of-play preferences can be chosen on a chess computer. And the robots will be able to learn what the user likes. On one level a robot could be set to cater, in every encounter, to the user's sexual tastes. Another level could allow for a random choice of sexual activities and/or positions, in order to give the user some surprises. Yet a third level could be a "teaching" mode that provides instruction for the sexual novice. By providing a host of different options, manufacturers will make sex robots appealing to just about every sexual orientation and taste. 


\subsection{Are Men and Women Different?}

Sigmund Freud (Nechvatal, no date available) might have foreseen robot sex as a serious possibility. Joseph Nechvatal (no date available) describes how Freud used to explain in his lectures that when we dream about complex machines they always signify the genitals, an explanation that might lead us to speculate that he would have regarded robot sex as little more than the practical implementation of this phenomenon, the replacement of a partner's genitals with the artificial genitals of a machine. If Freud had indeed considered this possibility, how would he have assessed the appeal of sexual robots to men and to women? Would he have predicted that men will be more attracted than women to the idea, or vice versa, or that there would be little or no difference to the sexes in the appeal of sexbots?

There are two major parts to this question. Firstly, do men in general and women in general differ in their sex drives? Second, will men and women be equally likely to embrace the technology of sexual robots, or will men want sex with fembots more than women will want sex with malebots, or vice versa, or any other combination thereof?

The first question is one that has long spawned huge differences of opinion amongst lay persons and psychologists alike, ranging from the widely quoted William Acton's (1857) pronouncement in 1857 that "the majority of women (happily for society) are not very much troubled with sexual feeling of any kind", to Barbara Ehrenreich's (1999) article in Time magazine, in which she revealed the equally astounding news that woman, not man, is destined to be "the sexual powerhouse of the species". To add to the confusion caused by the highly contrasting views of individual "experts" such as these, four leading textbooks on the subject have innocently combined to create even more doubt as to the truth of the matter: Our Sexuality (Crooks and Baur, 1999) is dismissive of the stereotypical view of men as having higher sex drives than women; Human Sexuality, the famous tome based on the work by William Masters, Virginia Johnson and Robert Kolodny (1995), acknowledges the existence of the stereotypical view but without coming down for it or against it; Sexual Interactions by Albert Allgeier and Elizabeth Allgeier (2000) also sits squarely on the fence of this issue; while in Understanding Human Sexuality, Janet Hyde and John DeLamater (1997) explored the possibility that women might have a higher sex drive than men but failed even to discuss the possibility that the reverse might be true.

It was not until recently that the psychology literature could boast what appears to be a definitive answer to the question, when Roy Baumeister, Kathleen Catanese, and Kathleen Vohs (2001) conducted an extremely comprehensive study based on more than 5,400 articles and papers in learned journals and conference proceedings, all of which contributed perceptions on sexual motivation, drive, and desire. Baumeister and his colleagues focussed specifically on the desire for sex for its own sake, which is linked very closely to sexual enjoyment - the amount of pleasure we derive from sexual activity. 
Baumeister and his group assessed sex drive in terms of the desired frequency of sex, the desired variety of sex acts and partners, the frequency of fantasizing about sex, the frequency of masturbation, the actual number of partners (as opposed to the desired number of partners), the frequency of thinking about sex, the willingness to forgo sex, and the willingness to make sacrifices in other spheres in order to obtain sex. Having surveyed the broad range of available evidence on the relative strength of sex drive in men and women, evidence that was extensive and that came from the diverse methodologies employed by thousands of research psychologists, they came to the following conclusion.

"By all measures, men have a stronger sex drive than women. Men think about sex more often, experience more frequent sexual arousal, have more frequent and varied fantasies, desire sex more often, desire more partners, masturbate more, want sex sooner, are less able or willing to live without sexual gratification, initiate more and refuse less sex, expend more resources and make more sacrifices for sex, desire and enjoy a broader variety of sexual practices, have more favorable and permissive attitudes towards most sexual activities, have fewer complaints about low sex drive in themselves (but more about their partners), and rate their sex drives as stronger than women. There were no measures that showed women having stronger drives than men."

However, Baumeister et al. (2001) are quick to point out that this overall conclusion

"... does not mean that women do not enjoy sex, nor does it mean that women do not desire sex. It certainly does not mean that women should not desire sex or that they should feel guilty over sexual desire or pleasure ... Our conclusion is merely that on average men desire sex more strongly and more frequently than women."

One of the reasons for this disparity is undoubtedly the overzealous sexual demands placed by many men on their women, demands that fail to take into account the levels of fatigue experienced by many mothers due to their childcare roles, and especially if they have jobs as well. Where there is a sexual imbalance in the sense of desired frequency, a robot could be the perfect solution for the enlightened couple.

Let us now address the second of our questions with which we started this discussion: will men and women be equally likely to embrace the technology of sexual robots? On the basis of Baumeister et al.'s (2001) conclusion it would be natural to expect that many more men than women will be enthusiastic about the idea of robot sex, and more likely to become customers when sexual robots are on the market at affordable prices. Because technology in general is accepted more slowly by women than it is by men, it might seem likely that women will be slower than men to investigate most aspects of the technology of sex, including sex with robots. On the other hand, the use and history of vibrators and their staggering sales figures, suggest that once robot sex gets some good PR from women this bias will be dramatically reduced and possibly eroded entirely. 
A second factor that might increase women's motivation for robot love and robot sex, is the recent increase in unwillingness on the part of men to marry. It seems that, since men are able nowadays to get sex much more easily than twenty or even ten years ago, they hesitate entering into long term relationships. This trend will leave many women faced with the prospect of a human lover uncommitted as to the long term. Instead these women might prefer to engage with a sexbot - always willing, always ready to please and to satisfy, and totally committed. This everavailability of malebots could bring about a dramatic and positive change in the parameters of human love relationships, not necessarily for more sex but rather for sex at the right time.

\subsection{When They Look Like Us}

Some people will find it relatively easy to get used to the idea of robots as surrogate humans and alternative sex partners. In general I would expect these to be the technologically aware, those who grow up hand-in-hand with technology, those whose doubts and questions will relate more to what robots can and cannot do than to their appearance. This sector of society will find pleasure and excitement in exploring the capabilities of robots, including their emotional capacities, their personalities, and their sexual capabilities and preferences.

Others, possibly because of deep reservations, possibly because of prejudice, possibly because their outlook is so literal that they will need to see realistic humanlike robots before they can come to accept the concept of androids as pseudo-peers, these people will take more time (and argument) to be convinced. In order to convince them, the appearance of the androids will be almost as important, if not more important, than their technical capabilities.

I have already discussed the general perception amongst Japanese robot designers, even as far back as the eighteenth century creators of the Karakuri tea-serving dolls, that in order to elicit the most positive reactions from humans, such creations should be humanlike in appearance. This perception can be seen in the way that the Japanese robots of today are increasingly endowed with the physical characteristics of humans. And as the number of domestic robots worldwide grows drastically, from about 400,000 in 2003 to an estimated 4.1 million in 2007 (United Nations, 2004), so the numbers of robot designers, robot development companies and robot research institutes will mushroom, all fuelled by a combination of the Yen earned from robot sales and government mega-investment. This massive research and development effort will rapidly lead to the creation of androids so humanlike in appearance that, from a few feet away, almost no-one will be able to tell the difference. In my view these "waxworks as androids" will be utterly convincing in both their appearance and their movement, by 2020 if not sooner.

At the Expo 2005 world exposition in Japan, Hiroshi Ishiguro, a robotics professor at Osaka University, unveiled the most human-looking robot yet. Ishiguro's previous version was called REPLIEE R1 and had the appearance of a five-year-old 
Japanese girl. It was made of hard plastic, its head could move in nine directions, and it could make gestures with its arms. The exposition's 22 million visitors, 95 per cent of whom were Japanese, were able to see his 2005 creation, REPLIEE Q1 (see Figure 10.2). She has skin made of a flexible silicone material rather than hard plastic, covering a complex system of 42 actuators ${ }^{15}$ located in the upper part of her body and powered by an air compressor, allowing the gynoid ${ }^{16}$ to turn and react in a humanlike way. REPLIEE Q1 can flutter her eyelids, she appears to breathe, she can move her hands just like a human, she is responsive to human touch, and she can mimic the human behaviour of slightly shifting her position from time to time.

Professor Ishiguro was not under any illusions in 2005 that REPLIEE Q1 would, in its present form, pass for a human. But he did believe that that stage in the acceptance of robots will soon be possible, even if only for a short time. "An android could get away with it for a short time, 5 to 10 seconds. However, if we carefully select the situation we could extend that, to perhaps 10 minutes. More importantly, we have found that people forget she is an android while interacting with her. Consciously, it is easy to see that she is an android, but unconsciously we react to the android as if she were a woman.” (Whitehouse, 2005)

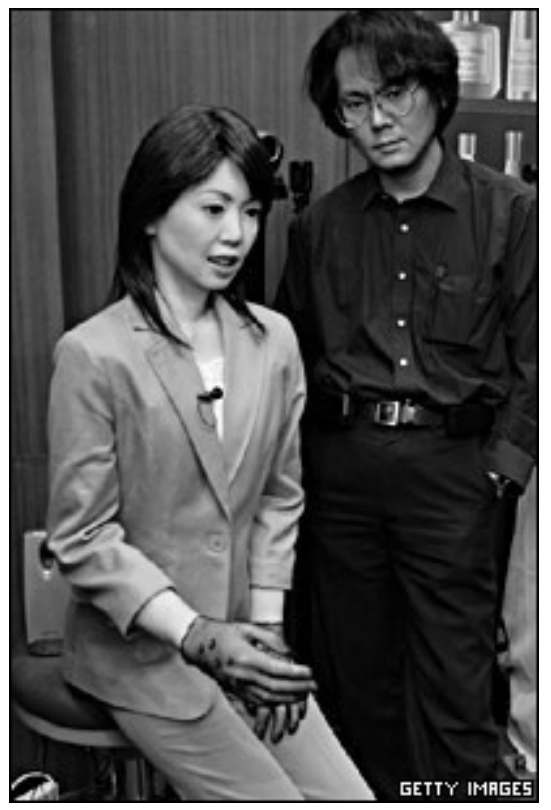

Figure 10.2: The REPLIEE Q1 robot.

\footnotetext{
${ }^{15}$ Devices that create movement.

${ }^{16}$ An android made in the (human) female form. This is not necessarily the same as a fembot, which is usually taken to mean having artificial female genitalia or suitable substitutes in the form of haptic interfaces.
} 
Just by looking at REPLIEE Q1 and comparing her with the stereotypical image of robots as laboratory prototypes, complete with wires and parts hanging out, we can see how quickly progress is being made in this field in Japan. As the android technology of the future combines with developments in haptic sexual interfaces, the first sex robots will start to appear on the market. This might happen as a result of commercial collaboration between the manufacturers of products such as RealDoll and the laboratories in Japan that are leading the way in android research and development. Or it could happen that the Japanese themselves decide that they do not need any such collaboration, and that, by the way, the "Dutch wives for hire" businesses should be major contributors to robot research budgets. Either way, I do not believe it will be many years before the latest announcements from Japanese robot researchers talk of robots as sex partners, and start to demonstrate such capabilities. Why not? The technology necessary for orgasm has been around for a while in the form of the vibrator, and more recently as the SYBIAN, the THRILLHAMMER and other similar machines. Turn back for a moment to Net Michelle's orgasmic experience, created by THRILLHAMMER via a teledildonic interface $^{17}$. How long can it take for the necessary fusion of technologies to occur?

As the first sexbots reach the market, the publicity for robot sex will take off with a bang. Initial news reports will most likely treat sexbots as a curiosity item, but this will not prevent their existence from becoming widely known. Very quickly softcore porn sites and Internet chat groups will start to display and discuss sexbots in action. As more and more people rush to their computer screens to watch others enjoying sex with robots, and as increasing numbers of sexual experimenters are interviewed by a media anxious to publish all the voyeuristic and vicarious details of the thrills and joys of robot sex, so the mainstream media will stop blushing and cash in on the act. Just as Marie Claire published an article in 1994 on the almost unthinkable idea of women paying for sex and enjoying $i^{18}$, so the women's magazines of 2014, if not earlier, will, I believe, be publishing articles on women's experiences in enjoying sex robots. The semi-private semi-public exhibition of teledildonics that took place in 2005 at the New York Museum of Sex ${ }^{19}$ can be seen as a pioneering media event in this field. Only a few were able to be present in New York that night, or at the other end of the teledildonic line in San Francisco, but the event was reported in the online version of Wired, the highly respectable leading edge hi-tech magazine. When such events attract increasing amounts of attention from the mainstream media, albeit as curiosities at first, the idea of sexual robots will quickly spread. The first sexbots to reach the market will be too expensive for most to buy, or even to hire, so for a while these products will be restricted to the upper socio-economic groups. But this was also true in the very early days of "home cinema"; and in the early days of AIBO - Sony's robotic dog. As the media interest in robot sex grows, more people will try the experience, buying and hiring sexbots in numbers sufficient to bring down prices, and thereby making sexbots available to men and women from a broader economic spectrum.

\footnotetext{
${ }^{17}$ See section 9.5 .

${ }^{18}$ See section 8.3 .

${ }^{19}$ See section 9.5 .
} 


\subsection{Therapist Sex Robots for Hire}

While much of the initial fascination with sexbots will be prompted by curiosity, it is reasonable to expect some interest to stem from advice given by therapists to their patients. People experiencing psychosexual problems will no longer need and lack the services of human sex surrogates - they can instead be referred to clinics where the surrogates are robots. This does, of course, raise all sorts of ethical and legal questions, especially in the litigious climate of the USA, but setting legal problems aside (and they will exist on a much smaller scale, if at all, in many countries), it seems to me inevitable that sex robots will be employed for therapeutic purposes, by the hour.

This raises the question, of course, what about cyber-prostitution? The johns and janes who pay for sex benefit in various ways from their encounters with prostitutes (one form of sex without human love), so they will equally benefit in various ways from sex with robots (another form of sex without human love). Robot prostitutes might become a popular method for learning sexual technique before entering into a human relationship. With a robot prostitute the control of disease is implicit simply remove the active parts and put them in the disinfecting machine. Cyber prostitutes, on the basis of the fees received for their services, could play an important role in the growth of the robotics industry and the ability of this industry to develop continually more advanced products. Certainly there are some questions to be answered by the lawmakers of the future regarding robot prostitution. Should it be illegal to have a bevy of robot prostitutes (a robot brothel). Why should it be, since all current laws cater only for human prostitutes? If such commercial transactions are made illegal, will the mafia attempt to control the manufacture of sexbots, spreading their availability and making them a source of huge revenues?

\subsection{The Ethics of Robot Prostitution}

In addition to the legal issues mentioned above, the use of sex robots in general and robot prostitution in particular raise a number of ethical issues, discussed by the author (Levy, 2007) in his paper Robot Prostitutes as Alternatives to Human Sex Workers. Three of the most glaring issues in this respect are: (1) the ethics, vis à vis oneself and society in general, of using robot prostitutes; (2) the ethics, vis à vis one's partner or spouse, of using robot prostitutes; and (3) the ethics, vis à vis human sex workers, of using robot prostitutes. We discuss these three issues briefly below.

First, for most of the clients of sex workers, self-respect is an important issue, due to the perception that there is still a moral stigma attached to commercial sex encounters. The clients will therefore often go to some lengths in their attempts to avoid being found out by those close to them or, even worse, being named-andshamed in public as some police forces do when they arrest johns. For this majority the issue of self-respect will be much better catered for by hiring robot prostitutes instead of human sex workers, because robots are artefacts and the same moral 
stigma does not therefore apply. Yet there will, at least for some time, be a moral stigma of a different sort. We understand sex with a person but most people do not appreciate the concept of sex with a robot, and what we do not understand we tend to stigmatize.

Second, how the use of a robot prostitute is perceived by a spouse or partner is open to many possibilities. Will a spouse or partner who considers infidelity with another human to be reasonable behaviour, be likely to be upset by the hire of a sexbot? Certainly there will be many who feel that the sexual demands placed on them within their relationship are excessive, and who will therefore appreciate a night off now and then, in the knowledge that what is taking place is nothing "worse" than a form of masturbation. There will also be some who positively relish the idea of robots, programmed to be sexually adept, teaching their partner to improve their lovemaking skills. Moreover, there will be couples, both of whom derive pleasure and sexual satisfaction from a threesome in which the third participant is willing to indulge in whatever sexual activity is asked of it (subject of course to its programming and engineering). In contrast there will some partners and spouses who find the very idea of sex with a robot to be an anathema. The ethics of using a robot prostitute within a relationship will therefore depend very much on the sexual ethics of the relationship itself when robots do not enter the picture.

Third, it is a common perception that prostitution itself is a "bad thing" for the sex workers. This is because it is seen, inter alia, as degrading them, encouraging them into a lifestyle in which an addiction to hard drugs often forms an integral part, and strongly increasing the likelihood of their catching AIDS or some other possibly fatal sexually transmitted disease. Furthermore there are the physical dangers to which sex workers are exposed from violent clients and from their pimps. Although not all sex workers agree with the perception of their profession as a bad thing, it is widely perceived as being so, suggesting that the introduction of robot prostitutes will generally be regarded as a "good thing" because it will most likely cause a dramatic drop in the number of human sex workers who ply their trade. The New York hooker quoted earlier in an article in The Guardian ${ }^{20}$ pointed the way to this problem - the compulsory redundancy of sex workers. This is an important ethical issue, since in many cases those who turn to prostitution as their occupation do so because they have literally no other way to earn the money they need.

\subsection{What Will Our Sex Lives be Like?}

There are obvious social benefits in robot sex - the likely reduction in teenage pregnancy, abortions, sexually transmitted diseases and paedophilia. Moreover, there are also clear personal benefits when sexual boundaries widen, ushering in new sexual opportunities, some bizarre, others exciting. In Impacts of Robotic Sex Joe Snell (1997) pointed to various ways in which robot sex could alter human relationships and human sexuality.

\footnotetext{
${ }^{20}$ See Section 8.5.
} 
“ Techno-virgins will emerge. An entire generation of humans may grow up never having had sex with other humans.

" Heterosexual people may use same-sex sexbots to experiment with homosexual relations. Or gay people might use other-sex sexbots to experiment with heterosexuality.

“ Robotic sex may become 'better' than human sex. Like many other technologies that have replaced human endeavours, robots may surpass human technique; because they would be programmable, sexbots would meet each individual's needs."

An important aspect of human sexuality is the possibility of failure or denial, making sex and the enjoyment of it somewhat capricious. In order to be better than human sex, the performance of sexbots might need to contain those subtleties of human sexuality that will enable them to mimic this capriciousness (Yeager, 2006). Things that are always great can become boring, but the anticipation, doubt and hope of each sexual experience can be instilled in their human owners if the sexbot is designed with these subtleties built-in.

There are many professions that call for being absent from one's sex partner for varying periods of time. Robots can be the perfect substitutes in these situations, satisfying one's sexual needs without creating any cause for concern about disease and fidelity. For sailors, who a century ago would have been traditional customers for dames de voyage ${ }^{21}$, a charming female robot would be a great alternative to masturbation or a visit to the local brothel when ashore. Ships' pursers will perhaps be loaning them out like library books, instead of administering penicillin jabs for the needy.

There are many other situations in which a sexbot would be the ideal solution. For those who lose a spouse or a long-term partner, whether to illness, death or as a one of the casualties of a broken relationship, robots could provide the answer. As one ages, it becomes clear that maximal sexual intimacy sometimes takes a very long time to evolve, years even, and that it redefines itself along the evolution of a loving relationship. Robots will be able to achieve this evolutionary process more quickly than humans, by retaining all the memories of living with their human other, analyzing the relationship characteristics exhibited by their human and by themselves, studying huge databases of relationships and how they are affected by different behaviours, and then tuning their own behaviour to the needs of their human mate. Humans often do not know what they really want or need, so intuitive robot sex partners are a real requirement, being able to discern whether their owner really wants sex or would prefer a nice glass of wine or a walk in the park.

${ }^{21}$ See Section 9.4. 


\subsection{Chapter Conclusions}

In this chapter I investigated RQ8: what mental obstacles exist to prevent the final step towards my second objective? I considered the question from various sides, as can be seen from the section titles. The diversity of viewpoints makes it difficult to come to a uniform chapter conclusion, in particular since the different viewpoints represent the perspectives from the different groups under investigation. Restricting myself to the first section, homosexuality, I believe that more psychological research is required. This holds true for the other sections, too. Yet, since my point of departure of this research (see chapter 1) is that the world is mainly technology driven, I believe that there is no technological barrier for developing the devices discussed in Chapter 9. I would like to conclude that if society follows the technological developments in this area of research, then all the mental obstacles discussed in the previous ten sections of this chapter will be overcome.

For a proper answer to PS2 I have investigated four research questions, the last of which was RQ8: what mental obstacles exist to prevent the final step towards my second objective? In the current chapter I have discussed ten possible obstacles, but on consideration of the results of my investigations I may conclude that all of these obstacles have had different levels of significance in relation to the progress that has been made in our sexual attitudes and mores over time. Homosexuality, for example, was the most serious of these obstacles to social progress, and in the minds of some people it still is. But whatever obstacles remain to be overcome will, I believe prove to be only temporary obstacles. 

PART FOUR 


\section{Chapter 11}

\section{CONCLUSIONS}

Each of the chapters in parts two and three of this thesis has discussed a particular aspect of emotional attachment, love or sex. In these discussions I have drawn parallels between attachment, love, and sex as we know them in human-human relationships, and as I predict they will develop in human-robot relationships. In order to justify these parallels, I have attempted to present empirical evidence to support the ways I foresee love and lust developing in the human-robot relationships of the future.

The evidence offered in those chapters lead to a number of chapter conclusions. Combining these conclusions will complete the whole jigsaw of my thesis. Attachment, love, and sex with robots are inevitable extensions of current human emotions and sexuality. Below I reiterate and summarize the chapter conclusions, and extrapolate from them to show how attachment, love, and sex with robots will change society.

\subsection{Emotional Feelings of Attraction (to People)}

The research findings of psychologists who have investigated the nature of romantic love suggest as an answer to RQ1 that it is a continuation of the process of infant attachment, a process by which different objects, such as a doll, a toy, a pet animal perhaps, or a virtual pet, become the focus of attachment. This attachment to a material possession can develop into a stronger relationship as a result of the possession's repeated use and the owner's interaction with it, as he or she gets to know it, as it becomes more a part of their life, being endowed with a special meaning for them, and sometimes making them feel that the possession is a part of their very being in a similar way that a spouse or partner may become a part of one's being.

This development of the attachment process provides the emotional foundation on which artificial intelligence researchers in general and roboticists in particular will be able to develop robots that exhibit all of the principal factors that contribute to why, when two people meet, love can be in the air, and can simulate these factors sufficiently well to engender love in their humans. Existing and future technologies for measuring human physiological responses will enable a robot to detect how much love its human feels, and thereby to make modifications to its behaviour so as to increase its appeal to its human. The combination of these developments will result in robots that have the potential to make us fall in love with them. Ergo, unless one harbours a prejudice against robots as love objects, there appears to be no good reason to dismiss the idea that humans might be susceptible to falling in love with robots. From the above observations I may (provisionally) conclude that, where 
this susceptibility exists, robots will be able to convert it into reality by behaving in ways that make themselves increasingly appealing to their human owners.

What will be the impact on society when robots reach such a level of sophistication, when they are able to engender and sustain feelings of romantic love in their humans? I believe that the social and psychological benefits will be enormous. Almost everyone wants someone to love, but many people have no-one. If this natural human desire can be satisfied for everyone who is capable of loving, will not the world be a much happier place? Many who would otherwise have become social misfits, social outcasts or even worse, will, instead, be better balanced human beings. Moreover, those who are devastated by the breakdown of their most significant human relationship will be able to speed their emotional recovery by rapidly indulging their desire to love, courtesy of a robot with the appropriately chosen specifications.

\subsection{Loving Our Pets}

In approaching the concept of love with a robot as I have done in RQ2, I feel it is necessary to dispel certain instinctive reactions that I have found in some people with whom I have discussed the subject. One of these reactions comes in the form: "A robot isn't human so how can you love it?" In order to counter this scepticism I have presented two important classes of counter-example: love for real pets and love for virtual pets.

Some owners derive even more satisfaction from their pet relationships than they do from their social relationships with people. Love for a pet is often very strong, sometimes even stronger than a person's love for other humans, and can be manifested in various ways: the offer of a reward for a missing animal; an owner bequeathing an extraordinarily large sum of money for the care of their pet, even making the pet a millionaire; spending considerable amounts on pet food, healthcare, and sometimes on their animal's grooming and clothing; and interacting with their pets in ways redolent of human-human relationships: giving them names, feeding them from their own plates at meal times, celebrating their birthdays, allowing them to sleep on the owners' beds, talking to them, and considering them as members of their family. An even more widespread indication of the strength of human love for pet animals can be observed when a pet dies, the intensity of the owner's feelings of grief often being very similar to those experienced with the bereavement of a spouse or partner. Sometimes an owner's love is seen in bizarre news reports: a groom designating his dog as best man, a divorcing couple battling in the courts over the custody of their pet; there is even a web site that offers owners the opportunity to "marry" their pets (for a suitable fee). All of these manifestations of love are appropriate ways to treat human loved ones.

From these observations I may conclude that the love that pet owners develop for their animals is firm evidence that humans are able and frequently willing to form bonds of love with non-humans. 


\subsection{Emotional Attachments to Virtual Pets}

The human propensity for loving pet animals also informs our understanding of the nature of human emotional attraction to virtual pets and to humanoid robots, which is the purpose of RQ3. For those people who value their relationships with their pet animal more highly than their relationships with other humans, it would not be surprising if a virtual pet or a robot were to be regarded in the same vein, supplanting other humans as the most natural objects of affection.

A virtual pet is a combination of some form of computer ${ }^{1}$, together with software that exhibits pet-like behaviour patterns, for example a TAMAGOTCHI. The owner must care for her TAMAGOTCHI in its virtual world, by pressing buttons to simulate the giving of food and drink, the playing of games, and other behaviours typical of a mother-child relationship, ensuring that the TAMAGOTCHI will survive and thrive. If the TAMAGOTCHI is neglected it can "grow ill" and "die", often causing heartbreak to its owner. The creature's behaviour patterns have been programmed to change with time, in order to give the owners the sense that each TAMAGOTCHI is unique and therefore provides a unique relationship for the owner, just as each pet animal and each human child are unique.

The TAMAGOTCHI's great attraction stems from its need for almost continous nurturing. This nurturing instinct is also a significant feature in human-pet relationships - the family pet always needs attention, and the pleasure it brings its keepers derives partly from the sustained dominance and importance of those who take care of it. It is this nurturing theme that engenders, in many TAMAGOTCHI owners, a feeling of love for their virtual pet, an experience that can substitute for owning and caring for a real pet or even a human baby.

The highest form of virtual pet is one that moves around your room, for example Sony's AIBO, the robot dog whose behaviour patterns include expressions of anger, disgust, fear, happiness, sadness, and surprise. The AIBO plays, it sleeps, it wags its tale, and it simulates feelings of affection and unhappiness. As a result of its animallike behaviour, AIBO engenders similar feelings of love from many of its owners to those felt by the owners of real pets, and some AIBO owners speak of AIBO having feelings, and as having unique mental qualities or personality. As the technology improves, and as robot pets become increasingly lifelike, the boundary between people's perceptions of robot pets and their perceptions of real animals will become increasingly blurred. A growing number of people will treat robots as if they are mental, social and moral beings, thus raising the general perception of robot creatures towards the level of biological creatures. What will this mean for society?

As robots become increasingly accepted as being similar to biological creatures, so we will come to treat them more like partners than like slaves. From these arguments and findings I may conclude that robotic pets and humanoid robots will increasingly exhibit caring and affectionate attitudes towards humans, and that the

\footnotetext{
${ }^{1}$ Usually a thumbnail sized electronic component called a microprocessor or micro-controller.
} 
effect of such attitudes will be to increase our liking for these robots. Humans long for affection, and tend to be affectionate towards those who offer it.

When robots are able to exhibit the whole gamut of human personality and physical characteristics, their emotional appeal to humans will have reached a critical level in terms of attracting us, inducing us to fall in love with them, seducing us in the widest sense of the word. We will recognize in these robots the same personality characteristics that we notice when we are in the process of falling in love with a human. If someone finds a sexy voice in their partner a real turn-on, they are likely to do so if a similar voice is programmed into a robot. If it is a particular trait that turns you on, your robot will come with that trait ready made or it will learn the trait as it discovers its importance to you.

Although the practice of treating computers and robots as our social partners is still very much in its infancy, the concept is gaining currency as more and more interactive personalities appear on the market, as they become steadily more lifelike, more intelligent, more emotional, and more emotionally appealing. And as the emotional appeal of robots increases, we humans will become increasingly vulnerable, in our relationships with robots, to one of the strongest of all emotions, to love.

When robot creatures are generally perceived as being similar to biological creatures (see above), the effect on society will be immense. It will be as though hordes of people from a hitherto unknown and far-off land have emigrated to our shores, a people who behave like us in many ways but who are, very clearly, different. Shakespeare's sixteenth century test: "If you prick us, do we not bleed?" will be failed by these hordes, but in most other respects they will be able to pass whatever tests are prescribed for identifying members of our species. Their capacity for serving as our companions, our lovers, and our life-partners, will be in many ways superior to those of mere mortals. And that, I feel, is the really scary aspect of love and sex with robots. Not the fact that robots will be able to perform almost any job better than the most accomplished human, to be the world's best surgeons, lawyers, politicians, chefs, .... but that in some ways they will be better husbands, wives, and lovers than our fellow human beings.

\subsection{Falling in Love with Virtual People (Humanoid Robots)}

Children of all ages own all sorts of electronic products. The love that yesteryear's children and young adults demonstrated for their FURBIES and TAMAGOTCHIs will form the basis for the adults of the future accepting robots, developing affection for them, and falling in love with them. This, essentially, is what is investigated in RQ4. Those who are born surrounded by electronic gizmos will grow up eager for and receptive to whatever new electronic inventions become available during their lifetimes, and when "malebots" and "fembots" are available for general consumption, the gizmo-savvy generations will be ready for them. But how long will it be before this is likely to happen? Electronic speech technologies are already 
at the stage where the best quality synthetic voices cannot be distinguished from human voices. Other human characteristics, such as the texture and sensitivity of our skin, our knowledge and some of our reasoning powers, our creativity ..., all are today capable of reasonably convincing simulation, and the modelling of human personality and emotion are within the current grasp of Artificial Intelligence researchers. Given the speed with which the humanisation of all these technologies is developing, our grandchildren can expect the appearance and behaviour of their robots to bear such an uncanny resemblance to those of their human friends that they will find it extremely difficult, if not impossible, to determine whether the being standing a few feet away is a human or a robot.

How will it affect us when we are no longer able, instinctively, to tell robot from human at a glance? How will it affect the way in which we interact with someone who we are meeting for the very first time, if we are not certain whether they are indeed a someone, or instead a something? Will the differences, such as they will be, between humans and robots, create a new form of discrimination? Will we humans be thinking and uttering the phrase: "You're only a robot" more often or less often than "You're only a human"? Which group will be most discriminated against, robots or humans?

A second interesting aspect of the great similarity between mid- $21^{\text {st }}$ century androids and humans, takes us back to the question Sherry Turkle asks in the Introduction to this thesis, "not what the computer will be like in the future, but instead, what will we be like? What kind of people are we becoming?" Extending this question, now more than 20 years old, by replacing "computers" with "androids", makes it all the more relevant to our future. One way to answer this question might perhaps be to use androids as the basis for our appraisals of ourselves, rather than to think of ourselves as the standard by which androids should be judged. Kaja Silverman (1991) makes this point in her essay "Back to the Future", in which she analyses Ridley Scott's film Blade Runner. She explains that the viewer "can discover more about his or her own psychic organization" by studying the android characters in the film than by looking at the humans.

\subsection{Human Beings, Sex, and Robots}

There are several reasons for desiring sex that have been enumerated by psychologists: the obtaining of pleasure (which Sigmund Freud believed to be the principal reason), as well as boredom, adventure, recreation, and simply having an opportunity for a sexual encounter. These reasons form the basis for answering RQ5. The most direct answers are given in tables 7.1 to 7.3. From the research results contained in these tables I may conclude that people enjoy sex primarily: (1) for pure pleasure, and (2) to express emotional closeness. For humans who have sex with robots, the physical delight of orgasm will be the same, assuming that the robot's construction provides for an accurate shaping and texture of its penis or vagina; while being bored, wanting adventure or recreation, and having an opportunity for a sexual encounter with a robot, are all reasons for wanting sex that 
will be equally applicable in human-robot relationships. Given this wide overlap in applicability between the motivations for wanting sex with a human and the reasons for wanting sex with a robot, it seems clear that there will be enormous numbers of people for whom these motivations prove sufficient to light their sexual fire.

Investigations by psychologists into the most common reasons why people have sex, reveal certain insights into how men and women will differ in their attitudes to sex with robots. When discussing their motivations for sex, women typically give reasons relating to love, while the answers from men typically focus much more on the physical pleasure. This suggests that most men who embrace sex with robots will do so primarily because they will want the pure physical pleasure of intercourse and orgasm, while most women will want not only a personal demonstration of the robot's virtuoso lovemaking skills but also to feel the robot's virtual love for them.

One of the effects on society of robot sex might be that this fundamental difference between the sexual motivations of men and women undergoes a rethink from both the male and the female points of view. As robots become not only our lovers, but also our tutors in lovemaking skills, they could enhance the sexual experience for many men and women by increasing, for each sex, the benefits and feelings most often appreciated by the opposite sex. Sexual robots could encourage men towards a deeper exploration of their feelings of emotional attraction to their human sex partners, while women could be encouraged and taught how to achieve greater physical pleasure from sex. The result of all this tuition would be higher levels of pleasure and satisfaction for men and for women, not only in their couplings with robots but also in their human sexual encounters.

\subsection{Why People Pay for Sex}

An analysis of the motivations behind paying for sex informs our understanding of why sex with robots will quickly become popular. This, in turn, casts an interesting light on commercial sex as we currently know it, the subject of RQ6, and helps our understanding of the role of the sex worker in society. To summarize my conclusions: men prefer an economic transaction without any "complications" (such as a relationship), and to a lesser extent to feel a measure of emotional closeness. For women the emotional closeness is more relevant, and they treat the economic transaction as love for sale rather than sex for sale. Payments for sex as part of therapy are of a different order; and are very much rarer than payments by men for pleasure and payments by women for love.

Many people, mostly but not exclusively men, admit to using the services of prostitutes on a regular basis. Clearly their encounters with prostitutes provide the pleasure and satisfaction they seek from sex, otherwise these clients would not be "regulars". Yet the clients, unless they are deluding themselves, know full well that their chosen sex objects do not love them or bear any affection other than for the size of their wallets, belying the argument that sex without the receipt of human love, or at least human affection, cannot be enjoyable and/or beneficial. The fact that 
prostitution continues to thrive, leads to the conclusion that, for a significant proportion of the population, neither affection nor love is an essential element in a sexual relationship. In fact, the opposite is often true - "uncomplicated sex", "sex without commitment" and "sex with no emotional ties", are key reasons, repeated often to researchers in this field to explain visits to prostitutes.

There are clear and significant parallels between the enjoyment and benefits derived by clients from sex with a prostitute and the enjoyment and benefits that will be derived by their owners from sexual robots. For men, in addition to the physical pleasure of orgasm, two of the most important aspects of their encounters with prostitutes are the desire for reciprocity and a need for companionship. In many cases the emotional functions and benefits of a client's visit to a prostitute are even more important to the client than the desire for sex, causing many clients to develop in their minds an illusion founded in the pampering and fake affection that many prostitutes exhibit. This illusion in the minds of the johns will be even more believable when the pampering and simulated affection emanate from a sexual robot, partly because, in the case of the prostitute, the john is repeatedly reminded, when paying for every encounter, of the connection between the sexual experience and money, whereas a robot's owner will quickly forget about the connection between their sexual couplings and the purchase price of the robot. In addition, robots will express their virtual affection and other emotions in a much more convincing manner than most prostitutes, because their emotions and enthusiasm will be programmed into them, instead of being acted out with little genuine enthusiasm for the need to convince.

Variety is another of the major reasons expressed by johns for their encounters with prostitutes. A robot will be able to provide endless variety: in terms of its conversation, its voice, its knowledge and its virtual interests, its personality, and just about every other aspect of its being, including variety in the nature and intensity of the sexual experiences it can deliver. Furthermore, robots will not only be able to satisfy any particular sexual desire expressed by their owners, but also to suggest sexual practices and techniques that their owners have never previously experienced, and to teach their owners to become better lovers for those occasions when they prefer human company to sex with their robot.

With robots able to provide variety, to offer sex without complications or constraints, and to meet the needs of those who have no success in finding human sex partners, clearly they will provide everything a prostitute provides and much more. And for those women who are swelling the ranks of today's sex tourists, beautifully toned malebot bodies can be made to order, with whatever vital dimensions are desired.

Given that all these aspects of sex will be available for purchase from robots, as they are from prostitutes, robots capable of satisfying the needs of the clients of sex workers will clearly have an important social role to play in decades to come. Sexual gratification on demand will be available to all who want it, with very little social stigma and without any fear of sexually transmitted disease. 
Because robot sex involves payment at some point in time, whether it be the purchase price of the robot or a Japanese style robot escort service ${ }^{2}$, there will be in practice considerable similarity between sex with a robot and sex with a prostitute. Why then, if sex with robots is a prospect for society to relish, should society deprecate prostitutes and those who employ their services? Is it logical to be in favour of machines that provide a service, but against those humans who provide that same service? Or should we, perhaps, be reassessing how society should regard sex workers? Compared with using robots, human sex workers have one major disadvantage - they are less easy to keep free from disease. Does this not suggest that it should not be the performance of commercial sex that needs to be wiped out, but the health risks? And if those risks could be eradicated in today's society, would we then not be able to accept the sex worker as a respected professional?

\subsection{Sex Technologies}

The history of devices for helping to achieve sexual gratification has demonstrated an increase in their use that parallels the development of the technologies that drive them. Therein lies the basis of the answer to RQ7. From the dames de voyage designed for late nineteenth century sailors, to the Thrillhammer and Sybian a century years later that provide women with artificial thrusting or rotating penises, the designers of sexual technology have become ever more inventive. And when the technologies of robotics and artificial intelligence become integrated with these various sexual technologies, as indeed they have already started to be, we will witness the first fully-fledged sexual robots. How will these real-life Barbarellas and Lawnmower Men change our sexual thinking and tastes? Rein de Wilde (2000) explains that it can be difficult to predict such changes: "But no matter how 'smart' new technologies may be, the nature of the social and cultural changes they trigger continues to be very hard to foretell." Nevertheless, I believe that in the case of sexbots, the trends discussed in this thesis are strong enough to minimize the difficulty of making realistic predictions such as those I have argued.

The launch of the RealDoll brand of sex dolls in 1996 was instigated by the desires of male customers who had specifically requested life-sized female forms that they wanted for fornication. Many of the customers of sex dolls presumably fantasize that these lifeless objects might in fact be alive in some sense, a phenomenon that Sigmund Freud (1919) described as "uncanny" in his essay of that title.

"When we proceed to review things, persons, impressions, events and situations which are able to arouse in us a feeling of the uncanny in a particularly forcible and definite form, the first requirement is obviously to select a suitable example to start on. Jentsch has taken as a very good instance 'doubts whether an apparently animate being is really alive; or conversely, whether a lifeless object might not be in fact animate'; and he

\footnotetext{
${ }^{2}$ See section 9.4 .
} 
refers in this connection to the impression made by waxwork figures, ingeniously constructed dolls and automata."

The fact that the RealDoll manufacturers can sell some 350 of them each year, at prices in excess of $\$ 6,000$, testifies to the demand for such products even though they are inanimate, lacking any moving parts that could enhance the physical experience. From this demand, and from the success of the first Japanese and South Korean rent-a-sex-doll services, it is reasonable to conclude that, when electronic devices are added to the design, converting the inanimate into artificial life forms, and when the price comes down and down as a result of the inevitable surge in demand, the resulting fembots, even though still rather rudimentary, will be an enormous commercial success.

A similar conclusion can be drawn in relation to the first moving malebots that will appear on the market. The soaring sales of vibrators in recent years, their popularity and their respectability, have enabled many millions of women to appreciate them as providing a reliable and satisfying method for achieving great orgasms. This huge success of vibrators as commercial products should be sufficient proof that women will welcome malebots with open arms. For women the thrill of a robot-induced orgasm will be even greater than that of a vibrator induced orgasm, because of all the additional love-making skills that robots will possess.

This conclusion, that malebots and fembots will inevitably become huge commercial successes, is indicative of how our sexual thinking and tastes will change. Initially much of the enthusiasm for coupling with sexbots will be prompted by curiosity, as we strive to discover how robot sex compares with the real thing. Many of those who are robot sex virgins will get their first experience as a result of wanting to know how it feels. But once this curiosity has been satisfied, and once the initial media exposure has made everyone aware of the pros and cons of the robot sexual experience, the demands of the market will drive sexbot researchers to work overtime in the development of newer and better technologies that can bring enhanced experiences. People will want better robot sex, and even better robot sex, and better still robot sex, their sexual appetites becoming avaricious as the technologies improve, and with their improvement the level of joy that they deliver with each experience. In short, I believe it quite possible that the terms "sex maniac" and "nymphomaniac" will take on new meanings or at least new dimensions, as what are perceived as natural levels of human sexual desire change to conform to what is newly available - great sex on tap for everyone, 24/7.

\subsection{The Mental Leap to Sex with Robots}

Although the idea of sex with robots has been mooted in the literature of Artificial Intelligence and some other scientific disciplines, as yet it is not yet taken seriously by a significant proportion of the population. But sexual ideas and attitudes change with time, as is clear from a comparison of the contemporary view of certain sexual practices with the mass of popular opinion on those same practices a century or 
more ago. Homosexual behaviour, including sodomy, provides the clearest example, having been punishable by death in many "civilized" countries less than 200 years ago, whereas nowadays it is accepted, in most countries, that what consenting adults do with each other in private is their business, and should not be subject to legislation. Furthermore, same sex marriages and civil unions are rapidly becoming relatively commonplace occurrences, where previously they would have been unthinkable. Other examples of significant changes in sexual mores with time include oral sex, once treated with a similar harshness to sodomy, but today being also almost de rigeur in most heterosexual relationships. And both fornication (sexual intercourse other than with one's spouse), and masturbation, have moved from being heavily stigmatised to being considered perfectly normal activities. These changes in the mass of opinion point to the answer of RQ8.

The huge changes in attitude that have developed over time towards these sexual practices have caused all four to be now widely regarded as acceptable, and as leading to fulfilling relationships and satisfactory sex lives. Progress in social ideas and social change are happening very much faster in the first decade of the twentyfirst century than they ever did in the past, and, as with science and technology, the rates of progress and development in social and sexual ideas are themselves accelerating, which will inevitably lead to even more rapid changes in the acceptability of new sexual practices, to the point where blow-up dolls and robots will become widely acceptable as sex partners within contemporary society.

On consideration of the ten possible obstacles I have discussed in chapter 10, and the results of my investigations into them, I may conclude that all of these obstacles have had different levels of significance in relation to the progress that has been made in our sexual attitudes and mores over time. Homosexuality, for example, was the most serious of these obstacles to social progress, and in the minds of some people it still is. But whatever obstacles remain to be overcome will, I believe prove to be only temporary obstacles.

The latest sexual revolution, often called cybersex, reflects both the advances in the technologies that make it possible and the norms and play areas of contemporary sexual culture. Technology now allows people who might previously have felt sexually repressed, guilty, unimaginative or shy, a way to express their sexuality almost without limitations, and to explore different sexual ideas and opportunities. Sex itself has become an activity which, instead of simply requiring the physical presence of a second person, is now, for many people, something different, whether it be the opportunity to meet potential sex partners in an Internet chat room, or one of the intimate activities that have been made possible through the development of dildonic and teledildonic devices. The sexual possibilities created by such devices are mind-boggling, so for many people sex today is already rather different, and the differences stem from the technologies. Amongst these differences are the lack of a necessity to worry about AIDS and other sexually transmitted diseases, even without a condom, since the use of haptic interfaces allows sex to take place between lovers who could be in entirely different locations, or between a human lover and an electronically controlled sex machine or some other form of artificial partner. 
It is difficult to predict exactly how long it will take for the full potential of these new sexual possibilities to be widely appreciated and adopted. Although new technology has a powerful influence on human behavior, there is often a lag in time between the emergence of the technology and the adaptation of social behavior to that technology. I believe that, because sexual desire is such a powerful human instinct, in the case of $21^{\text {st }}$ century sexual behaviour deriving from new technology the lag might well be minimal. Already there is a groundswell of interest in relationships with sexbots. An Internet survey in February 2003, investigating what sex technology most people desire, found that the clear favourite was "android love slaves". As robots appear on the market with physical characteristics that can be specified by the customer, and with all the knowledge in The Kama Sutra, The Joy of Sex, and countless similar books programmed into their memories, the demand for them will be enormous. Robots will be able to learn what the user likes, to cater to the user's sexual tastes, and to provide instruction for the sexual novice.

In addition to the reduction of the incidence of sexually transmitted diseases, there are other obvious social benefits in robot sex: the likely reduction in teenage pregnancy and abortions; the use of same-sex robots by heterosexuals wanting to experiment with homosexual relations, and similarly for gays and lesbians who might use opposite sex robots to experiment with heterosexuality. By providing a host of different options, manufacturers will make sex robots appealing to just about every sexual orientation and persuasion. Ultimately robot sex could become better for many people than sex with humans, as robots surpass human sexual technique and become capable of satisfying everyone's sexual needs.

\subsection{Answering the Problem Statements}

Problem statement PS1has been answered by my conclusions to research questions RQ1, RQ2, RQ3, and RQ4. This leads to the overall conclusion for PS1 that the emotions that humans feel for other humans, for pet animals, for virtual pets, and even for less animal-like artefacts - namely computers -, will be fully extended to embrace the robots of the future.

Problem statement PS2 has been answered by my conclusions to research questions RQ5, RQ6, RQ7, and RQ8. This leads to the overall conclusion for PS2 that the normal bounds of human sexuality will be fully extended to embrace the robots of the future.

\subsection{Future Research}

Four intriguing questions remain, as mentioned in Chapter 8. Although they are beyond the scope of my thesis I suggest them as topics for further research.

(1) Can the introduction of sexual robots help to reduce the violence that is wrought on (young) prostitutes? 
(2) Will the arrival of sexual robots render many people (women in particular) unemployed?

(3) Is it practically and scientifically possible to make an inventory of the factors that trigger an individual's sexual desires?

and

(4) Would a robot who is the perfect lover represent perfection as a partner? If so, what is our vision of the future? 


\section{References}

Abyss (2006). Abyss Creations LLC Web site. Available at http://www.realdoll.com

Acton (1857). The Functions and Disorders of the Reproductive Organs in Youth, in Adult Age, and in Advanced Life. John Churchill, London

Ainsworth, M. (1991). Attachments and Other Affectional Bonds Across the Life Cycle. Attachment Across the Life Cycle (eds. C. Parkes, J. Stevenson-Hinse, and P. Marris), pp. 33-51, Routledge, New York.

Alabama (2002). United States District Court Northern District of Alabama Northeastern Division, Civil Action No. CV-98-S-1938-NE, 2002.

Allen, J., Kenrick, D., Linder, D., and McCall, M. (1989). Arousal and Attraction: A Response-Facilitation Alternative to Misattribution and NegativeReinforcement Models. Journal of Personality and Social Psychology, Vol. 57, pp. 261-270.

Allen, K. (1995). Coping with Life Changes and Transitions: The Role of the Pet. Interactions, Vol. 13, No. 3, pp. 5-8.

Allen, K., Skykoff, B., and Izzo, Jr., J. (2001). Pet-ownership, but Not ACE Inhibitor Therapy, Blunts Home Blood Pressure Responses to Mental Stress. Hypertension, Vol. 38, pp. 815-820.

Allen, K., Blascovich, J., and Mendes, W. (2002). Cardiovascular Reactivity and the Presence of Pets, Friends and Spouses: The Truth about Cats and Dogs. Psychosomatic Medicine, Vol. 64, No. 5, pp. 727-739.

Allgeier, A. And Allgeier, E. (2000). Sexual Interactions. Houghton Mifflin, Boston.

Allis, S. (2004). Artificial Emotion. The Boston Globe, February 29.

Alma-Mahler (2005). Alma's Life.

Available at http://www.alma-mahler.at/engl/almas_life/puppet3.html

Amaro, F., Dantas, A., and Teles, L. (1995). Sexual Behaviour in the City of Lisbon. International Journal of STD and AIDS, Vol. 6, pp. 35-41.

Ambady, N., Koo, J., Rosenthal, R., and Winograd, C. (2002). Physical Therapists' Nonverbal Communication Predicts Patients' Health Outcomes. Psychology and Aging, Vol. 17, No. 3, pp. 443-452. 
American Medical Association (1972). Human Sexuality.

Amodio, D. and Showers, C. (2005). "Similarity Breeds Liking” Revisited. Journal of Social and Personal Relationships, Vol. 22, No. 6, December 2005, pp. 817836.

Ananova (2005). Robot Sex Dolls. Ananova Web site.

Available at http://www.ananova.com/news/story/sm_1361247.html

Anderson, W., Reid, C., and Jennings, G. (1992). Pet-ownership and Risk Factors for Cardiovascular Disease. The Medical Journal of Australia, Vol. 157, pp. 298-301.

Anderson, J.R. (1993). Rules of Mind. Lawrence Erlbaum, Hillsdale, NJ.

Anderson, M. and Anderson, S.L. (2006). Machine Ethics. IEEE Intelligent Systems, Vol. 21, No. 4, pp. 10-11.

Anonymous (1848). Prostitution in Berlin, and its Victims.

APPMA (2003). New Survey Shows America's Love Affair With Their Pets Stronger than Ever. American Pet Products Manufacturers Association. Available at http://www.appma.org/press_releasedetail.asp? $\mathrm{v}=\mathrm{ALL} \& \mathrm{id}=36$

Archer, J., Ireland, J., Mills, J., and Parker, S. (Unpublished). Human Attachment to Pet Dogs.

Archer, J. (1997). Why Do People Love Their Pets? Evolution and Human Behavior, Vol. 18, pp. 237-259.

Argus, J. (2003). Best Man's Friend is his Owner. Bradford Telegraph and Argus. Available at http://archive.thisisbradford.co.uk/2003/08/29/108654.html

Arkin, R., Fujita, M., Takagi, T., and Hasegawa, R. (2002). An Ethological and Emotional Basis for Human-Robot Interaction.

Available at http://www.cc.gatech.edu/ai/robot-lab/publications.html

Arkin, R. and Masahiro, F. (2003). An Ethological and Emotional Basis for HumanRobot Interaction. Proceedings of the IEEE/RSJ International Conference on Intelligent Robots and Systems - Special Issue on Socially Interactive Robots, Robotics and Autonomous Systems, Vol. 42, Nos. 3-4.

Aron, A., Dutton, D., Aron, E., and Iverson, A. (1989). Experiences of Falling in Love. Journal of Social and Personal Relationships, Vol. 6, pp. 243-257. 
Aron, A., Melinat, E., Aron, E., Vallone, R., and Bator, R. (1997). The Experimental Generation of Interpersonal Closeness: A Procedure and Some Preliminary Findings. Personality and Social Psychology Bulletin, Vol. 23, No. 4, pp. 363347.

Aron, A., Fisher, H., Mashek, D., Strong, G., Li, H., and Brown, L. (2003). Reward, Motivation and Emotion Systems Associated with Early-Stage Intense Romantic Love. Journal of Neurophysiology, Vol. 94, pp. 327-337.

Aronson, E. and Linder, D. (1965). Gain and Loss of Esteem as Determinants of Interpersonal Attractiveness. Journal of Experimental Social Psychology, Vol. 1, pp. 156-171.

Asahi Shimbun (2005). By 2010 Toyota will Fetch Tea and Tidy Your Home. The Asahi Shimbun, June 1st.

Ashenhurst, R.L. and Graham, S. (eds.) (1987). ACM Turing Award Lectures. The First Twenty years 1966-1985. ACM Press, New York, N.Y. Addison-Wesley Publishing Company, Reading, Ma.

Asimov, I. (1942). Runaround. Astounding Science Fiction, March 1942.

Asimov (1988). Prelude to Foundation. Easton Press, Norwalk, CT.

Balderston, M. and Mitchell, T. (2001). Virtual Vaginas and Pentium Penises: A Critical Study of Teledildonics and Digital S(t)imulation. Conference on Performance, Pedagogy, and Politics in Online Spaces, University of Maryland, April. Available at http:/www.georgetown.edu/ users/baldersm/ essays/ teledildonics.pdf

Barker, S. and Barker, R. (1988). The Human-Canine Bond: Closer than Family Ties? Journal of Mental Health Counseling, Vol. 10, pp. 46-56.

Barker, S. (1989). Pet Loss and Bereavement. Companion Animal Practice, Vol. 19, Nos. 4-5, pp. 3-5.

Barker, S. and Barker, R. (1990). Investigation of the Construct Validity of the Family Life Space Diagram. Journal of Mental Health Counseling, Vol. 12, pp. 506-514.

Barrio, C. (1966). Apparatus For the Reactivation of Certain Functions of the Human Body. U.S. Patent no. 3,472,223, filed February 15th 1966, granted October 14th 1969.

Bartels, A. and Zeki, S. (2000). The Neural Basis of Romantic Love. NeuroReport: Motivation, Emotion, Feeding, Drinking, Vol. 11, No. 17, pp. 3829-3834. 
Barton, L. (2005). Cited in: It's All About What You Want and When You Want IT. The Guardian, December 2nd.

Bass, D. (1988). The Evolution of Human Intrasexual Competition: Tactics of Mate Attraction, Journal of Personality and Social Psychology, Vol. 34, No. 4, pp. 616-628.

Baudrillard, J. (1983). Simulations, Semiotext(e). Foreign Agents Series, Autonomedia, New York.

Baudrillard, J. (1998). Simulacra and Simulations. In Poster, M. (Ed.), Jean Baudrillard, Selected Writings. Stanford University Press, Stanford, pp.166184.

Baumeister, R., Catanese, K. and Vohs, K. (2001). Is There a Gender Difference in Strength of Sex Drive? Theoretical Views, Conceptual Distinctions, and a Review of Relevant Evidence. Personality and Social Psychology Review, Vol. 5, No. 3, pp. 242-273.

Baun, M., Bergstrom, N., Langston, N., and Thomas, L. (1984). Physiological Effects of Human/Companion Animal Bonding. Nursing Research, Vol. 33, No. 3, pp. 126-129.

Beauvoir, S. de (1955). All Men Are Mortal. World Publishing Co., Cleveland.

Beck, A. and Katcher, A. (1983). Between Pets and People: The Importance of Animal Companionship. G.P. Putnam's Sons, New York.

Beck, A., Edwards, N., Friedman, B., and Khan, P. (2005). Value Sensitive Design: Robotic Pets and the Elderly. Available at http://www.ischool.washington.edu/ vsd/projects/aiboelderly.html

Beilin, P. (2005). First Trio 'Married' in The Netherlands. Available at http://www.brusselsjournal.com/node/301

Belk, R. (1988). Possessions and the Extended Self. Journal of Consumer Research, Vol. 15, pp. 139-168.

Bell, G. (1997). Laws of Predictions. Lecture at ACM '97. Available at http://research.microsoft.com/acm97/gb/tsld001.htm

Belove, L. (1980). First Encounters of the Close Kind (FECK). The Use of the Story of the First Interaction as an Early Recollection of a Marriage. Journal of Individual Psychology, Vol. 36, No. 2, pp. 191-208.

Berman (2004). The Health Benefits of Sexual Aids and Devices: A Comprehensive Study of their Relationship to satisfaction and Quality of Life. The Berman Center, Chicago, 2004. 
Bernstein, E. (2005). Desire, Demand, and the Commerce of Sex. Regulating Sex: The Politics of Intimacy and Identity (eds. Elizabeth Bernstein and Laurie Schaffner), pp. 101-128, Routledge, New York.

Berryman, J., Howells, K., and Lloyd-Evans, M. (1985). Pet-owner Attitudes to Pets and People: A Psychological Study. The Veterinary Record, Vol. 117, Nos. 2526, pp. 659-661.

Bickmore, T. (1998). Friendship and Intimacy in the Digital Age. MIT Media Laboratory Report, MAS 714 - Systems and Self.

Bickmore, T. (2003). Relational Agents: Effecting Change Through HumanComputer Relationships. Ph.D. Thesis, MIT, Cambridge, Massachusetts.

Bickmore, T. and Picard, R. (2004). Towards Caring machines. Proceedings of CHI, Vienna.

Bickmore, T. and Picard, R. (2005). Establishing and Maintaining Long-Term Human-Computer Relationships. ACM Transactions on Computer-Human Interaction, Vol. 12, No. 2, pp. 293 - 327.

Binsted, K. (1996). Machine Humour: An Implemented Model of Puns. Ph.D. thesis, Department of Artificial Intelligence, University of Edinburgh.

Blanchard, V. (2001). The Tapestry of Surrogate Partner Therapy. The School of ICASA Web site. Available at http://www.icasa.co.uk.

Bloch, I. (1909). The Sexual Life of Our Time. (Translated, M. Eden Paul), Rebman, London.

Bodmer, N.M. (1998). Impact of Pet-ownership on the Well-Being of Adolescents With Few Familial Resources. Companion Animals in Human Health (eds. C.C. Wilson and D.C.Turner), pp. 237-247, Sage Publications, Thousand Oaks, CA.

Bokkers, E. (2006). Effects of Interactions Between Humans and Domesticated Animals. Farming for Health (eds. J. Hassink and M. van Dijk), pp. 31-41. Springer-Verlag, Dordrecht.

Bombar, M. and Littig, L. (1996). Babytalk as a Communication of Intimate Attachment: An Initial Study in Adult Romances and Friendships. Personal Relationships, Vol. 3, pp. 137-158.

Bowen, N. (2004). Sugar Mamas. The Bulletin, Sydney.

Bowlby, J. (1969). Attachment. Attachment and Loss, Vol. 1, Hogarth Press, London.

Bowlby, J. (1988). A Secure Base. Basic Books, New York. 
Bradley, M. and Lang, P. (2000). Affective Reactions to Acoustic Stimuli. Psychophysiology, Vol. 37, 2000, pp. 204-215.

Braidotti, R. (1996). Cyberfeminism with a Difference. New Formations. No. 29 (Autumn 1996), pp. 9-25.

Brave, S., Nass, C., and Hutchinson, K. (2005). Computers That Care: Investigating the Effects of Orientation of Emotion Exhibited by an Embodied Computer Agent. International Journal of Human-Computer Studies, Vol. 62, pp. 161178.

Breazeal, C. (2002). Designing Sociable Robots. The MIT Press, Cambridge, MA.

Brewer, D., Potterat, J., Garrett, S., Muth, S., Roberts, J., Kasprzyk, D., Montano, D., and Darrow, W. (2000). Prostitution and the Sex Discrepancy in Reported Number of Sexual Partners. Proceedings of the National Academy of Science of the U.S.A., Vol. 97, No. 22, pp. 12385-12388.

Brickel, C. (1986). The Therapeutic Roles of Cat Mascots with a Hospital-Based Geriatric Population: A Staff Survey. Gerontologist, Vol. 19, pp. 368-372.

Brooke, J. (2004). Japan Seeks Robotic Help in Caring for the Aged. New York Times, March 5th.

Bryant, B.K. (1985). The Neighbourhood Walk: A Study of Sources of Social Support in Middle Childhood From the Child's Perspective. Monographs of the Society for Research in Child Development, Vol. 50, No. 3 (serial no. 210).

Bryant, C. (1993). On the Trail of the Centaur: Toward an Amplified Research Agenda for the Study of the Human-Animal Interface. Proceedings of the 1992 International Conference on Science and the Human-Animal Relationship, in Science and the Human Animal Relation (ed. E. Hicks ), Netherlands Universities Institute for Coordination of Research in Social Sciences, SISWO Publikatie 374, Amsterdam.

Bullough, B. and Bullough, V. (1998). Female Prostitution: Current Research and Changing Interpretations. Prostitution: On Whores, Hustlers, and Johns (eds. James Elias, Vern Bullogh, Veronica Elias and Gwen Brewer, pp. 23-44. Prometheus, Amherst, NY.

Burton, R. (trans.) (1883). The Kama Sutra of Vatsyayan. Hindoo Kama Shastra Society, London and Benares, privately printed.

Butler, J. (1990). Gender Trouble: Feminism and the Subversion of Identity. Routledge, New York.

Byrne, D. (1971). The Attraction Paradigm. Academic Press, New York, 1971. 
Byrne, D. and Murnen, S. (1998). Maintaining Loving Relationships. The Psychology of Love (eds. Sternberg, R. and Barnes, M.), pp. 293-310. Yale University Press, New Haven, Connecticut.

Cacioppo, J., Bernston, G., Klein, D., and Poehlmann, K. (1997). Psychophysiology of Emotion across the Life Span. Annual Review of Gerontology and Geriatrics, Vol. 17, 1997, pp. 27-74.

Cain, A. (1983). A Study of Pets in the Family System., New Perspectives on our Lives With Companion Animal (eds. A. Katcher and A. Beck), pp. 561-571. University of Pennsylvania Press, Philadelphia.

Cain, A. (1985). Pets as Family members. Pets and the Family,(ed. M. Sussman), pp. 5-10. The Haworth Press, New York.

Cañamero, D. and Fredslund, J. (2000). I Show You How I Like You. IEEE Transactions on Systems, Man and Cybernetics, Part A, Vol. 31, No. 5, pp. 454459.

Čapek, K. (1923). R. U. R. Doubleday, Page and Co., Garden City (transl. From Czech by Paul Selver).

Carmack, B. (1985). The Effects on Family Members and Functioning After the Death of a Pet. Pets in the family (ed. M. Sussman), pp. 149-164. The Haworth Press, New York, New York.

Carpenter, B. and Doran, R. (1986). A.M. Turing's ACE Report of 1946 and Other Papers. MIT Press, London.

Carroll, J., Vole, K.D., and Hyde, J. (1985). Differences Between Males and Females in Motives for Engaging in Sexual Intercourse. Archives of Sexual Behavior, Vol. 14, pp. 131-139.

Carter, J. (2001). Birds, Bees, and Venereal Disease: Toward an Intellectual History of Sex Education. Journal of the History of Sexuality, Vol. 10, No. 2, pp. 213249.

Cartwright, K. (2002). Interracial Marriages More Widely Accepted. The Statesman, Utah State University.

Available at http://www.utahstatesman.com/news/2002/10/02/Features/

Cary, H. (1922). Erotic Contrivances: Appliances Attached to, or Used in Place of, the Sexual Organs. Privately printed, Chicago.

Cassell, J. (2000). Embodied Conversational Agents (eds. J. Sullivan, S. Prevost and E. Churchill), MIT Press, Cambridge, Massachusetts. 
Catanzaro, T. (1984). The Human Animal Bond in Military Communities. The Pet Connection (eds. R. Anderson, B. Hart and L. Hart), pp. 341-347. Censhare, University of Minnesota, Minneapolis.

Catechism of the Catholic Church (1992).

Cavanagh, K., Zack, J., Shapiro, D., and Wright, J. (2003). Computer Programmes for Psychotherapy. Chapter 8 of Technology. Counselling and Psychotherapy: A Practitioner's Guide (eds. S. Goss and K. Anthony), pp. 220-227. Palgrave MacMillan, Basingstoke, UK.

Cherniak (1978). The Riddle of the Universe and its Solution. The Mind's I. (eds. D. Hofstadter and D. Dennett), pp. 269-276. Basic Books, New York.

Chodorow, N. (1978). The Reproduction of Mothering: Psychoanalysis and the Sociology of Gender. University of California Press, Berkeley.

Christopher, F.S. and Cate, R. (1984). Factors Involved in Pre-Marital Sexual Decision Making. Journal of Sex Research, Vol. 20, pp. 363-375.

Clarke, A. (1952). An Examination of the Operation of Residential Propinquity as a Factor in Mate Selection. American Sociological Review, Vol. 17, No. 1 (Feb., 1952), pp. 17-22.

Clarke A.C. (1968). 2001: A Space Odyssey. New American Library, New York.

CNN (2005). Judge: Evolution stickers unconstitutional. CNN Web site, January $14^{\text {th }} 2005$, Available at http:/www.cnn.com/2005/LAW/01/13/evolution.textbooks.ruling/

Cohen, S. and Syme, L. (1965). Social Support and Health, Academic Press, San Diego, California.

Cohen, S. and Hoberman, H. (1983). Positive Events and Social Supports as Buffers of Life Change to Stress. Journal of Applied Social Psychology, Vol. 13, pp 99125.

Cohen, H. (1995). The Further Exploits of AARON, Painter. Stanford Humanities Review, Vol. 4, No. 2, pp. 141-160.

Concordia (2004). Communication Technologies and Gender. Web site, Concordia University, 2004.

Available at http://gendertech.pariso.com/blog/archives/ artifacts/

Connell, R. (2004). Rent-a-Doll Blows Hooker Market Wide Open. Mainichi Daily News, December $16^{\text {th }}$.

Available at http://mdn.mainichi.co.jp/waiwai/0412/ 1216doll.html 
The Continuum Complete International Encyclopedia of Sexuality (2003). Eds. Francoeur, R. and Noonan, R.

Cope, D. (2001). Virtual Music: Computer Synthesis of Musical Style. MIT Press, Cambridge, MA. See also David Cope's home page at http://arts.ucsc.edu/faculty/cope/

Coradeschi, S. (2006). Human-Inspired Robots. IEEE Intelligent Systems, Vol. 21, No. 4, pp. 74-79.

Cott, N. (2000). Public Vows: A History of Marriage and the Nation. Harvard University Press, Cambridge, Massachusetts.

Covert, A., Whiren, A., Keith, J., and Nelson, C. (1985). Pets, Early Adolescents, and Families. Marriage and Family Review, Vol. 8, Nos. 3-4, pp. 95-108.

Cowie, R., Douglas-Cowie, E., Tsapatsoulis, N., Votsis, G., Kollias, S., Fellenz, W., and Taylor, J. (2001). Emotion Recognition in Human-Computer Interaction. IEEE Signal Processing Magazine, pp. 33-80.

Cowles, K. (1985). The Death of a Pet: Human Responses to the Breaking of the Bond. Pets in the family (ed. M. Sussman), pp. 135-148.

Crooks, R. and Baur, K. (1999). Our Sexuality. Brooks/Cole, Pacific Grove, California.

Csikszentmihalyi, M. and Rochberg-Halton E. (1998). The Meaning of Things: Domestic Symbols and the Self. Cambridge University Press, Cambridge, UK.

Dartel, M. van (2005). Situated Representation. Ph.D. Thesis. Universiteit Maastricht. Maastricht, The Netherlands. ISBN 9052784914.

Dartel, M.F. van, Sprinkhuyzen-Kuyper, I.G., Postma, E.O., and Herik, H.J. van den (2005). Reactive Agents and Perceptual Ambiguity. Adaptive Behavior, Vol. 13 , No. 3, pp. 227-242.

Darwin, C. (1859). On the Origin of Species by means of Natural Selection, or the Preservation of Favoured Races in the Struggle for Life. John Murray, London.

Dastani, M. and Meyer, J.-J. Ch. (2006). Programming Agents with Emotions. Proceedings of the $17^{\text {th }}$ European Conference on Artificial Intelligence (eds. G. Breuker, S. Coradeschi, A. Perini, and P. Traverso), pp. 215-219. IOS Press, Amsterdam, the Netherlands.

Davenport-Hines, R. (1990). Sex, Death and Punishment: Attitudes to Sex and Sexuality in Britain since the Renaissance. Collins, London.

Davis, C., Blank, J., Lin, H-Y., and Bonillas, C. (1996). Characteristics of Vibrator Use Among Women. Journal of Sex Research, Vol. 33, No. 4, pp. 313-320. 
Davis, D., Shaver, P., and Vernon, M. (2004). Attachment Style and Subjective Motivations for Sex. Personality and Social Psychology Bulletin, Vol. 30, No. 8, pp. 1076-1090.

Davis, K. (1937). The Sociology of Prostitution. American Sociological Review, Vol. 2, No. 2, pp. 744-755.

Davis, S. and Valla, F. (1978). Evidence for Domestication of the Dog 12,000 Years Ago in the Natufian of Israel, Nature, Vol. 276, pp. 608-610.

Davis, S. (2001). Animal Attraction. TV programme, Australian Broadcasting Corporation.

Dawkins, R. (1976). The Selfish Gene. Oxford University Press, Oxford.

Dawkins, R. (1990). The Selfish Gene (Revised edition). Oxford University Press, Oxford.

Day, S., Ward, H. and Perrotta, L. (1993). Prostitution and Risk of HIV: Male Partners of Female Prostitutes. British Medical Journal, Vol. 307, pp. 359-361.

DeLamater, J. (1989). Gender Differences in Sexual Scenarios. Females, Males and Sexuality, (ed. Kathryn Kelly), pp. pp. 127-139. SUNY Press, Albany, New York.

Dennett, D. and Hofstadter, D. (1981). Reflections. The Mind's I. (eds. D. Hofstadter and D. Dennett), pp.317-320. Basic Books, New York.

Derrida, J. (1974). Of Grammatology. John Hopkins University Press.

Dewey, J. (1934). Art As Experience. Minton, Balch and Company, New York.

Diana, L. (1985). The Prostitute and Her Clients: Your Pleasure is Her Business. Charles C. Thomas, Springfield, IL.

Döring, N. (2002). Studying Online-Love and Cyber-Romance. Online Social Sciences, (eds. Bernard Batinic, Reips, U.-D. and Bosnjak, M.), Hogrefe and Huber Publishers, Germany, pp. 333-356.

Drake-Hurst, E. (1990). Pet Loss and Grief. Ph.D. dissertation, Pepperdine University.

Draper, T. Clayton, W. (1992). Using a Personal Robot to Teach Young Children. The Journal of Genetic Psychology, Vol. 53, No. 3, pp. 269-273.

Dreyfus, H. (1965). Alchemy and Artificial Intelligence. The Rand Corporation, Santa Monica. 
Dreyfus, H. (1972). What Computers Can't Do. Harper and Row, New York.

Duck, S. (1991). Understanding Relationships. The Guilford Press, New York.

Economist (1995). Asia - Child Prostitution in Cambodia. The Economist, Vol. 338, No. 7995, p. 37.

Ehrenreich, B. (1999). The Real Truth about the Female. Time Magazine, Vol. 153, No. 9, pp. 57-71.

Ekman, P. (1992). An Argument for Basic Emotions. Cognition and Emotion, Vol. 6, Nos. 3-4, pp. 169-200.

Ekman, P. and Friesen, W. (1978). Facial Action Coding System. Consulting Psychologist Press, Palo Alto, California.

Elliot, W. (1997). Sexual Revolutions, Great and Small. The Politics of Population. Available at http://govt.mckenna.edu/welliott/Sexrevns.htm

Ellis, H. (1899). Studies in the Psychology of Sex: The Evolution of Modesty, the Phenomena of Sexual Periodicy, and Autoeroticism. The University Press, Watford.

Ericsson, L. (1980). Charges Against Prostitution: An Attempt at a Philosophical Assessment. Ethics, Vol. 90, pp. 337, 342, 347, 355.

Ewing, C. (2000). Court Overturns Ban on Use of Sexual Devices. Judicial Notebook, Vol. 31, No. 1, January.

Ferber, D. (2003). The Man Who Mistook His Girlfriend for a Robot. Popular Science, Vol. 263, Issue 3 (September).

Fidler, M., Light, P., and Costall, A. (1996). Describing Dog Behavior Psychologically: Pet Owners Versus Non-Owners. Anthrozoös, Vol. 9, pp. 196200.

Firestone, S. (1970). The Dialectic of Sex: A Case for Feminist Revolution. William Morrow, New York.

Fong, T., Nourbakhsh, I., and Dautenhahn, K. (2003). A Survey of Socially Interactive Robots. Robotics and Autonomous Systems, Vol. 42, Nos. 3-4, pp. 143-166.

Forest $^{1}$, P. van (1653). Observationum et Curationum Medicinalum ac Chirurgicarum Opera Omnia Quator Tomis Digesta., Ioan and Davidis Berthelin, Rouen, 1653.

\footnotetext{
${ }^{1}$ Also known as Alemarianus Petrus Forestus.
} 
Fox, C. (2007). Personal communication.

Fox, M. (1978). The Dog: Its Domestication and Behavior. Garland, New York.

Fraley, C. and Shaver, P. (2000). Adult Romantic Attachment: Theoretical Developments, Emerging Controversies, and Unanswered Questions. Review of General Psychology, Vol. 4, pp. 132-154.

Freud, S. (1912). Contributions to a Discussion on Masturbation. The Standard Edition of the Complete Psychological Works of Sigmund Freud, Volume XII (ed. J. Strachey). Psychoanalytic Electronic Publishing.

Freud, S. (1919). The Uncanny. In Sigmund Freud: Collected Papers (Vol. 4), transl. Riviere, J. Basic Books, New York, pp. 368-407.

Freud, S. (1905). Drei Abhandlungen zur Sexualtheorie, Deuticke, Vienna, translated as Three Essays on the Theory of Sexuality, Basic Books, New York, 2000.

Freud, S. (1938). The Basic Writings of Sigmund Freud. Translated by A.A.Brill, Modern Library, New York.

Friedmann, E. and Thomas, S. (1995) Pet-ownership, Social Support and One-Year Survival After Acute Myocardial Infarction in the Cardiac Arrhythmia Suppression Trial (CAST). The American Journal of Cardiology, Vol. 76, pp. 1213-1217.

Friedman, B., Kahn, P., and Hagman, J. (2003). Hardware Companions? - What Online AIBO Discussion Forums Reveal About the Human-Robotic Relationship. Proceedings of CHI 2003 Conference on Human factors in Computing Systems, pp. 273-280. Association for Computing Machinery, New York, NY.

Friedmann, E., Thomas, S., Stein, P., and Kleiger, R. (2003). Relation Between Petownership and Heart Rate Variability in patients with Healed Myocardial Infarcts. The American Journal of Cardiology, Vol. 91, No. 6, pp. 718-721.

Frude, N. (1983). The Intimate Machine. Century, London.

Gage, G. and Holcomb, R. (1991). Couples' Perception of Stressfulness of Death of the Family Pet. Family Relations, Vol. 40, pp. 103-105.

Gagnon, J., Giami, A., Michaels, S. And Colomby, P. de (2001). A Comparative Study of the Couple in the Social Organization of Sexuality in France and the United States. Journal of Sex Research, Vol. 38, No. 1, pp. 24-34. 
Garrity, T., Stallones, L., Marx, M., and Johnson, T. (1989). Pet Ownership and Attachment as Supportive Factors in the Health of the Elderly. Anthrozoös, Vol. 3, pp. 35-44.

Gathome-Hardy, J. (1998). Sex the Measure of All Things. Chatto and Windus, London.

Gell, A. (1992). The technology of enchantment... Anthroplogy, Art and Aesthetics, (eds. J. Coote and A. Shelton). Clarendon Press, Oxford.

Gerwolls, M. and Abott, S. (1994). Adjustment to the Death of a Companion Animal. Anthrozoös, Vol. 7, No.3, pp. 172-187.

Gilfoyle, T. (1992). City of Eros - New York City, Prostitution, and the Commercialization of Sex, 1790-1920 — W.W. Norton, New York.

Glage, U. and Glage, G. (1977). Massaging Apparatus. U.S. patent 4,059,100, filed July 18th 1976, granted November 22nd.

Goleman, D. (1997). Emotional Intelligence. Bantam Books, New York.

Goodale, C. (2001). Researchers Study How Robots Interact with Children. IEEE Institute Web site, November $1^{\text {st }} 2001$.

Good Vibrations, 2005. Personal communication.

Gordon, M. (2000). Our Night of Weimar Love. Susan Block, quoting Mel Gordon. Available at http://www.bigomagazine.com/features05/SBweimar.html

Granville, J. (1883). Nerve-Vibration and Excitation. J. and A. Churchill, London.

Grayson, K. and Shulman, D. (2000). Indexicality and the Verification Function of Irreplaceable Possessions: A Semiotic Analysis. Journal of Consumer Research, Vol. 27, pp. 17-30.

Gwinnell, E. (1998). Online Seductions: Falling in Love With Strangers on the Internet. Kodansha America Inc.

Hall, S. (2005). My Dog Was Best Man at My Wedding. Wanganui Chronicle, 22 July.

Hamamatsu (2006). Putting New Light on the Brain. Hamamatsu advertisement, Scientific American, Vol. 294, No. 5, May, rear cover. See also http://jp.hamamatsu.com/en/rd/publication/ 
Haraway, D. (1985). A Manifesto for Cyborgs. Socialist Review, No. 80, pp. 65108. Reprinted with minor revisions and corrections to notes in Coming to Terms: Feminism, Theory, Politics (ed. E Weed), pp. 173-204. Routledge, New York.

Hasbro (2007). History of Hasbro.

Available at http://www.hasbro.co.uk/index.asp?page $=7$

Hatfield, E. and Sprecher, S. (1995). Men's and Women's Preferences in Marital Partners in the United States, Russia and Japan. Journal of Cross-Cultural Psychology, Vol. 26, No 6, pp. 728-750.

Hausser, D., Zimmerman, E., Dubois-Arber, F., and Paccaud, F. (1991).Evaluation of the AIDS Prevention Strategy in Switzerland. Third Assessment Report (1989-1990). Institute Universitaire de Medicine Sociale et Preventive, Lausanne.

Hayes-Roth, (2003). What Makes Characters Seem Life-like? Lifelike Characters. Tools, Affective Functions and Applications (eds. H. Prendinger and M. Ishizuka, Springer-Verlag), New York, N.Y.

Hazan, C. and Shaver, P. (1987). Romantic Love Conceptualized as an Attachment Process. Journal of Personality and Social Psychology, Vol. 52, pp. 511-524.

Hazan, C. and Shaver, P. (1990). Love and Work: An Attachment-Theoretical Perspective. Journal of Personality and Social Psychology, Vol. 59, pp. 270280.

Hazan, C. and Zeifman, D. (1994). Sex and the Psychological Tether. Advances in Personal Relationships: A Research Annual (eds. D. Perlman and K. Bartholomew), Vol. 5, pp. 151-177.

Headey, B. (1999). Health Benefits and Health Cost savings Due to Pets: Preliminary Estimates from an Australian national Survey. Social Indicators Research, Vol. 47, pp. 233-243.

Headey, B. (2003). Pet-ownership: Good for Health? Medical Journal of Australia, Vol. 179, pp. 460-461.

Headey, B. and Grabka, M. (2004). The Relationship Between Pet-ownership and Health Outcomes: German Longitudinal Evidence. Discussion Papers, No. 434, German Institute for Economic Research, Berlin.

Hemptinne, G. de (2005). Hookers Learn to Give 'More than Sex'. Available at http://iafrica.com/loveandsex/features/232211.htm

Herik, H.J. van den (1983). Computerschaak, Schaakwereld en Kunstmatige Intelligentie. Ph.D. Thesis Delft University of Technology. Academic Service, Schoonhoven, The Netherlands. 
Herik, H.J. van den (1989). An Interview with Claude Shannon. ICCA Journal, Vol. 12, No. 4, pp. 221-226. ISSN 0920-234X.

Herik, H.J. van den (1991). Kunnen Computers Rechtspreken? Gouda Quint, Arnhem.

Herik, H.J. van den (1997). De les van Deep Blue. Advocaten dossier, No. 9, pp. 1930.

Herik, H.J. van den (1999). Computers Kunnen Rechtspreken. Privaatrecht in de 2le Eeuw Rechtsinformatica (ed. H. Franken), pp. 11-27. Kluwer, Deventer, The Netherlands. Reprinted as Kunstmatige Intelligentie in de Rechtspraak, LUC-Nieuws, Vol. 19, No. 1, pp. 12-19

Heslinga, K., Schellen, A., and Verkuyl, A. (1974). Not Made of Stone: The Sexual Problems of Handicapped People. Stafleu's Scientific Publishing Company, Leyden.

Hickrod, L. and Schmitt, R. (1982). Dog as best man. A Naturalistic Study of Interaction and Frame: The Pet. Urban Life, Vol 11, No. 1, pp. 55-77.

Hinds, P., Roberts, T., and Jones, H. (2004). Whose Job is it anyway? A Study of Human-Robot Interaction in a Collaborative Task. Human Computer Interaction, Vol. 19, pp. 151-181.

Hirsch-Pasek K. and Treiman, R. (1982). Doggerel: Motherese in a New Context. Journal of Child Language, Vol. 9, pp. 229-237.

Hodder, H.F. (2004). "The Future of Marriage." Harvard Magazine, NovemberDecember 2004, pp. 38-45.

Hoffman, V. and Bolton, R. (1997). Reasons for Having Sex and Sexual RiskTaking: A Study of Heterosexual Male STD Clinic Patients. AIDS Care, Vol. 9, No. 3, pp. 285-296.

Hofstadter, D. (1981). Reflections. The Mind's I. (eds. D. Hofstadter and D. Dennett), pp.276-283. Basic Books, New York.

Hofstadter, D. and Dennett, D. (1981). The Mind's Eye. Basic Books, New York.

Hoigard, C. and Finstad, L. (1992). Backstreets. Pennsylvania State University Press, University Park, Pennsylvania.

Holland, N. (1996). The Internet Regression.

Available at http://www.rider.edu/ suler/psycyber/holland.html

Holzman, H. and Pines, S. (1982). Buying Sex: The Phenomenology of Being a John. Deviant Behaviour, Vol. 4, pp. 89-116. 
Horáková, J. and Kelemen, J. (2003). Robots - Some Cultural Roots. In 4th International Conference on Computational Intelligence, Budapešt. Budapest Polytechnic, Hungarian Fuzzy Association, pp. 39-50. 2003, Budapest, Hungary.

Horn, J. and Meer, J. (1984). The Pleasure of Their Company. Psychology Today, Vol. 18, No. 8, pp. 52-59.

Horton, D. and Wohl, R. (1956). Mass Communication and Para-Social Interaction: Observations on Intimacy at a Distance. Psychiatry, Vol. 19, No. 3, pp. 215229.

Hsu, F-h. (2002). Behind Deep Blue. Building the Computer that defeated the World Chess Champion. Princeton University Press, Princeton.

Hyde, J. and DeLamater, J. (1997). Understanding Human Sexuality. 6th edition, McGraw-Hill, New York.

IJCAI (2007). IJCAI Proceedings 2007. (International Joint Conference on Artificial Intelligence.) Morgan Kaufmann, San Francisco.

IWRAW (2003). Country Report: The Philippines. International Women's Rights Action Watch.

Janus, S. and Janus, C. (1993). The Janus Report on Sexual Behavior. John Wiley and Sons, New York.

Jennings, G.L.R., Reid, I.C., Jennings, J., Anderson, W.P. and Dart, A. (1998). Animals and Cardiovascular Health. In Wilson, C.C. and Turner, D.C. (eds.), Companion Animals in Human Health, Sage Press, Thousand Oaks, CA, pp. 161-172.

Johnson, A., Wasdworth, J., Wellings, K., and Field, J., Blackwell (1994). Sexual Attitudes and Lifestyles. Oxford.

Johnson, A., Mercer, C., Erens, B., Copas, A., and Mcmanus, S. (2001). Sexual Behaviour in Britain: Partnerships, Practices and HIV Risk Behaviour. Lancet, Vol. 358, 2001, pp. 1835-1842.

Johnson, A. (2003). The Sexual Health of the Nation. Albert Norman Lecture Congress.

Jordan, J. (1997). User Buys: Why Men Buy Sex. Australian and New Zealand Journal of Criminology, Vol. 30, pp.55-71.

Juhasz, A. (1983). Variations in Sexual Behavior. Journal of Research and Development in Education, Vol. 16, No. 2, pp. 53-59. 
Kahn, P. (1999). The Human Relationship with Nature: Development and Culture. MIT Press, Cambridge, Massachusetts.

Kahn, P., Friedman, B., and Hagman, J. (2002). 'I Care About Him as a Pal': Conceptions of Robotic Pets in Online AIBO Discussion Forums. Conference on Human Factors in Computing Systems - CHI '02. Extended Abstracts on Human Factors in Computing Systems, Minneapolis, Minnesota.

Kahn, Jr., P., Freier, N., Friedman, B., Severson, R., and Feldman, E. (2004). Social and Moral Relationships with Robotic Others. Proceedings of the 13th International Workshop on Robot and Human Interactive Communication, pp. 545-550. Institute of Electrical and Electronics Engineers (IEEE), Piscataway, New Jersey.

Kahne, M.J. (1967). On the Persistence of Transitional Phenomena into Adult Life. International Journal of Psycho-Analysis, Vol. 48, 1967, pp. 247-258.

Kanda, T., Hirano, T. Eaton, D., and Ishiguro, H. (2004a). Interactive Robots as Social Partners and Peer Tutors for Children: A Field Trial. Human Computer Interaction, Vol. 19, No. 4, pp. 61-84.

Kanda, T., Ishigurio, H., Imai, M., and Ono, T. (2004b). Development and Evaluation of Interactive Humanoid Robots. Proceedings of the IEEE, Vol. 92, No. 11, pp. 1839-1850.

Kaplan, H. (1974). The New Sex Therapy: Active Treatment of Sexual Dysfunctions. Routledge, London.

Katcher, A. and Rosenberg (1979). Euthenasia and the Management of the Clients' Grief. Compendium on Continuing Education for the Small Animal Practitioner, Vol. 2, pp. 177-222.

Katcher, A. and Beck, A. (1983). New Perspectives on Our Lives with Companion Animals, pp. 42-69. University of Pennsylvania Press, Philadelphia.

Katcher, A., Friedmann, E., Beck, A., and Lynch, J. (1983). Talking, Looking, and Blood Pressure: Physiological Consequences of Interaction with the Living Environment. New Perspectives on Our Lives with Companion Animals. (eds. A. Katcher and A. Beck), pp 351-359. University of Pennsylvania Press, Philadelphia.

Keddie K. (1977). Pathological Mourning After the Death of a Domestic Pet., British Journal of Psychiatry, Vol. 131, pp. 21-25.

Keeley, G. (2006). Women to Get Their Very Own Stud Farm. The Times, May 2nd. 
Kellert, S. (1981). Knowledge, Affection and Basic Attitudes Toward Animals. American Society, NTIS No. PB81-173106. United States Department of the Interior Fish and Wildlife Service, Springfield, Virginia.

Kellert S. (1993). The Biological basis for Human Values of Nature. The Biophilia Hypothesis (eds. S. Keller and E. O. Wilson), Island Press, Washington DC.

Kelley, H., Berscheid, E., and Christensen, A. (1983). Epilogue: An Essential Science. Close Relationships, pp. 486-503. W.H. Freeman, New York, NY.

Kelly, A. and McKillop, K. (1996). Consequences of Revealing Personal Secrets. Psychological Bulletin, Vol. 120, No. 3, pp. 450-465.

Kermode, F. (2000). The Sense of an Ending: Studies in the theory of Fiction. (New edition.) Oxford University Press, Oxford.

Kernsmith, R. (2001). Social Bonds as Motivators for Deviant Behavior: An Unobtrusive Analysis of Prostitute Clients. Eastern Michigan University, 2001.

Kessler, I. (2005). Virtual Midnight Cowboys or 'London Gigolos'? Characteristics and Motivations of Male Escorts Offering Heterosexual Services Via the Internet in London and Society's Formal and Informal Responses. Research proposal presented at the International Critical Criminology Conference, Common Studies Session, New York.

Keyser, P. (1988). Suetonius "Nero" 41. 2 and the Date of Heron Mechanicus of Alexandria. Classical Philology, Vol. 83, No. 3 (Jul., 1988), pp. 218-220.

Kidd, A. and Kidd, R. (1985). Animals: Best Friends and Good Medicine. Medical and Health Annual, pp. 90-105.

Kim, J-H., Lee, K-H., Kim, Y-D., Lee, B-J., and Yoo, J-K. (2005). The Origin of Artificial Species: Humanoid Robot HanSaRam. Proceedings 2nd International Conference on Humanoid, Nanotechnology, Information Technology, Communication and Control, Environment and Management, Manila.

Kinsey, A., Porneroy, W. and Martin, C. (1948). Sexual Behavior in the Human Male. W.B. Saunders Company, Philadelphia.

Kinsey, A., Porneroy, W., Martin, C. and Gebhard, P. (1953). Sexual Behavior in the Human Female. W.B. Saunders Company, Philadelphia.

Klein, M and Klein, P. (2002). This Computer Responds to User Frustration: Theory, Design, Results and Implications. Interacting With Computers, Vol. 14, pp. 119-140. 
Kleine, S. and Baker, S. (2004). An Integrative Review of Material Possession Attachment. Academy of Marketing Science Review (online publication), Vol. 8, No. 1. Available at http://www.amsreview.org/articles/kleine01-2004.pdf.

Kleist, E. and Moi, H. (1993). Transmission of Gonorrhoea Through an Inflatable Doll. Genitourinary Medicine, Vol. 69, No. 4, August, p. 322.

Knowles, J. (2002). Masturbation - From Stigma to Sexual Health. Planned Parenthood Federation of America, Inc.

Available at http://www.plannedparenthood.org

Koller, M. (1974). Families: A Multigenerational Approach. McGraw-Hill, New York, NY.

Kon, I. (2004). Russia. In Francoeur, R. and Noonan, R. (eds.), The Continuum Complete Encyclopedia of Sexuality.

Available at http://www.kinseyinstitute.org/ccies/ru.php

Kopytoff, I. (1986). The Cultural Biography of Things: Commoditization as Process. The Social Life of Things: Commodities in Cultural Perspective, (ed. Appadurai, A.), Cambridge University Press, New York, pp. 64-94.

Lacroix, J. P. W., Murre, J. M. J., Postma, E. O., and Herik, H. J. van den (2006). Modeling Memory Using the Similarity Structure of Natural Input. Cognitive Science, Vol. 30, pp. 121-145.

Lago, D., Delaney, M., Miller, M., and Grill, C. (1989). Companion Animals, Attudes Towards Pets, and Health Outcomes Among the Elderly: A Long-Term Follow-Up. Anthrozoös, Vol. 3, pp. 25-34.

Lamarr, H. (1966). Ecstasy and Me: My Life as a Woman. Fawcett World Library, New York.

Laner, M. (1974). Prostitution as an Illegal Vocation: A Sociological Overview. Deviant Behavior: Occupational and Organizational Bases (ed. Clifton Bryant), pp. 406-418. Rand-McNally, Chicago.

Lang, P., Greenwald, M., Bradley, M., and Hamm, A. (1993). Looking at Pictures: Affective, Facial, Visceral, and Behavioural Reactions. Psychophysiology, Vol. 30, pp. 261-273.

Lang, P. (1995). The Emotion Probe: Studies of Motivation and Attention. American Psychologist, Vol. 50, pp. 372-385.

Langer E.J. (1989). Mindfulness. Addison-Wesley Publishing Co, Reading, Mass, pp. 100-113. 
Laslocky, M. (2005). Real Dolls: Love in the Age of Silicone. Available at http://www.saltmag.net/images/pdfs/RealDollsPDF.pdf [An earlier and shorter version of this article appeared on www.salon.com under the title Just Like a Woman, on October 11th 2005.]

Lauman, E., Michael, R., Gagnon, J., and Michaels, S. (1994). The Social Organization of Sexuality: Sexual Practices in the United States. University of Chicago Press.

Leigh, B. (1989). Reasons for Having and Avoiding Sex: Gender, Sexual Orientation, and Relationship to Sexual Behavior. The Journal of Sex Research, Vol. 26, No. 2, pp. 199-209.

Lem, S. (1974). Non Serviam. The Mind's I. (eds. D. Hofstadter and D. Dennett, pp. 296-317. Basic Books, New York.

Lenz, N. (2005). The Borghild-project - a discreet matter of the 3rd Reich. Available at http://www.borghild.de/indexe.htm

Lester, J. C., Converse, S. A., Kahler, S. E., Barlow, S. T., Stone, B. A., and Bhogal, R. S. (1997). The Persona Effect: Affective Impact of Animated Pedagogical Agents. Proceedings of the Conference on Computer Human Interaction, CHI '97, pp. 359-366.

Levine, D. (2000). Virtual Attraction: What Rocks Your Boat. Cyberpsychology and Behavior, Vol. 3, No. 4, pp. 565-573.

Levins, H. (1996). American Sex Machines. Adams Media Corporation, Holbrook, Massachusetts.

Levinson, B. and Thomas, C. C. (1969). Pet Oriented Child Psychotherapy. Springfield, Illinois.

Levinson, B. (1972). Pets and Human Development. Levinson, Wiedenfeld and Nicholson, London.

Levy, D.N.L, (2005). Robots Unlimited: Life in a Virtual Age. A.K.Peters, Wellesley, MA.

Levy, D.N.L. (2007). Robot Prostitutes as Alternatives to Human Sex Worker.

Lewis, T., Amini, F., and Lannon, R. (2001). A General Theory of Love. Vintage Book, New York, NY.

Libin, A. (2003). Persons And Their Artificial Partners: Robotherapy as an Alternative Non-pharmacological Approach in Therapy. Cybertherapy Conference 2003, Interactive Media Institute. 
Libin, E. and Libin, A. (2003). New Diagnostic Tool for Robotic Psychology and Robotherapy Studies. Cyberpsychology and Behavior, Vol. 6, No. 4, pp. 369374.

Libin, A. and Libin E. (2004). Person-Robot Interactions From the Robopsychologists' Point of View: The Robotic Psychology and Robotherapy Approach. Proceedings of the IEEE, Vol. 92, No. 11, pp. 1789-1803.

Linder, D. (2000). Speech on the Occasion of the 75th Anniversary of the Opening of the Scopes Trial, Kansas City (July 10, 2000). Available at http://www.law.umkc.edu/faculty/projects/ftrials/scopes/confspeech.html

Loebner, H. (1998). Being a John. In Elias, J., Bullough, V., Elias, V. and Brewer, G. (eds.), Prostitution: On Whores, Hustlers, and Johns. Prometheus Books, New York, pp. 221-225.

Lorenz, K. (1970). Studies in Animal and Human Behaviour, Volume I. Harvard University Press, Cambridge.

Luck, M., McBurney, P. and Preist, C. (2003). Agent Technology: Enabling Next Generation Computing. A Roadmap for Agent Based Computing. AgentLinkII, the European Network of Excellence for Agent-Based Computing, Southampton, UK.

Luck, M., Ashri, R. and D’Inverno, M. (2004). Understanding Agent Systems (Second Edition). Springer, New York.

Lyman, R. (2001). The Ethics of Sex Therapy.

Available at http://www.disbled.gr/at/?p=1650

Lynch, C. and Blinder, M. (1983). The Romantic Relationship: Why and How People Fall in Love, The Way Couples Connect, and Why They Break Apart. Family Therapy, Vol. X, No. 2, pp. 91-104.

Lynch, J. (1985). The Language of the Heart: The Body's Response to Human Dialogue. Basic Books, New York, NY.

Lynn, R. (2004). Ins and Outs of Teledildonics. Available at http://www.wired.com/news/culture/0,1284,65064,00.html

Madame B. (1899). La Femme Endormie. Paris (“printed in Melbourne”).

Maheu, M. (1999). The Future of Cyber-Sex and Relationship Fidelity." A Brave New World booklet.

Available at http://www.selfhelpmagazine.com/booklet/sexuality.html

Maines, R. (1999). The Technology of Orgasm. The John Hopkins University Press, Baltimore. 
Maines, R. (2001). Declaration Under Penalty of Perjury. Affidavit for the United District Court, Northern District, Alabama, April 30th.

Marches, J. and Turbeville, G. (1953). The Effect of Residential Propinquity on Marriage Selection. American Journal of Sociology, Vol. 58, No. 6, May, pp. 592-595.

Marie Claire (1994). Why Women Go to Male Prostitutes. Marie Claire UK Edition, February 1994, pp. 25-28.

Marten, J. (1708). A Treatise of All the Degrees and Symptoms of the Venereal Disease in Both Sexes. London.

Martin, C. and Nagao, D. (1989). Some Effects of Computerized Interviewing on Job Applicant Responses. Journal of Applied Psychology, Vol. 74, pp. 72-80.

Masters, W. and Johnson, V. (1970). Human Sexual Inadequacy. Little Brown, Boston.

Masters, W., Johnson, V. and Kolodny, R. (1986). Masters and Johnson on Sex and Human Loving. Little, Brown and Company, Boston.

Masters, W., Johnson, V. and Kolodny, R. (1995). Human Sexuality, 5th Edition. Harper Collins, New York.

McCarthy, J. and Wright, P. (2004). The Enchantments of Technology. Proceedings of Computers and Fun. British Computing Society, York. Also published in Funlogy: From Usability to Enjoyment (eds. M. Blyth, K. Overbeeke, A. Monk and P.Wright). Kluwer Academic Publishers, London.

McClelland, D. (1951). Personality. Holt, Reinhart and Winston, New York.

McGeown, K., Barzilay, R., Evans, D., Hatzivassiloglou, V., Schiffman, B., and Teufel, S. (2001). Columbia Multi-Document Summarization Approach and Evaluation. Document Understanding Conference, Workshop on Text Summarization, New Orleans, September 2001.

McGill, M., Rinehart H. and Winston (1985). The McGill Report on Male Intimacy. New York.

McKeganey, N. (1994). Prostitution and HIV: What do we Know and Where Might Research be Targeted in the Future? AIDS, Vol. 8, pp. 1215-1226.

McKeganey, N. and Barnard, M. (1996). Sex Work on the Streets: Prostitutes and their Clients. Open University Press, Buckingham, 1996.

McKeowan, H. (1976). Pinball Portfolio. Chartwell Books, Secaucus, New Jersey. 
McNab, W. (1993). Masturbation: The Neglected Topic in Sexuality Education. Family Life Education, Vol. 12, No. 2, pp. 10-15.

Meijer, M. (2007). Personal communication.

Melson, G. (1991). Children's Attachment to Their Pets: Links to Socio-Emotional Development. Children's Environments Quarterly, Vol. 82, 1991, pp. 55-65.

Melson, G. and Schwarz, J. (1994). Pets as Social Supports for Families with Young Children, Annual Meeting of the Delta Society, Reston, Virginia.

Melson, G. (1998). The Role of Companion Animals in Human Development., Companion Animals in Human Health (eds. C. Wilson and D. Turner), pp. 219236. Sage Publications, London.

Melson, G. (2001). Why the Wild Things Are: Animals in the Lives of Children. Harvard University Press, Cambridge, Massachusetts.

Melson, G., Kahn, P., Beck, A., Friedman, B., Roberts, T., and Garrett, E. (2005). Robots as Dogs? Children's Interactions with the Robotic Dog AIBO and a Live Australian Shepherd. Proceedings of CHI 2005 (ACM Conference on Computer-Human Interaction), Portland, Oregon, pp. 1649-1652.

Mettee, D., Taylor, S., and Friedman, H. (1973). Affect Conversion and the GainLoss Effect. Sociometry, Vol. 36, pp. 505-519.

Michael, R., Gagnon, J., Laumann, E. and Kolata, G. (1994). Sex In Amerca: A Definitive Survey. Little, Brown and Company, Boston.

Mitsubishi (2005). Life with a Robot. Wakumaru.

Available at http://www.mhi.co.jp/kobe/wakamaru/english/about/index.html

Moal, P. (1964). The Client of the Prostitute. The Participants in prostitution. Report of the International Abolitionist Federation Conference at Athens 1963, pp. 7-8. Geneva.

Monto, M. (2001). Prostitution and Fellatio. Journal of Sex Research, Vol. 58, No. 2, pp. 140-145.

Monto, M. (2005). Personal communication.

Moon, Y. (2000). Intimate Exchanges: Using Computers to Elicit Self-Disclosure from Consumers. Journal of Consumer Research, Vol. 26, No. 4, pp. 323-339.

Moreland, R. and Beach, S. (1992). Exposure Effects in the Classroom: The Development of an Affinity Among Students. Journal of Experimental and Social Psychology, Vol. 28, pp. 255-276. 
Mori, M. (1970). The Uncanny Valley. Energy, Vol. 7, No. 4, pp. 33-35 (in Japanese). Translation by MacDorman, K. and Minato, T. Available at http://www.androidscience.com/theuncannyvalley/proceedings2005/uncannyval ley.html

Morkes, J., Kernal, H., and Nass, C. (1998). Humor in task-Oriented ComputerMediated Communication and Human-Computer Interaction. Conference on Human Factors in Computing Systems CHI 1998, pp. 215-216. Los Angeles, California.

Morkes, J., Kernal, H., and Nass, C. (2000). Effects of Humor in Task-Oriented Human-Computer Interaction and Computer-Mediated Communication: A Direct Test of Social Responses to Communication Technology Theory. Human-Computer Interaction, Vol. 14, No.4, pp. 395-435.

Morries, M. (1978). The Three R's of Sex. Journal of Religion and Health, Vol. 17, pp. 48-56.

Moya, C. (2006). Artificial Vaginas and Sex Dolls: An Erotological Investigation. $\mathrm{PhD}$ thesis, The Institute for Advanced Study of Human Sexuality, San Francisco.

Mugford, R. and M'Cominsky, J. (1975). Some Recent Work on the Psychotherapeutic Value of cage Birds with Old People., Pet Animals and Society, (ed. Ronald Anderson), Bailliere Tindau, London.

Murry, I. and Arnott, J. (1993). Toward the Simulation of Emotion in Synthetic Speech: A Review of the Literature on Human Vocal Emotion. Journal of Acoustical Society of America, Vol. 93, No. 2, pp. 1097-1108.

Muschel, I. (1984). Pet Therapy with Terminal Cancer Patients. Social Casework, pp. 173-185.

Myers, G. (1998). Children and animals: Social development and our connections to other species. Westview Press, Boulder, Colorado.

Nass, C., Moon, Y., Fogg, B., Reeves, B., and Dyer, C. (1995). Can Computer personalities be Human personalities? International Journal of HumanComputer Studies, Vol. 43, pp. 223-239.

Nass, C., Moon, Y., and Green, N. (1996). Are Computers Gender Neutral? Gender Stereotypic Responses to Computers. Journal of Applied Social Psychology, Vol. 27, No. 10, pp. 864-876.

Nass, C. and Moon, Y. (2000). Machines and Mindlessness: Social Responses to Computers. Journal of Social Issues, Vol. 56, No. 1, pp. 81-103. 
NEC Personal Robot Research Center (2001). Psychological Research on Robots. Ochanomizu University study.

Available at http://www.incx.nec.co.jp/robot/english/univ/04/univ_e04.html

Nechvatal, J. (no date available). Sex Machine Art: From Mechanical Repetition into Electronic Flicker.

Available at www.geelhaar.de/TR/state/text/nec/sema.html

Nelson, T. (1974). ComputerLlib / Dream Machines, Self-Published, 1974. Reprinted by Microsoft Press, Redmond, Washington, 1988.

Newell, A. and Simon, H.A. (1976). Computer Science as empirical inquiry: Symbols and search. Communications of the Association for Computing Machinery, Vol. 19, pp. 113-126.

Noonan, R. (1984). Sex Surrogates: A Clarification of Their Functions. MA Thesis, New York University, January 201984.

Available at www.sexquest.com/surrogat.htm

Noonan, R. (2003). Sex Surrogates: The Continuing Controversy. Continuum Complete Encyclopaedia of Sexuality (eds. Nell Noonan and Robert Francoeur.), pp. 1279-1281. Continuum, New York.

Norton, W. (1992). The City of Eros: New York City, Prostitution and the Commercialization of Sex, 1790-1920. New York.

Ogburn, W. (1964). On Culture and Social Change. University Press of Chicago, Chicago.

Odendaal, J. (2000). Animal-Assisted Therapy: Magic or Medicine?, Journal of Psychosomatic Research, Vol. 49, No. 4, pp. 275-280.

Otero, T.F. and Cortés, M.T. (2003). Artificial Muscles with Tactile Sensitivity. Advanced Materials, Vol. 15, pp. 279-282.

Overall, C. (1992). What's Wrong With Prostitution?: Evaluating Sex Work. Signs, Summer 1992, pp. 705-721.

Overmars (2006). Presentation ICT Kenniscongres in The Hague.

Painter, G. (2002). The Sensibilities of Our Forefathers: The History of Sodomy Laws in the United States.

Available at http://www.sodomylaws.org/sensibilities/illinois.htm

Pantic, M. (2001). Facial Expression by Computational Intelligence Techniques. Ph.D. thesis. Delft University of Technology, Delft, The Netherlands. 
Patton, M. (1985). Masturbation from Judaism to Victorianism. Journal of Religion and Health, Vol. 24, No. 2, pp. 133-146.

Peck, D. (1978). Public Health and Sexual Promiscuity. Corrective and Social Psychiatry and Journal of Behavior, Technology Methods and Therapy, Vol. 25, No. 3.

Peckham, T. (1955). Gentlemen for Rent. Frederick Fell, New York.

Peretti, P. (1990). Elderly Animal Friendship Bonds. Social Behavior and Personality, Vol. 18, pp 151-156.

Perse, E., and Rubin, R. (1989). Attribution in Social and Para-Social Relationships. Communication Research, Vol. 16, No. 1, pp. 59-77.

Picard, R. (1997). Affective Computing. MIT Press, Cambridge, MA.

Picard, R., Vyzas, E., and Healey, J. (2001). Toward Machine Emotional Intelligence: Analysis of Affective Psychological State. IEEE Transactions on Pattern Analysis and Machine Intelligence, Vol. 23, No. 10, pp. 1175-1191.

Picard, R. and Klein, J. (2001). Computers that Recognize and Respond to User Emotion: Theoretical and Practical Implications. MIT Media Lab Report 538, 2001, reprinted in Interacting with Computers, Vol. 14, No. 2, 2002, pp. 119140.

Pines, A. (1999). Falling in Love: Why We Choose the Lovers We Choose. Routledge, New York.

Plaat, A. and Schaeffer, J. (1997). Kasparov versus Deep Blue: The Re-match. ICCA Journal, Vol. 20, No. 2, pp. 95-102.

Plant, D. (2005). The Rump Parliament. British Civil Wars and Commonwealth Website.

Available at http://www.british-civil-wars.co.uk/glossary/rump-parliament.htm

Plumridge, E., Chetwynd, J., Reed, A., and Gifford, S. (1997). Discourses of Emotionality in Commercial Sex: The Missing Client Voice. Feminism and Psychology, Vol. 7, No. 2, pp. 165-181.

Pomeroy W. (1968). Boys and Sex. Delacorte Press, New York.

Pomeroy W. (1969). Girls and Sex. Delacorte Press, New York.

Postma, E.O. (2003). De onderste steen boven. Inaugural Address. IKAT, Universiteit Maastricht, Maastricht, The Netherlands. 
Press Association (2004). Britons Embark on Computer Love Affair. The Guardian, February 24, 2004.

Prince Z. (2002). Thai Female Elite Demand Black Gigelos. The Independent Newspaper of the Morgan State University, November 8.

Proudfoot, J., Goldberg, D., Mann, A., Everitt, B., Marks, I., and Gray, J. (2003). Computerised, Interactive, Multimedia Cognitive Behavioural Therapy Reduces Anxiety and Depression in General Practice: A Randomised Controlled Trial. Psychological Medicine, Vol. 33, pp. 217-227.

Quackenbush, J. (1985). The Death of a Pet: How it Can Affect Owners. The Veterinary Clinics of North America: Small Animal Practice: Symposium of the Human-Companion Animal Bond (eds. J. Quackenbush and V. Voith), Vol. 15, No. 2, pp. 395-401.

Quackenbush, J. and Graveline, D. (1985). When Your Pet Dies. Simon and Schuster, New York, NY.

Rajaram, S., Garrity, T., Stallones, L., and Marx, M. (1993). Bereavement - Loss of a Pet and Loss of a Human. Anthrozoös, Vol. 7, No. 6, pp. 8-16.

Rajecki, D. and Rasmussen, J. (1995). Differences and Similarities in Humans' Perceptions of the Thinking and Feeling of a Dog and a Boy, Society and Animals, Vol. 3, pp. 117-137.

Raussi, S. (2003). Human-Cattle Interactions in Group Housing. Applied Animal Behaviour Science, Vol. 80, No. 3, pp. 245-262.

Raveis, V., Masgano, F., Darus, D., and Gottfriend, D. (1993). Psychological Consequences of Pet-ownership of Terminaly Ill Cancer patients. Delta Society Conference.

Reeves, B. and Nass, C. (1996). The Media Equation. Cambridge University Press, Cambridge, United Kingdom.

Reichardt, J. (1978). Robots: Fact, Fiction and Predication. Thames and Hudson, London.

Renée-Bloch, L. and Lemish, D. (1999). Disposable Love : The Rise and Fall of a Virtual Pet. New Media and Society, Vol. 1, No. 3, pp. 283-303.

Rheingold, H. (1991). Virtual Reality. Martin Secker and Warburg, London.

Riskin, J. (2003a). Eighteenth-Century Wetware. Representations, No. 83, pp. 97125. 
Riskin, J. (2003b). The Defecating Duck or the Ambiguous Origins of Artificial Life. Critical Enquiry, Vol. 29, No. 4, pp. 599-633.

Roberts, B. (2000). The Sexual Surrogate. InnerSelf Magazine, online magazine. Available at http://innerself.com/Sex_Talk/Sexual_Surrogate.htm

Robin, M. and Bensel, R. ten (1985). Pets and the Socialization of Children. Marriage and Family Review, Vol. 83, No. 4, pp. 63-78.

Robinson, B. (2005). Criminalizing Same-Sex Behavior: 'Sodomy' Legislation From Biblical Times to the 1960s.

Available at http://www.religioustolerance.org/hom_laws1.htm

RoboFesta Kanagawa (2001). Psychological Research on Robots. Ochanomizu University study.

Available at http://www.incx.nec.co.jp/robot/english/univ/04/univ_e04.html

Rost, D. and Hartmann, A. (1994). Children and Their Pets. Anthrozoös, Vol. 7, No. 4, pp. 242-254.

Rubenstein, S. (2003). Texas Housewife Busted for Hawking Erotic Toys. San Francisco Chronicle, December 16th.

Rubin, Z. (1973). Liking and Loving: An Invitation to Social Psychology. Holt, New York.

Rubin, R., and McHugh, M., (1987). Development of Parasocial Interaction Relationships. Journal of Broadcasting and Electronic Media, Vol. 31, pp. 279292.

Rynearson, E. (1978). Humans and Pets and Attachment, British Journal of Psychiatry, Vol. 133, pp. 550-555.

Samp, J. (1997). Critical Thoughts About Tamagotchi. Virtual Pet. Available at http://www.virtualpet.com/vp/farm/lleg/critical/ov.htm

Sanders, C. (2003). Actions Speak Louder than Words: Close Relationships between Humans and Nonhuman Animals. Symbolic Interaction, Vol. 26, No. 3, pp. 405-426.

Schaub, B. (2006). My Android Twin. New Scientist, Vol. 192, No. 2573, 14th October, pp. 42-46.

Scheibe, K. and Erwin, M. (1979). The Computer as Alter. Journal of Social Psychology, Vol. 108, No. 2, 1979, pp. 103-109. 
Schermer, B.W. (2007). Software agents, surveillance, and the right to privacy: a legislative framework for agent-enabled surveillance. Leiden University Press, Leiden. ISBN 9789087280215.

Schidrowitz, L. (1930). Bilder-Lexicon: Sexualwissenschaft, Verlag für Kulturforschung, Vienna/Leipzig.

Schmidt (1899). Heronis Alexandrini Opera quae supersunt omnia, Vol. I and Supplement, Teubner Series, Leipzig.

Schreiber, M. (2004). A Jewel in Japan's Hi-Tech Crown: Sex Dolls. Mark Schreiber, Asian Sex Gazette, April 21, 20. Reproduced courtesy of Asian Sex Gazette.

Available at http://www.asiansexgazette.com/asg/japan/japan01news18.htm

Schwaeblé, R. (1905). Les Détraquées de Paris. Études documentaries, Paris.

Scott, J. and Fuller, J. (1965). Genetics and the Social Behavior of the Dog. University of Chicago Press, Chicago.

Serpell, J. (1986). In the Company of Animals. Basil Blackwell, Oxford.

Serpell, J. (1991). Beneficial Effects of Pet-ownership on Some Aspects of Human Health and Behaviour. Journal of the Royal Society of Medicine, Vol. 84, No. 12, pp. 717-720.

Serpell, J. (1996). In the Company of Animals, 2nd (Revised) Edition. Cambridge, Cambridge University Press, Cambridge.

Serpell, J. (2003). Anthropomorphism and Anthropomorphic Selection - Beyond the 'Cute Response', Society and Animals, Vol. 11, No. 1, pp. 83-100.

Shannon, C. (1950). Programming a Computer for Playing Chess. Philosophical Magazine, Ser.7, Vol. 41, No. 314, March 1950.

Shaver, P., Schwartz, J., Kirson, D., and O’Connor, C. (1987). Emotion Knowledge: Further Exploration of a Prototype Approach. Journal of Personality and Social Psychology, Vol. 52, pp. 1061-1086.

Shibata, T. (2004). An Overview of Human Interactive Robots for Psychological Enrichment. Proceedings of the IEEE, Vol. 92, No. 11, November 2004, pp. 1749-1758.

Shih, J. (1994). Plague in Prostitution: HIV and AIDS in Thailand. Rhode Island Medicine, Vol. 77, No. 5, pp. 145-149. 
Siegel, J. (1990). Stressful Life Events and Use of Physician Services among the Elderly: the Moderating Effects of Pet-ownership. Journal of Personal Social Psychology, Vol. 58, pp. 1081-1086.

Silverman, K. (1991). Back to the Future. Camera Obscura: A Journal of Feminism and Film Theory, No. 27, pp. 109-132.

Sincere, R. (2005). Virginia Enters the 20th Century. The Augusta Free Press, January 20 th.

Slade, J. (2000). Pornography and Sexual Representation: A Reference Guide. Three Volumes, Greenwood Press, Westport, Connecticut.

Smith, S.L. (1983). Interactions Between Pet Dog and Family Members: An Ethological Study. New Perspectives on our Lives with Companion Animals (eds. A. Katcher and A. Beck), pp. 29-36. University of Pennsylvania Press, Philadelphia.

Snell, J. (1997). Impacts of Robotic Sex. The Futurist: A Magazine of Forecasts, Trends, and Ideas about the Future, July-August, pp. 32-34.

Sobel, P. (1973). Massaging Apparatus. U.S. patent No. 3,874,373, filed April 5th, granted April 1st 1975.

Søby, M. (1998). Collective Intelligence - Becoming Virtual. Paper 16, Kongress der Deutschen Gesellschaft für Erziehungswissenschaft: Medie-Generation, University of Hamburg.

Someya, T., Sekitani, T., Iba, S., Kato, Y., Kawaguchi, H., and Sakurai, T. (2004). A Large-Area, Flexible Pressure Sensor Matrix with Organic Field-Effect Transistors for Artificial Skin Applications. Proceedings of the National Academy of Sciences, Vol. 101, No. 27, pp. 9966-9970.

Sproull, L. and Kiesler, S. (1991). Connections: New Ways of Working in the Networked Organization. MIT Press, Cambridge, Massachusetts.

Stekel, W. (1950). Auto-erotism: A Psychiatric Study of Onanism and Neurosis. Liveright, New York.

Stengers, J. and Neck, A. van (2001). Masturbation: The History of a Great Terror. Palgrave/St. Martins, New York.

Stevenson, D. (2000). Recording the Unspeakable: Masturbation in the Diary of William Drummond, 1657-1659. Journal of the History of Sexuality, Vol. 9, No. 3, pp. 223-239. 
Stewart, M. (1983). Loss of a Pet-Loss of a Person. New Perspectives on Our Lives with Companion Animals, (eds. A. Katcher and A. Beck), pp. 390-404. University of Pennsylvania Press, Philadelphia.

Strangelove, M. (1998). Redefining the Limits to Thought within Media Culture: Collective Memory, Cyberspace and the Subversion of Mass Media. PhD Dissertation, University of Ottawa, 1998.

Stribling, A. (2003). The Effects of Regular Interaction with Pets and General happiness. Clemson University.

Available at http://cujo.clemson.edu/CUJO/journals/2003/journals/journal.htm

Suler, J. (1998). Mom, Dad, Computer (Transference Reactions to Computers). Revised version 1998 (originally posted 1996).

Available at http://www.rider.edu/ suler/psycyber/computertransf.html

Sullivan, E. and Simon, W. (1998). The Client: A Social, Psychological, and Behavioral Look at the Unseen Patron of Prostitution. Prostitution: On Whores, Hustlers, and Johns (eds. James Elias, Vern Bullogh, Veronica Elias and Gwen Brewer), pp. 134-154. Prometheus, Amherst, New York.

Superbabe (2006). Superbabe Web site.

Available at http://www.superbabe2000.com

Suzuki, N., Takeuchi, Y., Ishii K., and Michio Okada M. (2003). Effects of Echoic Mimicry Using Hummed Sounds on Human-Computer Interaction. Speech Communication, Vol. 40, pp. 559-573.

Tabori, P. (1969). The Humor and Technology of Sex. Julian Press, New York.

Tannahill, R. (1989). Sex in History. Sphere Books (Cardinal), London.

Taylor, G. (1959). Sex in History. Thames and Hudson, London.

Taylor, J.S. and Davidson, J.O. (1999). "Fantasy Islands: Exploring the Demand for Sex Tourism.", in Sun, Sex and Gold: Tourism and Sex Work in the Caribbean, Kamala Kampadoo (Ed.), Rowman and Littlefield, New York, 1999.

Taylor, J.S. (2001). Dollars Are a Girl's Best Friend? Female Tourists' Sexual Behaviour in the Caribbean. Sociology, Vol. 35, No. 3, pp. 749-764.

Taylor, J.S. and Davidson, J.O. (2005). Travel and Taboo: Heterosexual Sex Tourism to the Caribbean. Regulating Sex: The Politics of Intimacy and Identity (eds. Laurie Schaffner and Elizabeth Bernstein), pp. 83-100. Routledge, London.

Tennov, D. (1979). Love and Limerence: The Experience of Being in Love. Stein and Day, New York. 
Thielscher, M. (2005). Reasoning Robots. The Art and Science of Programming Robotic Agents. Springer-Verlag, Dordrecht.

Time (1977). Hite-ing Back. Time Magazine, December $12^{\text {th }}$.

Time (1983). The Computer Moves In. Time Magazine, Vol. 121, No. 1, January 3rd 1983.

Time (2005). Best Inventions 2005: Bot Crazy. Time, Nov $13^{\text {th }} 2005$. Available at http://www.time.com/time/business/article/0,8599,1129515-5,00.html

Times (1833). Execution. The Times, August 13, p. 4, col. b.

Times (1835). Reporting on the Central Criminal Court, Saturday September 26. The Times, September 28.

Trappl, R., Payr, S., and Petta, P. (2003). Emotions in Humans and Artifacts (eds.). MIT Press.

Treays (1997). What Sort of Gentleman Are You After? BBC TV documentary.

Triebenbacher, S. (1994). Pets as Transitional Objects: Their Role in Children's Emotional Development, Psychological Reports, Vol. 82, No. 1, pp. 191-200.

Triebenbacher, S. (1998). The Relationship Between Attachment to Companion Animals and Self-Esteem.Companion Animals in Human Health, (eds. C.C. Wilson and D.C.Turner), pp. 237-247. Sage Publications, Thousand Oaks, California.

Trost, R. (2005). Personal communication.

Turing, A.M. (1950). Computing Machinery and Intelligence. Mind, Vol. LIX, No. 236, October 1950, pp. 433-460.

Turkle, S. (1984). The Second Self. Simon and Schuster, New York.

Turkle, S. (1995). Life on the Screen: Identity in the Age of the Internet. Simon and Schuster, New York.

Turkle, S. (1999). New Media and Children's Identity (Edited summary). Media in Transition Conference, MIT. Available at http://web.mit.edu/m-it/conferences/m-i-t/summaries/plenary1_st.html

Turkle, S. (2006). Diary, London Review of Books, Vol. 28, No. 8, 20th April 2006, pp. 36-37. 
United Nations (2004). World Robotics 2004. United Nations Economic Commission for Europe and the International Federation of Robotics.

Available at http://www.unece.org/press/pr2004/04robots_index.htm

Vanwesenbeeck, I. and Graaf, R. de (1998). Sex Work and HIV in the Netherlands: Policy, Research and Prevention. The Dutch Response to HIV. Pragmatism and Consensus (ed. Theo Sandfort), pp. 86-107. UCL Press, London.

Virilio, P. (1995). The Art of the Motor. The University Press of Minnesota, Minneapolis.

Virtualpet (1997). Tamagotchi and Aspectual Shape. Available at http://www.virtualpet.com/vp/farm/lleg/critical/ana.htm

Voith, V. (1985). Attachment of People to Companion Animals. Veterinary Clinics of North America, Vol. 15, pp. 289-295.

(VSD, 2005): Value Sensitive Design: Robotic Pets and the Elderly. Alan Beck, Nancy Edwards, Batya Friedman, Peter Khan,

Available at www.ischool.washington.edu/vsd/projects/aiboelderly.html

Walker, B. Harper, J. Lloyd, Chr. And Caputi, P. (2003). Methodologies for the Exploration of Computer and Technology Transference. Computers in Human Behavior, Vol. 19, pp. 523-535.

Ward, H., Mercer, C., Wellings, K., Erens, B., Copas, A., Fenton, K. and Johnson, A. (2005). Who pays For Sex? An Analysis of the Increasing Prevalence of Female Commercial Sex Contacts Among men in Britain. Sexually Transmitted Infections, Vol. 81, pp. 467-471.

Watts, J. (2005). Sex and the Single Robot. The Guardian, February 2nd.

Weatherby, W.J. (1983). Hard Times on the Street Walk. The Guardian, February 23rd, p. 21.

Weizenbaum, J. (1976). Computer Power and Human Reason, W.H. Freeman, New York, NY.

West, J. (1987). Plug into the Ultimate Joy Ride. Penthouse Forum Magazine, December.

Whitehouse, D. (2005). Japanese Develop 'Female' Android. BBC News Website, July 27 th.

Whitley, B. (1988). College Students' Reasons for Sexual Intercourse: A Sex Role Perspective. 96th Annual Meeting of the American Psychological Association, Atlanta. 
Wiener, N. (1948). Cybernetics. Wiley, New York.

Wikipedia (2006). Hero of Alexandria. Wikipedia, 2006.

Available at http://en.wilipedia.org/wiki/Hero_of_Alexandria

Wilde, R. de (2000). The Digirati: A Critique of the Futures Industry. Published in Dutch as De Voorspellers. Een kritiek op de toekomstindustrie. De Balie, Amsterdam.

Wilks, K. (1999). When Dogs Are Man's Best Friend - the Health benefits of Companion Animals in the Modern Society. Proceedings Urban Animal Management Conference. Gold Coast.

Wilson, E.O. (1984). Biophilia: The Human Bond With Other Species. Harvard University Press, Cambridge, Massachusetts.

Winick, C. (1962). Prostitutes' Clients Perceptions of the Prostitutes and of Themselves. International Journal of Social Psychiatry, Vol. 8, No. 4, pp. 289299.

Winnicott, D. (1953). Transitional Objects and Transitional Phenomena. International Journal of Psychoanalysis, Vol. 34, No. 2, pp. 89-97.

Wood (2002). Living Dolls. Faber and Faber, London.

Woodcroft, B. (1851). The Pneumatics of Hero of Alexandria from the Original Greek, Taylor Walton and Maberbly, London.

Woods, S., Dautenhahn, K., and Schulz, J. (2004). The Design Space of Robots: Investigating Children's Views. Proceedings of IEEE Ro-man 2004, 13th IEEE International Workshop on Robot and Human Interactive Communication, pp. 47-52, Kurashiki, Japan, IEEE Press, Piscataway, New Jersey.

Woolridge, M. (2002), An Introduction to Multi-agent Systems. John Wiley and Sons, Chichester.

Wüllenweber, M., Friedel, F. and Feist, M. (2006). Kramnik vs. Deep Fritz 10: Computer Wins Match by 4-2. ICGA Journal, vol. 29, No. 4, pp. 208-213.

www.BetterHumans.com (February 2003).

Xantidis, L. and McCabe, M. (2000). Personality Characteristics of Male Clients of Female Commercial Sex Workers in Australia. Archives of Sexual Behavior, Vol. 29, No. 2, pp. 165-176.

Yeager, B. (2006). Personal communication. 
Young, R. (1989). Transitional Phenomena: Production and Consumption. Crises of the Self: Further Essays on Psychoanalysis and Politics (ed. B. Richards), pp. 56-72. Free Association Books, London.

Young, R. (1994). Mental Space. Process Press, London.

Zajonc, R. (1968). Attitudinal Effects of Mere Exposure. Journal of Personality and Social Psychology, Monograph Supplement 9, No. 2, pp. 1-27.

Zeleznikow, J.and Stranieri, A. (1995). The Split-Up System: Integrating Neural networks and Rules Based Reasoning in the Legal Domain. Proceedings of the Fifth International Conference on Artificial Intelligence and Law, ACM Press, New York, pp. 185-194.

Zoonen, L. van (2002). Gendering the Internet: Claims, Controversies and Cultures. European Journal of Communication, Vol. 17, No. 1, pp. 5-23. 



\section{Appendix A:}

\section{ADDITIONAL ASPECTS OF THE PHYSICAL DESIGN OF ROBOTS}

The eventual acceptance of robots as sentient beings, worthy of our friendship, our love, and our respect, will be greatly facilitated by the physical design and construction of robots whose appearance matches our notions of friendliness.

Masahiro Mori (1970) was one of the first roboticists to suggest that a robot with a human-like appearance will be likely to engender feelings of familiarity and affection from humans. This view is borne out by a study based on one of the first controlled experiments to examine the effect of a humanoid robot's appearance on people's responses, with a machine-like robot used as a comparison (Hinds, Roberts, and Jones, 2004). The study suggests that people may be more willing to share responsibility with a humanoid as compared with robots that are less human-like and more machine-like. If the physical design of a robot creates an appearance in the human image, the robot's physical actions and movements will provide immediate and easily comprehensible social cues, thereby enhancing a human's perception of their interaction with the robot and making it easier for the human to engage with it socially. If, for example, the human swears at the robot, it could stick out its tongue as a gesture of complaint. But if the robot did not have a tongue to stick out it would not be able to convey its feelings in this human-like way, while if the robot's tongue was not designed into its mouth but instead was located on the lower part of one of its legs, perhaps the action of sticking out its tongue might not have the same effect on the human. The additional aspects of the physical design of robots that we would like to emphasize, are feel and touch technologies (discussed in A1 below) and smell and taste technologies (in A2), and robot behaviours (in A3).

Children have been found to be particularly susceptible to influence by the appearance of a robot with which they are interacting. In an experiment conducted by Sarah Woods, Kerstin Dautenhahn, and Joerg Schulz (2004), children aged 9 to 11 were shown various robots and asked whether they believed particular robots would understand them if spoken to. A rather strong correlation was found between the appearance of a robot and the extent to which the children believed that particular robot to be capable of understanding them. One of the robots in the experiment, the one shown on the left in Figure A.1, was perceived by the children as being human-like in appearance, and 90 percent of the children believed that this robot would be able to understand them. But in the case of a much less human-like robot (shown on the right of Figure A.1), one that the children regarded as being machine-like in appearance, it was rated by 90 percent of the children as not being likely to be able to understand them. 

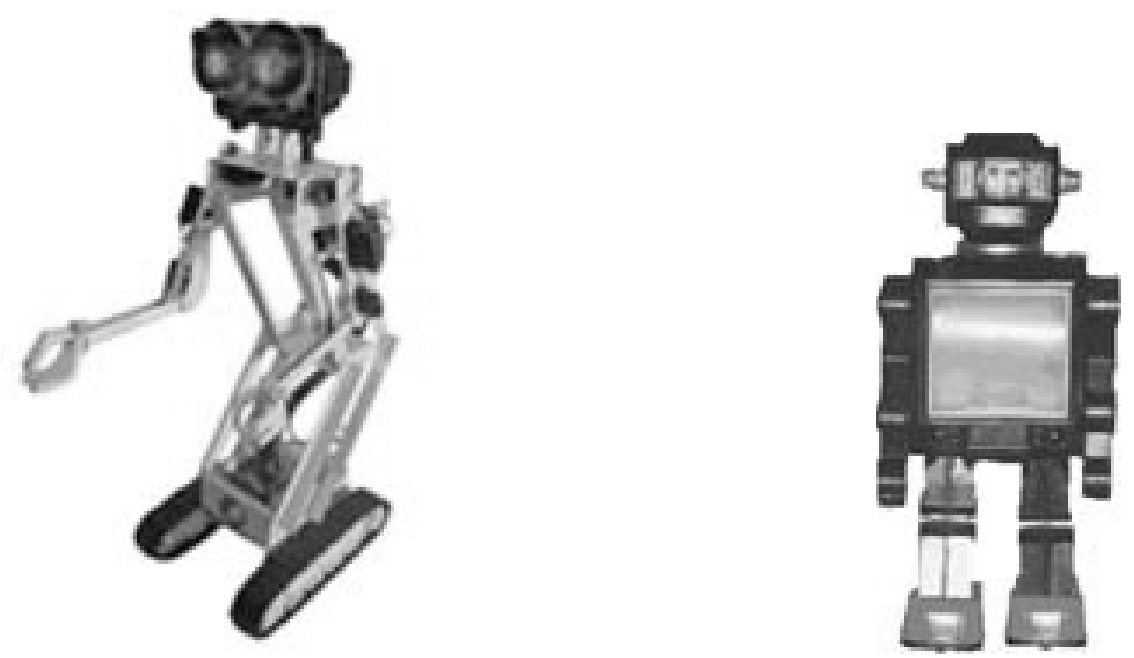

Figure A.1: Human-like and machine-like robots (adopted from Wood et al. (2004).

Even though a robot's appearance brings nothing to bear on its intellectual capabilities, it has been shown by psychologists that we humans, in general, prefer to interact with robots with whom we find it easy to identify, as compared to robots whose appearance is strikingly non-human ${ }^{1}$. But there is still a way to go before humanoids are as physically appealing as Stepford Wives and their malebot counterparts. In general, the more human-like the robot, the greater the level of familiarity that tends to be experienced by those who observe and interact with them. ${ }^{2}$ Although they are technically remarkable for their time, and great fun to watch, the robots of today are not exactly Mr Handsome or Ms Beautiful, nor are they as cuddly as pet cats, dogs, rabbits or FURBIES. The Carnegie-Mellon University robot, GRACE, who attended an academic conference in Canada in 2002, managed to find its way around the conference building well enough to register for the conference, reach a lecture room by itself (asking for directions only when

\footnotetext{
${ }^{1}$ See the discussion on similarity in section 3.5.

${ }^{2}$ In 1970 the renowned Japanese roboticist Masahiro Mori published Bukumi Ni Tani, (The Uncanny Valley), in which he speculated that, as robots come to appear more human to us, we will regard them with increasing familiarity, until a point is reached at which minor imperfections in their appearance and/or their actions engender an uncanny feeling in us. At that point our feelings of familiarity will diminish sharply, resulting in a steep dip in the curve that relates familiarity to how human-like the robot appears to us to be. Further along the curve, as the robots become even more human-like, there is a steep rise in familiarity. Mori called this dip the "uncanny valley".
}

Mori's interesting predictions in 1970 could not have any experimental basis due to the lack of availability of android robots. Until suitable experiments have been conducted with androids, ranging from inhuman-like to completely human-like, it will not be possible to verify Mori's expectations. Even if he is proven correct, the uncanny valley is only a blip on the curve, albeit a deep one, and when robots are completely human-like in their appearance the shape of Mori's curve suggests that our level of familiarity with them will similarly be at the top end of the scale. Recent research (Schaub, 2006) indicates that the uncanny valley has already been crossed. 
necessary), and deliver a lecture on how it worked. But GRACE did not look at all human-like or even animal-like. Its "face" was an image displayed on a computer screen that formed the top part of its construction, while the remainder of its body was a mass of metal parts, electronics, wheels, and much of the other paraphernalia that one would expect to find in an engineering laboratory. So, although GRACE performed admirably and with a certain measure of physical dexterity (she could navigate her way into an elevator and exit at the correct floor), she was not exactly anyone's idea of a great-looking date.

One might argue that only the capabilities of a robot should matter to us and not its looks, but I believe they will matter a lot, a belief that stems partly from an experience I had around the age of 10. The first time I visited Madame Tussaud's museum in London I asked a gentleman dressed in a uniform the way to some particular part of the exhibition, only to realise, after a second or two, that he was not on the museum staff, he was one of the waxworks. So convincing was the wax janitor's appearance that I had been fooled into thinking that "he" would respond to my question and would know the answer. After all, he looked just like I expected a museum janitor to look. This experience has doubtless been shared by many thousands of the museum's other visitors, and is a valuable lesson in understanding an important aspect of human-robot relationships. The appearance of a robot will affect how people perceive it, particularly their first impressions, as well as how they interact with it and the development of their relationships with it. If a robot has all the appearances of being human then we will increasingly adopt an anthropomorphic attitude towards it and we will find it much easier to accept the robot as being sentient, of being worthy of our affections, leading us to accept it as having character and being alive, whatever "alive" means for a robot ${ }^{3}$. With this in mind, the appearance of a robot's head and face are clearly extremely important factors in our initial reactions when meeting it. First impressions do count. This is why it is not sufficient for the GRACEs of the future to look like electronics laboratories on wheels, or even on awkwardly moving legs. They must walk in a human-like fashion and, above all, they must be appealing in their appearance. Only then will huge numbers of people want them as their friends and lovers.

One year after GRACE made her debut as a conference attendee, David Hanson, a graduate student at the University of Texas at Dallas, demonstrated a lifelike talking head. Its face has soft, flesh-coloured, artificial skin made of an elastic, flexible polymer developed by Hanson especially for this purpose. The face on Hanson's artificial head has finely sculpted cheekbones and big blue eyes. When connected to a computer the head can smile, it can frown, it can sneer, and its brow can develop furrows to give a worried look. This kind of expressive power will enable robots to interact more easily with humans, using their electronic minds to control their facial expressions and head movements in accordance with whatever emotions the robot wishes to display. Equally, the robot can turn its head, and particularly its eyes, towards a human, taking in through its vision system whatever emotional cues the human is exhibiting and using this information to help it react with appropriate

\footnotetext{
${ }^{3}$ Some of the implications of this question are discussed in Chapter 12 of Robots Unlimited. (Levy, 2005).
} 
facial expressions. This is part of the human mechanism for developing two-way emotional relationships, a mechanism that will be enhanced with the affective technologies described earlier in this chapter (see section 6.5).

The design of the head that Hanson demonstrated was based on that of his blue-eyed girlfriend, Kristen Nelson. In April 2002 he had gone to a bar in the trendy, Exposition Park area of Dallas, complete with a pair of callipers, in search of someone whose own head would be suitable as a model for what Hanson had in mind. There he saw Kristen, who he knew casually, and asked her: "Can I make you into a robot?" He did. The movements of Hanson's artificial head are made possible by a collection of 24 motors, invisible to the observer, that simulate the actions of most of the muscles in the human face. The motors are driven by two microprocessors and they employ nylon fishing line to tug the artificial skin when it needs to move. The eyes contain digital cameras to enable the head to see the people who are looking at it, and, if required, to imitate their facial expressions, courtesy of its "muscle" motors.

Following its first convincing demonstration, and the aura of publicity that surrounded it, the head attracted interest from companies in fields ranging from artificial limbs to sex dolls. That was in 2003. In the timeline for the development of sentient, lovable robots, Hanson's work puts head-design ahead of schedule. Add Hanson's artificial head to GRACE's body and already the physical appearance of robots will have reached new heights of acceptability. Just as a robot's emotional and intellectual makeup and its face and voice can be selected on an individual basis, so it can be designed with any wished-for physical characteristics, including skin, eye, and hair colour; size of genitalia and sexual orientation.

\section{A1 Feel and Touch Technologies}

In designing artificial skin for robots, the most important properties will probably not be its appearance and expressiveness, but rather its sensing capabilities - feel and touch. From a purely practical perspective, having a well-developed sense of feel will enable a robot to detect changes in its surroundings and to move accordingly. But the more romantic aspects of feel are those that concern us here how a robot can detect a physical expression of love, a caress or a kiss. Though perhaps with different research goals in mind, scientists in Japan, Italy, and the USA are working on hi-tech skin development. The sensuous robot will be one of the spin-offs of their research.

At the University of Tokyo a group led by Takao Someya is developing a synthetic skin, based on the technology for printing enormous numbers of flexible, low-cost pressure sensors on a large area of the "skin" material (Someya et al, 2004). Meanwhile, in Italy, at the University of Pisa, Danilo de Rossi and his team are making "skin" using artificial silicone, which has the properties of elasticity (human skin stretches if pulled), and sensitivity to pressure. In the USA, scientists at NASA are employing infrared sensors embedded in a flexible plastic covering - the sensors detect an object as the robot touches it and then send a signal to the robot's computer, its "brain", corresponding to the size, shape, and feel of the object. 
The different types of sensor and the different skin materials being investigated by these groups reflects the fact that the study of artificial skin technology is still in its infancy and there is not yet a consensus as to what materials and technologies make for the best artificial skin. Future artificial skin materials are likely to be more tactile and to provide even more sensors to cater for greater sensitivity, but from the perspective of skin as an important component of a robot love object or sex object, it is hardly important what type of sensors are being used nor how many. What is important is that robots will be able to feel and recognize the touch and caress of an affectionate human, to know when their human is making the first physical overtures of passionate romantic love. Similarly, a delicate sense of touch will be needed by a gentle robot lover, able to return its human's tender caresses and to initiate its own. Scientists at the Polytechnic University of Cartagena in Spain have created a sensitive robotic finger that can feel the weight of pressure it is exerting and can adjust the energy it uses accordingly (Otero and Cortés, 2003), allowing a robot to caress its human partner with the sensitivity of a virtuoso lover.

\section{A2 Smell and Taste Technologies}

One novel technology that will contribute to a robot's physical appeal is smell synthesis. The right kind of bodily fragrance can act as a powerful attraction and aphrodisiac. Hence, a recent flurry of interest in the technology of electronically creating scents to order. I am not necessarily talking about the kind of scent that comes in small bottles with big price tags. Instead the idea is to create electronically any smell to order. Just as your loudspeaker plays out digitally stored music, so the smell equivalent of a loudspeaker will spray out the digitally stored smells generated by this technology. Your robot can exude a favourite perfume, or a realistic counterfeit of your (human) loved one's body fragrance, or even a body fragrance of its own that has been designed to appeal to you and to cater to your hormones and to your personal desires.

The early attempts at bringing smell technology to the market were not exactly a great success. Despite serious investment, reportedly $\$ 20$ million in one company alone $^{4}$, the sweet smell of success eluded the pioneers in this field. By 2005 however a new generation of digital smells companies were racing to be the first to launch viable smell creation technology ${ }^{5}$, and technologies very similar to those employed in the generation of smells to order can also be employed in the creation of artificial flavours that taste just like the real thing.

The fascinating aspect of this technology, from the perspectives of love and sex, lies in the creation of scents that can set a partner's hormones running. These sense technologies will provide some of the foundation for the amorous and sexual attraction that humans will feel for robots. Sex usually involves several senses simultaneously: we enjoy the sight of our loved one, we enjoy the sound of their

\footnotetext{
${ }^{4}$ DigiScents Inc.

5 Trisenx (www.trisenx.com), the French company Exhalia (www.exhalia.com), SAV Products of California (www.savproducts.com) and an (as yet anonymous) Israeli company, all appear to have similar technology.
} 
voice; the feeling of their skin when we caress it and the feeling on ours when we are touched; we enjoy their smell and their taste. All of these senses heighten our erotic arousal, and all of their corresponding technologies can be designed into robots to make them both alluring and responsive.

\section{A3 Robot Behaviours}

An important facet of designing robots that promote satisfactory relationships with humans (satisfactory from the human point of view), is an analysis of the extent to which the robot needs to behave in a sociable way with humans in different types of situation. If, in a particular situation, a robot exhibits none of the normal human characteristics of emotion, it will probably appear to be insensitive, indifferent, even cold or downright rude. Solving this problem is not that simple. There might be some people, some nationalities, some age groups or one of the sexes, that do not perceive a robot to be any of these things in the given situation, simply because of their cultural, educational or social background. What is cold, rude or uncouth to one group in society might appear to be completely normal, acceptable, even friendly to another group. A sociable robot that has emotional intelligence will therefore need to be able to make this distinction, to decide how to behave with different people in the same situation in order to be perceived as sociable by all of them. (Robots will be programmed to want to be liked by everyone, just as you and I do.)

Other factors that might affect the appropriate way for a robot to behave include whereabouts the human-robot interaction is taking place. Is it in the home, where a more overtly friendly behaviour by the robot would be appropriate? Or is it at work, where the human might be the robot's boss (or vice versa) and therefore a more overtly respectful attitude would be required of the robot (or the human)? Robots will need to be endowed with many "rules" of sociability for all sorts of situations and contexts, and this ruleset can be expanded through the use of learning technologies. If a robot acts in a manner that appears rude to a human, the robot can simply be told "that is rude", whereupon, like a well brought up child, the robot can learn to improve its manners and behaviour.

An interesting question here is whether robots should merely be designed to imitate human sociability traits, or whether robots should be taught to go further and create sociability traits of their own, traits that are atypical of humans but which can, nevertheless, be appreciated by humans. To do so would be a form of creativity, possibly no more difficult to program than the task of composing "Mozart's" 42 nd symphony or painting a canvas that can sell in an art gallery for thousands of dollars - tasks that have already been accomplished by AI researchers ${ }^{6}$.

At the ATR Intelligent Robotics and Communication Laboratories in Kyoto, a robot called RoBOviE has been developed as a testbed for ideas in robot-human communication (Kanda et al, 2004). RoBOVIE has a human-like body that is only 4 feet tall, so as not to be overly intimidating to the humans outside the laboratory with whom it comes into contact from time to time. ROBOVIE has two arms, two

\footnotetext{
${ }^{6}$ See Chapter 5 of Robots Unlimited (Levy, 2005).
} 
eyes and a system of three wheels to enable it to move around. (Legs are not yet considered a necessity for ROBOVIE's principal sphere of activity, which is communication with humans rather than tasks involving movement.) ROBOVIE has an artificial skin, to which have been attached various sensors, 16 of them, made from pressure-sensitive rubber. It can speak, it can hear and recognize human speech, and it can charge its own batteries when necessary.

ROBOVIE's developers believe that there is a strong correlation between the number of appropriate behaviours that it can generate and how intelligent a robot appears to be. The more often a robot can behave in what is perceived to be an appropriate manner, the more highly will its intelligence be regarded. The scientists developing ROBOVIE plan to continue to develop new behaviour patterns until ROBOVIE has advanced to the point where it is much more lifelike than a simple automaton. Part of this progress will come from the robot's tendency to initiate interaction with a human user, rather than merely being reactive. You and I do not always wait until we are spoken to before we say something, so why should a robot? You and I do not always wait until someone stretches out their hand to us and says "Hi. Nice to meet you." Nor should a robot. ROBOVIE will, in appropriate circumstances, shake hands with you, hug you, greet, kiss and converse with you, play simple games such as rock-scissors-paper, and sing to you. And these are just some of the behaviour patterns it had been taught up to mid-2004.

ROBOVIE's arms, eyes, and head also contribute to the robot's ability to interact with humans and to how they perceive it, partly because of the importance of eye contact in the development of human relationships and therefore in the creation of empathetic robots. We humans greatly increase our understanding of what others are saying to us, the subtext as well as the words themselves, when we establish eye contact and observe a speaker's body gestures. Research has repeatedly shown that, during a conversation, a human becomes immediately aware of the relative position of their own body and that of the person to whom they are speaking - the body language improves the communication. This explains the tendency for Japanese roboticists to build human-shaped robots, endowing their robots with effective communication skills and employing the results of research from cognitive science to create more natural communication between robot and human.

Experiments with a group of 26 university students showed that ROBOVIE exhibits a high level of performance when interacting with humans, while the students generally behaved as though they were interacting with a human child, many of them maintaining eye contact with the robot for more than half the duration of the experiment. Some of the students even joined in with the robot in its exercise routines, moving their own arms in time with the robot's movements. The natural appearance of the students' interactions in the experiment was attributed to the human-like appearance and behaviour of the robot. 



\section{Summary}

The thesis investigates the past and present development of our relationships with computers. Emphasis is put on the question how these relationships are continuing to progress towards intimacy, culminating in the prospect of robots becoming our artificial partners. It is a fascinating area which, only fifty years ago, was completely within the realm of science fiction, but which is now moving towards becoming a reality. The study consists of four parts.

The goal of my research is to answer a twofold problem statement (PS) concerning the types of relationship between human beings and some kind of robot that will be created during the coming decades. The structure of the research is described in Part One, consisting of Chapters 1 and 2. The two strands of the problem statement are as follows.

PS1: $\quad$ To what extent will the emotions that humans feel for other humans, for pet animals, for virtual pets, and even for less animal-like artefacts - namely computers -, be extended to embrace the robots of the future?

In order to answer PS1 it is necessary to examine the reasons (1) why humans develop strong emotional feelings of attraction (leading to attachment or love) to other humans, (2) why humans develop strong emotional attachments to pet animals and to virtual pets, and (3) why humans develop emotional attachments to computers. We can then consider how these reasons might also apply to humanrobot relationships.

PS2: $\quad$ To what extent will the normal bounds of human sexuality be extended with respect to the robots of the future?

In order to answer PS2 it is necessary to examine, largely from a psychological perspective, (1) the reasons why humans enjoy sex, (2) why humans desire sex, and (3) whether love as we know it, love from our chosen sex object, is an essential factor for our sexual enjoyment and gratification. Having sufficient knowledge of these topics we can then consider how and to what extent their normal bounds will be extended to human-robot relationships.

My research objectives are therefore twofold, namely to investigate: (1) whether humans will develop strong emotional feelings of attraction (leading to attachment or love) to robots as (what will be regarded as) "normal" extensions of our feelings (attachment or love) towards other humans - this is investigated in Part Two (Chapters 3 to 6); and (2) whether making love with robots will be as normal as making love with humans - this is investigated in Part Three (Chapters 7 to 10). Part Four (Chapter 11) contains conclusions.

In order to achieve these objectives I have formulated eight research questions (RQs). 
Chapter 1 starts with a brief introduction to Artificial Intelligence and Robotics, then formulates my twofold problem statement, and lists my research objectives and research questions. There follows a description of my research methodology and an overview of the structure of the thesis.

Chapter 2 provides the relevant historical background to the thesis - a brief overview of the successes achieved in creating mechanical artefacts, robots, and sociable computers, over a period of more than two thousand years. This historical overview starts with artefacts that were purely mechanical in their functioning; then it continues with early thinking and socially interesting artefacts (tea-carrying dolls, for example), progressing eventually to the early goals and achievements of the new science of Artificial Intelligence, of which Robotics is a branch.

In chapter 3 I address the first of my research questions: is it possible to trace what (precisely) causes people to develop strong emotional feelings of attraction (leading to attachment or love)? I begin by investigating the connection between the psychological phenomena of attachment, which starts in infancy, and romantic love. In an attempt to obtain some insight into the question: "Why do people fall in love?", I examine ten principal causes of falling in love that have been identified by research psychologists. I then compare these factors with the phenomenon of falling in love on the Internet. Later in the thesis I use these ten causes as benchmarks for my investigation into the relationships that will develop during the coming decades between humans and robots.

In chapter 4 I investigate my second research question: what characterizes the affective relationship between humans and pets? It is a topic that has been well researched during the past twenty years. This topic is relevant to my own research, partly because it demonstrates that many people develop quite strong emotional attachments to these non-humans, thereby proving that it is not essential to be human in order to be the focus of love from a human.

The question: "Why do people love their pets?" is discussed, and the answers and the strength of the love that people exhibit for their pets also informs our understanding of why many humans form strong emotional attachments, including love, for virtual pets such as the TAMAGOTCHI and Sony's robotic dog AIBO.

The subject of my research in chapter 5 is love for virtual pets. My third research question reads: what is the attractive power of a virtual pet? My research here provides us with much insight into the social relationships between human beings and computers. It is highly relevant because computers, in one form or another, form the core, the brain, of virtual pets and robots. The main conclusion of that chapter is that humans do indeed develop emotional feelings for virtual pets.

In chapter 6 , the principal subject is the nature of the emotional relationships that many people develop with some sort of computer-driven artefact, and specifically the relationships that we will develop with the humanoid robots of the future. Here I investigate my fourth research question: what is the attraction of a humanoid robot 
for a human being? I start the chapter with an investigation of people's attitudes to relationships in general, followed by a discussion on why many people actually prefer interacting with computers to interacting with other people. This leads to ideas on robotic psychology and behaviour, and in turn to the differences between emotions in humans and emotions in robots. I then investigate the extent to which robots might recognize human emotions, and how the recognition process contributes to the falling-in-love process. I also discuss robot personalities and their influence on robots' relationships with humans. My examination of the process of designing robot personalities includes an introduction to the concept of robot chromosomes - a recent development. I apply the ten factors discussed in chapter 3 (the factors that cause humans to fall in love with humans) to human-robot relationships, in order to investigate what this comparison proves. For a deeper understanding of the topic of human-robot relationships I subsequently investigate more concepts directly related to love, namely: robot fidelity, passion, and the intensity of robot love, all of which are closely related to the mood and desires of one of the partners. The logical culmination of the investigations in this chapter, and indeed of Part Two of this thesis, is a discussion on "Marrying a Robot".

Chapters 7 to 10 present what I believe compelling arguments to show that sex with robots will become a norm rather than being an oddity. I start by examining sexual relationships between humans.

I commence this analysis in chapter 7, where I investigate my fifth research question: why do people enjoy sex? I consider only those aspects of this question that are likely to be relevant when extending the question to robots. The most direct evidence on this topic is presented in tables 7.1 to 7.3 , which list the most commonly stated reasons for having sex (with a human) - reasons that mostly appear to apply equally to the concept of sex with a robot. This evidence is employed to help support my argument, in chapter 8 , on the inevitability that many people will also enjoy sex with robots.

The main thrust of chapter 8 , is to investigate my sixth research question: why do people pay for sex? Two of the most frequently stated reasons, from both men and women clients, are the desire to experience variety, both in the choice of sex partner and in the sexual experiences themselves; and to be able to enjoy sex without the complications and restraints of a relationship. Many of the women who pay for sex are also seeking some emotional closeness, but this is considerably less true of male clients. I explore this question because sex with a prostitute and sex with a robot are both experiences that come without any genuine love from the sex provider. Whatever passes for love in these encounters is pure acting (in the case of the human sex worker) or pure programming (in the case of a robot), which are not dissimilar in their lack of genuineness. My thinking here is to demonstrate this and other parallels that apply both to sex with a prostitute and sex with a robot.

Chapter 9 explores the engineering and technologies of various types of sexual artefacts, some of which date back more than a century, and thereby this chapter answers my seventh research question: what technologies are available to be used as sex technologies? From the history of dolls as lover substitutes, through the earliest 
vibrators and other sex machines designed for the pleasure of women, I trace the evolution of sex devices to the much more sophisticated products of today, including expensive silicone dolls that can satisfy some people's sexual desires and do so sufficiently well to generate income for the recently launched business of doll "escort" services in Japan and South Korea. I also examine the technologies of virtual sex and the Internet, an astounding mixture of sexual technologies including the relatively new domains of Virtual Reality and Teledildonics. By considering the development of these technologies during recent decades, the reader should be able to understand at least some of the sexual possibilities of the robots of a few decades from now, given the inevitable advances in Artificial Intelligence research.

Having explained the reasons why humans will desire sex with robots, and having demonstrated advances in the technologies of sexual artefacts that are leading very much in the direction of robot sex, I discuss in chapter 10 the changes in thinking, in attitudes, and in sexual mores, that have occurred in the past in relation to sex. These changes provide the answer to my eighth and final research question: what mental obstacles exist to prevent the final step towards the second objective? My argument here is rather straightforward. It is that the change in attitudes to homosexuality, oral sex, fornication, and masturbation, changes that our world has witnessed during the past two centuries and especially during the last fifty years, have been no less dramatic than the changes in attitude that will be required to accept the concept and practice of sex with robots as being natural extensions of human sexual relationships.

Chapter 11 summarizes my conclusions to research questions RQ1, RQ2, RQ3, and RQ4, leading to the overall conclusion for PS1, that the emotions that humans feel for other humans, for pet animals, for virtual pets, and even for less animal-like artefacts - namely computers - will be fully extended to embrace the robots of the future. In chapter $11 \mathrm{I}$ also summarize my conclusions to research questions RQ5, RQ6, RQ7, and RQ8, leading to the overall conclusion for PS2, namely that the normal bounds of human sexuality will be fully extended to embrace the robots of the future. On these two overall conclusions I rest my case, namely that love and sex with robots are inevitable as extensions to our ideas, feelings, and practices in the realm of relationships. The question is not if, but when, all this will happen. It is my belief that the answer is "much sooner than you might think". Finally, I provide four recommendations for further research. 


\section{Samenvatting}

Het proefschrift onderzoekt de vroegere en huidige ontwikkeling van onze relaties met computers. De nadruk valt daarbij op de vraag hoe deze relaties zich verder ontwikkelen naar een zekere mate van intimiteit, die culmineert in het vooruitzicht dat robots onze artificiële partners worden. Dit is een fascinerend onderzoeksgebied, dat vijftig jaar geleden ondenkbaar was en zou worden verwezen naar science fiction. Maar nu is het bezig werkelijkheid te worden. Het onderzoek bestaat uit vier delen.

Het doel van mijn onderzoek is een tweevoudige probleemstelling (PS) te beantwoorden betreffende de typen van relaties tussen enerzijds mensen en anderzijds een soort robot die zal worden ontworpen in de komende decennia. De structuur van het onderzoek wordt uiteengezet in Deel Eén, dat bestaat uit de hoofdstukken 1 en 2 . De twee onderdelen van de probleemstelling luiden als volgt.

PS1: In hoeverre zullen emoties die mensen voelen voor andere mensen, voor huisdieren, voor virtuele huisdieren en zelfs voor minder dierachtige artefacten - zoals computers - worden uitgebreid tot het gebied van de robots van de toekomst?

Ten einde PS1 te beantwoorden is het nodig om de redenen te onderzoeken (1) waarom mensen zulk sterke emotionele gevoelens van aantrekking voor andere mensen ontwikkelen (leidend tot affectie of liefde), (2) waarom mensen sterke emotionele affectie ontwikkelen tot huisdieren en virtuele dieren, en (3) waarom mensen emotionele affectie ontwikkelen voor computers. Daarna kunnen we onderzoeken waarom die redenen ook van toepassing zouden kunnen zijn op mensrobot relaties.

PS2: In hoeverre zullen de normale grenzen van de menselijke seksualiteit worden uitgebreid ten aanzien van de robots van de toekomst?

Om PS2 te beantwoorden is het nodig om de redenen te onderzoeken, vooral vanuit een psychologisch perspectief, (1) waarom mensen plezier beleven aan seks, (2) waarom mensen naar seks verlangen, en (3) of liefde zoals we die kennen, liefde van het door ons gekozen seksobject, een essentiële factor is voor ons seksuele plezier en ons gerak. Als we voldoende kennis hebben over deze onderwerpen kunnen we vervolgens onderzoeken hoe en in welke mate de normale grenzen uitgebreid zullen worden tot mens-robot relaties.

Mijn onderzoeksdoelen zijn eveneens tweevoudig, namelijk om te onderzoeken (1) of mensen sterke emotionele gevoelens van aantrekking (leidend tot affectie en liefde) tot robots zullen ontwikkelen en wel of dit gebeurt op dezelfde wijze als (wat toe nu toe wordt gezien als) de "normale" uitbreidingen van onze gevoelens (affectie en liefde) naar andere mensen - dit wordt onderzocht in Deel Twee (hoofdstukken 3 tot 6); en (2) of liefde bedrijven met robots net zo normaal zal zijn als liefde 
bedrijven met mensen - dit wordt onderzocht in Deel Drie (hoofdstukken 7 tot 10). Deel Vier (hoofdstuk 11) bevat de conclusies.

Om de twee onderzoeksdoelen te bereiken heb ik acht onderzoeksvragen (research questions, RQs) geformuleerd.

Hoofdstuk 1 begint met een korte inleiding op Kunstmatige Intelligentie en robots. Daarna formuleer ik mijn tweevoudige probleemstelling, beschrijf ik mijn onderzoeksdoelen, en vermeld ik de onderzoeksvragen. Vervolgens beschrijf ik mijn onderzoeksmethodologie en sluit ik af met een overzicht van de structuur van het proefschrift.

Hoofdstuk 2 geeft de voor het proefschrift relevante historische achtergrond - een kort overzicht van de successen die behaald zijn bij het maken van mechanische artefacten, robots, en sociale computers, over een periode van meer dan tweeduizend jaar. Dit historische overzicht begint met de artefacten die zuiver mechanisch waren in hun functioneren. Daarna komen de artefacten die een beetje kunnen denken en die sociaal interessant zijn (bijv. de tea-carrying dolls); dit gaat door tot de eerste doelstellingen en bereikte successen van de nieuwe wetenschap, Kunstmatige Intelligentie, waarvan Robotics een onderdeel vormt.

In hoofdstuk 3 behandel ik de eerste onderzoeksvraag: is het mogelijk na te gaan wat (precies) de oorzaken zijn dat mensen sterke emotionele gevoelens van aantrekking (leidend tot affectie en liefde) ontwikkelen? Ik begin hierbij te onderzoeken wat de relaties zijn tussen de psychologische fenomenen van aantrekking, die in de kinderjaren start, en romantische liefde. Teneinde enig inzicht te krijgen in de vraag: waarom worden mensen verliefd? onderzoek ik tien voorname oorzaken van het verliefd worden die als zodanig zijn geïdentificeerd door onderzoekspsychologen. Vervolgens vergelijk ik deze factoren met het verschijnsel 'verliefd worden via Internet'. Nog weer later gebruik ik deze tien oorzaken als benchmarks voor mijn onderzoek naar de relaties die zich gedurende de komende decennia tussen mensen en robots zullen ontwikkelen.

In hoofdstuk 4 behandel ik mijn tweede onderzoeksvraag: wat karakteriseert de affectieve relatie tussen mensen en huisdieren? Het is een onderwerp dat grondig onderzocht is in de laatste twintig jaar. Het onderwerp is relevant voor mijn onderzoek, deels omdat het aantoont dat veel mensen tamelijk sterke emotionele affecties hebben naar bedoelde niet-mensen; daarbij bewijzen ze dat het niet wezenlijk is om mens te zijn teneinde toch het voorwerp van liefde te zijn vanuit een mens.

De vraag: "waarom houden mensen van hun huisdieren?" is diepgaand onderzocht. De antwoorden tezamen met de sterkte van de liefde die mensen tonen voor hun huisdieren geven ons informatie en maken het begrijpelijk waarom zoveel mensen sterke emotionele affectie, tot liefde toe, gevoelen voor virtuele huisdieren, zoals de TAMAGOTCHI en Sony's robot dog AIBO. 
Het onderwerp van mijn onderzoek in hoofdstuk 5 is liefde voor virtuele huisdieren. Mijn derde onderzoeksvraag luidt: wat is de aantrekkingskracht van een virtueel huisdier? Het onderzoek op dit gebied geeft ons veel inzicht in de sociale relaties tussen mensen en computers. Het is zeer relevant, want computers vormen in de een of andere gedaante, de kern (het verstand) van virtuele huisdieren en van robots. De belangrijkste conclusie van het hoofdstuk is dat mensen inderdaad emotionele gevoelens ontwikkelen voor virtuele huisdieren.

Het hoofdonderwerp van hoofdstuk 6 is de aard van de emotionele relaties die veel mensen ontwikkelen met een computergestuurd artefact, en in het bijzonder wat de relaties zijn die mensen zullen ontwikkelen met de mensachtige robots van de toekomst. Dit leidt tot de volgende meer precieze onderzoeksvraag: wat is de aantrekkelijkheid van een mensachtige robot voor een mens? Ik begin het hoofdstuk met een onderzoek naar de houding van mensen in relaties in het algemeen. Dan volgt een discussie over waarom veel mensen in werkelijkheid de voorkeur geven aan interactie met computers boven interactie met mensen. Dit leidt tot ideeën over de verschillen tussen emoties bij mensen en emoties bij robots. Vervolgens onderzoek ik in hoeverre robots menselijke emoties zouden kunnen herkennen en hoe het herkenningsproces bijdraagt tot het proces van verliefd worden. Verder bespreek ik de robotpersoonlijkheden en hun invloed op de relaties van robots en mensen. Mijn onderzoek van het proces van het ontwerpen van robotpersoonlijkheden behelst een inleiding op het concept van robotchromosomen - een nieuwe ontwikkeling. Voorts pas ik de tien factoren uit hoofdstuk 3 toe op de mens-robot relaties, om na te gaan wat deze vergelijking oplevert. Voor een beter begrip van het onderwerp mens-robot relatie onderzoek ik vervolgens meer concepten die direct gerelateerd zijn aan de liefde, namelijk: robottrouw, hartstocht, en de intensiteit van robotliefde; al deze drie zaken zijn nauw verbonden met de gemoedsgesteldheid en de wensen van een van de partners. Het logische hoogtepunt van de onderzoekingen in dit hoofdstuk, en ook van Deel Twee is de discussie over "trouwen met een robot".

De hoofdstukken 7 tot en met 10 geven naar mijn mening met overtuigende argumenten aan dat seks met robots normaal zal worden, eerder dan uitzonderlijk. Ik begin met seksuele relaties tussen mensen te onderzoeken. De analyse neemt een aanvang in hoofdstuk 7. Daar beantwoord ik mijn vijfde onderzoeksvraag: waarom beleven mensen plezier aan seks? Ik onderzoek alleen aspecten van deze vraag die relevant zijn voor een mogelijke uitbreiding naar de robotwereld. De meest directe evidenties over dit onderwerp worden getoond in de tabellen 7.1, 7.2 en 7.3. Daarin staan de meest gebruikelijke redenen voor het hebben van seks (mens met mens) het zijn redenen die veelal gelijkelijk toegepast kunnen worden op het hebben van seks met een robot. Deze evidenties worden later gebruikt om mijn argumenten in hoofdstuk 8 te ondersteunen, namelijk dat het onvermijdelijk is dat mensen plezier zullen beleven aan seks met een robot.

De essentie van hoofdstuk 8 is het beantwoorden van de zesde onderzoeksvraag: waarom betalen mensen voor seks? De twee meest getoonde antwoorden, zowel van mannen als van vrouwen, zijn (1) de wens om verscheidenheid te beleven, zowel in de keuze van de sekspartner als in de seksuele ervaringen zelf en (2) om seks te 
hebben zonder de complicaties en gebondenheid van een relatie. Veel vrouwen die voor seks betalen zoeken ook naar emotionele geborgenheid, maar dit is in belangrijke mate minder het geval bij mannen. Ik onderzoek de vraag omdat seks met een prostitué en seks met een robot beide ervaringen zijn die niet gepaard gaan met enige echte liefde vanuit degene die (datgene dat) de seks aanbiedt. Wat doorgaat voor liefde in deze ontmoetingen is slechts "acteren" (in het geval van de menselijke sekswerknemer) of zuiver programmeerwerk (in het geval van de robot); beide zaken zijn niet ongelijk wat betreft het gebrek aan echtheid. Mijn idee is dat aan te tonen en andere parallellen te trekken die allebei toepasbaar zijn op seks met een prostitué en een robot.

In hoofdstuk 9 onderzoek ik de engineering en andere technologische zaken van diverse artefacten. Sommige van hen dateren van meer dan een eeuw geleden. Het hoofdstuk beantwoordt mijn zevende onderzoeksvraag: welke technologieën zijn beschikbaar om te worden gebruikt als sekstechnologieën? Vanuit de geschiedenis van de dolls als plaatsvervangsters voor een geliefde, via de eerste vibrators en andere seksmachines die ontworpen zijn voor het gerak van vrouwen trek ik de ontwikkeling van seksapparaten door naar de veel meer uitontwikkelde producten van vandaag de dag, inclusief de peperdure silicone dolls die de wensen van sommige mensen goed kunnen vervullen en dat zelfs zo goed doen dat zij een inkomen genereren voor onlangs opgezette firma's van doll "escort" services in Japan en Zuid Korea. Ik onderzoek ook de technologieën met inbegrip van de relatief nieuwe domeinen van Virtual Reality en Teledildonics. Wanneer we de ontwikkeling van nieuwe technologieën gedurende de laatste decennia bezien, dan kan de lezer zich tenminste een voorstelling maken van de seksuele mogelijkheden van robots over enkele decennia. Hierbij nemen we aan dat de ontwikkelingen binnen de Kunstmatige Intelligentie op dezelfde manier zullen voortgaan.

Nadat ik hierboven heb uitgelegd (1) waarom mensen seks met robots willen, en (2) hoe groot de vooruitgang van de technologieën van de seksuele artefacten wel niet is, ga ik in hoofdstuk 10 in op de veranderingen die deze ontwikkeling teweeg brengt in denken, in de benadering, en in de seksuele gewoonten ten opzichte van het verleden. Deze veranderingen vormen een antwoord op mijn achtste onderzoeksvraag: welke mentale obstakels bestaan er die de laatste stappen naar het bereiken van het tweede onderzoeksdoel kunnen verhinderen? Mijn argumentatie is hier tamelijk direct. Ik argumenteer dat de veranderingen in onze houding ten opzichte van homoseksualiteit, orale seks, fornicatie, en masturbatie, veranderingen waren waarvan de wereld de afgelopen 200 jaar (en meer in het bijzonder de afgelopen 50 jaar) getuige is geweest, en dat deze veranderingen niet minder drastisch waren dan de veranderingen in houding die nodig zijn om seks met robots te accepteren als begrip en in de praktijk.

In hoofdstuk 11 vat ik allereerst mijn conclusies over de onderzoeksvragen RQ1 tot en met RQ4 samen. Zij leiden tot een conclusie voor PS1, namelijk dat de emoties die mensen voelen voor andere mensen, voor huisdieren, voor virtuele huisdieren, en zelfs voor minder dierlijke artefacten - te weten computers - uitgebreid zullen worden tot het gebied van de robots van de toekomst. 
Verder vat ik eveneens mijn conclusies samen over de onderzoeksvragen RQ5 tot en met RQ8. Zij leiden tot een conclusie voor PS2, namelijk dat de normale grenzen van menselijke seksualiteit volledig uitgebreid zullen worden naar de robots van de toekomst.

$\mathrm{Na}$ deze twee hoofdconclusies beschouw ik mijn onderzoek als beëindigd, want liefde en seks met robots zijn onvermijdelijke uitbreidingen van onze ideeën, gevoelens, en praktische handelingen in het kader van relaties. De vraag is niet of dit zal gebeuren, maar wanneer. Ik ben ervan overtuigd dat het antwoord is "veel sneller dan u denkt". Aan het einde doe ik nog vier aanbevelingen voor verder onderzoek. 



\section{Curriculum Vitae}

David Levy was born in London on March 14 1945. He attended secondary school at Queen Elizabeth's Grammar School Barnet and East Barnet Grammar School. He studied Pure Mathematics, Statistics, and Physics at St. Andrews University, Scotland, from 1963 to 1967, where he graduated with a B.Sc. degree. He taught practical classes in computer programming at the Computer Science Department of Glasgow University from 1967 to 1971, before moving into the world of business and professional chess playing and writing. (He wrote more than thirty books on chess.) Having represented England at chess while he was still at school, he was selected to play for Scotland in six World Student Team Championships (19651970) and in six Chess Olympiads (1968-1978). In 1968 he won the Scottish Chess Championship, and in 1975 he shared that same title. He was awarded the International Master title by FIDE, the World Chess Federation, in 1969, and the International Arbiter title in 1976.

The development of David's interest in Artificial Intelligence started with computer chess, which was a logical combination of his addiction to chess and his work in the field of computing. In 1968 he started a bet with four Artificial Intelligence professors, that he would not lose a chess match against a computer program within ten years. He won that bet, and another one for a further five years, succumbing only twenty-one years after making the first bet, and then to a forerunner of the program that defeated Garry Kasparov in 1997. David was first elected President of the International Computer Chess Association (ICCA) in 1986, and after a gap from 1992 to 1999 was elected once again, a position he has held since then (the association now being named the International Computer Games Association (ICGA)). Since 1977 David has been involved in the development of many chess playing and other programs for consumer electronic products.

David's interest in Artificial Intelligence expanded beyond computer games into other areas of AI, including human-computer conversation. In 1994 he brought together a team to investigate pragmatic solutions to the problem, resulting in his team winning the Loebner Prize competition in New York in 1997. Since then David has published a primer on A.I., Robots Unlimited. His fiftieth book, Love and Sex with Robots, will be published in November 2007.

David has had a lifelong interest in organising mind sports events, and was one of the organisers of the World Chess Championship matches in London (1986 and 1993), as well as the World Checkers Championship match between the human champion and a computer program (1992 in London and 1994 in Boston), in addition to dozens of computer chess championships and similar events. His hobbies include classical music and playing poker.

David has two children, Alastair (born 1979) and Katherine (born 1984). He lives in London with his wife Christine and only one cat (their other three having passed away not so long ago). 


\section{SIKS Dissertation Series}

1998

01 Johan van den Akker (CWI) DEGAS - An Active, Temporal Database of Autonomous Objects

02 Floris Wiesman (UM) Information Retrieval by Graphically Browsing Meta-Information

03 Ans Steuten (TUD) A Contribution to the Linguistic Analysis of Business Conversations within the Language/Action Perspective

04 Dennis Breuker (UM) Memory versus Search in Games

05 Eduard Oskamp (RUL) Computerondersteuning bij Straftoemeting

1999

01 Mark Sloof (VU) Physiology of Quality Change Modelling; Automated Modelling of Quality Change of Agricultural Products

02 Rob Potharst (EUR) Classification using Decision Trees and Neural Nets

03 Don Beal (UM) The Nature of Minimax Search

04 Jacques Penders (UM) The Practical Art of Moving Physical Objects

05 Aldo de Moor (KUB) Empowering Communities: A Method for the Legitimate UserDriven Specification of Network Information Systems

06 Niek Wijngaards (VU) Re-Design of Compositional Systems

07 David Spelt (UT) Verification Support for Object Database Design

08 Jacques Lenting (UM) Informed Gambling: Conception and Analysis of a Multi-Agent Mechanism for Discrete Reallocation

\section{0}

01 Frank Niessink (VU) Perspectives on Improving Software Maintenance

02 Koen Holtman (TU/e) Prototyping of CMS Storage Management

03 Carolien Metselaar (UvA) Sociaal-Organisatorische Gevolgen van Kennistechnologie; een Procesbenadering en Actorperspectief

04 Geert de Haan (VU) ETAG, A Formal Model of Competence Knowledge for User Interface Design

05 Ruud van der Pol (UM) Knowledge-Based Query Formulation in Information Retrieval

06 Rogier van Eijk (UU) Programming Languages for Agent Communication

07 Niels Peek (UU) Decision-Theoretic Planning of Clinical Patient Management

08 Veerle Coupé (EUR) Sensitivity Analyis of Decision-Theoretic Networks

09 Florian Waas (CWI) Principles of Probabilistic Query Optimization

10 Niels Nes (CWI) Image Database Management System Design Considerations, Algorithms and Architecture

11 Jonas Karlsson (CWI) Scalable Distributed Data Structures for Database Management

\section{1}

01 Silja Renooij (UU) Qualitative Approaches to Quantifying Probabilistic Networks

02 Koen Hindriks (UU) Agent Programming Languages: Programming with Mental Models

03 Maarten van Someren (UvA) Learning as Problem Solving

04 Evgueni Smirnov (UM) Conjunctive and Disjunctive Version Spaces with Instance-Based Boundary Sets

05 Jacco van Ossenbruggen (VU) Processing Structured Hypermedia: A Matter of Style 
06 Martijn van Welie (VU) Task-Based User Interface Design

07 Bastiaan Schonhage (VU) Diva: Architectural Perspectives on Information Visualization

08 Pascal van Eck (VU) A Compositional Semantic Structure for Multi-Agent Systems Dynamics

09 Pieter Jan 't Hoen (RUL) Towards Distributed Development of Large Object-Oriented Models, Views of Packages as Classes

10 Maarten Sierhuis (UvA) Modeling and Simulating Work Practice BRAHMS: a Multiagent Modeling and Simulation Language for Work Practice Analysis and Design

11 Tom van Engers (VU) Knowledge Management: The Role of Mental Models in Business Systems Design

\section{2}

01 Nico Lassing (VU) Architecture-Level Modifiability Analysis

02 Roelof van Zwol (UT) Modelling and Searching Web-Based Document Collections

03 Henk Ernst Blok (UT) Database Optimization Aspects for Information Retrieval

04 Juan Roberto Castelo Valdueza (UU) The Discrete Acyclic Digraph Markov Model in Data Mining

05 Radu Serban (VU) The Private Cyberspace Modeling Electronic Environments Inhabited by Privacy-Concerned Agents

06 Laurens Mommers (UL) Applied Legal Epistemology; Building a Knowledge-Based Ontology of the Legal Domain

07 Peter Boncz (CWI) Monet: A Next-Generation DBMS Kernel for Query-Intensive Applications

08 Jaap Gordijn (VU) Value Based Requirements Engineering: Exploring Innovative ECommerce Ideas

09 Willem-Jan van den Heuvel (KUB) Integrating Modern Business Applications with Objectified Legacy Systems

10 Brian Sheppard (UM) Towards Perfect Play of Scrabble

11 Wouter Wijngaards (VU) Agent Based Modelling of Dynamics: Biological and Organisational Applications

12 Albrecht Schmidt (UvA) Processing XML in Database Systems

13 Hongjing $\mathrm{Wu}$ (TU/e) A Reference Architecture for Adaptive Hypermedia Applications

14 Wieke de Vries (UU) Agent Interaction: Abstract Approaches to Modelling, Programming and Verifying Multi-Agent Systems

15 Rik Eshuis (UT) Semantics and Verification of UML Activity Diagrams for Workflow Modelling

16 Pieter van Langen (VU) The Anatomy of Design: Foundations, Models and Applications

17 StefanManegold (UvA) Understanding, Modeling, and Improving Main-Memory DataBase Performance

\section{3}

01 Heiner Stuckenschmidt (VU) Ontology-Based Information Sharing in Weakly Structured Environments

02 Jan Broersen (VU) Modal Action Logics for Reasoning About Reactive Systems

03 Martijn Schuemie (TUD) Human-Computer Interaction and Presence in Virtual Reality Exposure Therapy

04 Petkovic (UT) Content-Based Video Retrieval Supported by Database Technology

05 Jos Lehmann (UvA) Causation in Artificial Intelligence and Law - A Modelling Approach

06 Boris van Schooten (UT) Development and Specification of Virtual Environments

07 Machiel Jansen (UvA) Formal Explorations of Knowledge Intensive Tasks 
08 Yong-Ping Ran (UM) Repair-Based Scheduling

09 Rens Kortmann (UM) The Resolution of Visually Guided Behaviour

10 Andreas Lincke (UT) Electronic Business Negotiation: Some Experimental Studies on the Interaction between Medium, Innovation Context and Cult

11 Simon Keizer (UT) Reasoning under Uncertainty in Natural Language Dialogue using Bayesian Networks

12 Roeland Ordelman (UT) Dutch Speech Recognition in Multimedia Information Retrieval

13 Jeroen Donkers (UM) Nosce Hostem - Searching with Opponent Models

14 Stijn Hoppenbrouwers (KUN) Freezing Language: Conceptualisation Processes across ICT-Supported Organisations

15 Mathijs de Weerdt (TUD) Plan Merging in Multi-Agent Systems

16 Menzo Windhouwer (CWI) Feature Grammar Systems - Incremental Maintenance of Indexes to Digital Media Warehouse

17 David Jansen (UT) Extensions of Statecharts with Probability, Time, and Stochastic Timing

18 Levente Kocsis (UM) Learning Search Decisions

2004

01 Virginia Dignum (UU) A Model for Organizational Interaction: Based on Agents, Founded in Logic

02 Lai Xu (UvT) Monitoring Multi-Party Contracts for E-Business

03 Perry Groot (VU) A Theoretical and Empirical Analysis of Approximation in Symbolic Problem Solving

04 Chris van Aart (UvA) Organizational Principles for Multi-Agent Architectures

05 Viara Popova (EUR) Knowledge Discovery and Monotonicity

06 Bart-Jan Hommes (TUD) The Evaluation of Business Process Modeling Techniques

07 Elise Boltjes (UM) VoorbeeldIG Onderwijs; Voorbeeldgestuurd Onderwijs, een Opstap naar Abstract Denken, vooral voor Meisjes

08 Joop Verbeek (UM) Politie en de Nieuwe Internationale Informatiemarkt, Grensregionale Politiële Gegevensuitwisseling en Digitale Expertise

09 Martin Caminada (VU) For the Sake of the Argument; Explorations into Argument-Based Reasoning

10 Suzanne Kabel (UvA) Knowledge-rich Indexing of Learning Objects

11 Michel Klein (VU) Change Management for Distributed Ontologies

12 The Duy Bui (UT) Creating Emotions and Facial Expressions for Embodied Agents

13 Wojciech Jamroga (UT) Using Multiple Models of Reality: On Agents who Know how to Play

14 Paul Harrenstein (UU) Logic in Conflict. Logical Explorations in Strategic Equilibrium

15 Arno Knobbe (UU) Multi-Relational Data Mining

16 Federico Divina (VU) Hybrid Genetic Relational Search for Inductive Learning

17 Mark Winands (UM) Informed Search in Complex Games

18 Vania Bessa Machado (UvA) Supporting the Construction of Qualitative Knowledge Models

19 Thijs Westerveld (UT) Using Generative Probabilistic Models for Multimedia Retrieval

20 Madelon Evers (Nyenrode) Learning from Design: Facilitating Multidisciplinary Design Teams

\section{5}

01 Floor Verdenius (UvA) Methodological Aspects of Designing Induction-Based Applications

02 Erik van der Werf(UM) AI Techniques for the Game of Go 
03 Franc Grootjen (RUN) A Pragmatic Approach to the Conceptualisation of Language

04 Nirvana Meratnia (UT) Towards Database Support for Moving Object data

05 Gabriel Infante-Lopez (UvA) Two-Level Probabilistic Grammars for Natural Language Parsing

06 Pieter Spronck (UM) Adaptive Game AI

07 Flavius Frasincar (TU/e) Hypermedia Presentation Generation for Semantic Web Information Systems

08 Richard Vdovjak (TU/e) A Model-Driven Approach for Building Distributed OntologyBased Web Applications

09 Jeen Broekstra (VU) Storage, Querying and Inferencing for Semantic Web Languages

10 Anders Bouwer (UvA) Explaining Behaviour: Using Qualitative Simulation in Interactive Learning Environments

11 Elth Ogston (VU) Agent Based Matchmaking and Clustering - A Decentralized Approach to Search

12 Csaba Boer (EUR) Distributed Simulation in Industry

13 Fred Hamburg (UL) Een Computermodel voor het Ondersteunen van Euthanasiebeslissingen

14 Borys Omelayenko (VU) Web-Service Configuration on the Semantic Web; Exploring How Semantics Meets Pragmatics

15 Tibor Bosse (VU) Analysis of the Dynamics of Cognitive Processes

16 Joris Graaumans (UU) Usability of XML Query Languages

17 Boris Shishkov (TUD) Software Specification Based on Re-usable Business Components

18 Danielle Sent (UU) Test-Selection Strategies for Probabilistic Networks

19 Michel van Dartel (UM) Situated Representation

20 Cristina Coteanu (UL) Cyber Consumer Law, State of the Art and Perspectives

21 Wijnand Derks (UT) Improving Concurrency and Recovery in Database Systems by Exploiting Application Semantics

\section{6}

01 Samuil Angelov (TU/e) Foundations of B2B Electronic Contracting

02 Cristina Chisalita (VU) Contextual Issues in the Design and Use of Information Technology in Organizations

03 Noor Christoph (UvA) The Role of Metacognitive Skills in Learning to Solve Problems

04 Marta Sabou (VU) Building Web Service Ontologies

05 Cees Pierik (UU) Validation Techniques for Object-Oriented Proof Outlines

06 Ziv Baida (VU) Software-Aided Service Bundling - Intelligent Methods and Tools for Graphical Service Modeling

07 Marko Smiljanic (UT) XML Schema Matching - Balancing Efficiency and Effectiveness by means of Clustering

08 Eelco Herder (UT) Forward, Back and Home Again - Analyzing User Behavior on the Web

09 Mohamed Wahdan (UM) Automatic Formulation of the Auditor's Opinion

10 Ronny Siebes (VU) Semantic Routing in Peer-to-Peer Systems

11 Joeri van Ruth (UT) Flattening Queries over Nested Data Types

12 Bert Bongers (VU) Interactivation - Towards an E-cology of People, our Technological Environment, and the Arts

13 Henk-Jan Lebbink (UU) Dialogue and Decision Games for Information Exchanging Agents

14 Johan Hoorn (VU) Software Requirements: Update, Upgrade, Redesign - Towards a Theory of Requirements Change

15 Rainer Malik (UU) CONAN: Text Mining in the Biomedical Domain 
16 Carsten Riggelsen (UU) Approximation Methods for Efficient Learning of Bayesian Networks

17 Stacey Nagata (UU) User Assistance for Multitasking with Interruptions on a Mobile Device

18 Valentin Zhizhkun (UvA) Graph Transformation for Natural Language Processing

19 Birna van Riemsdijk (UU) Cognitive Agent Programming: A Semantic Approach

20 Marina Velikova (UvT) Monotone Models for Prediction in Data Mining

21 Bas van Gils (RUN) Aptness on the Web

22 Paul de Vrieze (RUN) Fundaments of Adaptive Personalisation

23 Ion Juvina (UU) Development of Cognitive Model for Navigating on the Web

24 Laura Hollink (VU) Semantic Annotation for Retrieval of Visual Resources

25 Madalina Drugan (UU) Conditional Log-Likelihood MDL and Evolutionary MCMC

26 Vojkan Mihajlovic (UT) Score Region Algebra: A Flexible Framework for Structured Information Retrieval

27 Stefano Bocconi (CWI) Vox Populi: Generating Video Documentaries from Semantically Annotated Media Repositories

28 Borkur Sigurbjornsson (UvA) Focused Information Access using XML Element Retrieval

2007

01 Kees Leune (UvT) Access Control and Service-Oriented Architectures

02 Wouter Teepe (RUG) Reconciling Information Exchange and Confidentiality: A Formal Approach

03 Peter Mika (VU) Social Networks and the Semantic Web

04 Jurriaan van Diggelen (UU) Achieving Semantic Interoperability in Multi-Agent Systems: A Dialogue-Based Approach

05 Bart Schermer (UL) Software Agents, Surveillance, and the Right to Privacy: a Legislative Framework for Agent-Enabled Surveillance

06 Gilad Mishne (UvA) Applied Text Analytics for Blogs

07 Natasa Jovanovic' (UT) To Whom It May Concern - Addressee Identification in Face-toFace Meetings

08 Mark Hoogendoorn (VU) Modeling of Change in Multi-Agent Organizations

09 David Mobach (VU) Agent-Based Mediated Service Negotiation

10 Huib Aldewereld (UU) Autonomy vs. Conformity: an Institutional Perspective on Norms and Protocols

11 Natalia Stash (TU/e) Incorporating Cognitive/Learning Styles in a General-Purpose Adaptive Hypermedia System

12 Marcel van Gerven (RUN) Bayesian Networks for Clinical Decision Support: A Rational Approach to Dynamic Decision-Making under Uncertainty

13 Rutger Rienks (UT) Meetings in Smart Environments; Implications of Progressing Technology

14 Niek Bergboer (UM) Context-Based Image Analysis

15 Joyca Lacroix (UM) NIM: A Situated Computational Memory Model

16 Davide Grossi (UU) Designing Invisible Handcuffs. Formal investigations in Institutions and Organizations for Multi-agent Systems

17 Theodore Charitos (UU) Reasoning with Dynamic Networks in Practice

18 Bart Orriens (UvT) On the Development and Management of Adaptive Business

19 David Levy (UM) Intimate Relationships with Artificial Partners 